\title{
SYNTHETIC APPROACHES TO MYCELIANAMIDE
}

A thesis submitted in part fulfilment of conditions governing candidates

for the degree of

Doctor of Philosophy

in the

Australian National University

by

George V. Meehan B.Sc.(Hons.)

June, 1967 . Chemistry Department,

The Australian National University

School of General Studies, CAN BERRA. 


\section{AUTHOR'S STATEMENT}

The work presented in this thesis is entirely the author's own except where the work of others is specifically acknowledged. 


\section{ACKN OWLEDGEMEN TS}

I express my deep gratitude to my supervisor Dr. R.F.C. Brown whose direction, constructive advice, and continued interest were invaluable throughout my project. I also wish to thank other members of the academic and technical staff for their freely-given assistance. In particular, I record my gratitude to Dr. R.N. Warrener for helpful discussions during the sabbatical leave of Dr. R.F.C. Brown. A generous sample of mycelianamide from Mr.R.W. Rickards is gratefully acknowledged.

The award of a Commonwealth Postgraduate Scholarship is gratefully acknowledged. 


\section{TABLE OF CONTENTS}

$\underline{\text { Page }}$

Author's Statement

Acknowledgements

Table of Contents

Summary

GENERAL IN TRODUCTION

SECTION I

Introduction and Synthetic scheme

Discussion of Results

(a) Basic Synthetic Steps

(b) Benzylidene Condensations

SECTION II

Introduction and Synthetic scheme

Discussion of Results

(a) Basic Synthetic steps

(b) Discussion of N.M.R. Spectra

48

(c) Elimination Reactions

(d) Mechanism of the Elimination Reaction

(e) Miscellaneous Reactions

CON CLUSIONS

EXPER IMEN TAL

92

REFERENCES

156

APPENDIX 


\section{SUMMARY}

This thesis describes two unsuccessful approaches to the synthesis of the antibiotic mycelianamide. The first of these, the condensation of a benzaldehyde with the preformed dihydroxamic acid ring of the antibiotic, was not realisable under a wide variety of reaction conditions. In part this was due to the instability of this heterocyclic ring to the action of strong bases, but under the milder conditions employed, to the unexplained inability of this system to undergo the required condensation. This is in direct contrast to the facile condensation of benzaldehydes with the deoxy-analogues, the 2,5-piperazinediones.

The second approach attempted the elaboration of the antibiotic via an intermediate which already incorporated a protected benzylidene linkage. Although initially successful, this approach too, was thwarted at a penultimate stage. During the reintroduction of the olefinic bond via a thermal $\beta$ elimination of a sulphoxide (or the corresponding thioether) concomitant elimination of one of the hydroxamic protecting groups occurred, leading to a mono-deoxymycelianamide system. 
Considerable attention has been paid to the mechanism of this elimination reaction. In particular, it has been shown that the thermal elimination as formaldehyde, of only one of the methoxyl groups of mycelianamide dimethyl ether, requires far milder conditions than those needed for the sulphoxide $\beta$ elimination of the present synthesis. The facility of the elimination of formaldehyde has been attributed to the severe steric interaction between the $N-4$ methoxyl group and the aromatic ring, resulting from the proposed trans configuration of the mycelianamide system. A preliminary study of simple model systems has supported this steric argument and shown that the thermal elimination of aldehydes from alkylated hydroxamic acids promises to be a general reaction.

In the light of these studies, several modifications of the present synthetic approach are suggested. which may ultimately lead to the synthesis of mycelianamide. 
GENERAL INTRODUCTION 


\section{GENERAL INTRODUCTION}

A common structural feature of many metabolites from several micro-organisms, has been found to be the acylhydroxylamine or hydroxamic acid group. The ironcontaining growth factors (sideramines ${ }^{1}$ ), are representative, in that they contain three such groups which can occupy the six coordination sites of the Iron III atom. Typical examples of such growth factors are the structurally related ferrichromes ${ }^{2,3}$ and ferrioxamines ${ }^{4,5}$ eg. ferrioxamine $B(1)$.

Although strictly still a sideramine, mycobactin $P(2)^{6,7}$, a growth factor for Mycobacterium johnei isolated from Mycobacterium phlei, shows considerable structural complexity. Thus one of the two hydroxamates is present in a cyclic system, and the third coordinating ligand is furnished by a phenolic hydroxyl group and the basic nitrogen of an oxazoline ring. Further examples of mould metabolites which contain a cyclic hydroxamic acid grouping are norcardamine $(3)^{8,9}$, and the pyrazine derivatives aspergillic acid $(4)^{10,11}$, from Aspergillis flavus, and pulcherriminic acid (5) ${ }^{12,13}$, from Candida pulcherrima. 


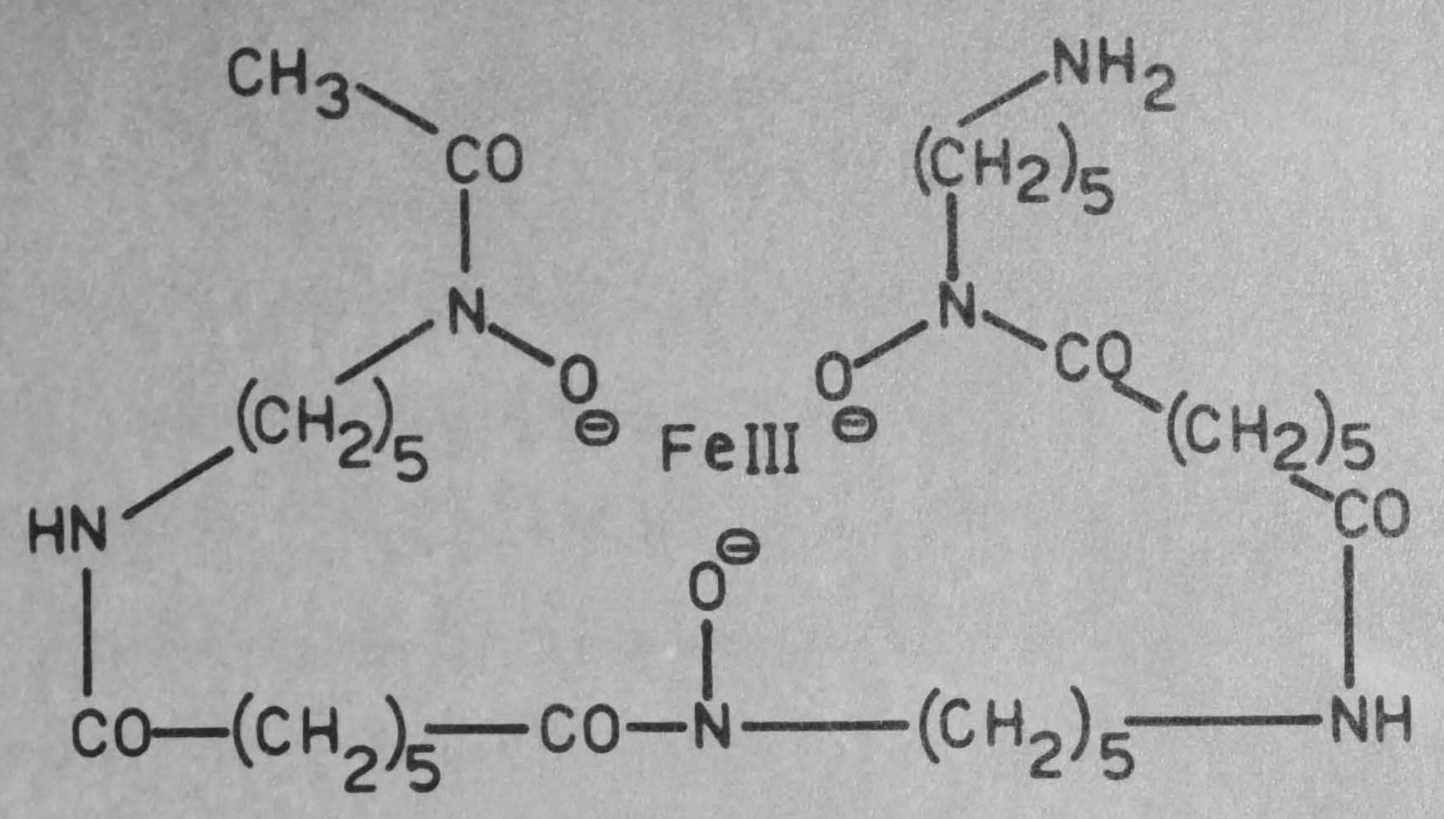

(1)

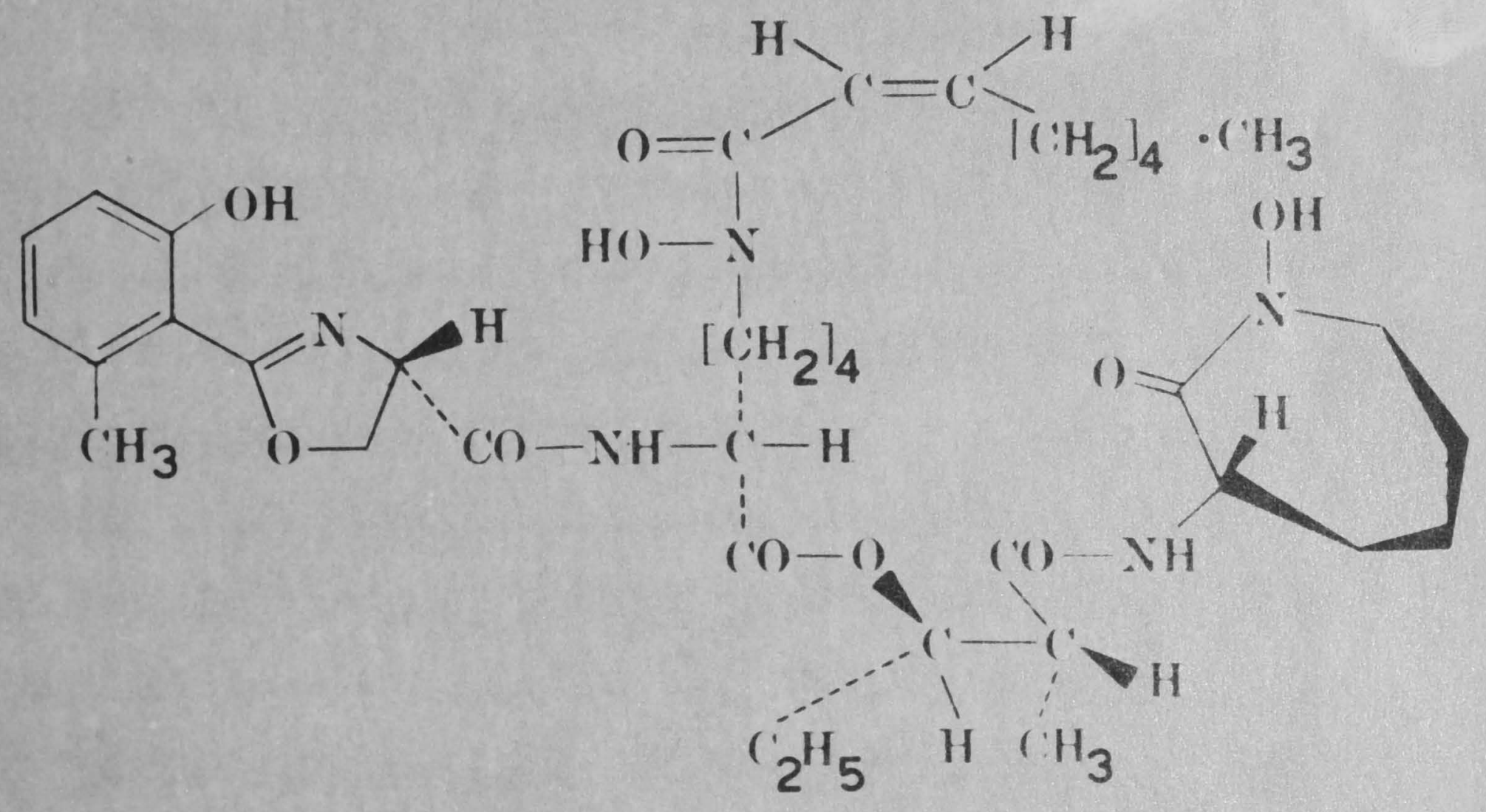

(2) 


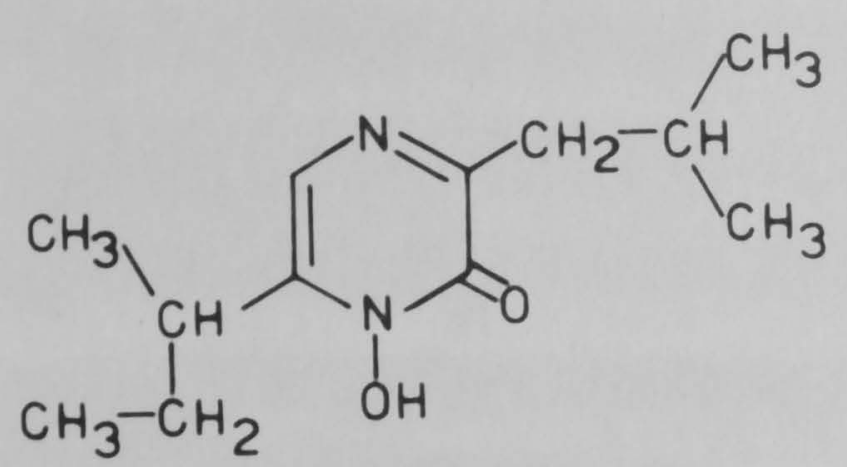

(4)

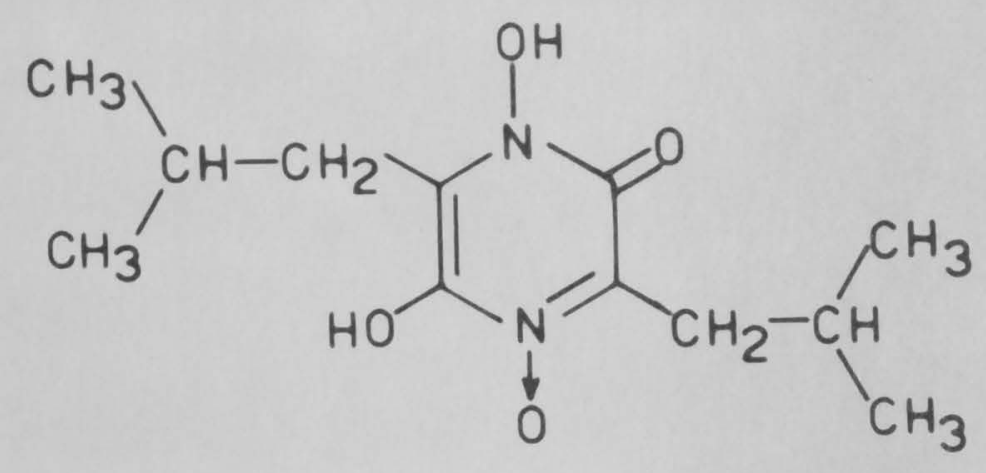

(5)

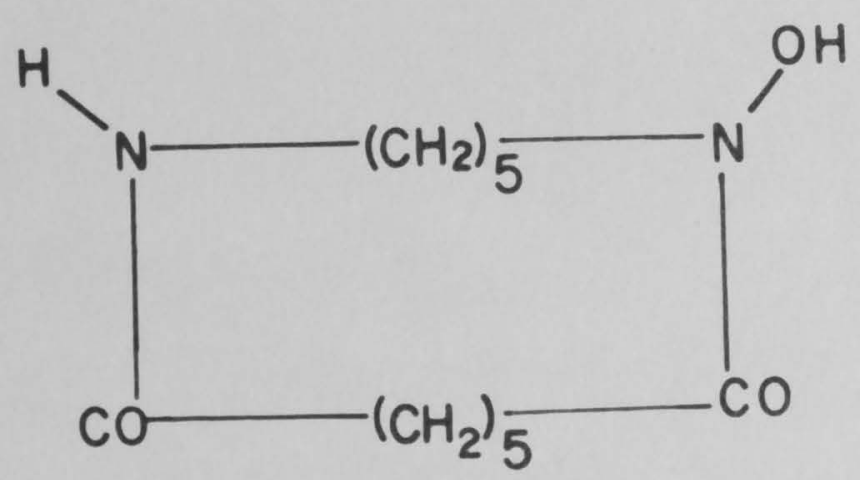

(3) 
The object of the present synthetic investigation, the antibiotic mycelianamide provides yet another structural modification; while still containing a cyclic hydroxamic acid, this is linked via an aromatic ring, to a terpenoid side chain.

\section{The structure of mycelianamide}

$$
\text { Mycelianamide, } \mathrm{C}_{22} \mathrm{H}_{28} \mathrm{O}_{5} \mathrm{~N}_{2} \text {, an antibiotic }
$$

isolated from the mycelium of strains of Penicillium griseofulvum Dierckx was originally examined by oxford and Raistrick ${ }^{14}$, who suggested the structural formula (6).

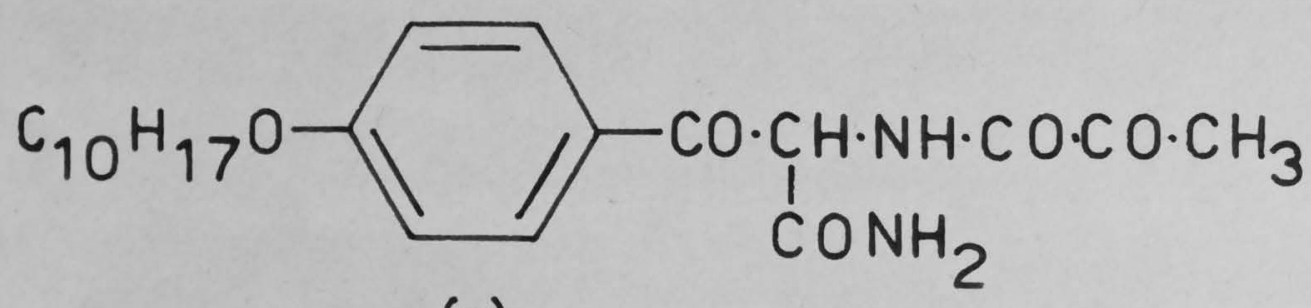

(6)

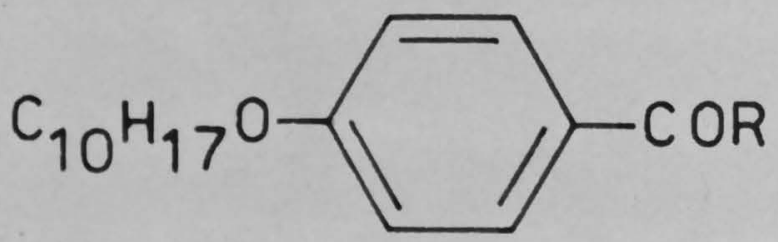

(7)

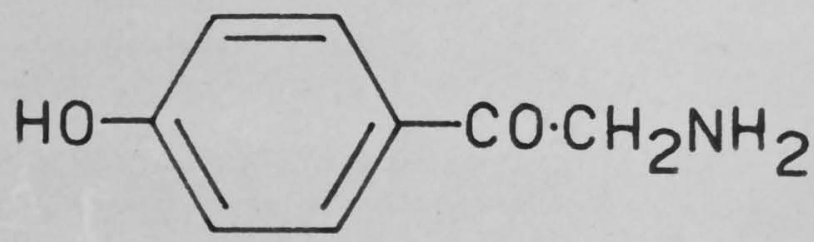

(8)

They showed that treatment of mycelianamide with ammonia yielded $\mathrm{p}$-myceloxybenzamide $\left(7 ; \mathrm{R}=\mathrm{NH}_{2}\right)$, while 
mild alkaline hydrolysis produced p-myceloxybenzoic acid $(7 ; \mathrm{R}=\mathrm{OH})$. Acid hydrolysis afforded ammonia and $\omega-$ amino p-hydroxyacetophenone (8), together with an unsaturated hydrocarbon, $\mathrm{C}_{10} \mathrm{H}_{16}$, mycelene, which contained a persistent oxygenated impurity. Mycelene appeared to be a monocyclic unconjugated diene giving on ozonolysis, formaldehyde and a diketone, $\mathrm{C}_{8} \mathrm{H}_{14} \mathrm{O}_{2}$.

In view of the ease of fission of the ether link, it was suggested that the mycelyl radical was derived from an allyl alcohol. Mycelianamide was nonbasic but was soluble in carbonate solutions and gave a red colouration with ferric chloride.

More recently, Birch and co-workers ${ }^{15,16}$ have carried out investigations which have led to the elucidation of most of the structural features of mycelianamide. Initially they showed that structure (6) was incorrect, since mycelianamide was recovered with unchanged optical rotation after dissolution in sodium carbonate solution. In such a reaction the enolic salt derived from (6) would be expected to be optically inactive.

C-Methyl analyses of mycelianamide indicated that probably three such groups were present; since pmyceloxybenzamide appeared to possess two C-methyl groups, the nitrogen-containing portion of the molecule was taken to contain one. It was this portion of the molecule which 
conferred on mycelianamide, the positive ferric test and the solubility in carbonate solutions. Evidence for an acyldioxopiperazine structure such as (9) for mycelianamide, was obtained by further investigation of acid and basic hydrolysis experiments.

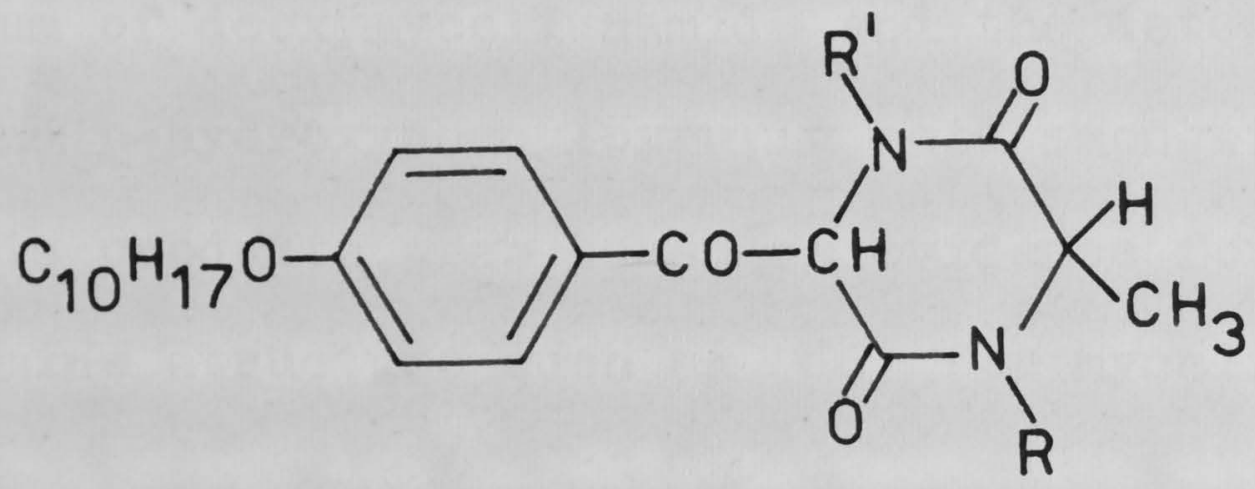

$$
\begin{aligned}
& R=O H, R^{\prime}=H \\
& \text { or } \\
& R=H, R^{\prime}=O H
\end{aligned}
$$

(9)

Thus alanine, carbon dioxide, ammonia, and (8) were detected as products of acid hydrolysis, while under alkaline conditions p-myceloxybenzoic acid $(7 ; \mathrm{R}=\mathrm{OH})$ and p-myceloxybenzamide $\left(7 ; \mathrm{R}=\mathrm{NH}_{2}\right)$ were produced.

However, mild reduction of mycelianamide with zinc dust and acetic acid, afforded deoxymycelianamide, $\mathrm{C}_{22} \mathrm{H}_{28} \mathrm{O}_{3} \mathrm{~N}_{2}$, which lacked two oxygen atoms, was insoluble in alkali, gave a negative ferric test and exhibited an ultra-violet (u.v•) absorption spectrum very similar to that of mycelianamide. The actual absorption was very

* The products of acid and base hydrolysis of mycelianamide are not easily rationalised and will be discussed in more detail at a later stage where they bear relation to the present synthetic investigation. 
similar to that of p-methoxybenzylideneacetone $\left(\lambda_{\max }{ }^{233,318 \mathrm{~m} \mu}\right)$ and the hypsochromic shift on reduction

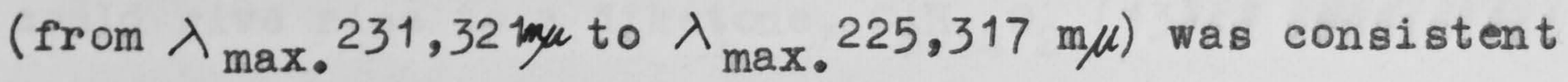
with the removal of hydroxyl groups from nitrogen.

The above evidence, together with a strong band at $1675 \mathrm{~cm}^{-1^{3}}$ in the infra-red (1.r.) absorption spectrum of deoxymycelianamide and the detection of alanine and p-hydroxyphenylpyruvic acid amongst the acid hydrolysis products, was taken as evidence for a bisacylhydroxylamine structure such as (10) for mycelianamide.

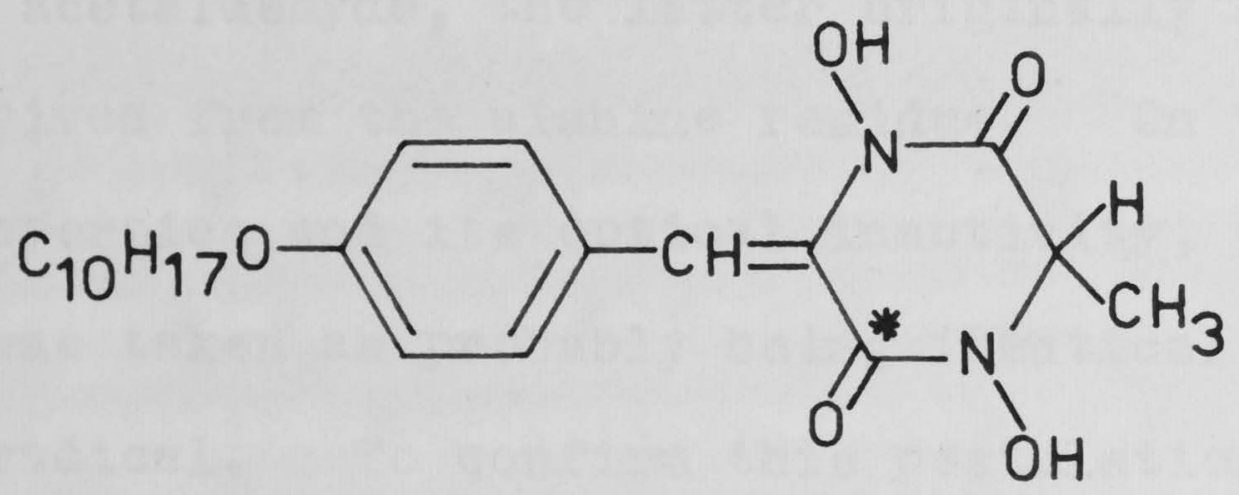

(10)

The $\mathrm{C}_{10}$ formula of the side chain suggested the presence of a terpenoid unit. In fact the occurrence of a geranyl side chain was compatible with previous studies $^{14}$ of the acid hydrolysis product, mycelene. Thus geraniol was known to undergo cyclisation under the conditions of the hydrolysis, to afford amongst other

* A band characteristic of unstrained cyclic amides, including piperazinediones. 
products, dipentene (11) which could give formaldehyde on ozonolysis, and $\alpha$-terpinene (12) which on ozonolysis could give rise to a diketone, $\mathrm{C}_{8} \mathrm{H}_{14} \mathrm{O}_{2}$ (13).

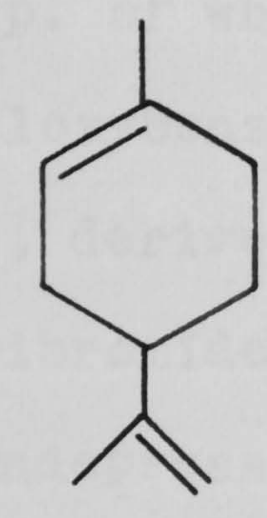

(11)

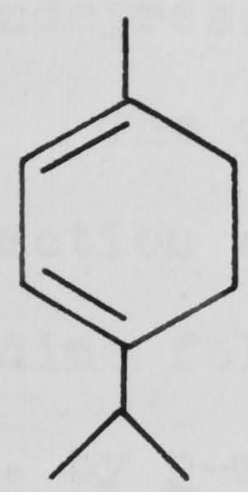

(12)

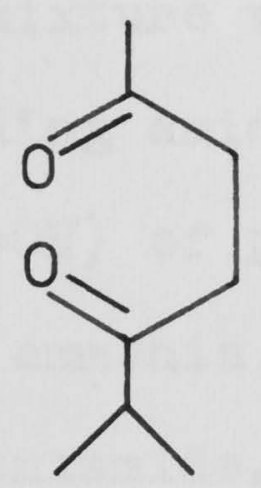

(13)

Ozonolysis of mycelianamide gave mainly acetone but some acetaldehyde, the latter originally being thought to be derived from the alanine residue. On the basis of these properties and its optical inactivity, the mycelyl radical was taken as probably being identical with the geranyl radical. To confirm this postulation,

p-geranyloxybenzoic acid $(14 ; \mathrm{R}=\mathrm{OH})$ and $\mathrm{p}$-geranyloxybenzamide $\left(14 ; \mathrm{R}=\mathrm{NH}_{2}\right.$ ) were synthesised for comparison with the corresponding mycelyl compounds.

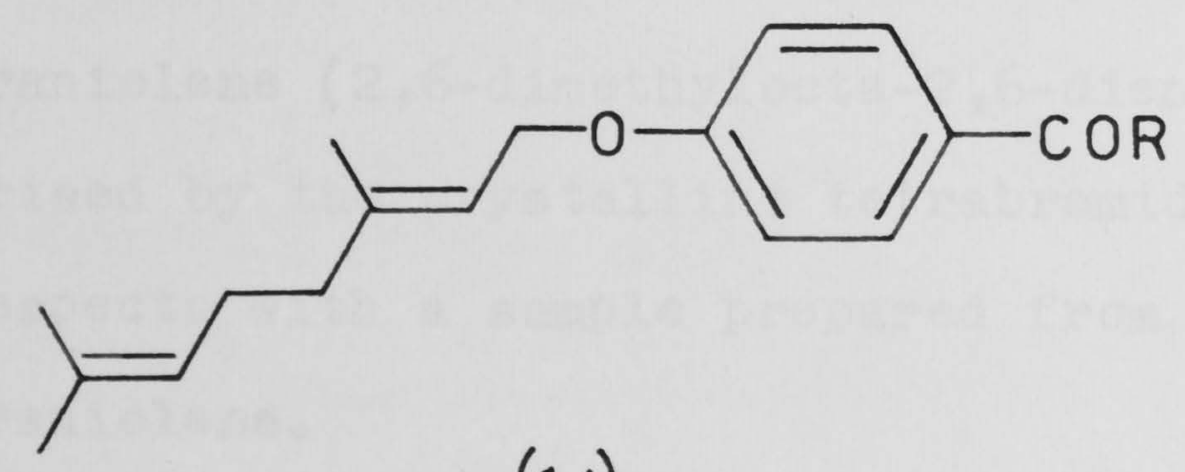

(14) 
Accordingly, the action of geranyl bromide on methyl-p-hydroxybenzoate in the presence of potassium carbonate and subsequent $h_{y}$ drolysis, gave ( $\left.14 ; \mathrm{R}=\mathrm{OH}\right)$, the m.p. of which was undepressed on admixture with p-myceloxybenzoic acid. The corresponding amide (14; $\mathrm{R}=\mathrm{NH}_{2}$ ), derived by the action on (14; $\mathrm{R}=\mathrm{OH}$ ) of phosphorous tribromide and pyridine followed by ammonia, was in turn undepressed in m.p. by p-myceloxybenzamide. However, the i.r. spectra of the synthetic acid and amide showed slight differences in the region $8-14 \mu$ from those of the corresponding hydrolysis products, these differences being greater than would be expected if the substances were identical.

In order to clarify this discrepancy, the ozonolysis of $\mathrm{p}$-myceloxybenzamide was investigated; acetone and acetaldehyde were detected, but none of the expected laevulaldehyde or acid. Facile hydrogenolysis of the side chain of mycelianamide was effected by the action of sodium and methanol in liquid ammonia. The reduction product, a hydrocarbon probably identical with methylgeraniolene $(2,6$-dimethylocta-2,6-diene), was characterised by the crystalline tetrabromide identical in all respects with a sample prepared from authentic methylgeraniolene. 
The combined evidence presented above led Birch and co-workers to suggest (15a) or $(15 b)$ as the most likely formulation for mycelianamide.

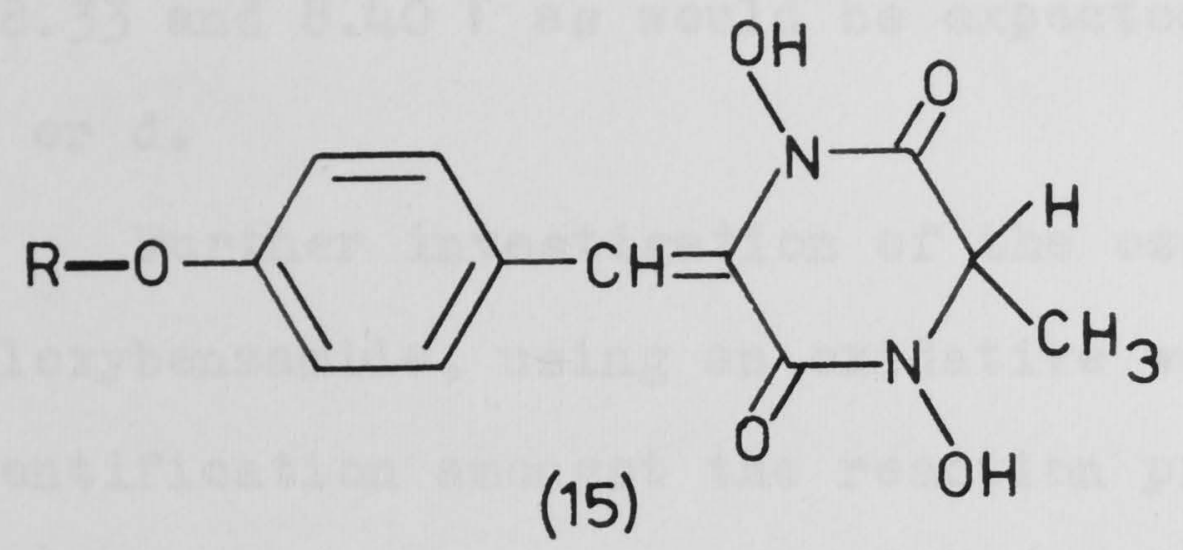

(a) $\mathrm{R}=$

(b) $R=$

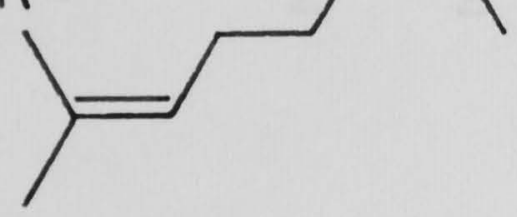

(c) $\mathrm{R}=$

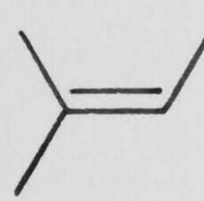

(d)

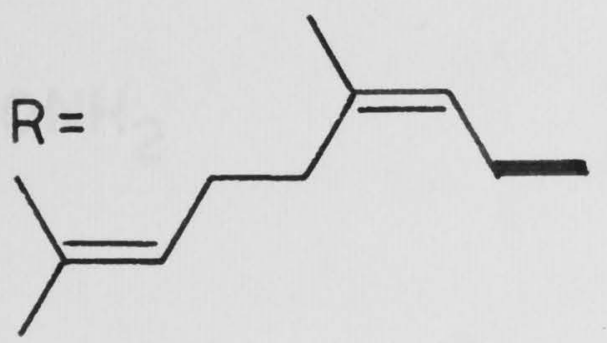

Motivated by the discrepancy between the side chain structure a or b suggested for mycelianamide by Birch and co-workers, and the usual structures formed from its demonstrated precursor, mevalonic acid, Bates and co-workers ${ }^{17}$ have re-examined the structure of the mycelianamide side chain. The nuclear magnetic resonance (n.m.r.) spectra of mycelianamide and $p$-myceloxybenzamide were not compatible with structures having side chains of type $a$ or $b$ but strongly favoured side chains of a type 
c or d. Thus the absorptions for the methylenes next to oxygen appeared as doublets at $5.4 T(J=7 \mathrm{cps})$ and there were three essentially unsplit methyl groups at $8.27,8.33$ and $8.40 \tau$ as would be expected with groups of type $c$ or d.

Further investigation of the ozonolysis of p-myceloxybenzamide, using an oxidative work up, led to the identification amongst the reaction products, of 4carbamoylphenoxyacetic acid (16) and laevulinic acid, isolated as the 2,4-dinitrophenylhydrazone.

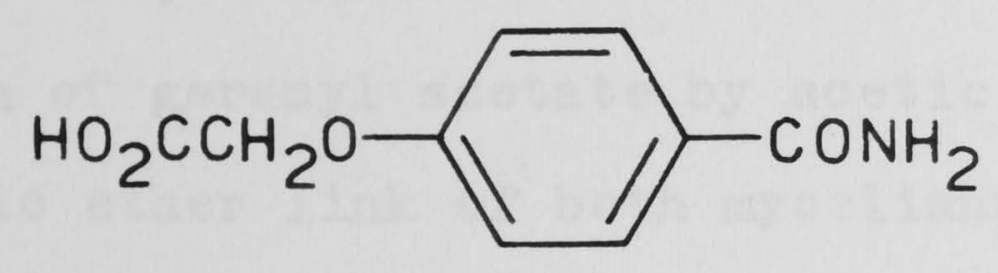

(16)

In order to distinguish between structures containing side chains of type $c$ or $d, p$-geranyloxybenzamide ( 14; $\mathrm{R}=\mathrm{NH}_{2}$ ) and $\mathrm{p}$-neryloxybenzamide (17) were synthesised stereospecifically from geraniol and nerol by the reaction of the corresponding allyl bromides with the sodium salt of p-hydroxybenzamide. p-Myceloxybenzamide was found to be identical with $\left(14 ; \mathrm{R}=\mathrm{NH}_{2}\right),($ mixed m.p., i.r. and n.m.r. spectra), but was depressed in m.p. by (17). 


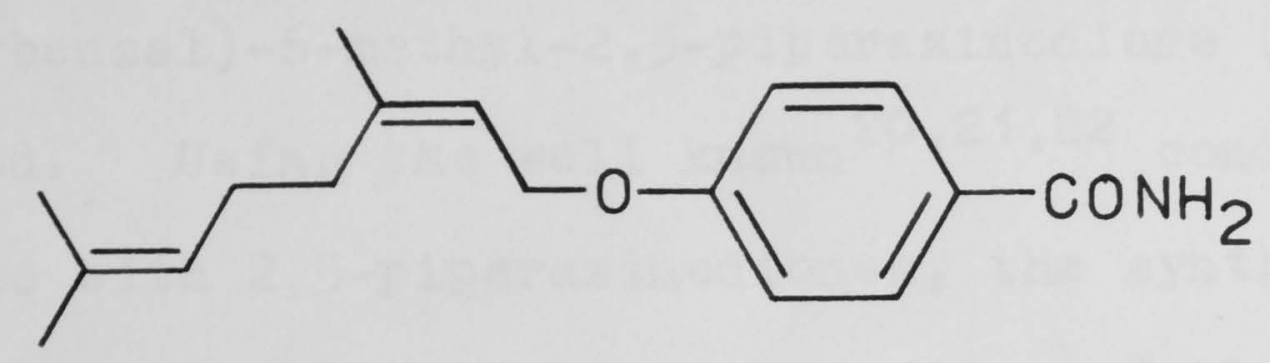

(17)

This additional evidence led to the advancement of $(15 c)$ as the correct structure of mycelianamide. Since the commencement of the present investigation, two communications directly related to the structure of mycelianamide have been published. In the first of these, Gallina and co-workers ${ }^{18}$ observed the production of geranyl acetate by acetic acid cleavage of the allylic ether link of both mycelianamide and deoxymycelianamide. Together with the previously-mentioned studies, this provides conclusive evidence that the terpenoid side chain of mycelianamide is indeed the geranyl group. They also studied the hydriodic acid hydrolysis of mycelianamide, from which L-alanine and optically impure L-tyrosine were isolated. Thus the configuration of the asymmetric centre of mycelianamide was established as being of the (S) series.

In a subsequent communication from the same group $^{19}$, the isolation of the other residue expected from 
the acetic acid cleavage of deoxymycelianamide, DL-3(4'-hydroxybenzal) -6-methyl-2,5-piperazinedione $(18 ; \mathrm{R}=\mathrm{H})$ was reported. Using the well known $20,21,22$ condensation of aldehydes with 2,5-piperazinediones, the synthesis of ( $18 ; \mathrm{R}=\mathrm{H}$ ) was accomplished by condensation of DL-3-methyl2,5-piperazinedione (19), with p-hydroxybenzaldehyde in acetic anhydride-sodium acetate, to give ( $18 ; \mathrm{R}=\mathrm{AC})$. Subsequent hydrazinolysis afforded $(18 ; \mathrm{R}=\mathrm{H})$, which by alkylation with geranyl bromide gave racemic deoxymycelianamide (20) as outlined in Chart I.

Although one structural feature, the geometry \# of the olefinic link, remains undetermined, the investigations described above, allow the structure of mycelianamide to be confidently taken as :- 3-( $4^{\prime}$-geranyloxybenzal)6-(s)-methyl-1,4-dihydroxy-2,5-piperazinedione (21).

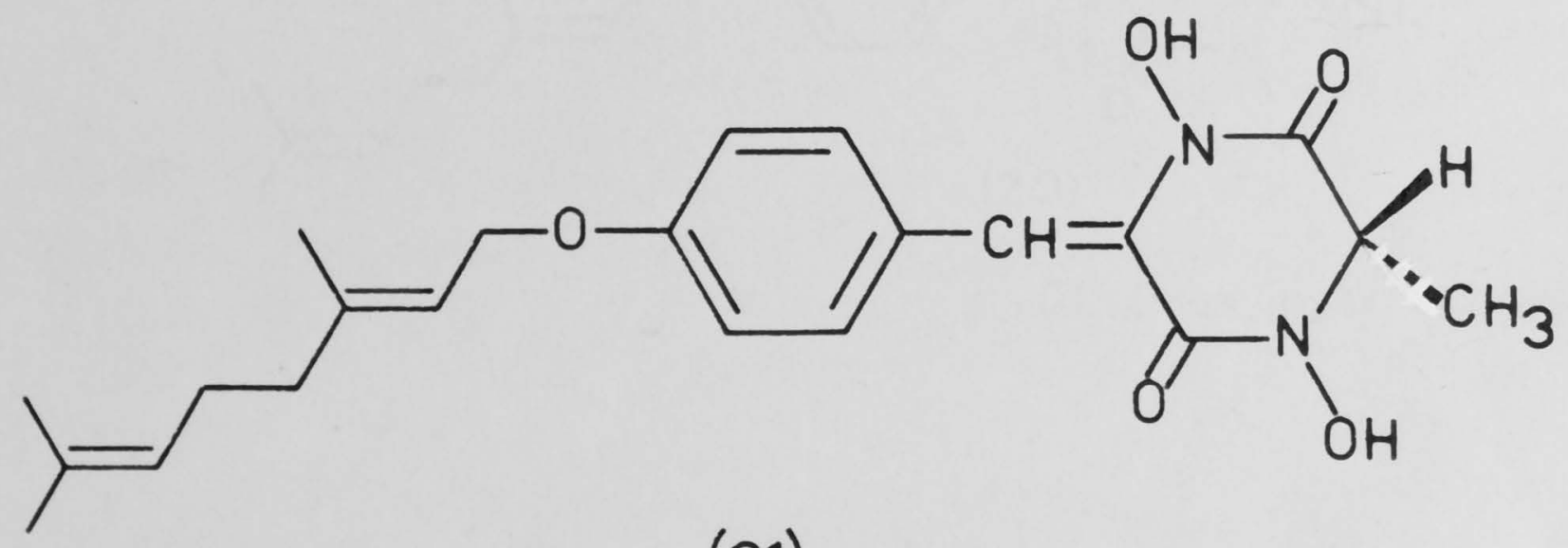

(21)

* Some indirect evidence conceming the geometrical isomerism of mycelianamide has been furnished by the present synthetic investigation (see section II of this thesis). 

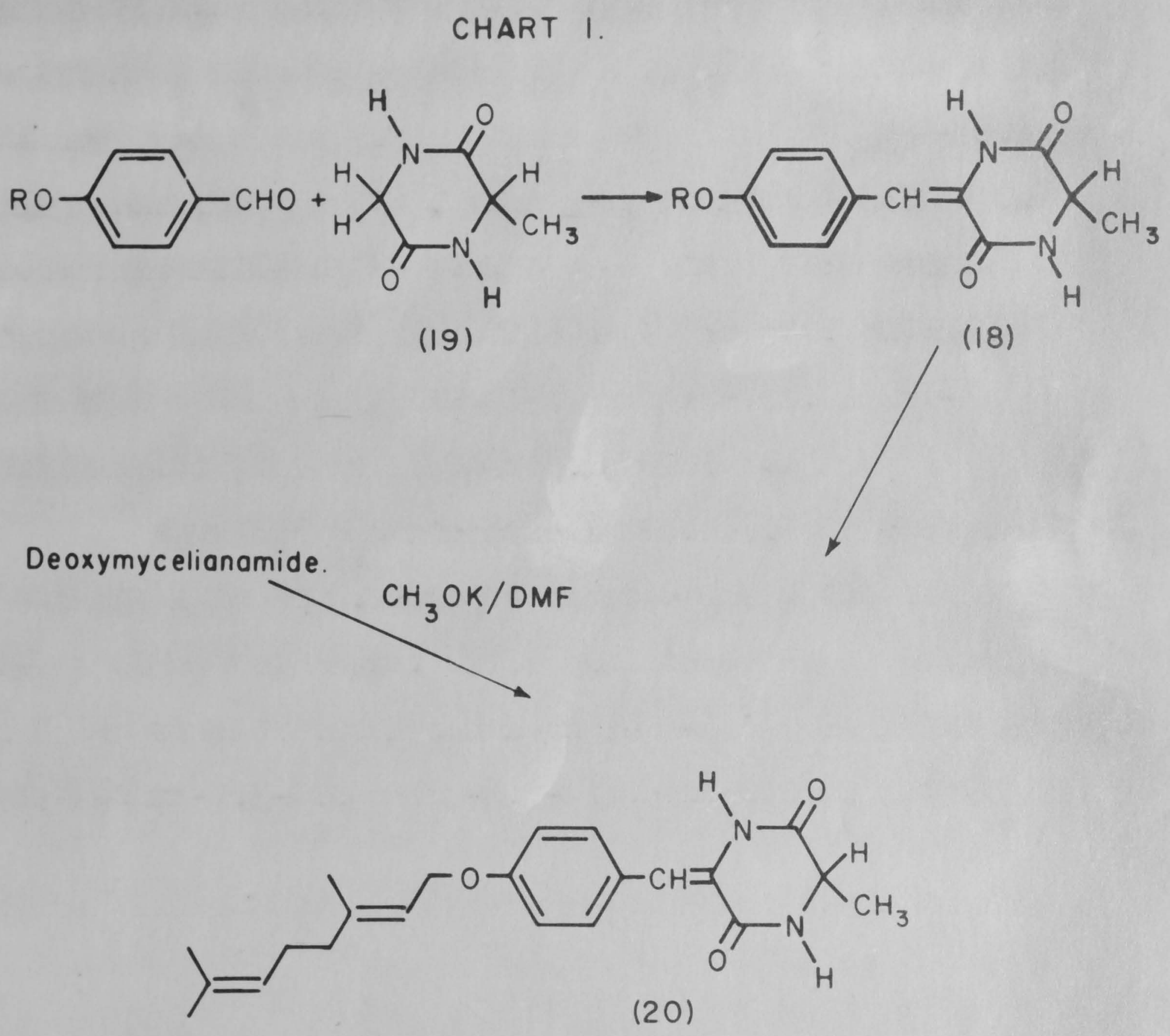

DL Deoxymycelianamide 


\section{Biosynthesis of mycelianamide}

The efficient incorporation of labelled precursors by the mould Penicillium griseofulvum Dierckx, into the side chain of mycelianamide, has made this antibiotic a fruitful source of biosynthetic investigation. Griseofulvin, produced simultaneously in an approximately constant ratio throughout the growth of the mould, has been shown to be derived directly from acetic acid 23,24 . Hence this mould provided an opportunity to study the relative effectiveness of various sources for the production of an isoprenoid chain and a substance directly formed from acetic acid.

Birch and co-workers $25,26,27$ have demonstrated the incorporation of several labelled precursors into the side chain of mycelianamide, by establishing the labelling pattern of the methylgeraniolene derived by hydrogenolysis of the labelled antibiotic produced. Incorporation of both $\left[\right.$ carboxy- $\left.{ }^{14} \mathrm{C}\right]$ acetic acid and 3 -methyl $\left[1-{ }^{14} \mathrm{C}\right]$ but-2-enoic acid, gave rise to methylgeraniolene with the distribution of $\left[{ }^{14} \mathrm{C}\right]$ shown in (22a). The latter precursor was not incorporated as such, but underwent degradation to $\left[\right.$ carboxy $\left.-{ }^{14} \mathrm{C}\right]$ acetic acid before biosynthesis, since the labelling of the griseofulvin produced simultaneously, was the same as previously observed 23,24 . 


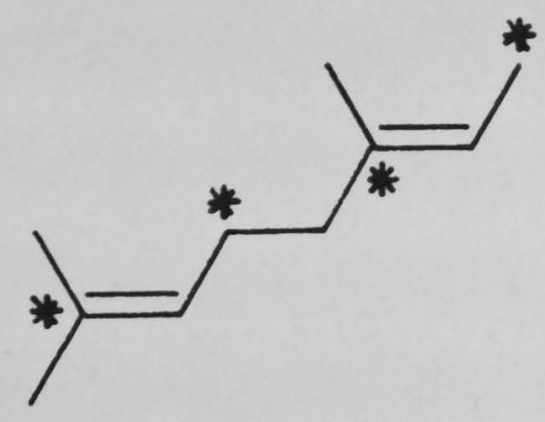

(22a)

Methylgeraniolene labelled as in (22b) was produced by the incorporation of $\left[2-{ }^{14} \mathrm{C}\right]$ mevalonic lactone by the mould. In this case, the griseofulvin isolated was completely inactive, thus demonstrating the role of this precursor as an irreversible intermediate in terpene biosynthesis.

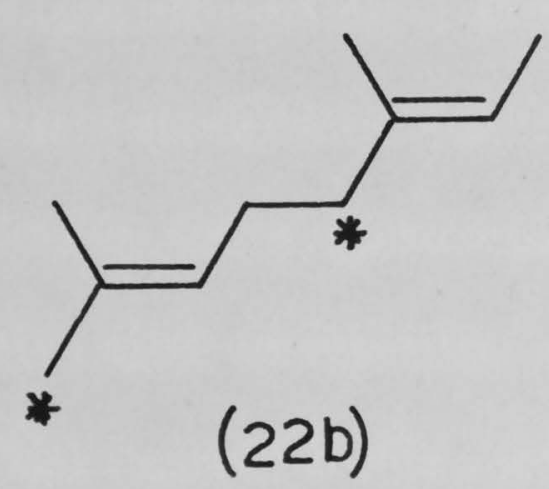

Although it was reported ${ }^{16}$ that labelled tyrosine was readily incorporated by the mould into the mycelianamide molecule, no thorough investigation of the benzenoid and heterocyclic rings of the antibiotic had been published.

However in a symposium lecture, Birch and Smith 28 gave further details of the biosynthetic experiments 
using $\left[1-{ }^{14} \mathrm{C}\right]$ tyrosine. The labelled mycelianamide, on acid hydrolysis, gave rise to carbon dioxide containing all the radioactivity, together with unlabelled alanine. Although the mechanism of the formation of the carbon dioxide is not clear, the only reasonable origin is from the asterisked carbon atom in structure (10) corresponding to the expected 1-position of tyrosine.

The myceloxybenzamide $\left(7 ; \mathrm{R}=\mathrm{NH}_{2}\right)$ produced by the action of ammonia was not radioactive, and the p-hydroxyphenylpyruvic acid produced by reduction to deoxymycelianamide and then hydrolysis, was still radioactive. The results were consistent with a biosynthetic scheme as outlined in Chart II. Although the exact sequence of steps is not known, the formation of the hydroxamic acid ring of mycelianamide was readily explained by oxidation of a piperazinedione initially formed from tyrosine and alanine.

A biosynthetic scheme essentially the same as that described above has been advanced elsewhere 29 . 
CHART II.
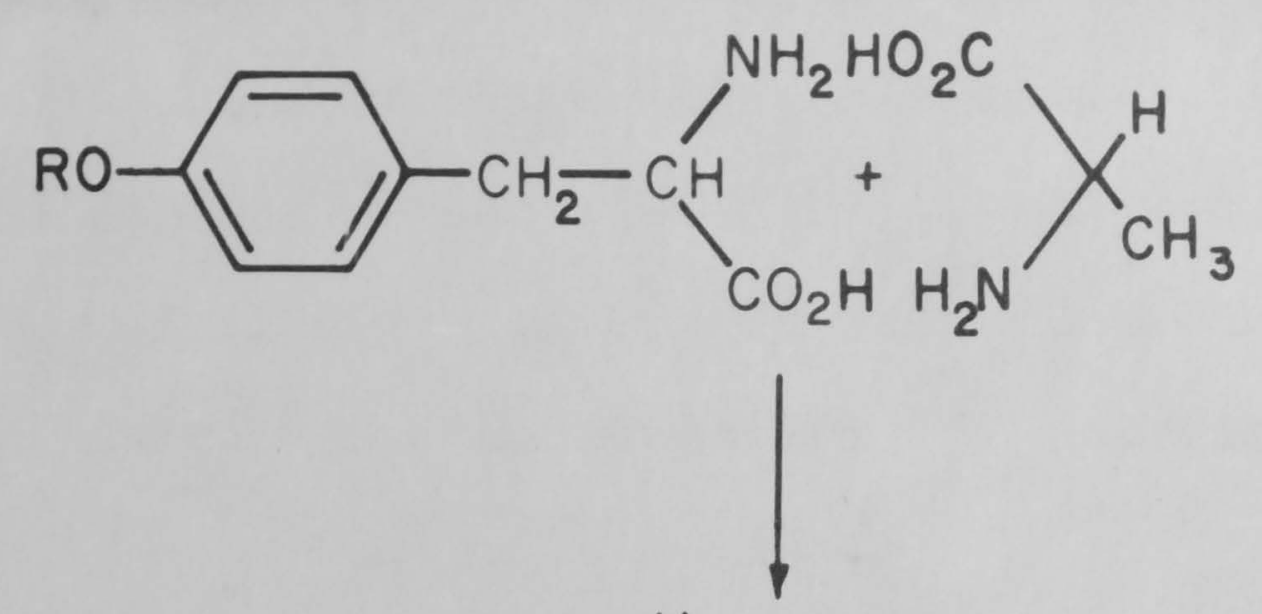<smiles>[R]Oc1ccc(CC2NC(=O)C(C)(C)N([Tl])C2=O)cc1</smiles><smiles>[3H][13IH]</smiles><smiles>[R2]c1ccc(CC2(O)NC(=O)C(C)(C)N([2H])C2=O)cc1</smiles><smiles>[R20]O[R10]([H])([O-])O</smiles>

MYCELIANAMIDE 
SECTION I 
SECTION I

\section{Introduction and synthetic scheme}

When faced with the task of devising a rational synthesis of a molecule such as mycelianamide, one drawback immediately becomes obvious - viz. the relative structural simplicity of the molecule. While keeping the problem to a manageable size, this simplicity severely limits the scope of possible synthetic approaches. Accepting this restriction, any variation consists in the choice of the most efficient means of carrying out individual steps in the general scheme chosen. In the present work two general approaches were devised, and are described in the two main sections of this thesis.

The first approach was prompted by the formal resemblance ${ }^{\#}$ of the heterocyclic ring of mycelianamide to the corresponding 2,5-piperazinedione system. In particular, it was thought that an extension of the facile benzylidene condensations undergone by the latter system (10c. cit.) could be made to the $N$-hydroxy analogues. Thus the basis of the proposed synthesis of mycelianamide consisted of the condensation of an aldehyde such as (23) with the preformed cyclic dihydroxamic acid ( $\left.24 ; R^{\prime}=H\right)$.

* Experience has since proven this resemblance not to be borne out experimentally. 


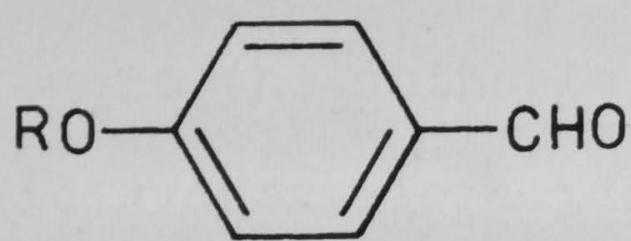

(23)

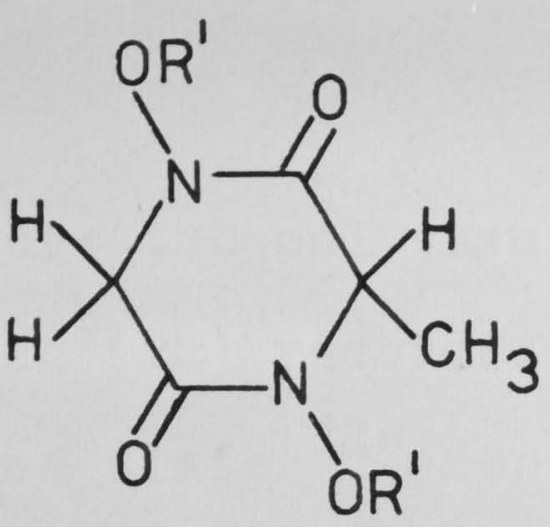

(24)

Since under basic conditions the hydroxamic acid $\left(24 ; R^{\prime}=H\right)$ would probably be present as the monoanion $(25 a, 25 b)$ or the dianion (26), the extra ionisation needed to initiate the required condensation was expected to be disfavoured. Protection of the hydroxamic acid functions by alkylation or acylation should circumvent this difficulty.<smiles>CC1C(=O)N(O)C(C)C(=O)N1[O-]</smiles>

(25a)<smiles>CC1C(=O)N([O-])C(=O)C(=O)N1O</smiles>

(25b)<smiles>CC1C(=O)N([O-])C(C)C(=O)N1[O-]</smiles>

(26)

Considerable variation was possible in the choice of protecting groups for the aldehyde (23) and the hydroxamic acid (24), and of the conditions employed in the condensation reaction. Although sodium acetate-acetic anhydride has been found most effective for the piperazinedione system, pyridine and potassium hydroxide in ethanol 
have also been used. 22

To the author's knowledge the only synthesis of cyclic hydroxamic acids such as (24) recorded in the literature, were those of Cook and slater ${ }^{12 a}$ reported in a communication related to structural studies on pulcherriminic acid (10c. cit.). Thus the cyclic hydroxamic acids $\left(27 ; \mathrm{R}=\mathrm{Bu}^{\mathrm{n}}\right.$ or $\mathrm{Bu}^{\mathrm{i}}$ ) were obtained from the corresponding $\alpha$-hydroxylamino acids as outlined in Chart III. This route paralleled the recorded synthesis of 2,5 piperazinediones from bromoacylamino esters. 30 
CHART III.

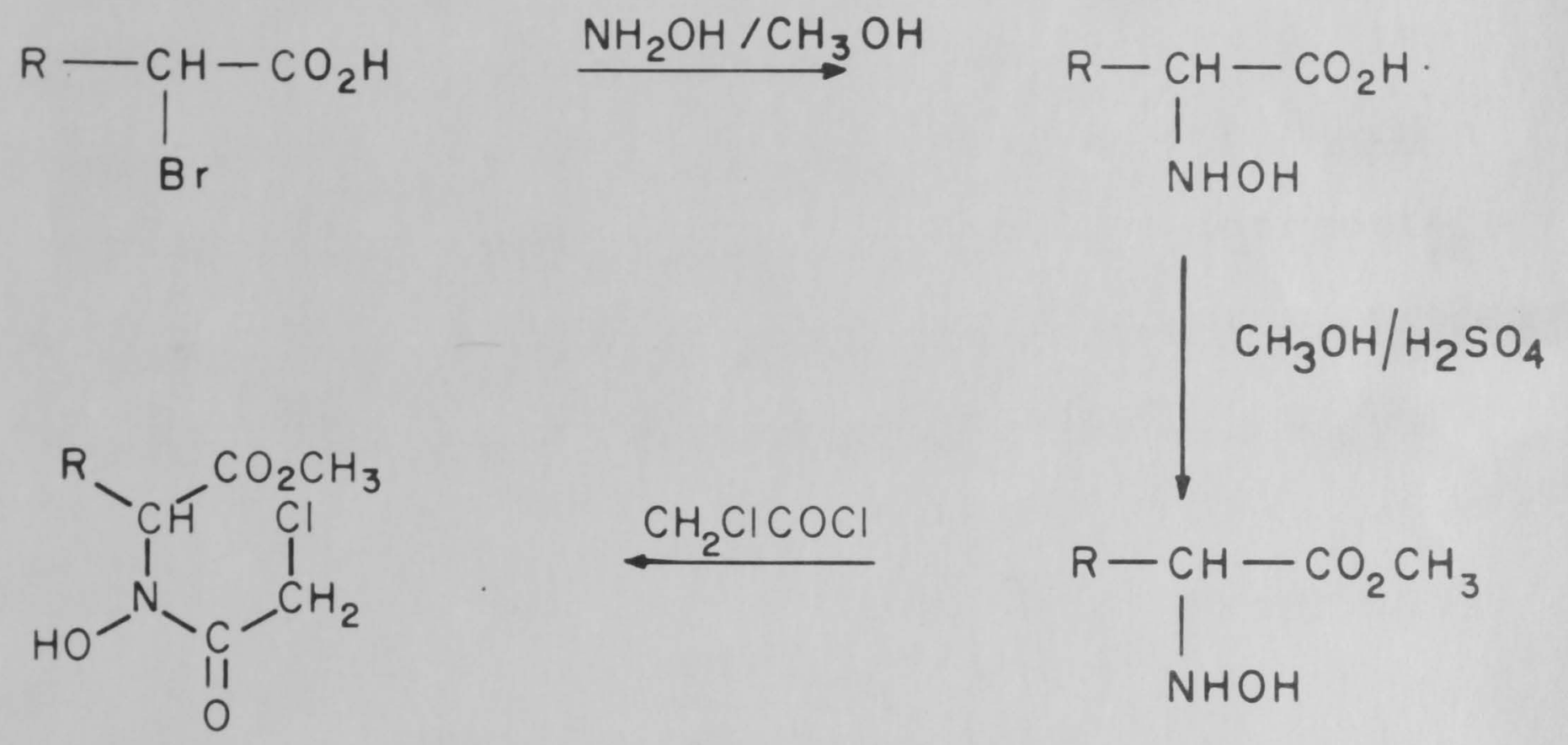

$\mathrm{NH}_{2} \mathrm{OH} / \mathrm{CH}_{3} \mathrm{OH}$<smiles>[R]C1C(=O)N(O)C([2H])C(=O)N1O</smiles>

(27) 


\section{Discussion of results}

\section{(a) Basic synthetic steps}

It was expected that an analogous scheme to that of Cook and slater could be employed for the synthesis of $\left(24 ; R^{\prime}=H\right)$. However when $\alpha$-bromopropionic acid was treated with methanolic hydroxylamine (regenerated from the hydrochloride with sodium methoxide), an intractible water - soluble gum was produced, from which none of the required acid $\left(28 ; \mathrm{R}=\mathrm{CO}_{2} \mathrm{H}\right.$ ) could be obtained.<smiles>[R]C(C)NO</smiles>

(28)<smiles>COC(=O)C(C)N(O)C(=O)CCl</smiles>

(29)

An alternative route was envisaged via the hydroxylamino nitrile (28; $R=C N)$ reported ${ }^{31}$ by Neelakantan and Hartung. Thus, reaction of acetaldehyde with hydroxylamine hydrochloride and sodium cyanide at $0^{\circ}$, afforded (28; $\mathrm{R}=\mathrm{CN})$ in variable yield (max. $31 \%$ ). Methanolysis of the nitrile was effected by saturating a methanolic solution with dry hydrogen chloride, yielding the methyl ester $\left(28 ; \mathrm{R}=\mathrm{CO}_{2} \mathrm{CH}_{3}\right)$ as a light yellow oil. 
Reaction of the methyl ester with one mole of chloroacetyl chloride afforded the chloroacetyl derivative (29), as a low melting solid.

\section{Initial attempts to isolate the hydroxamic}

acid ( $\left.24 ; R^{\prime}=H\right)$ from the cyclisation of (29) with hydroxylamine $e^{*}$, were uniformly unsuccessful. ${ }^{x x}$ subsequent experience (vide infra), showed that the presumed failure of some of these cyclisations, was more a failure of conventional isolation procedures.

Thus, treatment of (29) with a four molar excess of methanolic hydroxylamine containing a trace of potassium iodide effected the required cyclisation. The extremely water-soluble dihydroxamic acid ( $\left.24 ; R^{\prime}=H\right)$, was isolated in fair yield $(69 \%)$, by the tedious but effective process of consecutive cation and anion exchange chromatography. Methylation with diazomethane afforded the dimethyl ether $\left(24 ; \mathrm{R}^{\prime}=\mathrm{CH}_{3}\right)$, the n.m.r. spectrum of which was entirely consistent with the proposed structure. The overall yield of $\left(24 ; R^{\prime}=H\right)$ from acetaldehyde was a meagre $6.7 \%$

F Regenerated from the hydrochloride by the action of the equivalent amount of methanolic sodium methoxide.

F* Typical variations in the reaction conditions were the use of a two to ten molar excess of hydroxylamine, the presence of an excess of base (sodium methoxide), and a range of reaction temperature from ambient temperature to heating under reflux. In addition, the corresponding mono 0-benzyl hydroxamic acid could not be isolated from the reaction of (29) with 0-benzyl hydroxylamine. 32 
An alternative scheme for the synthesis of the hydroxamic acid $\left(24 ; R^{\prime}=H\right)$ was envisaged by analogy with the synthesis of hydroxamic acids in the pyridine and quinoline series 33,34 . The basis of this method is illustrated in Chart IV for a representative pyridine. Several o -pyridone derivatives have also been oxidised directly to hydroxamic acids (albeit in low yield), with an excess of perbenzoic acid. 35

In the present work, it was proposed to utilise the former method, via the di-0-alkyl derivative (30), possibly obtainable by alkylation of a piperazinedione with triethyloxonium fluoroborate 37 . Unfortunately the use of either of the above-mentioned hydroxamic acid syntheses was precluded by the extreme insolubility of representative piperazinediones (eg. glycine and alanine anhydride), in the solvents usually employed in such reactions.

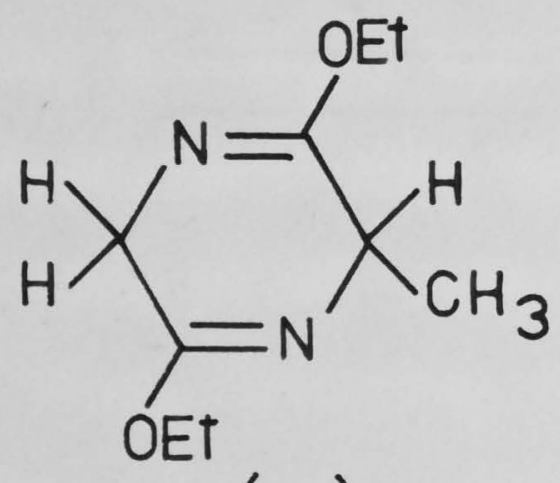

(30)

\$ Triethyloxonium fluoroborate has been used with conspicuous success for the apparently exclusive 0alkylation of cyclic amides.38,39 A recent publication 40 , however, indicates that at least in the case of $\alpha$-pyridone, this selectivity is not operative. 


\section{CHART IV.}
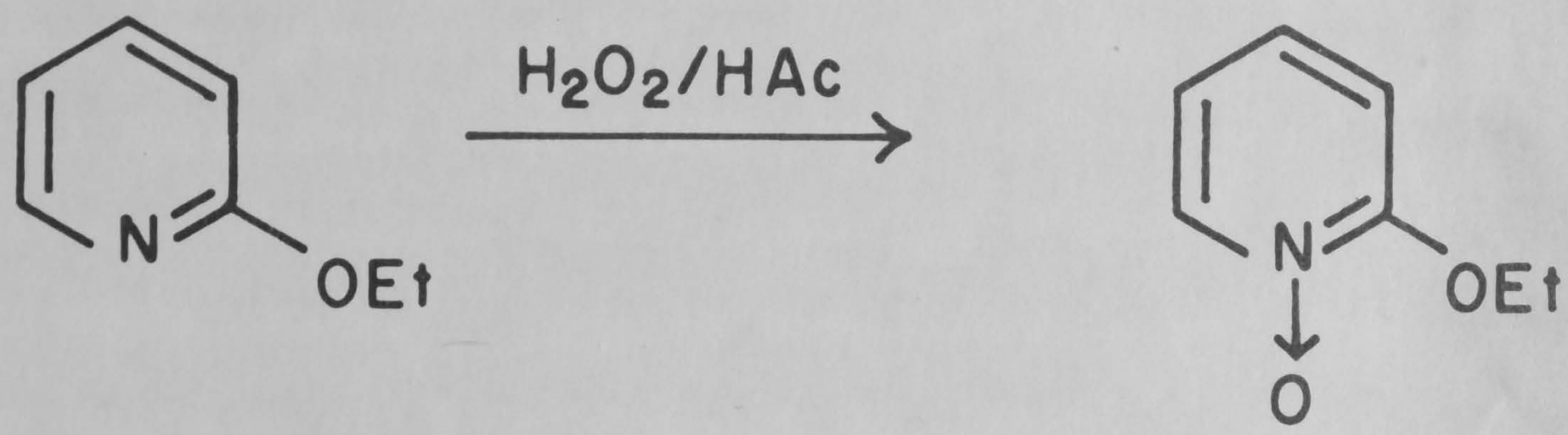

dil. $\mathrm{HCl}$.
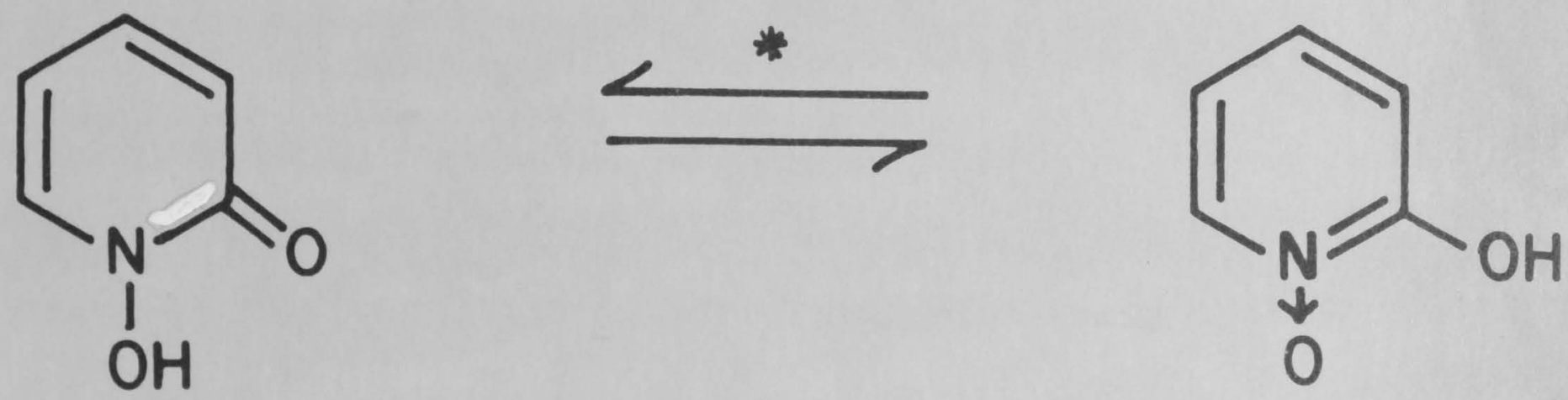

* U.V. stuaies 34,36 have shown that the 2-

hydroxypyridine-N-oxides exist in the hydroxamic acid rather than the $\mathrm{N}$-oxide form. 


\section{(b) Benzylidene condensations}

The attempts to condense the hydroxamic acid $\left(24 ; \mathrm{R}^{\prime}=\mathrm{H}\right)$ or the dimethyl ether $\left(24 ; \mathrm{R}^{\prime}=\mathrm{CH}_{3}\right)$ with a number of aldehydes are summarised in Tables (I) and (II). A wide variety of reaction conditions were employed, ranging from dimethylformamide-sulphur trioxide to dimethylsulphoxide anion-dimethylsulphoxide. The required condensation reaction was not effected in any of these experiments. ${ }^{*}$ Despite such failure, individual experiments merit discussion, in an attempt to explain the striking difference between the observed results and the success of similar condensations in the piperazinedione series (10c. cit.).

p-Acetoxybenzoic acid, isolated in 28 and $47 \%$ yields respectively, was the only crystalline product identified from the reaction of the hydroxamic acid (24; $\left.\mathrm{R}^{\prime}=\mathrm{H}\right)$ or the dimethyl ether $\left(24 ; \mathrm{R}^{\prime}=\mathrm{CH}_{3}\right)$ with $\mathrm{p}-$ hydroxybenzaldehyde in sodium acetate - acetic anhydride. The recovery of the acid rather than the aldehyde, is most likely due to oxidation under the conditions of the reaction - viz. $120-130^{\circ}$ in the presence of atmospheric

* A useful diagnostic test for the failure of the condensation reaction was the absence of $u_{0} v \cdot$ absorption at ca. $300 \mathrm{m \mu}$ in the crude product. Mycelianamide, which should serve as a reasonable model, shows $u_{\bullet} v$. absorption at $321 \mathrm{~m} \mu$ (10c. cit.). 


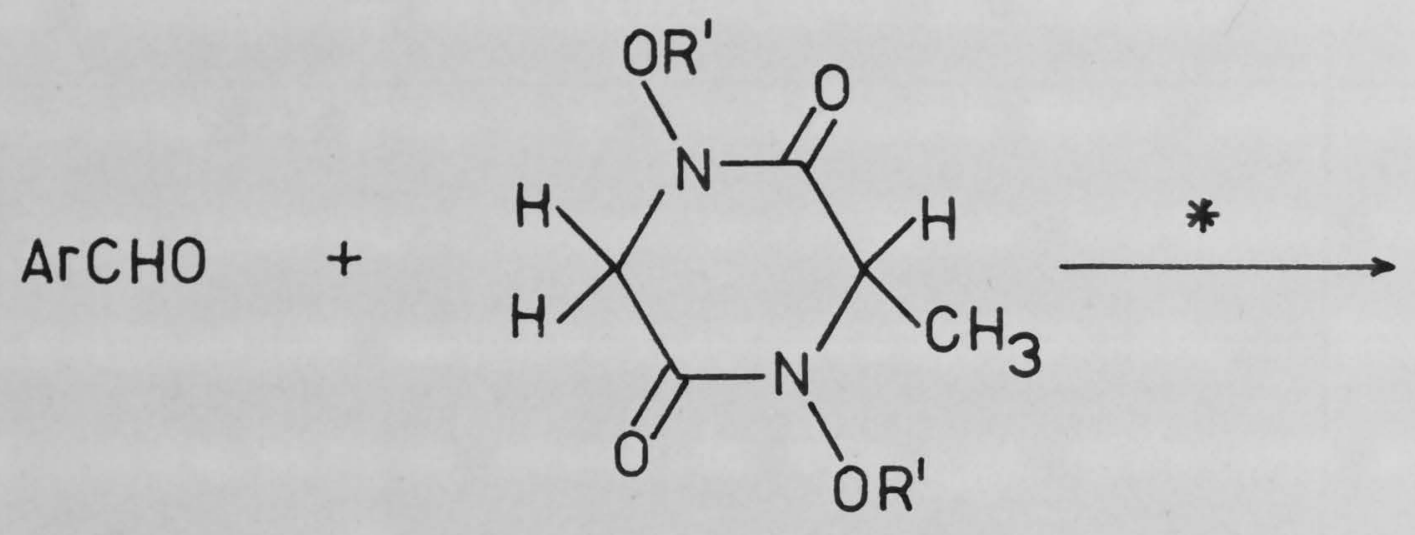

(24)

TABLE I

Hyaroxamic Acid $\left(24 ; \mathrm{R}^{\prime}=\mathrm{H}\right)$

\begin{tabular}{|c|c|c|c|}
\hline Run & $\begin{array}{l}\text { Aldehyde } \\
(\text { ArCHO })\end{array}$ & * Reagent and Conditions & Result \\
\hline 1 & $\begin{array}{l}\text { p-Hydroxy- } \\
\text { benzalde- } \\
\text { hyde }\end{array}$ & $\begin{array}{l}\mathrm{NaAC} / \mathrm{AC}_{2} \mathrm{O} \\
120-130^{\circ} / 8 \mathrm{hr} .\end{array}$ & a \\
\hline 2 & $\begin{array}{l}\text { p-Anisal- } \\
\text { dehyde }\end{array}$ & $\begin{array}{l}\mathrm{NaNH}_{2}(3.4 \text { molar excess }) \\
\mathrm{INH}_{3} / 4 \mathrm{hr} .\end{array}$ & $\mathrm{b}$ \\
\hline 3 & $\begin{array}{l}\text { p-Anisal- } \\
\text { dehyde }\end{array}$ & $\begin{array}{l}\operatorname{DMSO}^{\ominus}(4 \text { molar excess }) \\
\text { DMSO/4hr./room temp. }\end{array}$ & c \\
\hline
\end{tabular}

(a) p-Acetoxybenzoic acid recovered by chromatography.

(b) Aldehyde (ArCHO) recovered.

(c) DMSO $^{\ominus}$ reacted with aldehyde.

(d) (24) Recovered. 
TABLE II

Dimethyl Ether (24; $\mathrm{R}^{\prime}=\mathrm{CH}_{3}$ )

\begin{tabular}{|c|c|c|c|}
\hline Run & $\begin{array}{l}\text { Aldehyde } \\
\text { (ArCHO) }\end{array}$ & * Reagent and Conditions & Result \\
\hline 4 & $\begin{array}{l}\text { p-Hydroxy- } \\
\text { benzalde- } \\
\text { hyde }\end{array}$ & $\begin{array}{l}\mathrm{NaAC} / \mathrm{AC}_{2} \mathrm{O} \\
120^{\circ} / 8 \mathrm{hr}\end{array}$ & a \\
\hline 5 & $\mid \begin{array}{l}\text { p-Anisal- } \\
\text { dehyde }\end{array}$ & $\begin{array}{l}\mathrm{DMSO}^{\ominus}(1.2 \text { molar excess }) \\
\text { DMSO/5hr./room temp. }\end{array}$ & c \\
\hline 6 & Piperonal & $\begin{array}{l}\mathrm{CH}_{3} \mathrm{O}^{\ominus} / \mathrm{CH}_{3} \mathrm{OH} \\
7 \mathrm{hr} \cdot / \text { reflux }\end{array}$ & $b$ \\
\hline 7 & Piperonal & $\begin{array}{l}\mathrm{DMF} / \mathrm{SO}_{3} \text { (2 molar excess) } \\
\text { ca. } 100 \% \text { hr. }\end{array}$ & $b, d$ \\
\hline 8 & Piperonal & $\begin{array}{l}\mathrm{DMF} / \mathrm{SO}_{3} \text { ( } 8 \text { molar excess) } \\
\text { ca. } 100^{\circ} / 1 \mathrm{hr} .\end{array}$ & $b, d$ \\
\hline 9 & $\begin{array}{l}\text { p-Nitro- } \\
\text { benzalde- } \\
\text { hyde }\end{array}$ & $\begin{array}{l}\mathrm{DMF} / \mathrm{SO}_{3} \text { ( } 8 \text { molar excess) } \\
\text { ca. } 100^{\circ} / 4 \cdot 5 \mathrm{hr} .\end{array}$ & $b, d$ \\
\hline 10 & $\begin{array}{l}\text { p-Nitro- } \\
\text { benzalde- } \\
\text { hyde }\end{array}$ & $\mathrm{DMF} / \mathrm{KF}$ & $b, d$ \\
\hline
\end{tabular}

$a, b, c$ and $d$ see Table I. 
oxygen. More careful examination of the reaction product might also have raised the yield of recovered aldehyde, since appreciable amounts of oily products were present (see Experimental section).

Under the identical conditions but without the addition of p-hydroxybenzaldehyde, the dimethyl ether $\left(24 ; \mathrm{R}^{\prime}=\mathrm{CH}_{3}\right.$ ) was recovered in better than $50 \%$ yield. 2,5-Piperazinedione is converted quantitatively into the $\mathrm{N}, \mathrm{N}^{\prime}$-diacetyl derivative under these conditions. In fact $U \mathrm{Uda}^{22}$, postulated the intermediacy of the latter in the normal condensation reaction of 2,5-piperazinedione, since the same bis adduct (31), is formed from both (32) and $(33)$.

* As evidenced by the integrated n.m.r. spectrum of the crude reaction product. Thin layer chromatography (t.1.c.) also confirmed this result. 

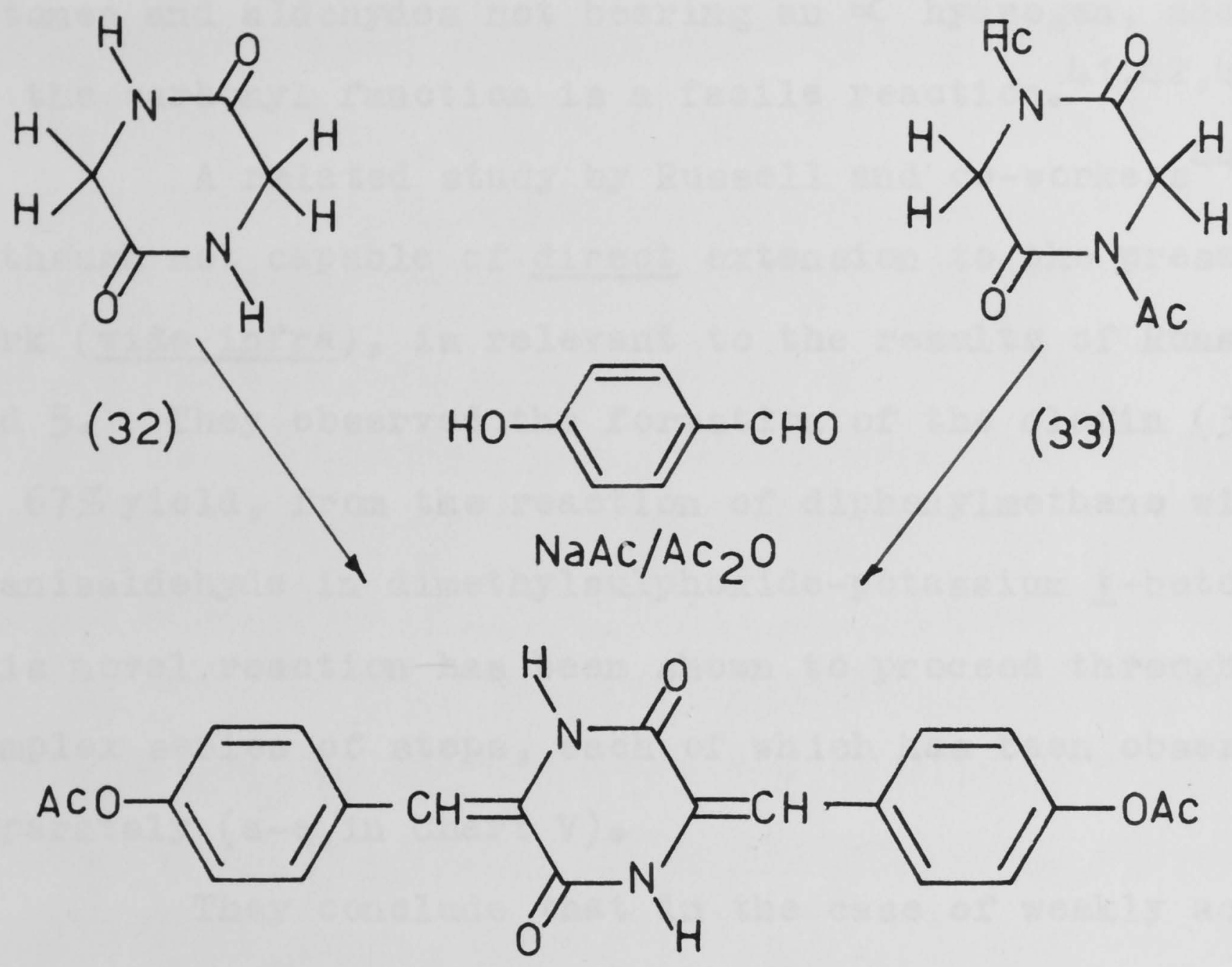

(31)

The use of dimethyl sulphoxide anion ${ }^{41}$ as the base in the condensation reaction (Runs 3 and 5), led to an adduct of the anion and the aldehyde, as the only product isolated. Corey and Chaykovsky ${ }^{41}$ found that the usual reaction of dimethylsulphoxide anion with enolisable ketones was a proton transfer leading to enolates, from which the ketones can be recovered by acidification. However in the case of camphor, and certainly with aromatic

* Although the exact nature of the adduct has not been determined, it had an i.r. absorption spectrum identical with that of the crude product formed by the reaction of dimethylsulphoxide anion with panisaldehyde under similar conditions. 
ketones and aldehydes not bearing an $\alpha$ hydrogen, addition to the carbonyl function is a facile reaction. $41,42,43$
A related study by Russell and co-workers ${ }^{44}$, although not capable of direct extension to the present work (vide infra), is relevant to the results of Runs 3 and 5. They observed the formation of the olefin (34) in $67 \%$ yield, from the reaction of diphenylmethane with p-anisaldehyde in dimethylsulphoxide-potassium $\underline{t}$-butoxide. This novel reaction has been shown to proceed through a complex series of steps, each of which has been observed separately (a-e in Chart V).

They conclude that in the case of weakly acidic active methylene compounds, the condensation reaction may proceed via the dimethylsulphoxide-aldehyde adduct; with stronger carbon acids, direct condensation with the aldehyde is probably operative.

With a view to obtaining a qualitative measure of the acidity of the methylene protons of the dimethyl ether ( $\left.24 ; \mathrm{R}^{\prime}=\mathrm{CH}_{3}\right)$, the n.m.r. spectrum in $\mathrm{a}_{6}$-dimethylsulphoxide-potassium $\underline{t}$-butoxide was measured; within 15 min. the signals due to $\mathrm{Ha}, \mathrm{Hb}$, and $\mathrm{Hc}$ had disappeared. Initially this was taken to indicate a fairly rapid proton exchange at these positions. Subsequent aqueous acidic work-up of the reaction mixture, however, led to the isolation of only small amounts of a mixture of water- 


\section{CHART V}

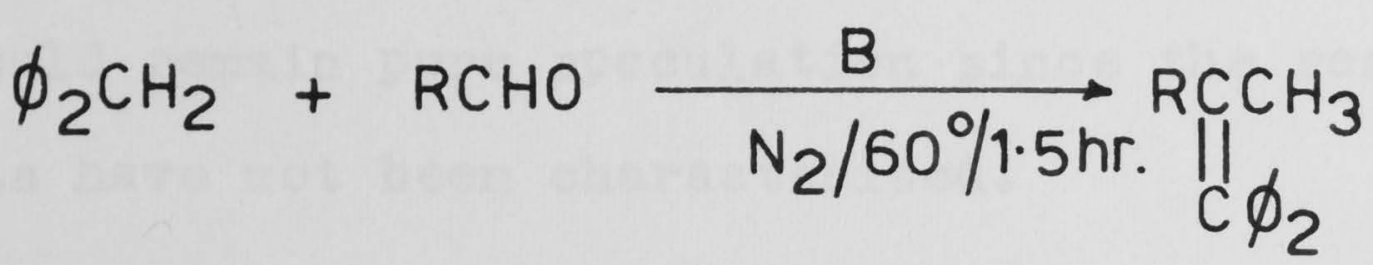

$$
\begin{aligned}
& \left(\mathrm{B}=\mathrm{K} \pm \mathrm{BuO} / \mathrm{DMSO}: \mathrm{R}=\underline{\mathrm{p}}-\mathrm{CH}_{3} \mathrm{O}-\mathrm{C}_{6} \mathrm{H}_{4}\right)
\end{aligned}
$$

(a) Addition of DMSO to the aldehyde.

$$
\mathrm{RCHO}+\mathrm{CH}_{3} \mathrm{SOCH}_{3} \frac{\mathrm{B}}{30 \% 10 \mathrm{~min} .} \mathrm{RCHOHCH}_{2} \mathrm{SOCH}_{3}
$$

(b) Dehydration to an unsaturated sulphoxide.

$\mathrm{RCHO}+\mathrm{CH}_{3} \mathrm{SOCH}_{3} \frac{\mathrm{B}}{60 \% / 1.5 \mathrm{hr} .} \mathrm{RCH}=\mathrm{CHSOCH}_{3}(47 \%)$

(c) Michael addition of diphenylmethane.

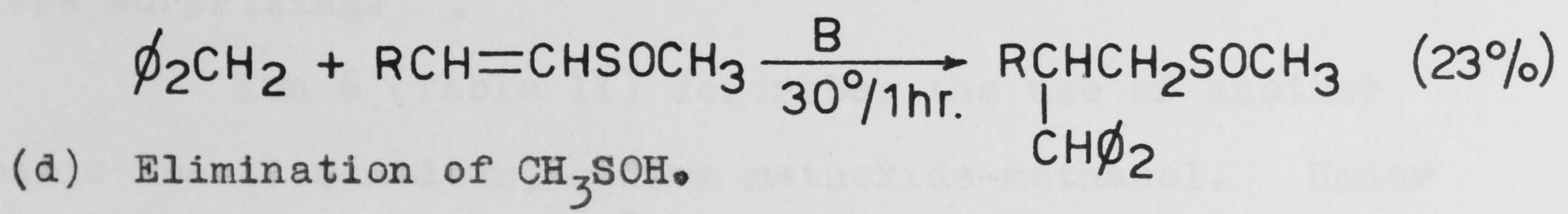<smiles>[R]CC([R])C[Sb](C)=O</smiles>

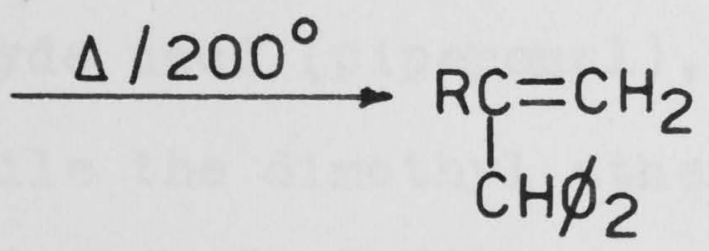

(e) Rearrangement of the terminal olefin.<smiles>[R][C][R]</smiles><smiles>CC(C)=[18O]</smiles> 
soluble products not containing any unchanged starting material." Several mechanistic pathways for the decomposition of $\left(24 ; \mathrm{R}^{\prime}=\mathrm{CH}_{3}\right.$ ) with base can be envisaged, but they would remain pure speculation since the reaction products have not been characterised.

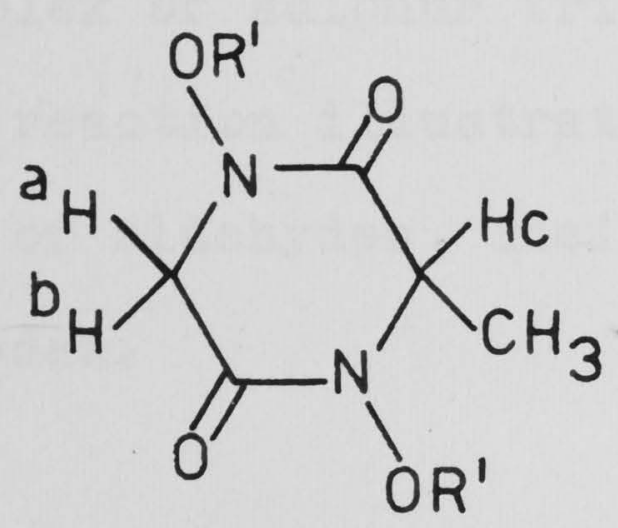

(24)

The instability of the dimethyl ether to the action of strong base, together with the results of Russel and co-workers (10c. cit.), makes the present experience with dimethylsulphoxide anion (Runs 3 and 5) less surprising.

Run 6 (Table II) describes the use of another basic reaction medium, sodium methoxide-methanol. Under these conditions, the aldehyde used (piperonal), was recovered in good yield, while the dimethyl ether was apparently destroyed. Subsequently, this was confirmed by the conversion of the dimethyl ether to a mixture of water-soluble products, when subjected to the action of

* As evidenced by t.1.c. (see Experimental section). 
methanolic sodium methoxide. In contrast, 2,5piperazinedione was recovered in $88 \%$ yield from an identical reaction.

Since the use of strong bases was precluded, a milder condensing agent was sought. One which had been used successfully for the synthesis of azalactones such as (35), was a complex of sulphur trioxide and dimethylformamide. 45 The reaction illustrated below was successful with a variety of aldehydes, including vanillin and p-hydroxybenzaldehydes.

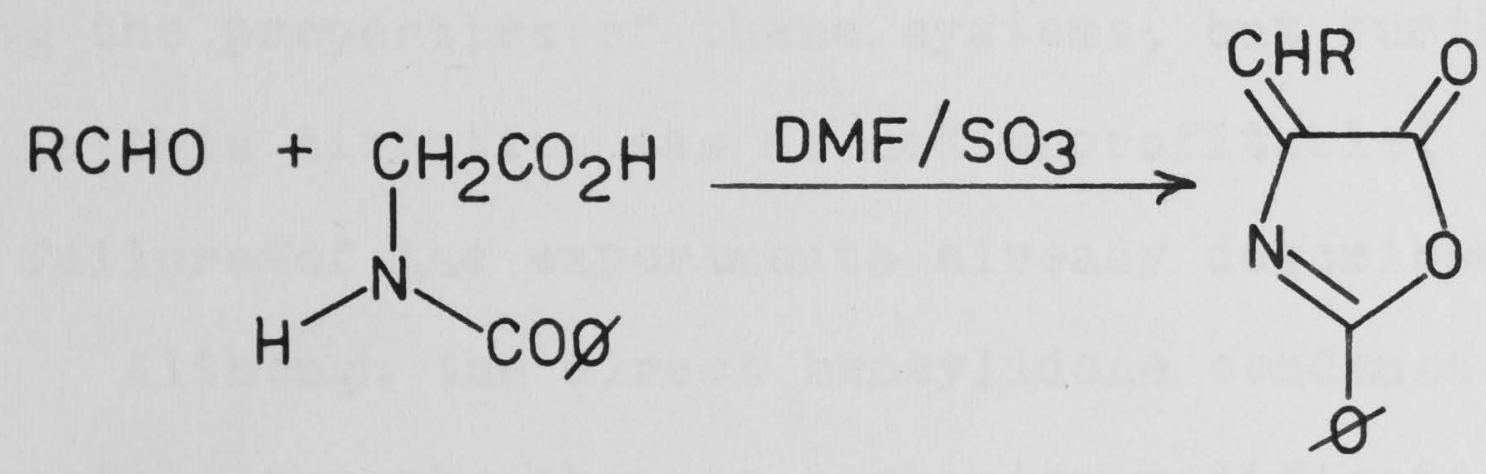

(35)

Experiments using the dimethylformamide-sulphur trioxide reagent are summarised in Runs 7,8 and 9 of Table II; in each case, both reactants (aldehyde and dimethyl ether) were recovered almost quantitatively, by chromatography of the crude reaction mixture. A similar result was observed using potassium fluoride in dimethyl formamide. $46 \%(R$ un 10$)$.

* Reference 46 describes the use of potassium fluoride in ethanol. 
Therefore, under a wide variety of reaction conditions, the benzylidene condensation approach to synthesis of mycelianamide was unsuccessful. In part this was due to the instability of the cyclic dihydroxamic acid ring to the action of strong bases, but under the milder conditions employed, to the unexplained inability of this heterocyclic system to undergo the required condensation with aldehydes. Some measure of the acidity of methylene protons of the hydroxamic acid $\left(24 ; R^{\prime}=H\right)$ or the dimethyl ether $\left(24 ; \mathrm{R}^{\prime}=\mathrm{CH}_{3}\right.$ ) might still be useful in understanding the properties of these systems, but further effort in this direction was deemed unprofitable, in view of the failure of the experiments already described.

Although the direct benzylidene condensation was unsuccessful, the phosphonate carbanion modification 48 of the Wittig reaction provided an appealing alternative. This reaction, which in some instances has advantages over the normal Wittig procedure, is depicted in general terms in Chart VI. However, application to the present problem was thwarted by the reluctance of the dimethyl ether (24; $\mathrm{R}^{\prime}=\mathrm{CH}_{3}$ ), to brominate with either $\mathrm{N}$-bromosuccinimide or bromine in acetic acid.

* After the completion of the work described in section I of this thesis, it was learned that another group engaged upon the synthesis of mycelianamide had also found a similar approach unsuccessful. 47

\# Thin layer chromatography indicated the formation of small amounts of unknown products with this reagent, but unchanged dimethyl ether was the only product isolated by chromatography on silica gel. 
CHART VI.
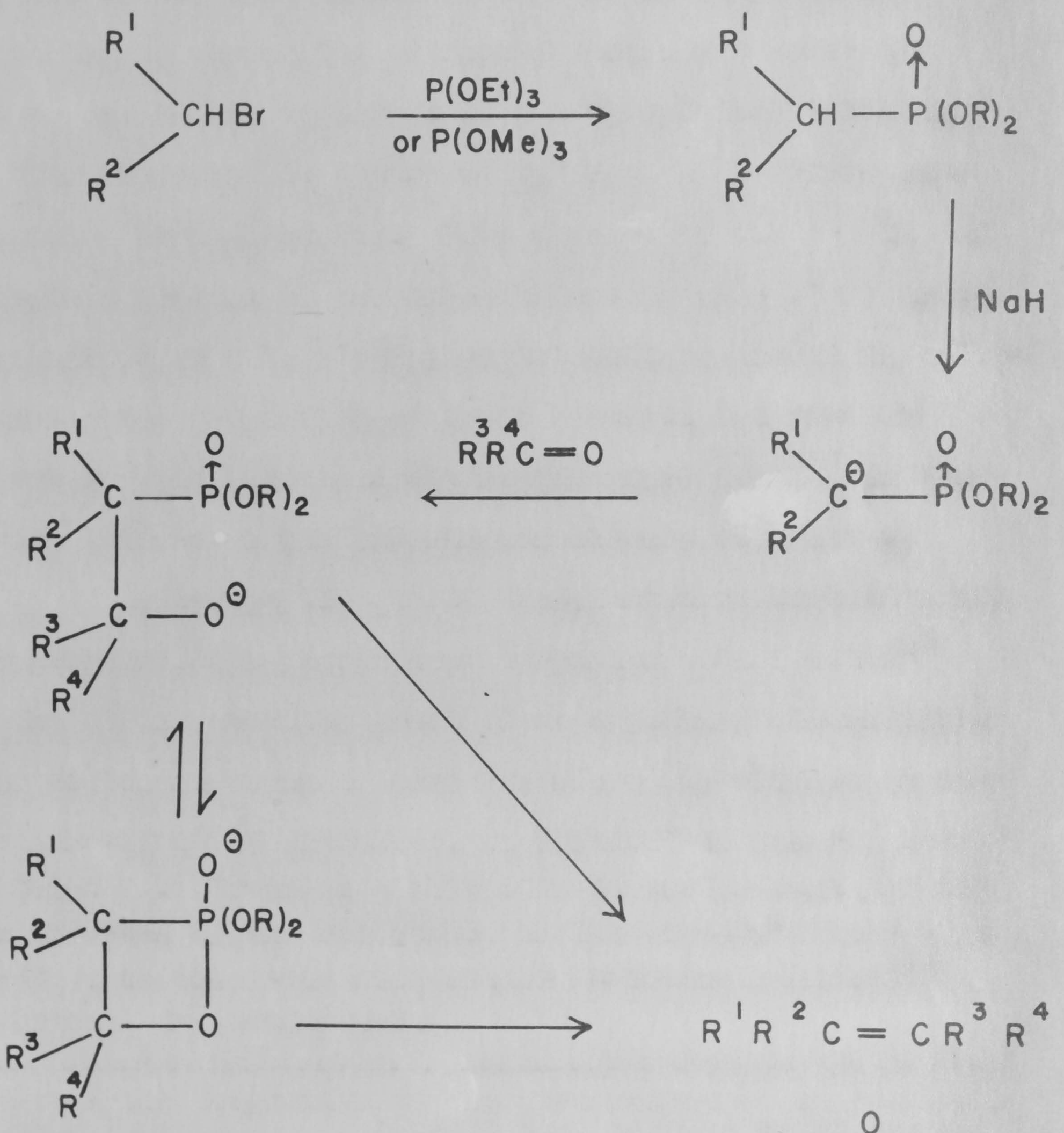

$R^{1} R^{2} C=C R^{3} R^{4}$

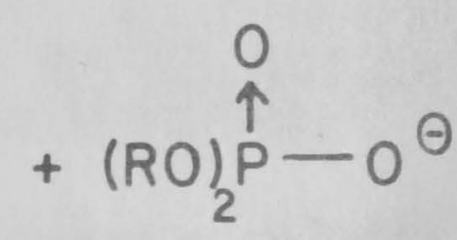


SECTION II 


\section{SECTION II}

\section{Introduction and Synthetic scheme}

The failure of the benzylidene condensation approach to the synthesis of mycelianamide, implied that an alternative approach involving a preformed benzylidene linkage was desirable. Such a study and the ramifications arising therefrom, are described in section II of the thesis.

An appealing starting material was provided by the nitrocinnamic ester (36) obtained 49 from nitroacetic ester and benzylidene-N-butylamine. A para-substituted derivative of (36) would provide the aromatic ring of mycelianamide, as well as the functionalisation required for introduction of the terpenoid side chain and synthesis of the heterocyclic ring of the antibiotic.

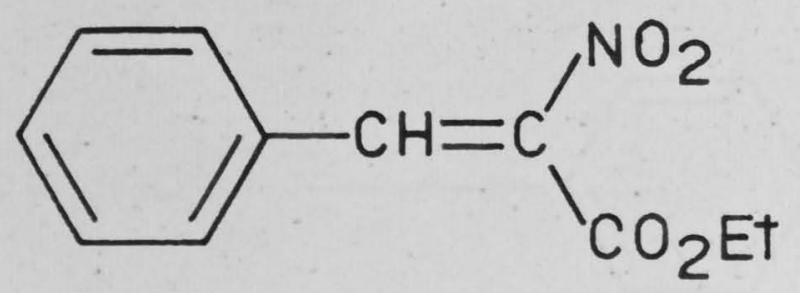

(36)

* Appropriately protected if necessary. 
A synthetic scheme devised on this basis is described in Charts VII and VIII. Individual steps of the proposed synthesis will be discussed with reference to their feasibility and to analogies which exist in the chemical literature.

In view of the experience already gained in this synthetic investigation, the protection (Step 1) and reintroduction (Step 7 (ii)) of the olefinic bond were expected to be critical stages in the overall synthesis. Discussion of these two operations will be deferred, except to comment that the initial protection was necessitated by the prediction that reduction of an intermediate such as (A) would lead to a saturated oxime rather than an $\alpha, \beta$-unsaturated hydroxylamine. The report ${ }^{50}$ that $\beta$-nitrostyrene (37) is reduced to the oxime of phenylacetaldehyde (38), by the action of aluminium amalgam or zinc in acetic acid, lends support to this prediction.

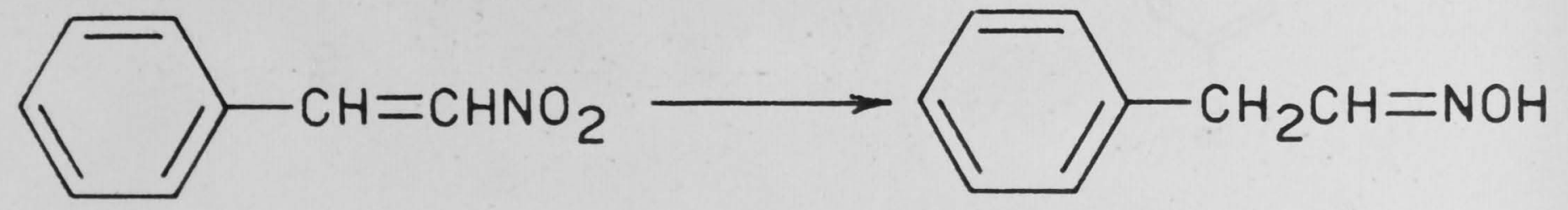


CHART VII.

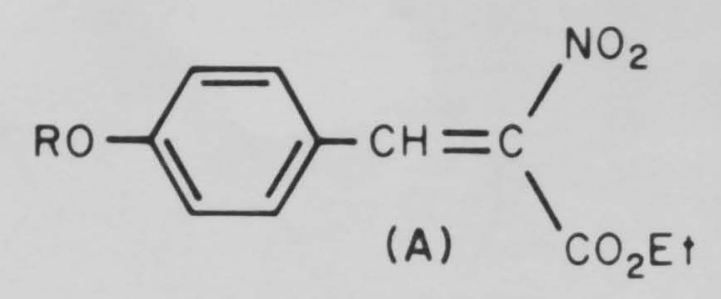

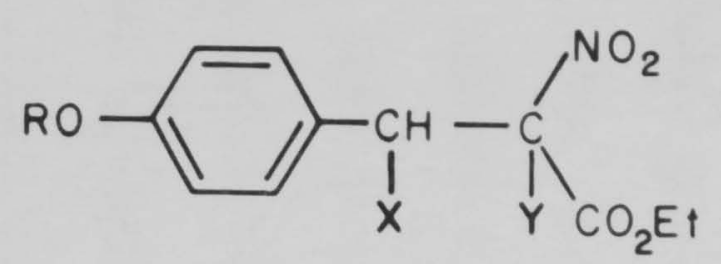

(B)

EP 2

$\mathrm{Al} / \mathrm{Hg}$.

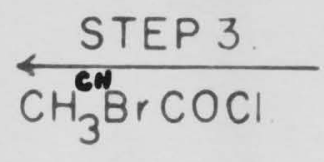

(D)

STEP 4

$\mathrm{NH}_{2} \mathrm{OH}$

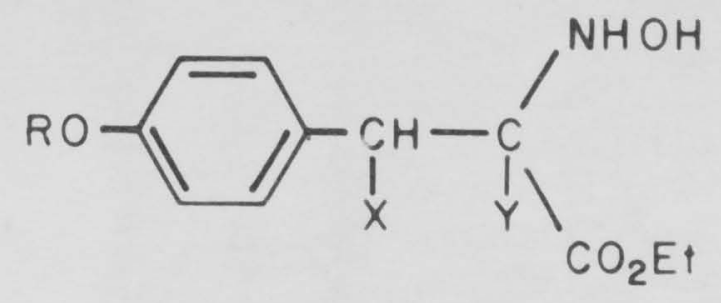

(C) 
CHART VIII.<smiles>[R20]c1ccc(C([X])C2([Y])C(=O)N(O)C(C)(C)C(=O)N2O)cc1</smiles><smiles>[R]ON1C(=O)C(C)(C)N([R])C(=O)C1([Y])C([X])c1ccc(O)cc1</smiles>

STEP 6 Geranyl bromide

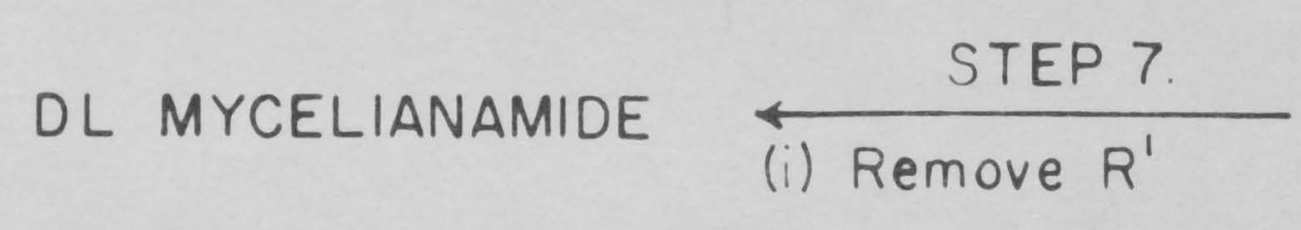
(ii) $-X Y$

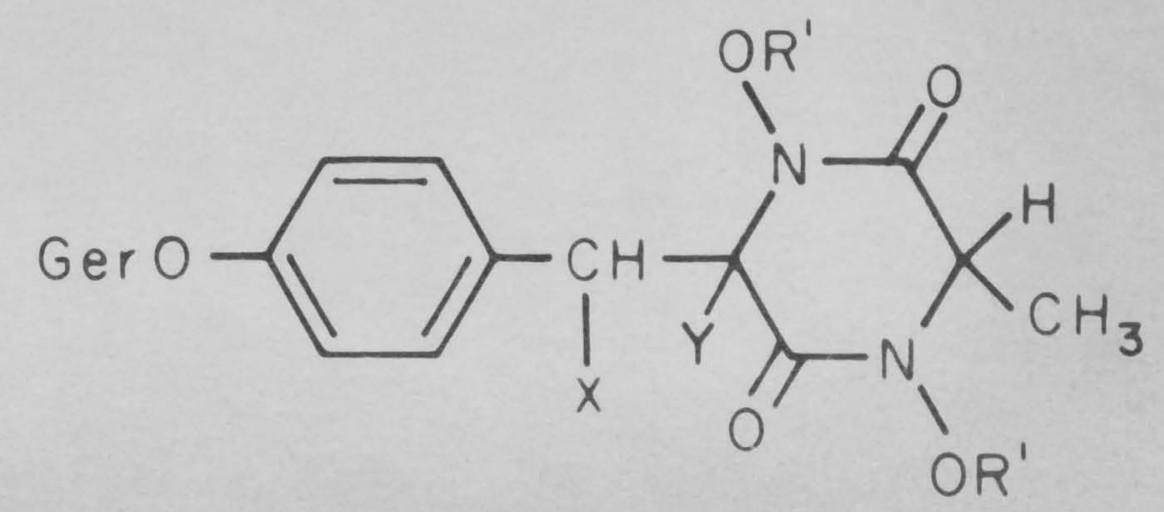

(G) 
Reduction of a nitro ester such as (B) to the hydroxylamine oxidation state has a direct analogy in the aluminium amalgam reduction of nitroacetic ester itself. 51 In this case both ethyl hydroxylamino acetate and the over-reduction product, glycine ethyl ester, were produced. Modification of the reaction conditions might prevent such over-reduction. Steps 3 and 4 directly parallel the corresponding acylation and cyclisation processes in the synthesis of the simple dihydroxamic acid (24; $\left.\mathrm{R}^{\prime}=\mathrm{H}\right)$. The isolation of a hydroxamic acid such as (E) was again expected to be difficult, with the added complication of the formation of another asymmetric centre in the acylation step.

The multiple process represented by the transformation $(E)-\rightarrow(F)$ requires that the protecting group $R^{\prime}$ be stable under the conditions needed for the removal of $R$ and vice versa. The latter group should also be stable to the basic conditions of the cyclisation (step 4 ). Additionally, introduction and removal of such protecting groups should be performed under fairly mild conditions, in view of the acid and particularly, base lability of the mycelianamide system ( $\left.10 c_{\text {e cit. }}\right) 0^{\text {\# }}$ A wide range of protecting groups has been developed and at least one recent general review is available。 52

s. Such considerations also indicate that the reintroduction of the olefinic linkage should be a penultimate stage of the overall synthesis. 
Precedent for the geranylation (Step 6) is provided by the structural studies of mycelianamide previously discussed. $15-17$

Problems inherent in the interrelated processes of Steps 1 and 7 (ii) are central to the proposed synthesis and deserve detailed comment. Ideally, the method used for the protection and subsequent reintroduction of the olefinic bond should be stereospecific. In addition, the protecting group must survive a variety of subsequent steps and the conditions for its removal must ensure the continued stability of the basic structure of mycelianamide. One group of olefin syntheses which satisfy these criteria to a greater or lesser degree, are those which proceed via initial oxidation of the double bond. of these, the elegant procedure of Corey et.al. 53,54, which is both stereospecific and orientationally specific, is probably the best available. This method, which involves elimination of 1,2-thionocarbonates or 1,2trithiocarbonates by heating with trialkyl phosphites, is illustrated below in general terms. 


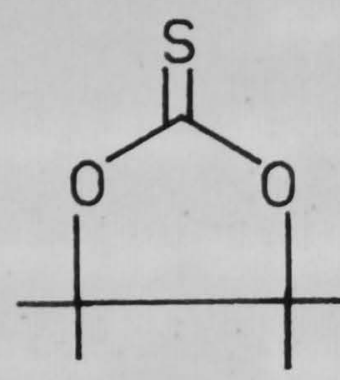

$$
\left.+(R O)_{3} P \frac{\Delta}{\text { cis elim. }}\right\rangle\left\langle\begin{array}{l}
+(R O)_{3} P S \\
+\mathrm{CO}_{2}
\end{array}\right.
$$

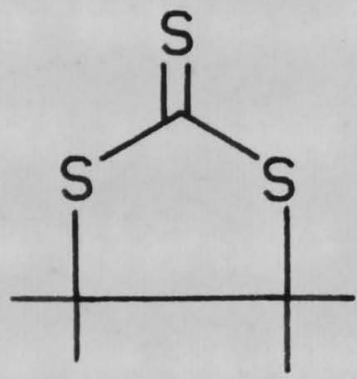

$+(\mathrm{RO})_{3} \mathrm{P} \frac{\Delta}{\underline{\text { cis elim }}}$

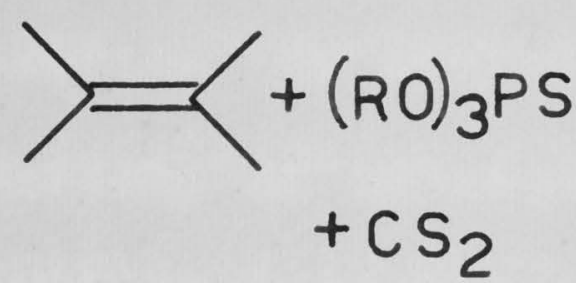

Procedures which also employ a similar principle include the acid-catalysed elimination of 1,3dioxolans 55 , the elimination of episulphides with alkyl lithium reagents, trialkyl phosphines or trialkyl phosphites ${ }^{56}$, the Raney nickel elimination of ethylene thioketals $\mathrm{s}^{57}$ and the trialkyl phosphite-induced elimination of epoxides. 58 The reductive elimination of epoxides (probably via transient iodohydrins) reported by Cornforth et.al. 59 may also be included in this category. However, application of any of the abovementioned syntheses to the present work was deemed improbable due to the resistance to oxidation expected of intermediates such as (A). . $^{\text {XI }}$

I The ease of reduction of the mycelianamide system (Ioc. cit.) imposes a severe limitation on the use of any reductive procedure.

w\# This prediction has been given experimental support (vide infra). 
Another extensive group of olefin syntheses involves the addition 60 and subsequent elimination ${ }^{61}$ of halogens or halogen acids. Such methods were removed from consideration since intermediates such as ( $D ; X$ or $\left.Y=H a I_{0}\right)$ would contain more than one halogen of comparable reactivity. Previous (aluminium amalgam reduction) and subsequent (hydroxylamine cyclisation) reactions could lead to complex mixtures of products.

A third general group of olefin-forming reactions are those which proceed via a predominantly cis intramolecular cyclic thermal elimination $\left(E_{i}\right)$ mechanism. The well documented xanthate $e^{62-64}$ and ester $65-67$ pyrolyses are representative examples. Probably of more synthetic utility is the Cope elimination of $\mathrm{N}, \mathrm{N}$-dialkylamine oxides to give olefin and the corresponding $N, N$-dialkyl hydroxylamine. Initial studies ${ }^{68}$ showed that a $\boldsymbol{\beta}$ hydrogen was a necessary condition for this elimination and a mechanism involving an intra- or intermolecular attack of the $\beta$ hydrogen by the $N$-oxide oxygen was proposed. Subsequent studies 70,71 established that the elimination was intramolecular and stereospecifically cis. A planar five membered transition state such as (39) was

* A mechanism analogous to that of the Hofmann exhaustive methylation which proceeds via hydroxide ion attack on the hydrogen $\boldsymbol{\beta}$ to the quaternary nitrogen.69 
therefore probably involved. Comparisons with the Hofmann procedure have been made for unsymmetrically substituted cases where more than one olefinic product is possible. 72,73

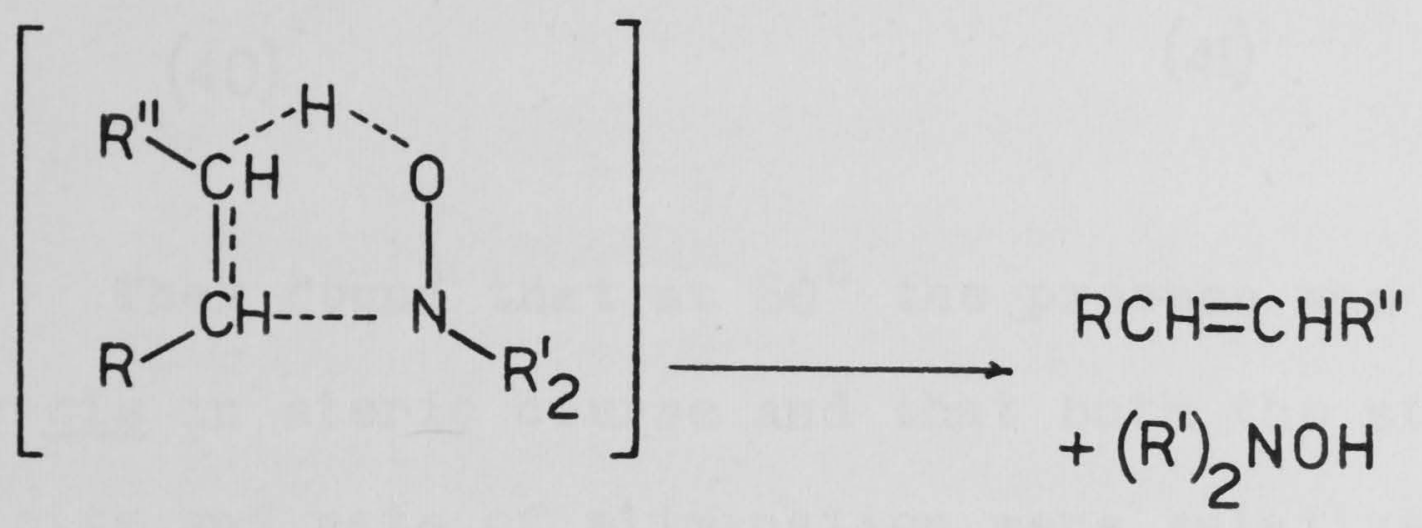

(39)

More recently, kinetic studies of the Cope elimination 74,75 have uncovered significant rate enhancements when the eliminations were carried out in scrupulously dried solvents (eg. tetrahydrofuran and dimethylsulphoxide). Under such conditions appreciable rates of elimination were obtained at $25^{\circ}$.

A viable alternative to the Cope elimination has become available in the analogous $\beta$ elimination reaction of sulphoxides. In their original study, Kingsbury and Cram $^{76}$ observed the pyrolytic elimination of the four diastereomeric racemates of 1,2-diphenyl-1-propyl phenyl sulphoxide (40), to give cis and trans $\alpha$-methylstilbenes (41).

* For example when the hydrate of threo-N, N-dimethyl-3phenyl-2-butylamine-N-oxide was dissolved in dioxane and the water removed with molecular sieves at $25^{\circ}$, the reaction went to completion in the course of drying. 


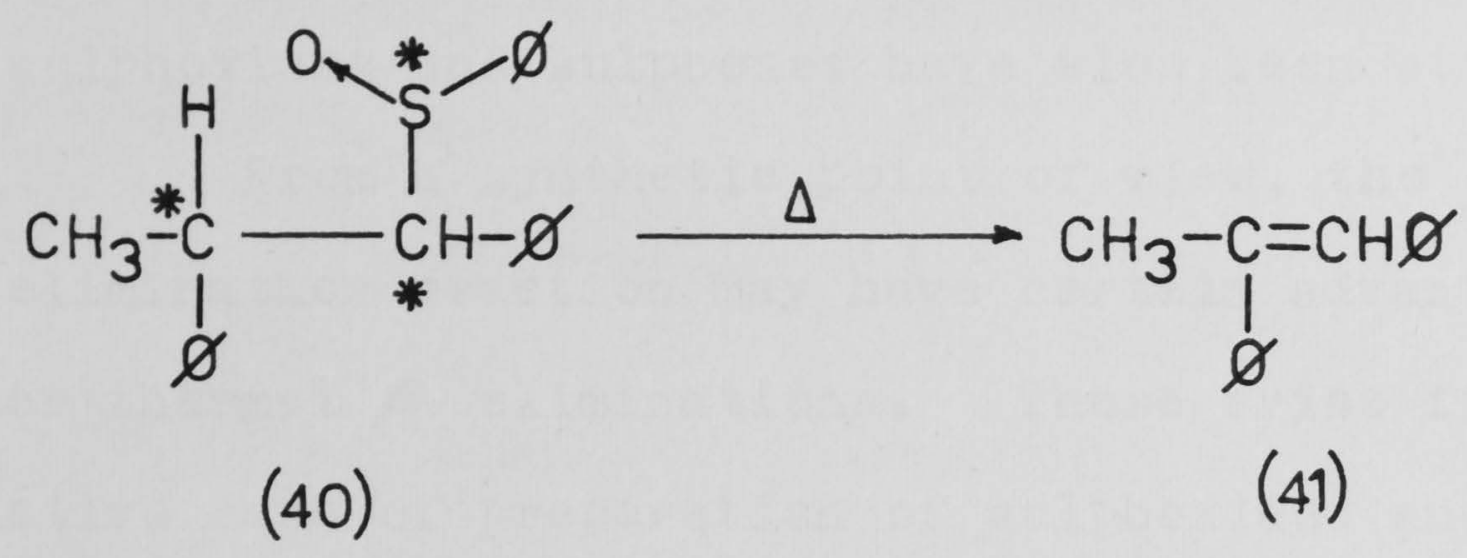

They found that at $80^{\circ}$ the process was predominantly cis in steric course and that both the stereospecificity and rate of elimination were relatively insensitive to marked changes in the polarity of the reaction medium. These observations were consistent with an intramolecular cyclic $\left(E_{i}\right)$ elimination, directly aralogous to the Cope elimination. At the higher temperatures studied $\left(\right.$ ca. $\left.120^{\circ}\right)$, the reaction was not stereospecific and a radical mechanism which could assume either steric course, was proposed. The sulphones corresponding to (40) were completely unreactive in the elimination reaction at temperatures up to $120^{\circ}$. Since the original study described above, numerous communications have appeared supporting the general applicability of thermal $\beta$ elimination reactions of sulphoxides to olefin synthesis. Thus olefins have been prepared by the pyrolysis of dialkylsulphoxides $77-80$, arylmethyl sulphoxides ${ }^{81}$, alicyclic sulphoxides ${ }^{82}$ and a 
steriodal sulphoxide. 83 Base-catalysed $\beta$ eliminations of sulphoxides and sulphones have also been studied $84-86^{\%}$.

From a synthetic point of view, the sulphoxide elimination reaction may have certain advantages over other thermal $\boldsymbol{\beta}$ eliminations. These arise from the relative ease of preparation of sulphoxides and the high yields and low temperatures ( their transformation to olefins. Considerations such as these and others delineated below, made the $\boldsymbol{\beta}$ elimination of a sulphoxide (or a closely related group) the method of choice in the present investigation.

Such a choice requires that the original protection of the double bond (step 1) should involve Michael addition of a thiol. Precedent for such a reaction exists in the study of the base-catalysed addition of thiols to $\propto$-nitroolefins reported by Heath and Lambert. 88 Representative examples from this study are displayed in Chart IX. Intermediates such as (A) should be even more

* Reference 85 also describes a competitive $\gamma$ elimination to form cyclopropanes.

* Rate enhancements using dry solvents, similar to those reported for the Cope elimination (loc, cit.), might also be realisable with sulphoxides. However such effects would be less dramatic in the latter case, since the sulphoxide bond is probably best described as a double bond whereas the $\mathrm{N}$-oxide bond is dipolar in nature. 87

*** Potentially, such an addition allows the $\boldsymbol{\beta}$ elimination of sulphonium salts 86,89 as a further alternative to sulphoxide pyrolyses. 
CHART IX.

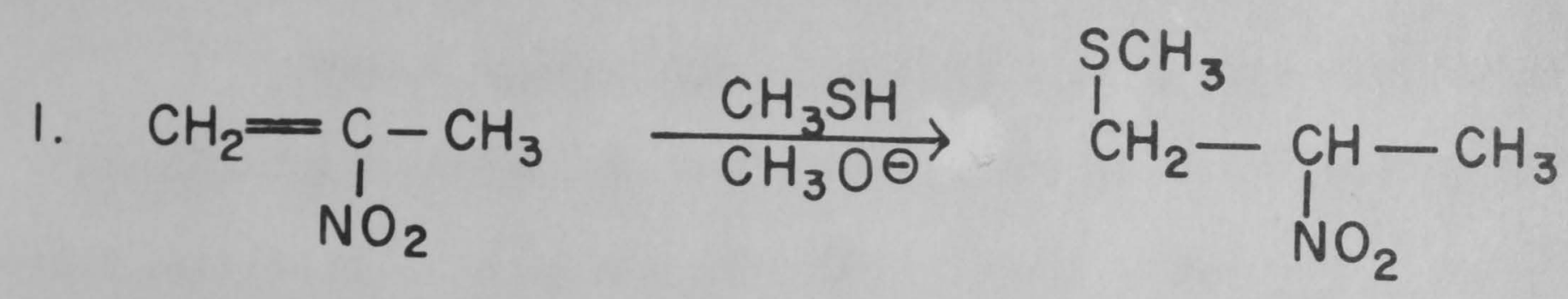

2. $\left.\right|_{\mathrm{NO}_{2}} ^{\mathrm{CH}_{3}}-\underset{\mathrm{CHCH}_{3}}{\mathrm{C}} \frac{\mathrm{CH}_{3} \mathrm{SH}}{\mathrm{CH}_{3} \mathrm{O}^{\Theta}} \mathrm{CH}_{3}-\mathrm{CH}-\underset{\mathrm{NO}_{2}}{\mathrm{CH}}-\mathrm{SH}_{3}-\mathrm{CH}_{3}$

3. $\Phi-\mathrm{CH}=\mathrm{CHNO}_{2} \frac{\mathrm{CH}_{3} \mathrm{SH}}{\mathrm{CH}_{3} \mathrm{O}^{\ominus}} \underset{\mathrm{SCH}_{3}}{\rightarrow} \underset{\mathrm{CH}}{\mathrm{C}}-\mathrm{CH}_{2} \mathrm{NO}_{2}$

4. $\underset{\mathrm{NO}_{2}}{\stackrel{\mathrm{CH}_{2}}{2}=\mathrm{CHCH}} \stackrel{\Phi \mathrm{SH}}{\mathrm{CH}_{3} \mathrm{O} \theta} \underset{\mathrm{NO}_{2}}{\longrightarrow} \underset{\mathrm{S} \Phi}{\mathrm{CH}_{2}}-\underset{\mid}{\mathrm{CH}}-\mathrm{CH}_{3}$

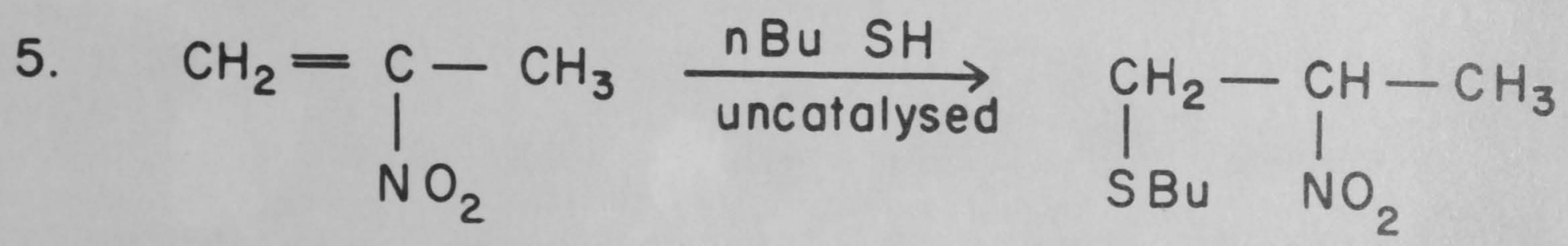


activated towards nucleophilic attack, than any of the examples discussed by these authors.

One significant disadvantage of protection of the double bond by means of addition of a dialkylamine and subsequent elimination of the $\mathrm{N}$-oxide, is that the primary addition product, probably (42), might be difficult to reduce to the hydroxylamine oxidation state (Step 2). An added complication could be a displacement reaction at the ester grouping.

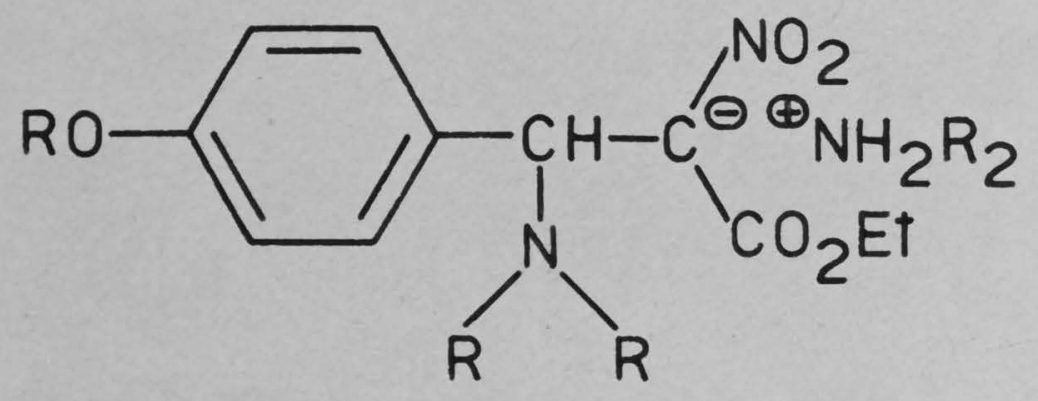

(42)

A limitation common to all methods which involve additions to olefins such as (A), is the likely production of erythro and threo racemates. Even if the additions are stereospecific, intermediates such as ( $B ; Y=H)$ would epimerise rapidly under basic conditions. Separation of isomers at such an early state in the overall synthesis would be a major drawback. The alternative of carrying a mixture of isomers through to a penultimate stage of the synthesis would be equally untenable. 
From the foregoing discussion it is obvious that an a priori synthesis which is completely unambiguous is improbable. A basic problem is the multiple functionality exhibited by the synthetic intermediates. This imposes a severe limitation on the range of processes which can be utilised and also requires them to be highly selective. The present investigation was often a compromise between the principles outlined above and the needs of practical feasibility. 


\section{Discussion of results}

(a) Basic synthetic steps

Repetition of the work of Dornow and Menzel 49

indicated that the single isomer (m.p. $73^{\circ}$ ) of the nitrocinnamic ester (36) reported by these authors, was accompanied by a second oily isomer. In particular, the n.m.r. spectrum of the chromatographed mixture exhibited a duplication of the signals expected of (36). Although the oily isomer could not be obtained free from the crystalline modification, the crude product was almost certainly a mixture of the $\underline{c i s}^{\text {XF }}$ and $\underline{\text { trans }}^{\text {XX }}$ isomers (43) and (44).

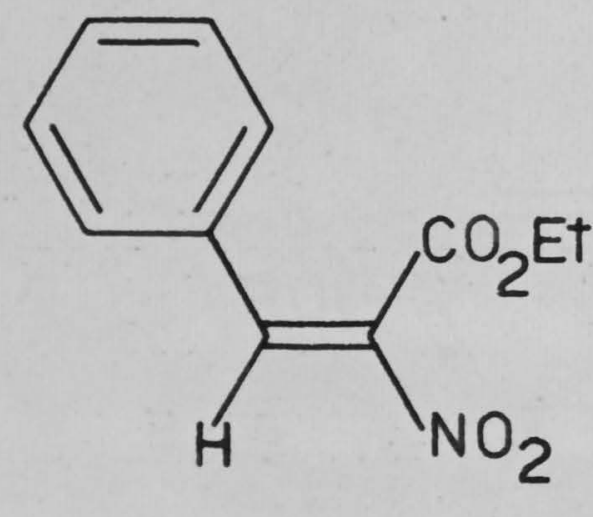

(43)

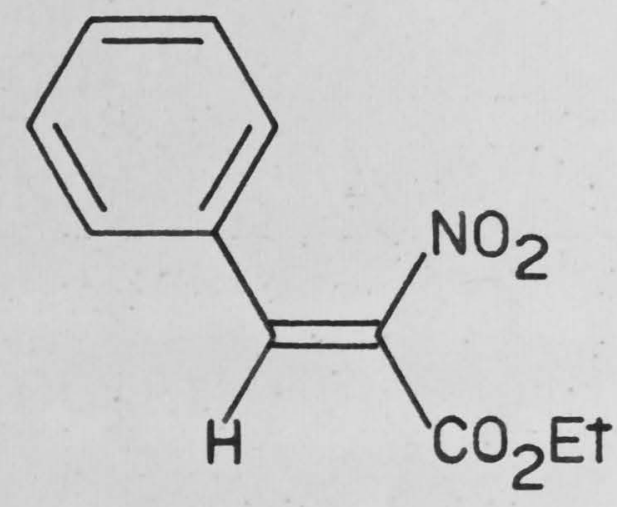

(44)

* Except for the methyl protons of the carbethoxyl group which had the same chemical shift in both isomers. \#F Throughout this thesis molecules such as (36) are said to have the cis stereochemistry when the aryl and carbonyl functions are is disposed about the double bond. Molecules with the trans stereochemistry have these groups trans to one another. 
Ideally, the protecting group $\mathrm{R}$ of the intermediate (A) (Chart VII) should be stable to base hydrolysis. Initial studies made with the tetrahydropyranyl group were thwarted by the non-crystalline nature of the intermediates $(45-47 ; R=T H P)$. This made their characterisation difficult and separation of possible isomers of (47; R=THP) virtually impossible. Although less desirable as a protecting group, the benzoyloxy group resulted in crystalline intermediates $(45,47 ; \mathrm{R}=\mathrm{CO} \varnothing)$.

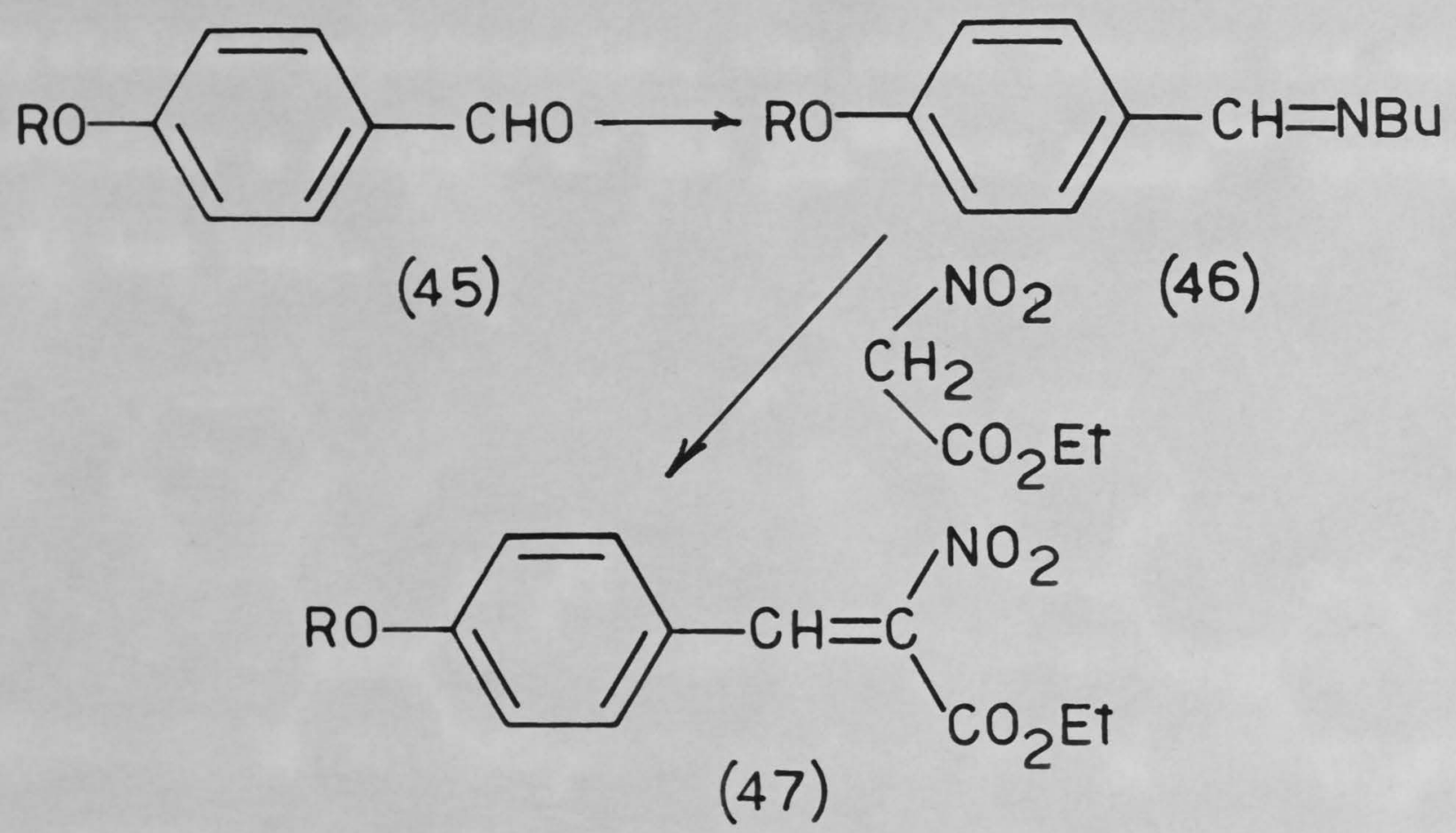

In accord with the analogous synthesis of (36), the nitroolefin ( $47 ; \mathrm{R}=\mathrm{CO} \varnothing)$ was obtained as a separable mixture of the crystalline cis and trans isomers (48) and (49). Relevant spectral data for the mixtures (36) and ( $47 ; \mathrm{R}=\mathrm{CO} \varnothing$ ) as well as those for trans ethyl cinnamate (50), trans $\boldsymbol{\beta}$-nitrostyrene $(51)^{90}$ and ethyl- $\alpha$-cyanocinnamate $(52)^{91}$, are collected in Table III. 
CHART $X$

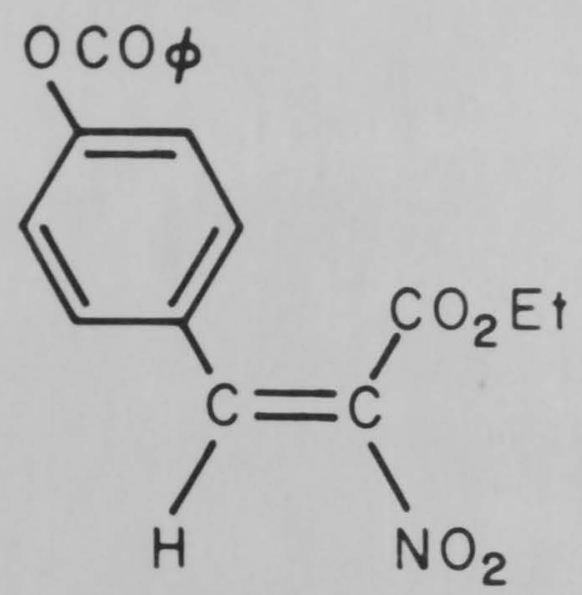

(48)

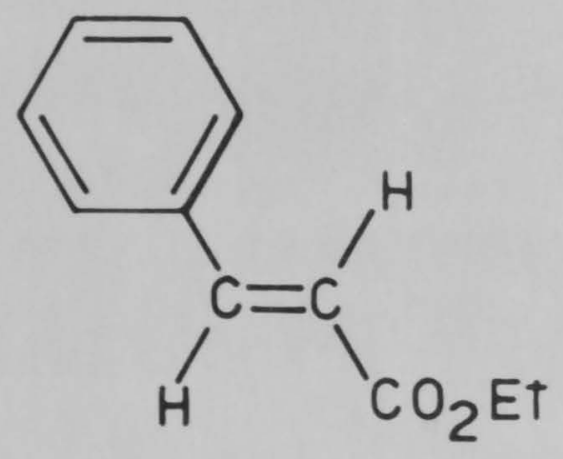

(50)

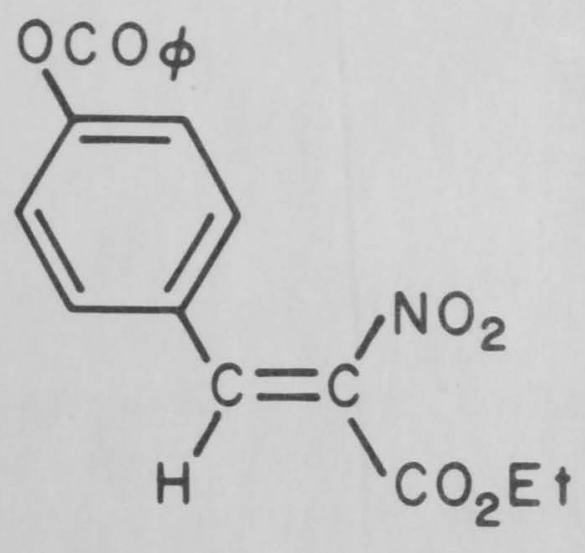

(49)

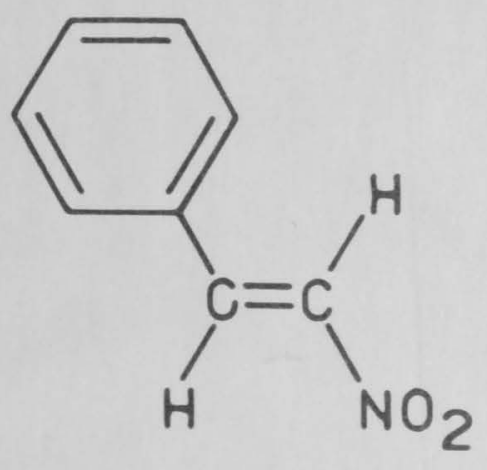

(51)

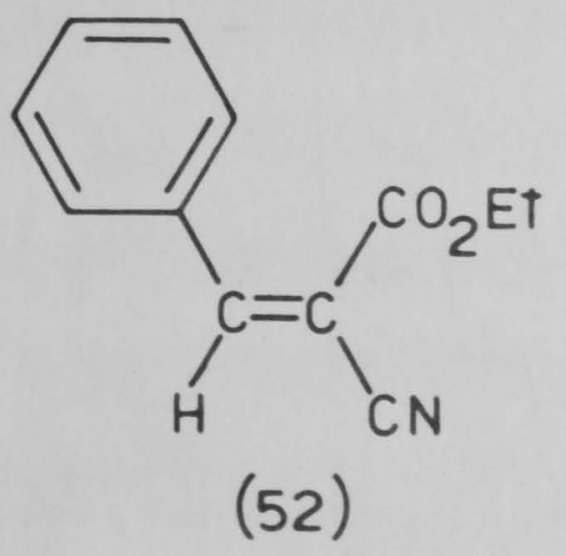


TABLE III

\begin{tabular}{|c|c|c|c|}
\hline \multirow{2}{*}{ Compound } & \multirow{2}{*}{$\lambda_{\max } \cdot(m \mu)$} & \multicolumn{2}{|c|}{ Chemical Shift $(T)$} \\
\hline & & vinylic $\mathrm{H}$ & $\mathrm{CO}_{2} \mathrm{CH}_{2} \mathrm{CH}_{3}^{\mathrm{a}}$ \\
\hline (36) high m.p. & 214,280 & 2.44 & 5.59 \\
\hline low $m_{\bullet} p_{0}$ & - & 1.93 & $5 \cdot 55$ \\
\hline$(47 ; \mathrm{R}=\operatorname{CO} \varnothing)$ & & & \\
\hline high $m . p$ & 223,283 & $2 \cdot 4^{b}$ & 5.60 \\
\hline low m•p. & 231,317 & 1.96 & 5.55 \\
\hline$(50)$ & 221,276 & $2.30,3.57^{c}$ & $5 \cdot 70$ \\
\hline (51) & 226,311 & $1.99,2.46^{\mathrm{d}}$ & - \\
\hline$(52)$ & - & 1.78 & 5.62 \\
\hline
\end{tabular}

a. Quartet $(J=7.0 \pm 0.5 \mathrm{cps}$ )

b. Obscured by aromatic protons.

c. $A$ and $B$ protons of $A B$ quartet ( $J_{A B}=16.0 \pm 0.5 \mathrm{cps}$ )

d. $A$ and $B$ protons of $A B$ quartet (J $A B=14.0 \pm 0.5 \mathrm{cps}$ ) 
Inspection of the n.m.r. data of Table III indicates that both the vinylic protons of (51) absorb at lower field than the corresponding protons of (50). Additionally, the low field doublet of the former appears a approximately the same chemical shift as the vinylic protons of the low m.p. modifications of (36) and (47; $\mathrm{R}=\mathrm{CO} \varnothing$ ). It was thus tempting to assign these modifications the cis configurations (43) and (48) and the high m.p. modifications the corresponding trans configurations (44) and (49). However such assignments ${ }^{\text {F }}$ would only be tentative and would require independent confirmation. Addition of methyl mercaptan to a mixture of (48) and (49) containing a trace of pyridine, afforded a single crystalline isomer of the nitro ester $\left(53 ; \mathrm{R}_{\mathrm{NO}}\right)$. The n.m.r. spectrum of the addition product was consistent with it being a single isomer. Rapid equilibration occurred when a trace of pyridine was added to a solution of $\left(53 ; \mathrm{R}_{\mathrm{NO}}\right)$ in deuterochloroform, the n.m.r. spectrum then displaying signals for both the erythro and threo isomers (ca. equimolar mixture). This behaviour is illustrated in Chart XI in which only signals above $4.0 \tau$ are shown, since the complex aromatic signals show very little change on equilibration.

* Knowledge of the configuration of these isomers is not central to the present synthesis, since $(47 ; R=C O \varnothing)$ was subsequently used as a mixture. However, the tentative assignments described above are consistent with elimination reactions described in a later section of this thesis. 


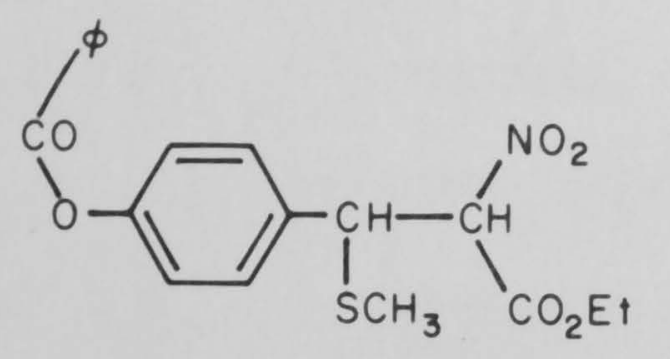

SOLVENT: $\mathrm{CDCl}_{3}$
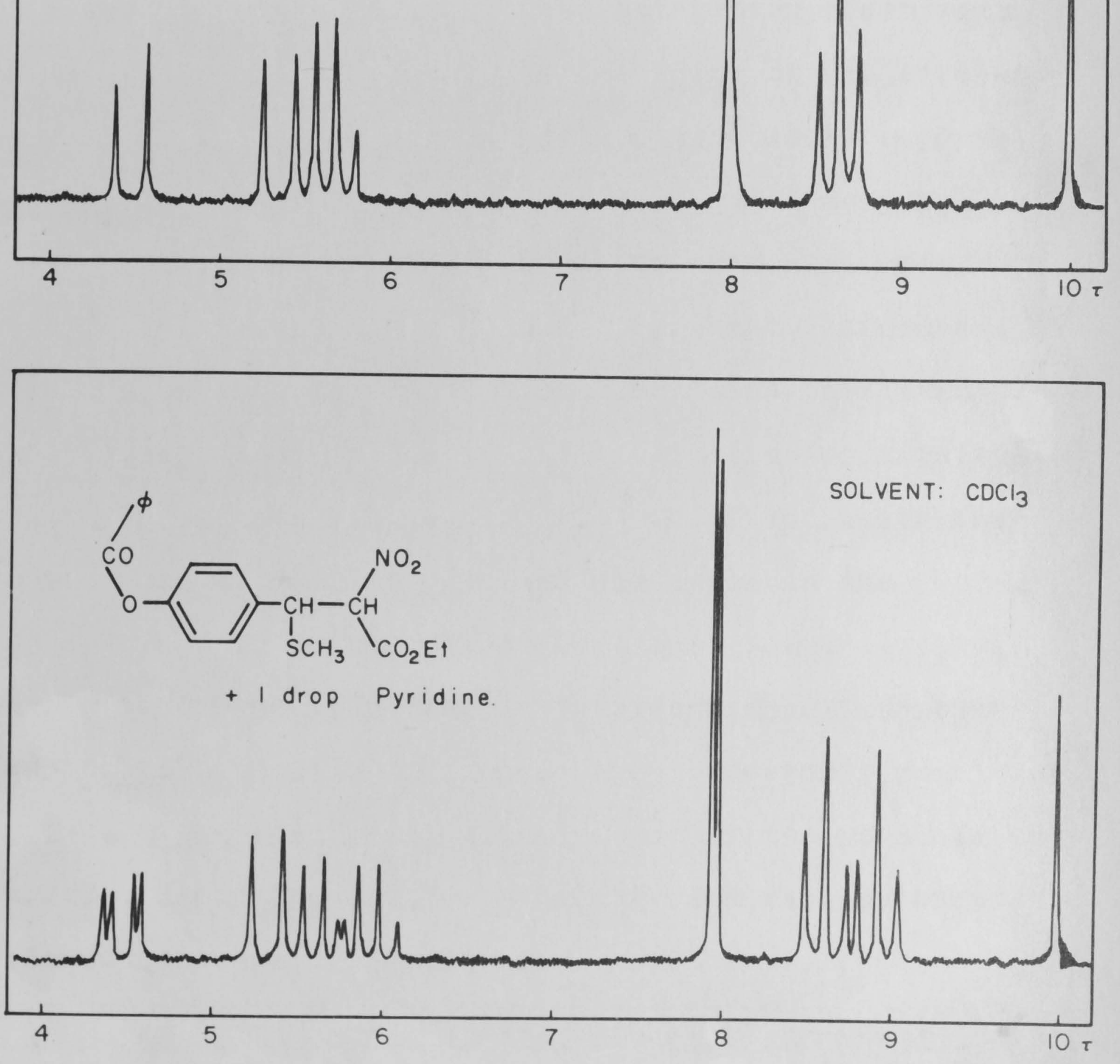


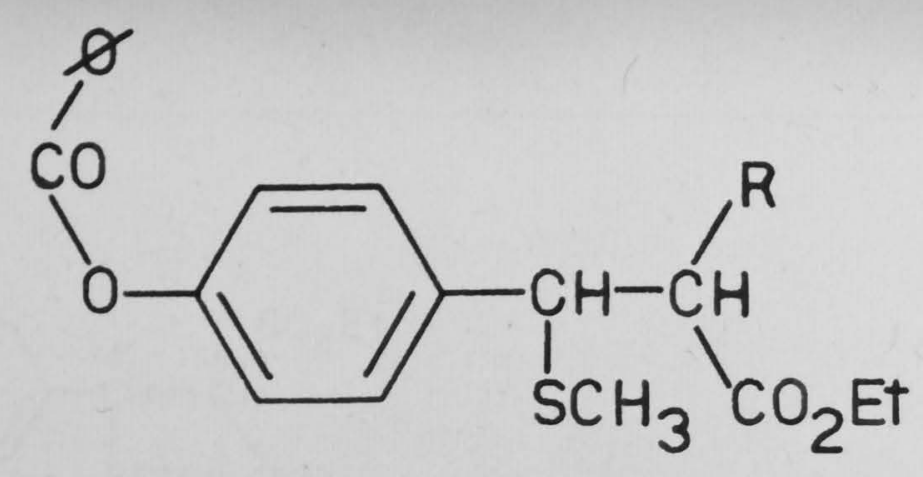

(53)

In contrast to the above behaviour, addition of methyl mercaptan to the crystalline isomer of (36) led directly to a mixture of erythro and threo isomers. A similar mixture resulted from the addition of methanol to the same olefin. Chart XII displays the n.m.r. spectra of these two mixtures which at equilibrium contained a predominance of one isomer. In accord with prediction, addition of dimethylamine to the above nitroolefin gave rise to a complex mixture of products, part of which probably resulted from a displacement reaction at the carbethoxyl group.

The behaviour of (36) towards Michael addition indicates that the single isomer of (53) probably resulted from a selective crystallisation of one of the possible isomers. Such a result, while unexpected, was fortunate for the continuation of the overall synthesis.

As a model for step 2 of the proposed synthesis, the nitro ester $\left(54 ; \mathrm{R}=\mathrm{NO}_{2}\right)^{92}$ was reduced with aluminium 

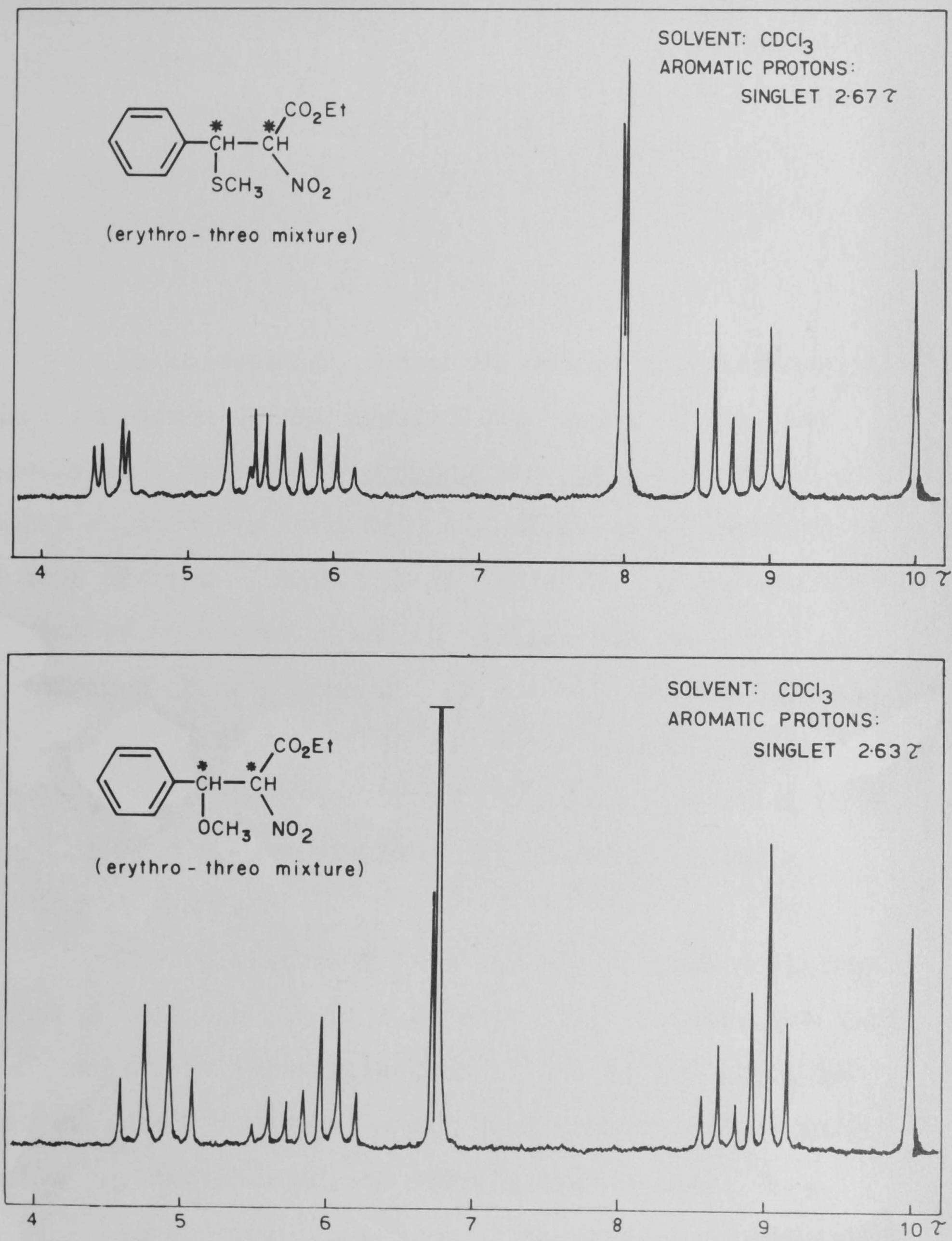
amalgam 93 in moist ethyl acetate at $0^{\circ}$, to afford the hydroxylamino ester ( $54 ; \mathrm{R}=\mathrm{NHOH})$, albeit in low yield. Under exactly similar conditions, the nitro ester (53; $\mathrm{R}=\mathrm{NO}_{2}$ ) was reduced smoothly to a single isomer of the hydroxylamino ester ( $53 ; \mathrm{R}=\mathrm{NHOH})$. No over-reduction to the amine was observed.

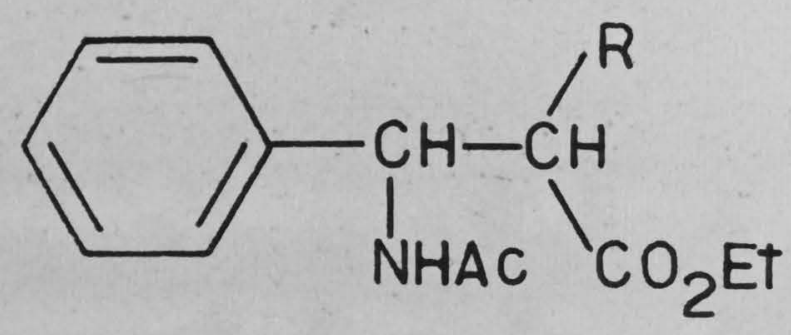

(54)

Acylation of ( $53 ; \mathrm{R}=\mathrm{NHOH}$ ) with exactly one mole of $\alpha$-bromopropionyl chloride afforded the hydroxamic acid (55) in $49 \%$ yield. As expected, this intermediate, although crystalline, was a mixture of isomers as shown by the m.p. $\left(119-124^{\circ}\right)$ and the n.m.r. spectrum. Thin layer chromatography showed the presence of two closerunning compounds, each of which, when removed from the plate and rechromatographed, ran as a single spot. In subsequent experiments the nitro ester was reduced and acylated directly, without purification. Under these conditions the hydroxamic acid (55), isolated by chromatography on silica gel and then recrystallisation, was 
obtained as a single isomer m.p. $130-132^{\circ}$, which ran as a single spot on t.l. c.

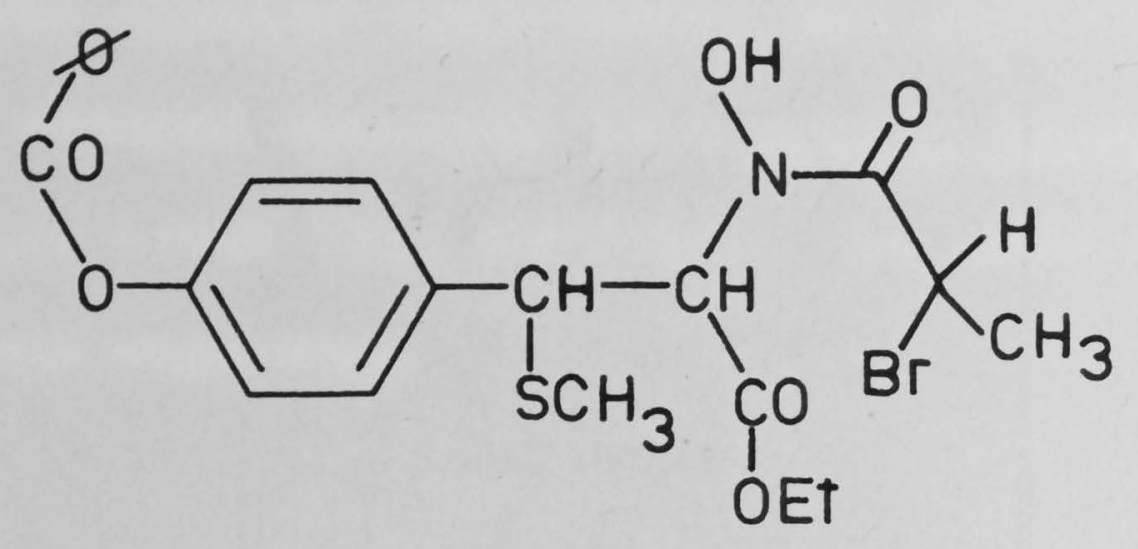

(55)

The n.m.r. spectra of the isomeric modifications of (55) are recorded in Chart XIII. Comparison of these spectra with those of Chart XI indicates that the stereochemistry established in $\left(53 ; \mathrm{R}=\mathrm{NO}_{2}\right)$ has been retained. The isomers of (55) are therefore a result of the introduction of another asymmetric centre in the acylation step. Initial attempts to cyclise (55) with hydroxylamine $e^{* *}$ or 0 -benzyl hydroxylamine were inconclusive, in accord with previous experience. ${ }^{*}$ After many exploratory studies, it was found that treatment of (55)

* Again this is probably a result of selective crystallisation of one isomer. The single isomer was used to seed recrystallisations of all subsequent batches of (55) which was never obtained in greater than $50 \%$ yield. \# Regenerated from the hydrochloride with sodium methoxide.

\#F See the synthesis of the simple hydroxamic acid (24; $\left.\mathrm{R}^{\prime}=\mathrm{H}\right)$, Section I of this thesis. 
CHART XIII

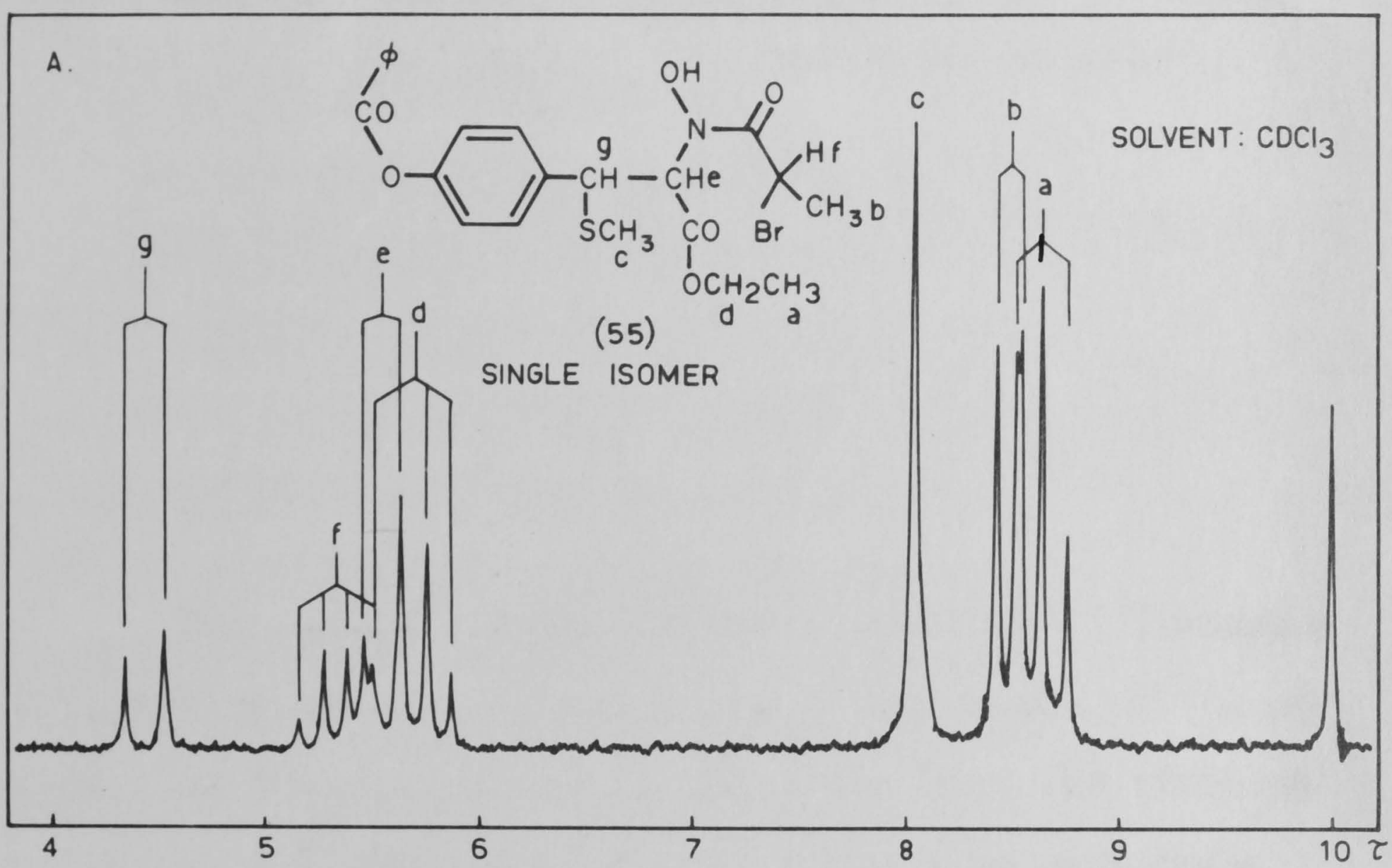

B.

(55) MIXTURE OF ISOMERS

SOLVENT: $\mathrm{CDCl}_{3}$

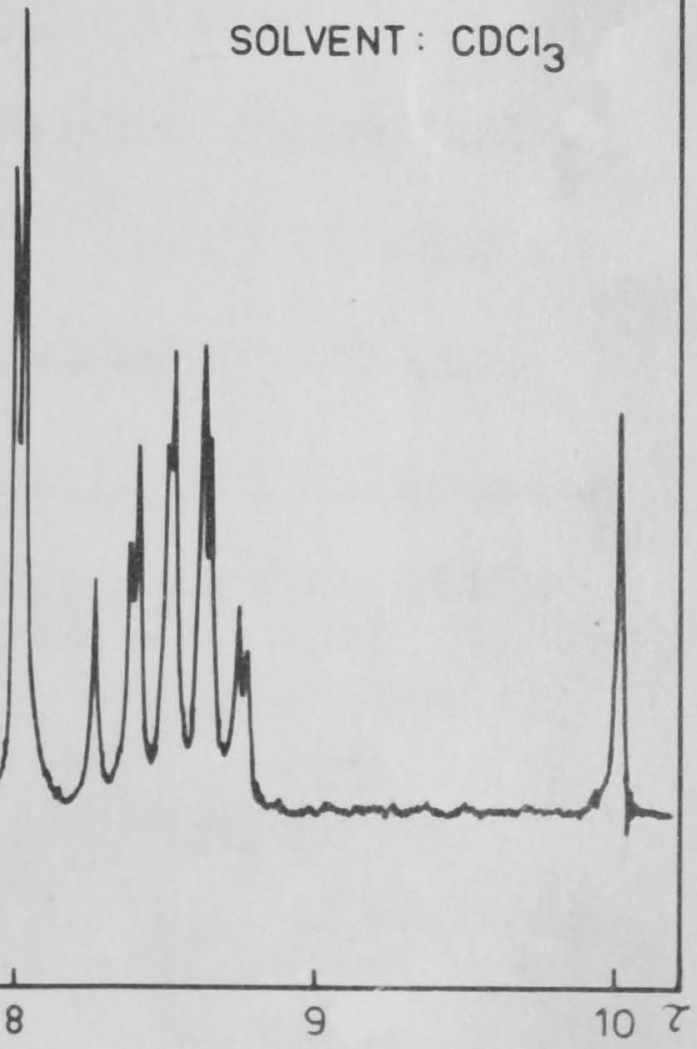


with a twenty-fold excess of anhydrous methanolic hydroxylamine 94 effected cyclisation, but with concomitant hydrolysis of the p-benzoyloxy group. The water-soluble cyclisation product, the cyclic dihydroxamicl(56) was isolated in $59 \%$ yield by partition chromatography on buffered cellulose powder.

Confirmation of the structure of the cyclisation product was provided by the n.m.r. spectrum, (in $\mathrm{d}_{6}$ dimethylsulphoxide) and by its conversion to a number of derivatives outlined in Chart XIV. Treatment of (56) with acetic anhydride in pyridine (or preferably with acetyl chloride) gave the triacetate (57) which exhibited the characteristic ${ }^{95}$ high i.r. frequency for the hydroxamic acetates $\left(1800 \mathrm{~cm}^{-1}\right)$. The phenolic acetate absorbed at the normal position 96 of $1760 \mathrm{~cm}^{-1}$.

Methylation of (56) with an excess of ethereal diazomethane, surprisingly led to a crystalline dimethyl ether as the major product ( $58 \%$ ), accompanied by a trace of the trimethyl ether. Acetylation of the dimethyl ether afforded an acetate which exhibited i.r. absorption at $1760 \mathrm{~cm}^{-1}$. This observation indicates that exclusive methylation of the two hydroxamic acid groups had occurred.

\% N.m.r. spectroscopy was an invaluable tool in this investigation since most of the synthetic intermediates exhibited highly characteristic spectra. A general discussion of these spectra will be presented at a later stage. 
The dimethyl ether was thus (58) and the derived acetate (59). Although unexplained, the selective methylation of (56) potentially allows the synthesis at least of the dimethyl ether of mycelianamide.

Initial attempts to convert some of the abovementioned intermediates to substrates suitable for elimination reactions, were uniformly unsuccessful. Thus (55) was recovered unchanged when treated with methyl iodide at room temperature or under reflux, while at $100^{\circ}$ in a sealed tube, extensive decomposition occurred. Similarly (57) was unaffected by refluxing methyl iodide. As a model for sulphoxide and sulphone syntheses, the nitro ester (53) was treated with two moles of $\underline{m}$-chloroperbenzoic acid in chloroform at room temperature - the sulphone (60) resulted in high yield.

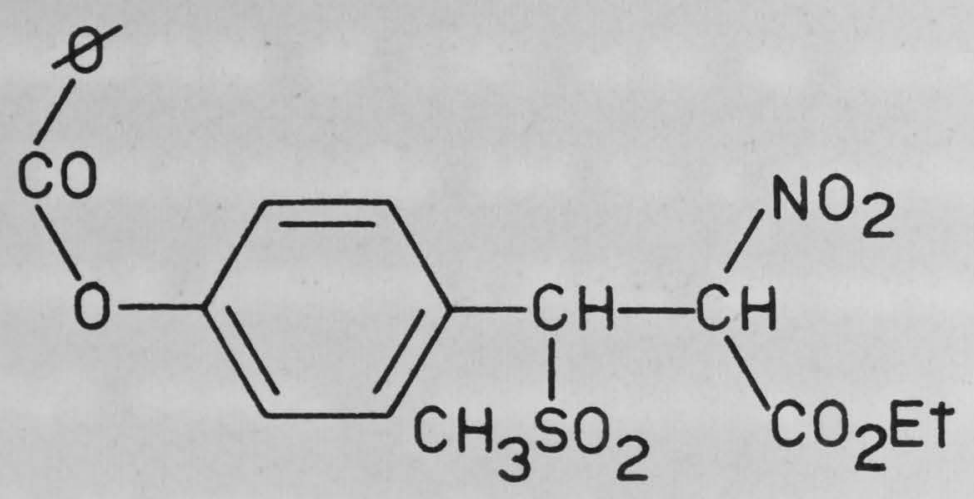

(60) An attempt to prepare the corresponding sulphoxide
oxidation of ( 53 ) with one mole of m-chloroperbenzoic
acid, gave an entirely different result which will be
discussed at a later stage.

by 
CHART XIV.

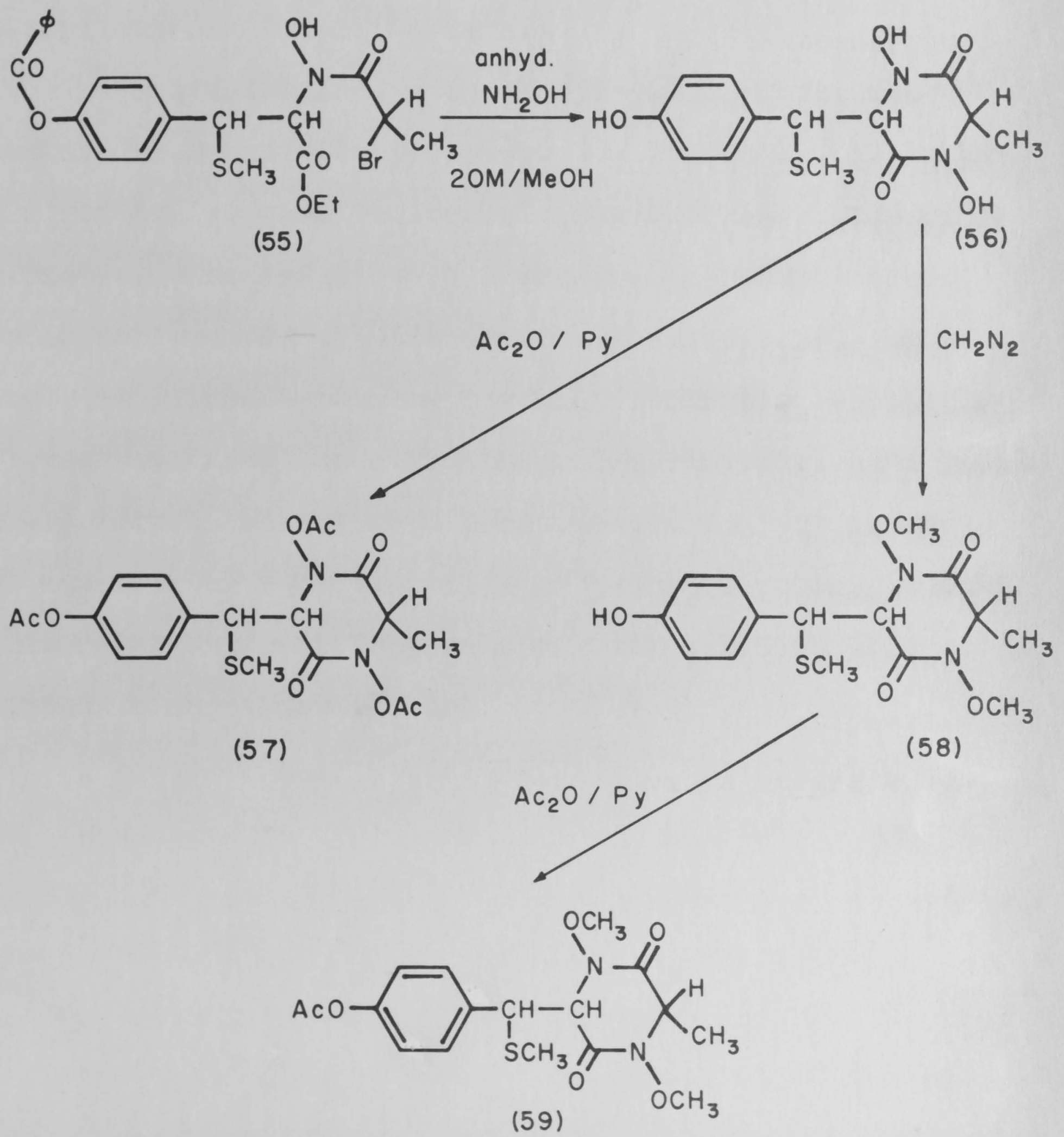


Analogous oxidations were realisable with the cyclic thioethers $(57,59)$. Treatment of $(57)$ with one mole of m-chloroperbenzoic acid afforded the sulphoxide $(61)^{\text {\# }}$ which could be readily oxidised to the corresponding sulphone (62). The former product was converted by the action of methanolic ammonia 97 , into the trihydroxysulphoxide (63). A similar oxidation of (59) gave the acetoxy-dimethoxysulphoxide (64).

Subsequent elimination reactions carried out were invariably plagued by the lack of appreciable quantities of the above intermediates. This is a problem common to all synthetic investigations but was accentuated in the present work by the often modest yields and the need for extensive chromatographic purification of intermediates. As a representative example, the yield of the sulphoxide (64) from the schiff base ( $46 ; R=\operatorname{Co} \varnothing)$ was a meagre $4.1 \%$

* The sulphoxides were obtained free of the corresponding sulphones if only one mole of the peracid was added to the thioether in chloroform at 0 . 

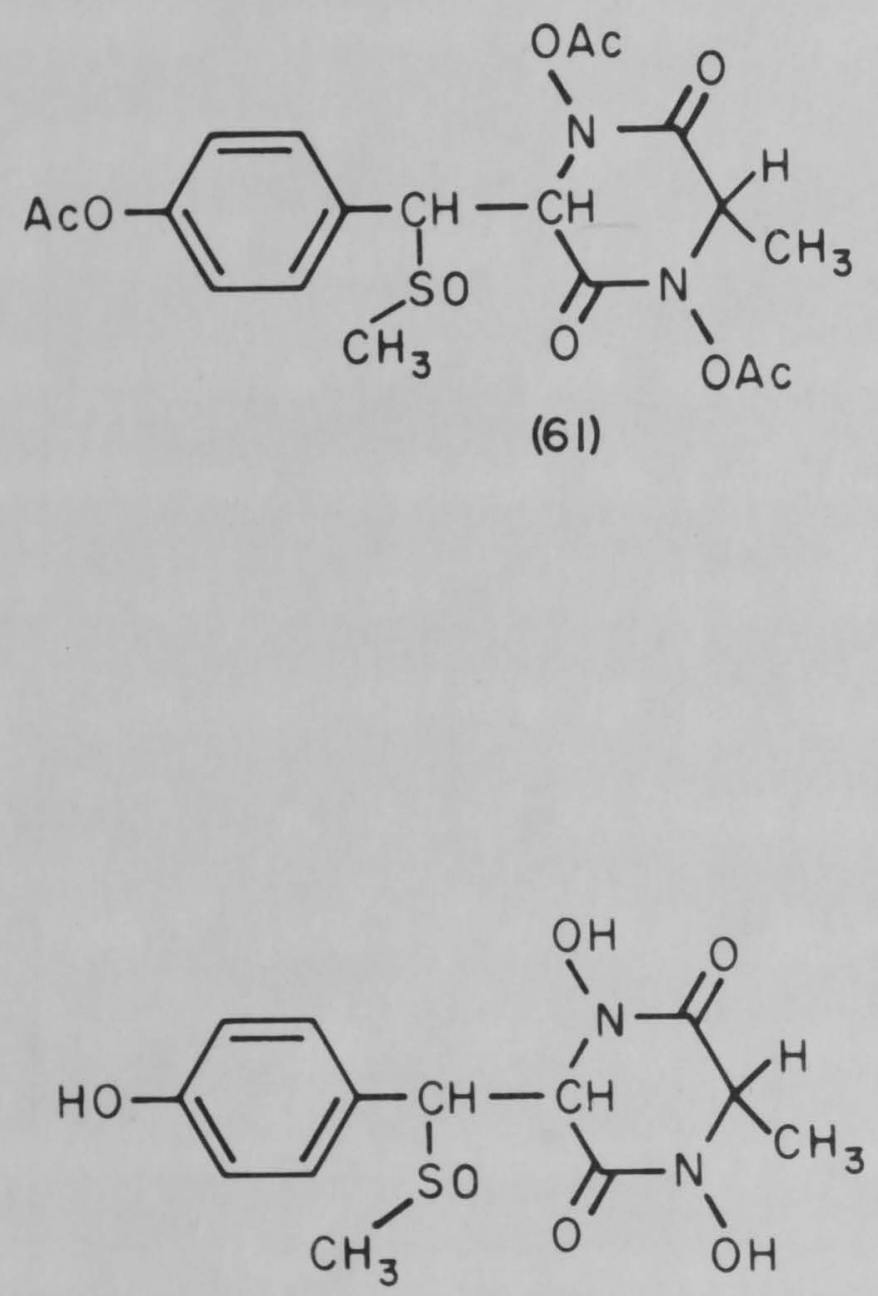

(63)

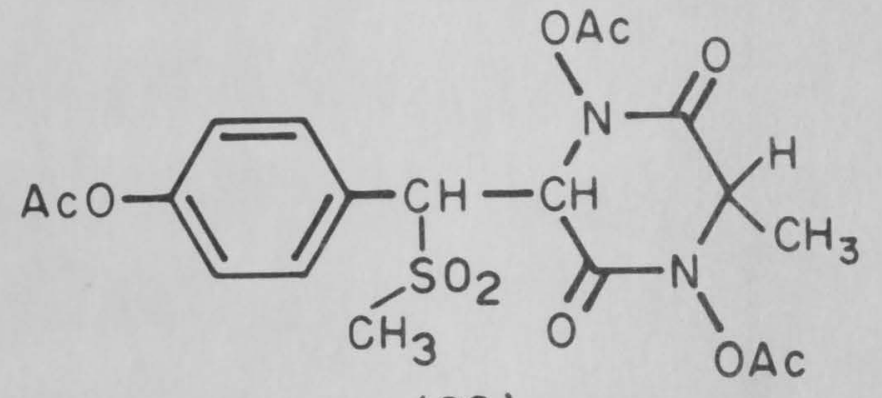

(62)

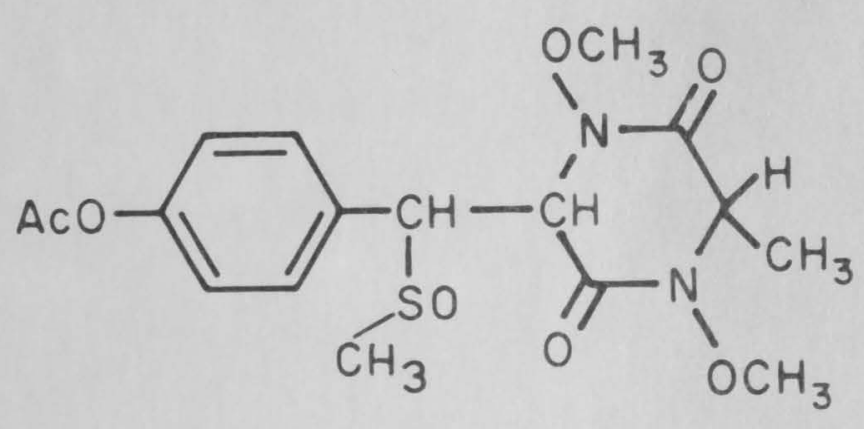

(64) 
(b) Discussion of n.m.r. spectra

The $n \cdot m_{\bullet} \cdot$. spectra of synthetic intermediates after ( $47 ; \mathrm{R}=\mathrm{CO} \varnothing$ ) are collected in Table IV (acyclic series) and Table V (cyclic series). All spectra were run as deuterochloroform solutions except where otherwise noted. In addition to the recorded absorptions, the aromatic protons of the compounds of Table IV appeared as a quartet at ca. $1.8 \tau(2 \mathrm{H}$, ortho protans) and a complex multiplet centred at ca. $2.6 \tau$. For the cyclic series, the aromatic protons appeared as simplified $\mathrm{A}_{2} \mathrm{~B}_{2}$ patterns (quartets) centred at $2.6-3.2 \pi$, with the exception of the sulphoxides (61) and (64). These two cases exhibited complex multiplets at ca. $2.8 \tau$.

A brief inspection of the n.m.r. data of Tables IV and $V$ indicates that this spectral tool was invaluable in the present investigation. Almost without exception, characteristic absorptions were observed for all the protons of the synthetic intermediates. Although no thorough study of the n.m.r. spectra of this series was made, particular assignments merit discussion. In general, assignments were made on the basis of consistency throughout the series, using the accepted electronegativity and anisotropic effects of the functional groups involved. The S-methyl protons exhibit downfield shifts on proceeding from thioether to sulphoxide and from 


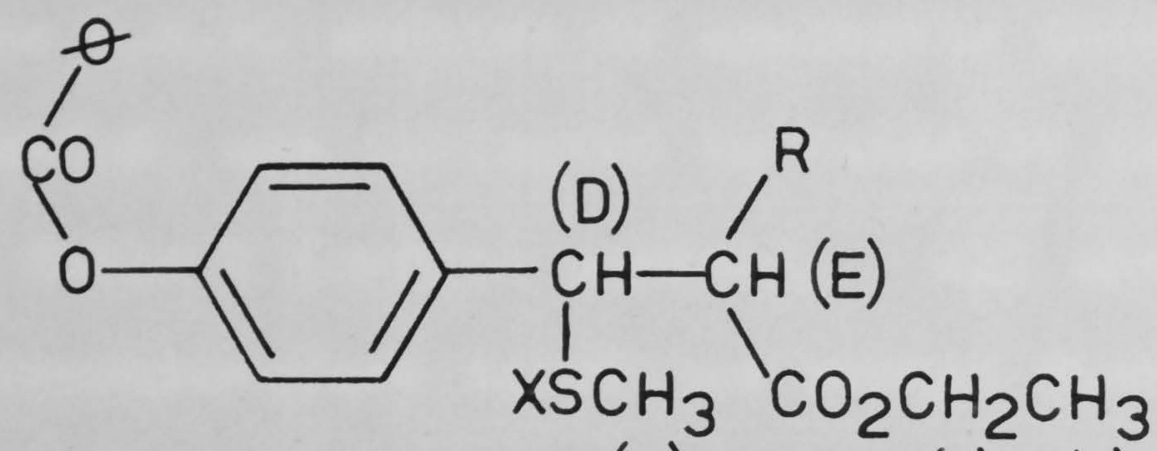

(B)

(C) (A)

\begin{tabular}{|c|c|c|c|c|c|c|}
\hline \multirow{2}{*}{\multicolumn{2}{|c|}{ Compound }} & \multicolumn{5}{|c|}{ Chemical shift $(\tau)$} \\
\hline & & $(A)^{a}$ & $(B)^{b}$ & $(c)^{c}$ & $(D)^{d}$ & $(E)^{d}$ \\
\hline (53) & $\begin{array}{l}\text { single is omer } \\
\mathrm{R}^{=} \mathrm{NO}_{2} \\
\mathrm{X}=\mathrm{Nil}\end{array}$ & 8.64 & 8.00 & 5.63 & 5.36 & 4.49 \\
\hline$(60)$ & $\begin{array}{l}\mathrm{R}=\mathrm{NO}_{2} \\
\mathrm{X}=\mathrm{O}_{2}\end{array}$ & 8.62 & 7.18 & $5 \cdot 58$ & $4 \cdot 68$ & 4.01 \\
\hline (53) & $\begin{array}{l}\mathrm{R}=\mathrm{NHOH} \\
\mathrm{X}=\mathrm{N} i \mathrm{I}\end{array}$ & 8.70 & 8.03 & $5 \cdot 74$ & $5.96^{e}$ & $5.96^{e}$ \\
\hline$(55)^{f}$ & $\begin{array}{l}\text { single isomer } \\
\mathrm{R}=\mathrm{NOHCOCHCH} \\
X=\mathrm{Br} \\
\mathrm{X} \text { il }\end{array}$ & 8.63 & 8.04 & 5.66 & $4 \cdot 40$ & 5.53 \\
\hline
\end{tabular}

a. Triplet $(J=7 \cdot 5 \pm 0.5 \mathrm{cps}$, ) e. Chemical shift of $(D) \alpha(E)$ b. Singlet protons indistinguishable.

c. Quartet $(J=7 \cdot 5 \pm 0.5 \mathrm{cps}$.) f. Signals for $-\mathrm{CHCH} 3$ group d. $A \propto B$ protons of $A B$ quartet 8.47 (doublet $J=7.0 \div 0.5 \mathrm{cps}$. ( $\mathrm{J}_{\mathrm{AB}}=11.0 \pm 0.5 \mathrm{cps}$ ) $\quad 5.30$ (quartet $\mathrm{J}=7.0 \pm 0.5 \mathrm{cps}$ ) 


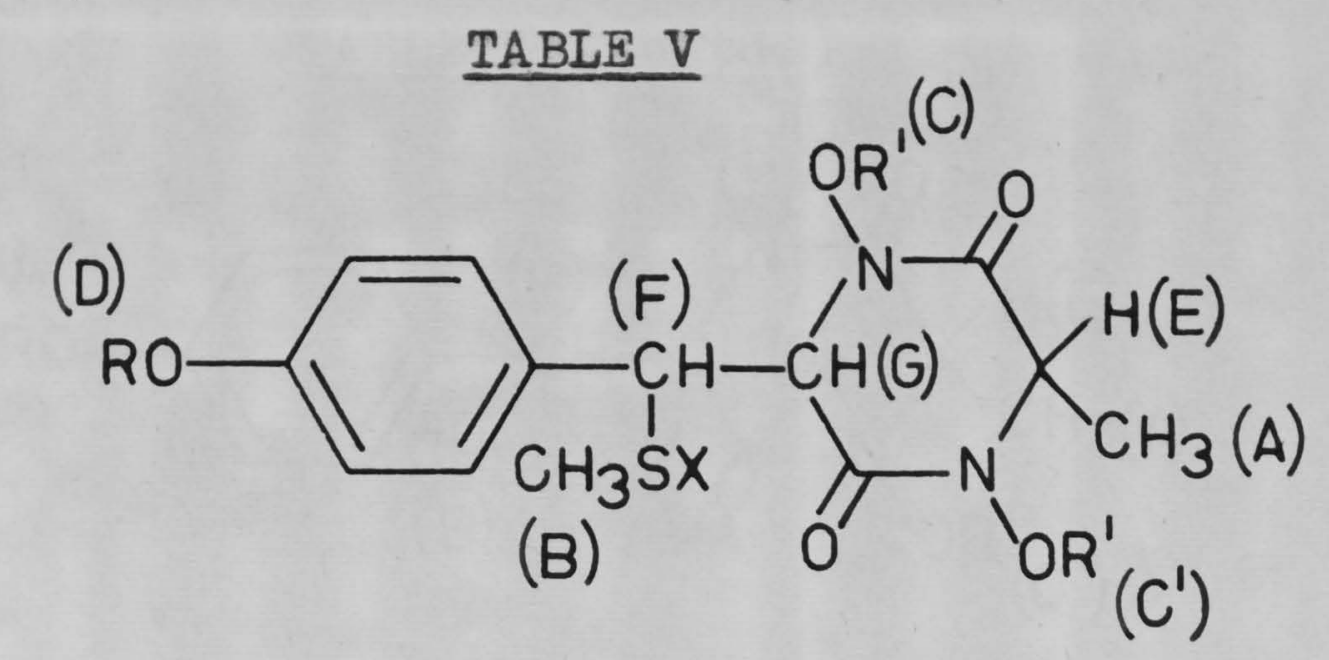

\begin{tabular}{|c|c|c|c|c|c|c|c|c|}
\hline & \multirow{2}{*}{ Compound } & \multicolumn{7}{|c|}{ Chemical shift $(T)$} \\
\hline & & $(\mathrm{A})^{\mathrm{a}}$ & $(B)^{b}$ & $(c) \alpha\left(c^{1}\right)^{b}$ & $(D)^{b}$ & $(E)^{c}$ & $(F)^{\mathrm{d}}$ & $(G)^{d}$ \\
\hline $56^{e}$ & $\begin{array}{l}\left(\mathrm{R}=\mathrm{R}^{\prime}=\mathrm{H}\right) \\
(\mathrm{X}=\mathrm{N} \text { iI) }\end{array}$ & 9.43 & 8.11 & - & - & 6.03 & $5 \cdot 38$ & 5.63 \\
\hline 57 & $\begin{array}{l}\left(\mathrm{R}=\mathrm{R}^{\prime}=\mathrm{AC}\right) \\
(\mathrm{X}=\mathrm{N} \perp I)\end{array}$ & 9.27 & 7.95 & $7.80,7.64$ & $7 \cdot 72$ & 5.80 & 5.06 & 5.44 \\
\hline 58 & $\begin{array}{l}\left(\mathrm{R}=\mathrm{H} ; \mathrm{R}^{\wedge}=\mathrm{CH}_{3}\right) \\
(\mathrm{X}=\mathrm{N} \text { iI })\end{array}$ & 9.27 & 7.99 & $6.22,6.07$ & - & $5 \cdot 84$ & 5.07 & $5 \cdot 55$ \\
\hline 59 & $\begin{array}{l}\left(\mathrm{R}=\mathrm{AC} ; \mathrm{R}^{\prime}=\mathrm{CH}_{3}\right) \\
(\mathrm{X}=\mathrm{N} \mathrm{il})\end{array}$ & 9.26 & 7.99 & $6.26,6.09$ & $7 \cdot 72$ & $5 \cdot 90$ & 5.08 & $5 \cdot 50$ \\
\hline
\end{tabular}




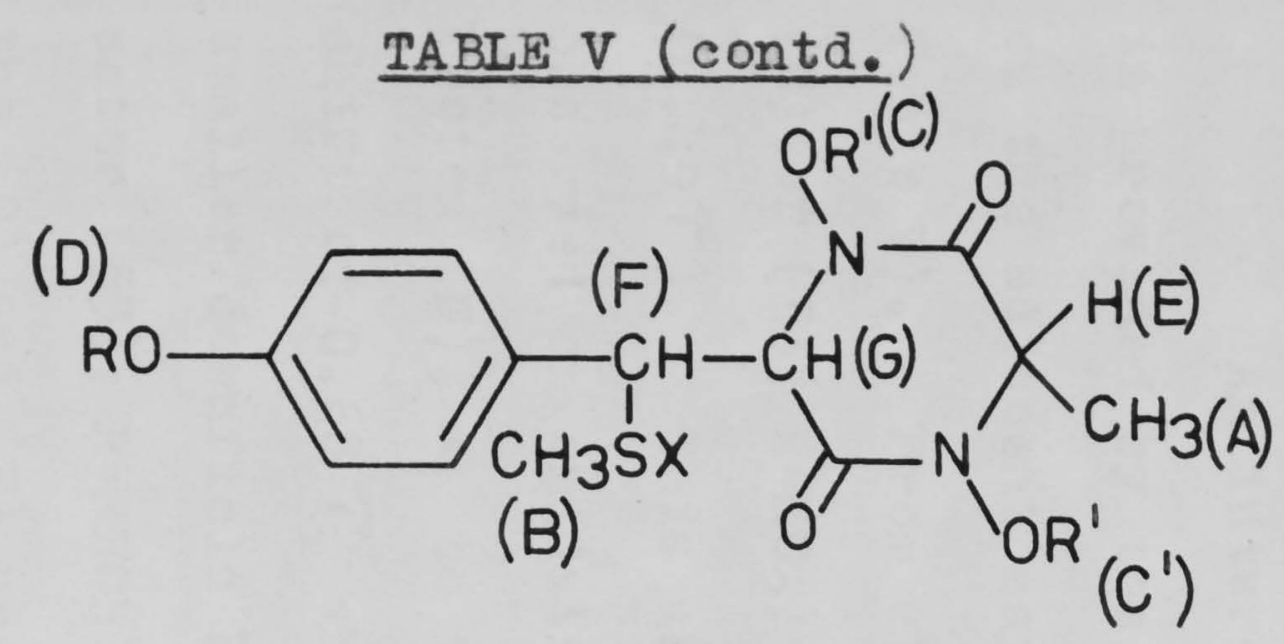

\begin{tabular}{|c|c|c|c|c|c|c|c|c|}
\hline & \multirow{2}{*}{ Compound } & \multicolumn{7}{|c|}{ Chemical Shift $(\tau)$} \\
\hline & & $(A)^{a}$ & $(B)^{b}$ & $(c) \propto\left(c^{1}\right)^{b}$ & $(D)^{b}$ & $(E)^{c}$ & $(F)^{\bar{d}}$ & $(G)^{d}$ \\
\hline $63^{e}$ & $\begin{array}{l}\left(\mathrm{R}=\mathrm{R}^{\mathrm{P}}=\mathrm{H}\right) \\
(\mathrm{X}=0)\end{array}$ & 9.60 & 7.71 & - & - & 6.01 & 5.04 & 5.82 \\
\hline 61 & $\begin{array}{l}\left(R=R^{\prime}=A c\right) \\
(X=0)\end{array}$ & 9.33 & 7.51 & $7.81,7.63$ & 7.71 & 5.75 & 4.68 & 5.60 \\
\hline 62 & $\begin{array}{l}\left(\mathrm{R}=\mathrm{R}^{\mathrm{P}}=\mathrm{AC}\right) \\
\left(\mathrm{X}=\mathrm{O}_{2}\right)\end{array}$ & 9.28 & 7.14 & $7.82,7.66$ & 7.71 & 5.75 & 4.42 & 5.09 \\
\hline 64 & $\begin{array}{l}\left(\mathrm{R}=\mathrm{Ac} ; \mathrm{R}^{\prime}=\mathrm{CH}_{3}\right) \\
(\mathrm{X}=0)\end{array}$ & 9.41 & 7.56 & $6.27,6.02$ & 7.72 & 5.87 & 4.59 & 5.60 \\
\hline
\end{tabular}

a. Doublet $(J=7.0 \pm 0.5 \mathrm{cps}$.

b. Singlet

d. $A \propto B$ protons of $A B$ quartet

c. Quartet $(J=7.0 \pm 0.5 \mathrm{cps}$. ( $J_{A B}=2.0 \pm 0.5 \mathrm{cps}$. )

e. Spectra $r$ un in $a_{6}$-DMSO 
thioether to sulphone, of $0.40-0.44 \tau$ and $0.81-0.82 \tau$ respectively. These shifts are consistent with the greater electronegativity of the sulphinyl and sulphonyl groups relative to the methylthio group. The phenolic acetate of $(57),(61)$ and $(62)$ was assigned the $7.71 \tilde{\tau}$ absorption by comparison with the same group which is unique in the dimethylated derivatives (59) and (64). An interesting variation throughout this series is provided by the $A B$ pattern exhibited by the protons on the adjacent asymmetric centres ( D,E Table IV: F,G Table V). From electronegativity considerations, proton (E) of $\left(53 ; \mathrm{R}^{2} \mathrm{NO}_{2}\right)$ was assigned to the lowfield doublet (4.49 $\tilde{\tau})$. This assignment was supported by the shifts observed on oxidation of $\left(53 ; \mathrm{R}^{2} \mathrm{NO}_{2}\right)$ to the sulphone (60). Proton (D), $\propto$ to the sulphonyl group, shows a downfield shift of $0.68 \tau$ while the $\beta$ proton (E) exhibits the smaller downfield shift of $0.48 \tau$. The hydroxylamino ester (53); $\mathrm{R}=\mathrm{NHOH}$ ) provides an intermediate case in which the (D) and (E) protons have the same chemical shift. Using the argument outlined above, the assignments for the $A B$ protons are reversed in the cyclic series (Table V) and the hydroxamic acid (55). Thus the lowfield doublet $(F)$ shows a downfield shift of $0.54 \tilde{r}$ on proceeding from (57) to (62). Proton (G), $\boldsymbol{\beta}$ to the sulphonyl group of (62) moves downfield by only $0.35 \tau$. 
Although the $\propto$ proton (F) still shows a downfield shift in the sulphoxide relative to the thioether, the $\beta$ hydrogen $(G)$ is consistently moved to higher field. The observation is the reverse of that expected from electronegativity considerations and is probably due to an anisotropic effect of the sulphinyl group. The shifts discussed above are summarised in Table VI.

\section{TABLE VI}

\begin{tabular}{|l|c|c|}
\hline Transformation & $\alpha \mathrm{H}\left(\tau \mathrm{sxCH}_{3}-\tau_{\mathrm{SCH}_{3}}\right)$ & $\beta \mathrm{H}\left(\tau \mathrm{sxCH}_{3}-\tau_{\mathrm{SCH}}\right)$ \\
\hline $\mathrm{SCH}_{3} \rightarrow \mathrm{sO}_{2} \mathrm{CH}_{3}$ & & \\
$(53) \rightarrow(60)$ & -0.68 & -0.48 \\
$(57) \rightarrow(62)$ & -0.64 & \\
\hline $\mathrm{SCH}_{3} \rightarrow \mathrm{SOCH}_{3}$ & & +0.35 \\
$(57) \rightarrow(61)$ & -0.38 & +0.10 \\
$(59) \rightarrow(64)$ & -0.49 & +0.19 \\
$(56) \rightarrow(63)$ & -0.34 & \\
\hline
\end{tabular}

A striking difference between the $A B$ protons of the acyclic and cyclic series is the magnitude of the coupling constant $J_{A B}$. For the former series this is $11.0 \pm 0.5 \mathrm{cps}$, while for the latter $2.0 \pm 0.5 \mathrm{cps}$. The observed vicinal coupling constant for such systems has been shown to be a weighted mean derived from the 
populations of the two gauche rotamers (each $\mathrm{J}_{\mathrm{AB}}=1-3 \mathrm{cps}$ ) and the trans rotamer $\left(\mathrm{J}_{\mathrm{AB}}=\mathrm{ca} \cdot 11-13 \mathrm{cps}\right)^{98}$. In the present case this implies that the trans rotamer is favoured in the acyclic series and the gauche rotamers in the cyclic series. Reference to Chart XI shows that $J_{A B}$ is the same for the erythro and threo isomers of this series. Hence the configuration of the single isomer obtained throughout cannot be ascertained from the n.m.r. data.

One common feature of all the intermediates of Table $\mathrm{V}$ is the relatively high field absorption (9.269.60 T) for the C-methyl group of the hydroxamic acid ring. This highfield position is normally characteristic of a methyl group in a hydrocarbon environment 99 and is the more surprising since in the present intermediates, the carbon bearing the methyl group is flanked by two electronwithdrawing substituents. In contrast, the simple dihydroxamic acid ( $24 ; \mathrm{R}^{\prime}=\mathrm{H}$ ) having no aromatic substituent shows the corresponding methyl absorption at $8.39 \tau$. Mycelianamide and other elimination products obtained in the present work (vide infra), also exhibit this methyl absorption in the range $8.3-8.6 \tau$. The substantially planar benzylidene linkage of these compounds prevents the proximity of the aromatic ring and the C-methyl group. The foregoing observations suggest that the relatively highfield position for the methyl group of the 
intermediates of Table $\mathrm{V}$ is a result of shielding by the aromatic ring. Assuming the planarity of each of the hydroxamic functions, two sets of conformations are possible; those with the C-6 methyl group and the $\mathrm{C}-3$ aromatic side chain cis disposed and those with these groups trans. In the former case, conformations such as (65; Chart XVI) which would lead to effective shielding of the methyl group, would in turn be extremely unfavourable. However intermediate conformations such as the planar example (66), could still result in significant shielding. The other extreme conformation of this series (67), would not be expected to shield the methyl group. For the trans series, the only conformation which could lead to shielding of the methyl group, (68), would in turn shield the $\mathrm{C}-3$ methine proton to an even greater extent. In practice, the absorption for the latter group was found in the range $5.75-6.03 \tau$. This range is that expected for a proton attached to a carbon bearing two electron-withdrawing substituents and implies negligible shielding by the aromatic ring. It is therefore probable that the intermediates of Table $\mathrm{V}$ have the $\mathrm{C}-3$ and $\mathrm{C}-6$ substituents in a cis orientation.

* An X-ray study ${ }^{100}$ has shown that in the solid state, 2,5-piperazinedione exists in a planar conformation. 
CHART XVI
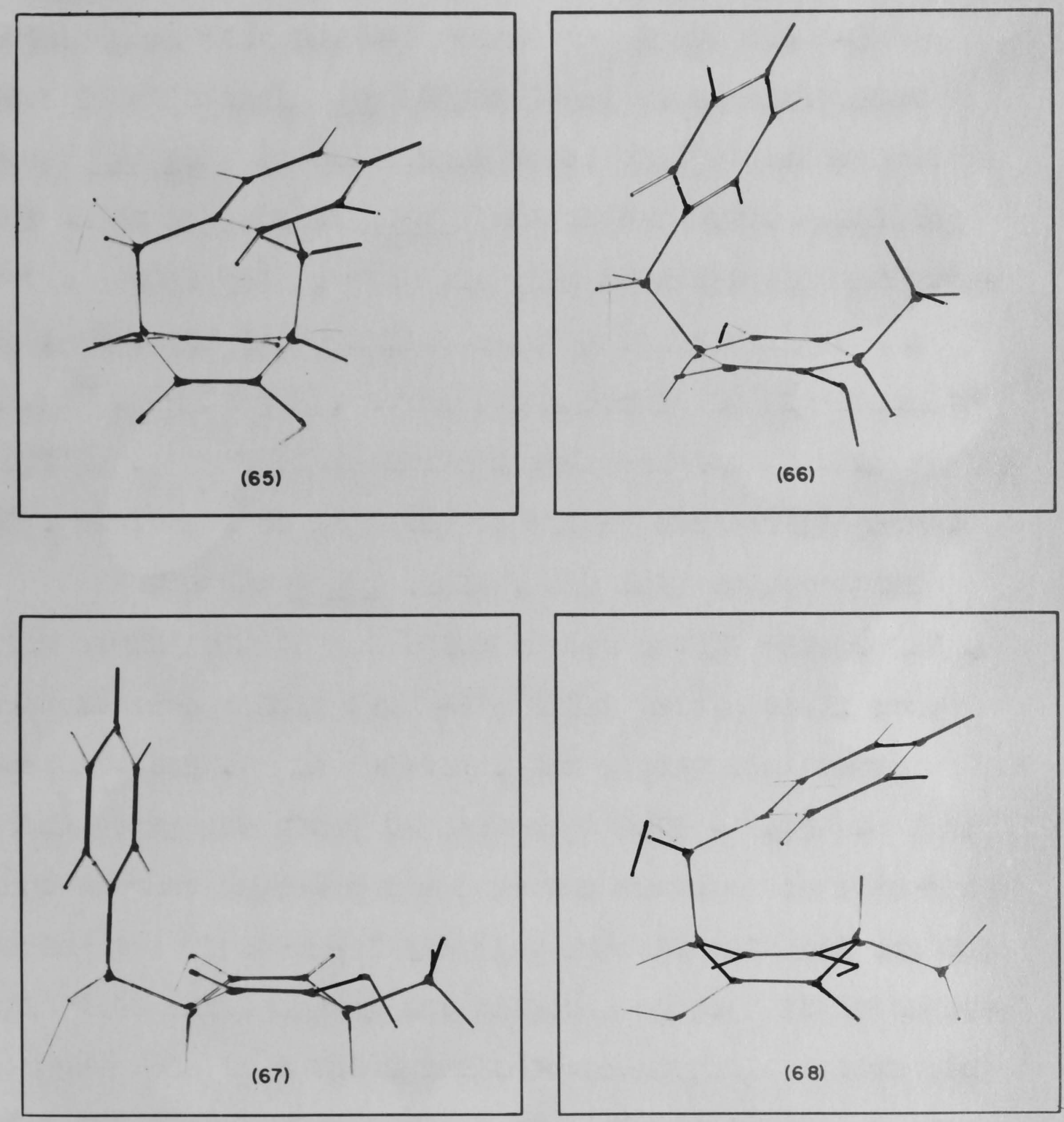
(c) Elimination reactions

As mentioned previously, treatment of the nitro ester $\left(53 ; \mathrm{R}^{2} \mathrm{NO}_{2}\right)$ with one mole of $\underline{\text { m-chloroperbenzoic }}$ acid in chloroform at $0^{\circ}$, did not lead to the isolation of the corresponding sulphoxide. Instead elimination occurred to afford a mixture of the nitroolefins (48) and (49) as shown by the n.m.r., u.v. and i.r. spectra. In particular, the n.m.r. spectrum indicated a predominance of the high m.p. isomer which tentatively has been assigned the trans stereochemistry (49). An attempt was made to obtain a qualitative measure of the rate of this elimination by carrying out the reaction in deuterochloroform and following the change in the n.m.r. spectrum. Although at this temperature $\left(33^{\circ}\right)$ the sulphone $(60)$ was formed along with the corresponding sulphoxide, it was evident that the initial oxidation was complete within $8 \mathrm{~min}$. and that the elimination went to completion in less than $5 \mathrm{hr}$.

Assuming a cis stereochemistry for the elimination, the preferential formation of the trans olefin should define the configuration ${ }^{*}$ of the nitro ester

* The configuration derived by this method, although tentative, is consistent with the stereochemistry proposed for subsequent elimination products (vide infra). 
(53; $\mathrm{R}=\mathrm{NO}_{2}$ ). However with such an acidic compound the elimination could be trans and base catalysed; in the n.m.r. study the lone pair on oxygen of $m$-chlorobenzoic acid might be a strong enough base to effect such an elimination.

As a model more closely related to the cyclic sulphoxides (61), (63) and (64), the icyclic hydroxamic acid (55) was treated with one mole of m-chloroperbenzoic acid in chloroform at $0^{\circ}$. The crude product (still containing $\underline{m-c h l o r o b e n z o i c ~ a c i d), ~ g a v e ~ a ~ p o s i t i v e ~ f e r r i c ~}$ test, showed no n.m.r. absorption for the S-methyl group (or the corresponding sulphoxide), and exhibited very broad u.v. absorption at ca. $285 \mathrm{~m} \mu$. These observations indicated that the sulphoxide of (55) had eliminated within $12 \mathrm{hr}$. at room temperature.

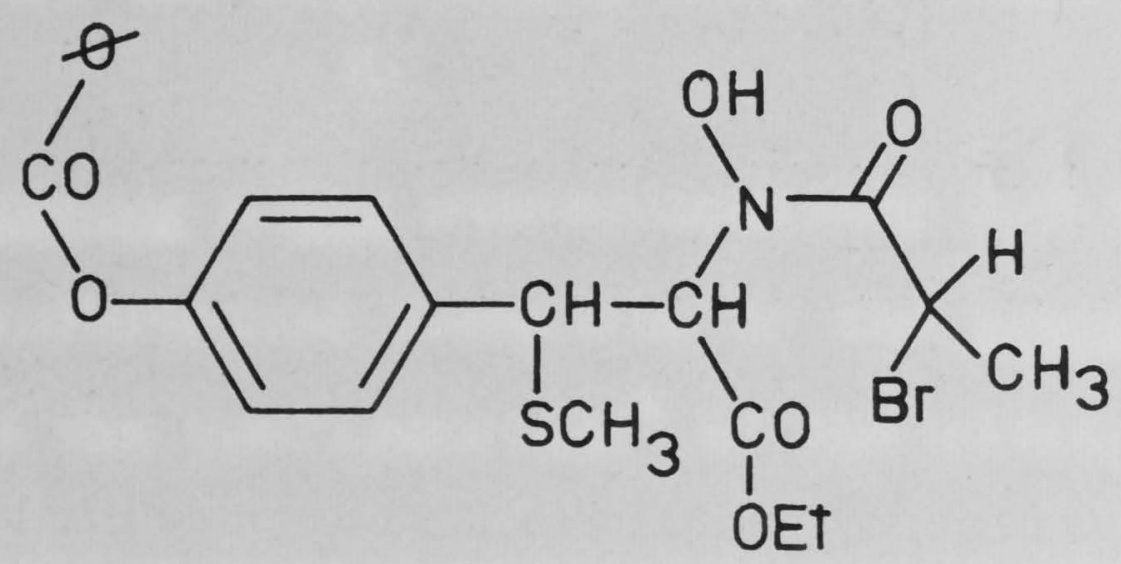

(55) 
Washing a chloroform solution of the crude elimination product with aqueous sodium bicarbonate led to extensive decomposition, as did chromatography on untreated silica gel or neutral alumina. Subsequently it was found that chromatography could be performed safely using acid-washed silica. However, despite repeated chromatography the elimination product could not be obtained crystalline and while homogeneous on t.l.c., was obviously a mixture as shown by the n.m.r. spectrum. In order to simplify the analysis of the foregoing elimination, the hydroxylamino ester ( $53 ; \mathrm{R}=\mathrm{NHOH}$ ) was acetylated with acetyl chloride to give the hydroxamic $\operatorname{acid}(69)$.

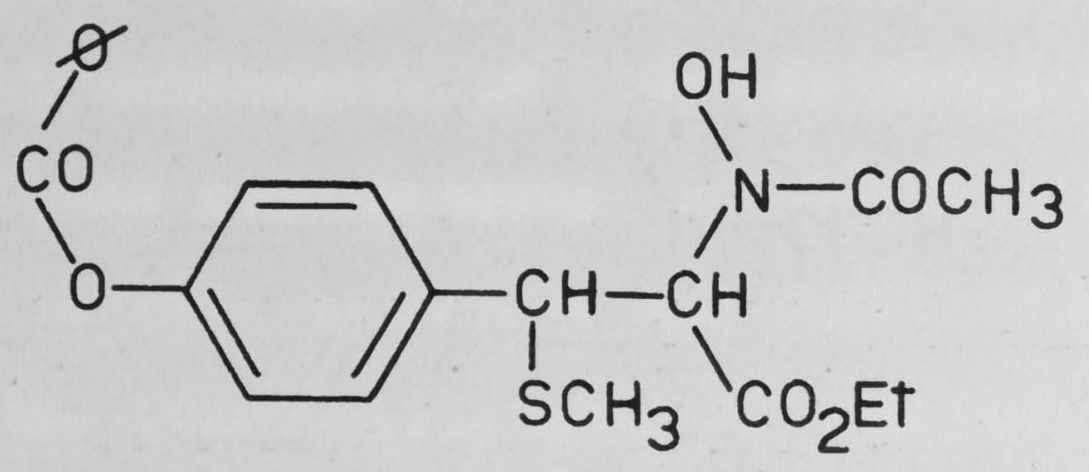

(69)

Oxidation of (69) with one mole of peracid again led to the elimination of the sulphur substituent. In this case, the crystalline elimination product (m.p. 128-

* In order to remove the m-chlorobenzoic acid. 
$132^{\circ}$ ), isolated by repeated chromatography and then recrystallisation, gave a positive ferric test and was homogeneous on t.l.c. A benzylidene linkage was suggested by $u_{\bullet} v$. absorption at 224 and $282 \mathrm{~m} \mu$ and i.r. absorption was exhibited at $3100,1735,1707$ and $1630 \mathrm{~cm}^{-1}$. The n.m.r. spectrum, recorded in Chart XVII, shows the absorptions expected of the elimination product ( 70$)$, but discrepancies in the integration indicated that structurally similar impurities were still present. Despite the inhomogeneity of the elimination product, it seems certain that facile $\beta$ elimination of an intermediate sulphoxide had occurred, to give predominantly the olefin $(70)$.

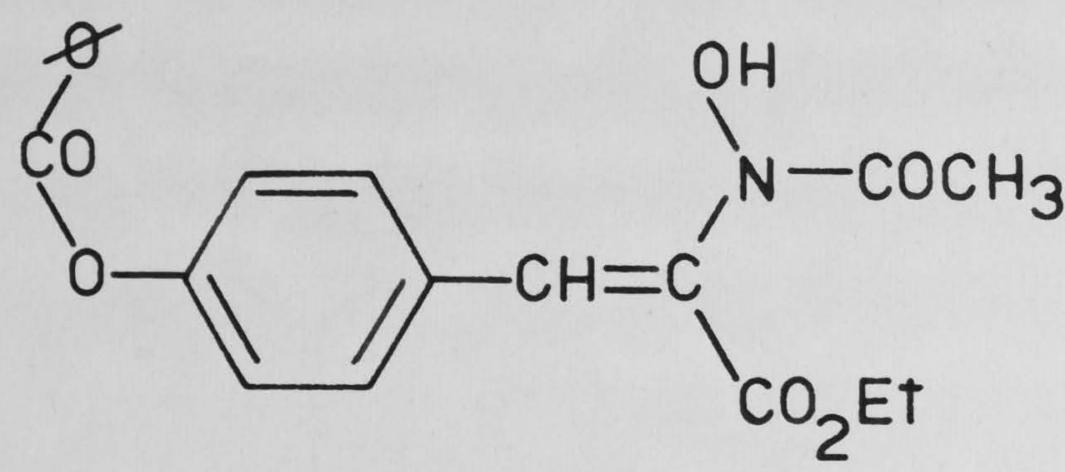

(70)

With at least the feasibility of $\beta$ elimination of sulphoxides assured by the foregoing model experiments, attention was turned to the sulphoxides which were potential precursors of mycelianamide or its derivatives. A preliminary experiment involved heating under reflux a 


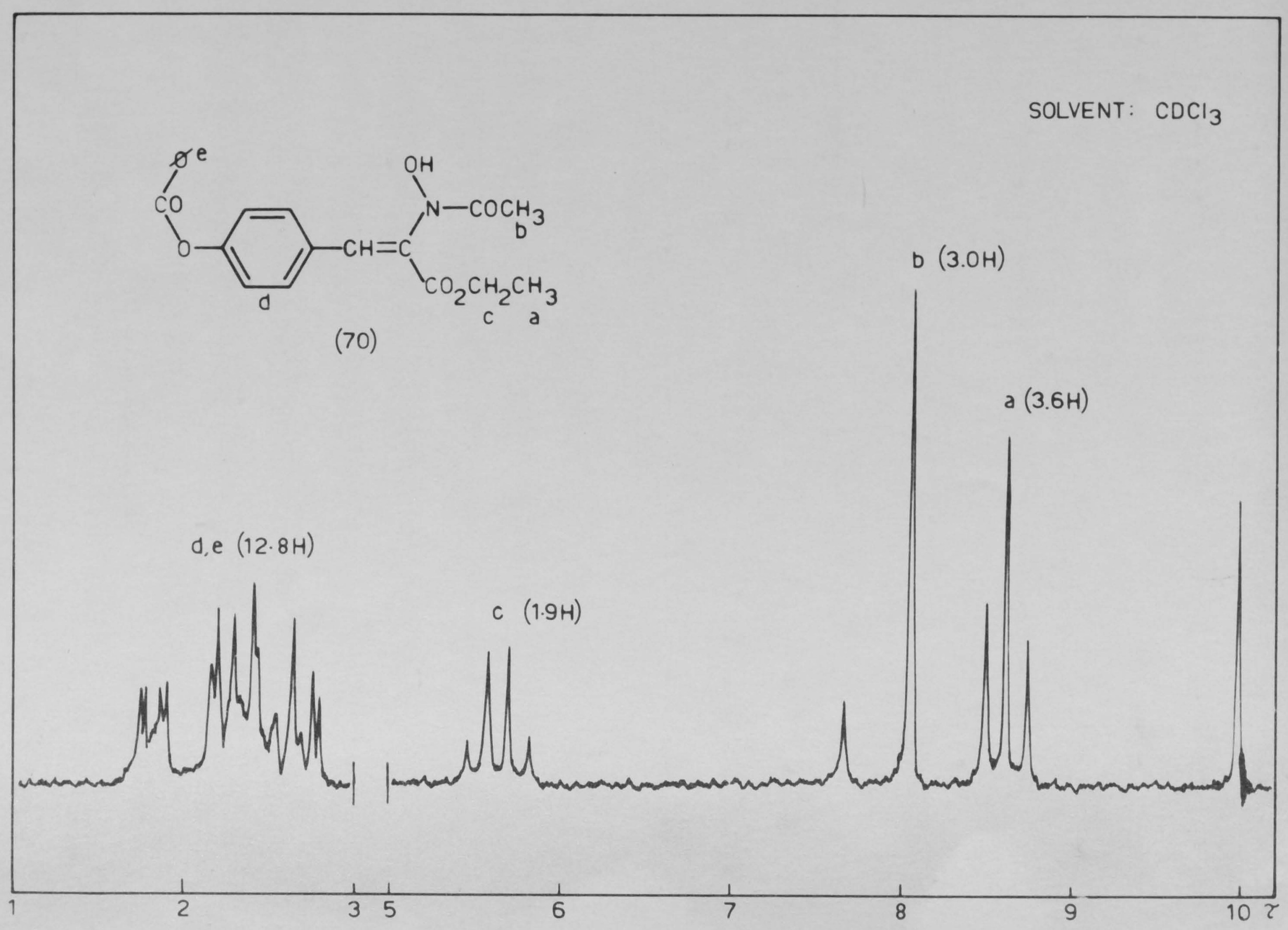


benzene solution of the triacetoxysulphoxide (61). Under these conditions oxidation to the sulphone ${ }^{\text {\# }}(62)$ in quantitative yield was observed. Subsequent elimination reactions were therefore carried out in sealed evacuated tubes as the most convenient method of excluding atmospheric oxygen.

Pyrolysis of a dioxan solution of (61) for $60 \mathrm{hr}$, at $80-85^{\circ}$ led to a complex mixture of products which exhibited negligible $u_{\bullet} v_{\bullet}$ absorption near $300 \mathrm{~m} \mu$. An $n \cdot m \cdot r$. study of this pyrolysis in $d_{6}$-dimethylsulphoxide at $77^{\circ}$ indicated that decomposition of the sulphoxide was complete within $9 \mathrm{hr}$. Again a complex mixture of products was produced; no effective separation was realised by chromatography on silica gel. Although the products of elimination have not been characterised, the loss of at least one of the hydroxamic acetates can be inferred from the i.r. spectra. Thus the intensity of the hydroxamic acetate absorption $\left(1800 \mathrm{~cm}^{-1}\right)$ of $(61)$ is ca. twice that of the phenolic acetate absorption $\left(1760 \mathrm{~cm}^{-1}\right)$; the 1.r. spectrum of the crude elimination product (Iiquid film) shows these absorptions of about equal intensity.

Numerous pathways for the decomposition of the sulphoxide (61) can be envisaged besides the required $\beta$ elimination. One such breakdown is provided by analogy

* Which would then be insensitive to thermal elimination. 76 
with the pyrolysis of hydroxylamine benzoates. Thus the benzoate (71) is transformed smoothly into the imine (72) by brief heating under reflux in xylene or benzene. ${ }^{101}$

In the present work, a similar elimination might provide a starting point for further decomposition. However, since the elimination products have not been characterised, such speculation is not profitable.

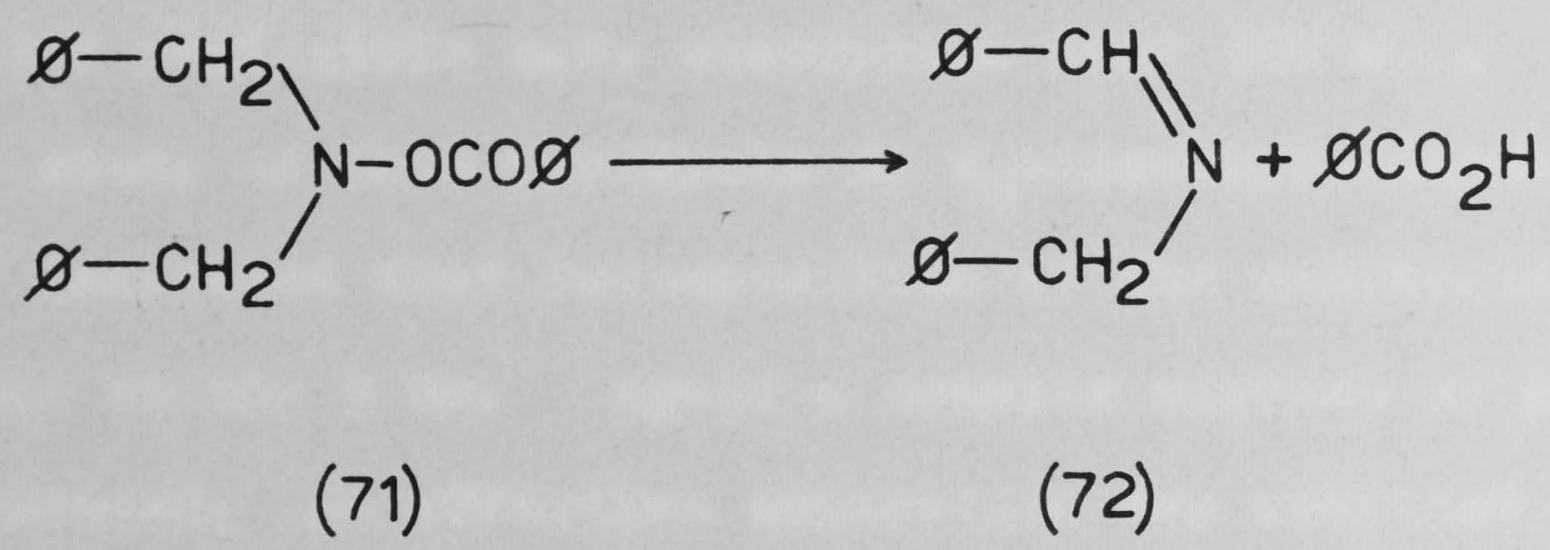

Similarly inconclusive results were observed using the trihydroxysulphoxide (63). Pyrolysis in $\mathrm{d}_{6}{ }^{-}$ dimethylsulphoxide at $77^{\circ}$ was a slow reaction, taking ca. $130 \mathrm{hr}$. before the sulphoxide had completely decomposed. This may reflect an energy barrier which must be overcome in proceeding from the hydrogen bonded form (73) to the configuration (74) necessary for an $\mathrm{E} i \boldsymbol{\beta}$ elimination.

* The i.r. $S=0$ stretching frequency for (63) (1010 $\left.\mathrm{cm}^{-1}\right)$ is $30-35 \mathrm{~cm}^{-1}$ lower than the corresponding absorption of the triacetoxysulphoxide (61) $\left(1045 \mathrm{~cm}^{-1}\right)$ and the acetoxy dimethoxysulphoxide $(64)\left(1040 \mathrm{~cm}^{-1}\right)$. This shift to lower frequency is consistent with the hydrogen-bonded formulation. 
Although the crude product gave a positive ferric test and exhibited broad $u \cdot v \cdot$ absorption at $\underline{\mathrm{ca}} \cdot 318 \mathrm{~m} \mu \mathrm{a}$ complex mixture of products was indicated by the $n \cdot m \cdot r$. spectrum. No effective separation of the hydroxamic acid components of the mixture was realised by chromatography on buffered paper. This pyrolysis, while it may have given traces of components having a benzylidene linkage, was obviously complex and certainly of little synthetic utility.<smiles>CC1C(=O)N(O)C(C(Br)[Se](C)=[OH+])C(=O)N1O</smiles>

(73)

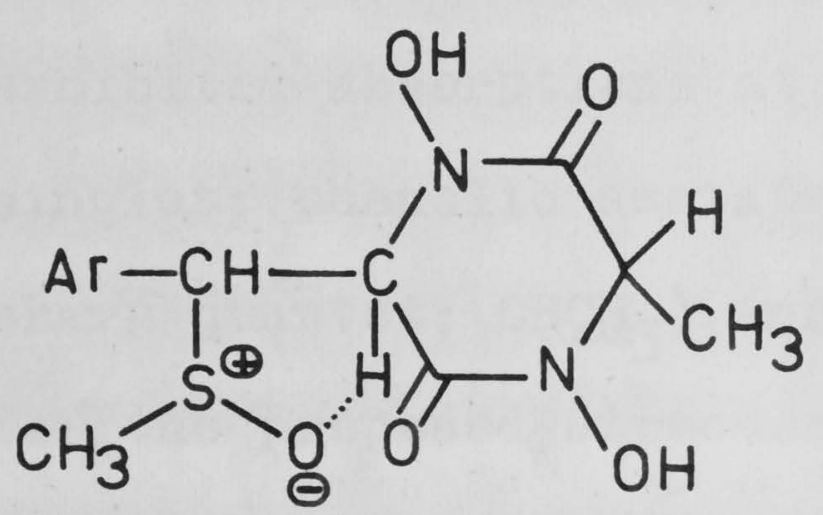

(74)

In contrast to the behaviour of the foregoing sulphoxides, the acetoxy dimethoxysulphoxide (64) eliminates smoothly in dioxan at $80-85^{\circ}$. After $60 \mathrm{hr}$. at this temperature a single elimination product for which structure (75) is proposed, was isolated in $71 \%$ yield. 


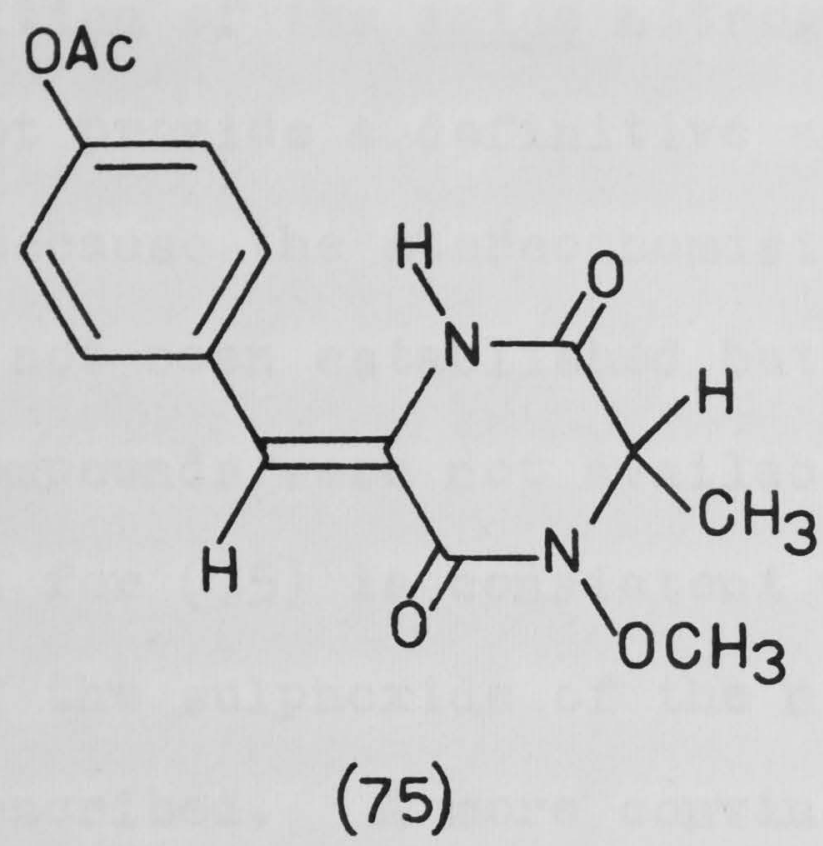

The gross structural features of the elimination product could be deduced from the spectral data. In particular, the n.m.r. spectrum exhibited absorptions at 8.38 (doublet; $\mathrm{CHCH}_{3}$ ), 7.70 (singlet; phenolic acetate), 6.12 (singlet; $\mathrm{NOCH}_{3}$ ), 5.55 (sharp quartet; $\mathrm{CHCH}_{3}$ ) and $1.9 \tau$ (broad; NH). Support for the proposed structure was provided by i.r. absorption at $3250,1760,1690$ and $1640 \mathrm{~cm}^{-1}$. The benzylidene linkage was assured by $u_{\bullet} v$. absorption at 222 and $297 \mathrm{~m} \mu$ which shows a hypsochromic shift compared to deoxymycelianamide $\left(\lambda_{\max }, 225,317 \mathrm{~m} \mu\right)$. This shift is in the direction expected for a p-acetoxyl group versus a p-geranyl group. For example p-acetoxybenzylidene acetone shows $u_{\bullet} v_{\text {. absorption }}$ at 223 and $289 \mathrm{~m} \mu$, while p-methoxybenzylidene acetone shows a bathochromic shift to $233,318 \mathrm{~m} \mu_{\bullet}{ }^{103}$

Two structural features are not provided by the spectral data viz. the stereochemistry of the olefinic 
link and the position of the amide nitrogen. Ultraviolet data cannot provide a definitive answer to the former, in part because the stereochemistry of mycelianamide itself has not been established but also because suitable model compounds were not available. However the trans formulation for (75) is consistent with the elimination reaction of the sulphoxide of the nitro ester (53; $\mathrm{R}=\mathrm{NO}_{2}$ ) already described. A more convincing argument for the trans stereochemistry of (75) is provided by mechanistic considerations (vide infra) which also indicate that the deoxygenation occurring in the present elimination had taken place from N-4 rather than N-1. Approaches to a chemical proof of the latter point are discussed at the end of this section.

As mentioned previously, base-catalysed eliminations of sulphoxides have also been employed in olefin synthesiso $84-86$ Treatment of the sulphoxide (64) with potassium $t$-butoxide in $\mathrm{a}_{6}$-aimethylsulphoxide produced an immediate dark brown colouration and led to the rapid degeneration of the n.m.r. spectrum. Subsequent aqueous work-up" led to the isolation of a water-soluble product which, while exhibiting broad u.v. absorption at ca. $314 \mathrm{~m} \mu$, was shown by t.1.c. to contain at least eleven components; no further study of this reaction mas made.

* See Experimental section. 
Parallel with the sulphoxide eliminations described above, similar pyrolyses of the thioethers (56), (58) and (59) were investigated. Pyrolysis of the trihydroxy thioether $(56)$ in dioxan at $110^{\circ}$ or in $\mathrm{d}_{6}-$ dimethylsulphoxide at $110^{\circ}$ was a slow reaction; in the latter solvent appreciable amounts of the sulphoxide remained undecomposed after ca. $90 \mathrm{hr}$. The crude elimination product was an intractible mixture which, while showing broad $u_{\bullet} v$. absorption at ca. $318 \mathrm{~m} \mu$, was not amenable to chromatographic separation.

Pyrolysis of the dimethoxy thioether (58) in dioxan at $80-85^{\circ}$ for $60 \mathrm{hr}$. indicated that a slow elimination was occurring. When the temperature was raised to $100^{\circ}$ and the reaction time extended to $100 \mathrm{hr}$, a single elimination product ( 76 ) was isolated in high yield ( $88 \%$ ). The structure of (76) is based on acetylation to the previously described elimination product (75) and the spectral data discussed below.

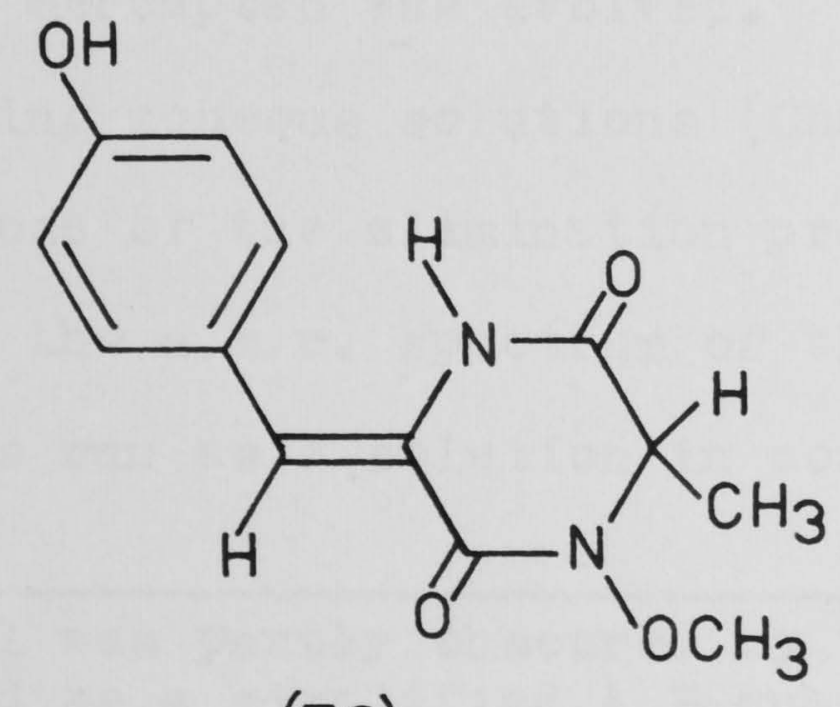

(76) 
The n.m.r. spectrum of (76) run as $\mathrm{d}_{6}-$ dimethylsulphoxide solution showed the following absorptions, 8.55 (doublet; $\mathrm{CHCH}_{3}$ ), 6.24 (singlet; $\mathrm{NOCH}_{3}$ ), 5.44 (quartet; $\mathrm{CHCH}_{3}$ ), 3.29 (singlet ${ }^{\text {3x }}$, vinylic $\mathrm{H}$ ) and $0.3 \tau$ (broad; $\mathbb{N}, \underline{H}$ ). Support for the functionality of (76) was provided by i.r. absorption at $3400,3300,1690$ and $1630 \mathrm{~cm}^{-1}$. The benzylidene linkage was again assured by the $u_{\bullet} v \cdot$ absorption spectrum ( $\lambda_{\max }, 228,320 \mathrm{~m} \mu$ ) which shows a close resemblance to that of $(18 ; \mathrm{R}=\mathrm{H})^{\text {H.F }}$ ( $\left.\lambda_{\max }, 226,319 \mathrm{~m} \mu\right)$, produced by acetic acid cleavage of deoxymycelianamide. ${ }^{19}$

A similar pyrolysis of the acetoxy dimethoxy thioether (59) in dioxan at $100^{\circ}$ for $70 \mathrm{hr}$. afforded (75) in $65 \%$ yield.

As an alternative to thermal elimination, the acid-catalysed elimination of the thioethers (56), (58) and (59) was investigated. In each case when the thioether was dissolved in concentrated sulphuric acid and water added, methyl mercaptan was evolved. The u.v. spectra of the resulting aqueous solutions (Chart XVIII) were similar to those of the elimination products (75) and (76). However, when the n.m.r. spectrum of the dimethoxy thioether (58) was run as a solution in concentrated sulphuric

* This signal was partly obscured by the aromatic protons which appeared as a simplified $\mathrm{A}_{2} \mathrm{~B}_{2}$ quartet. ** See General Introduction. 
CHART XVIII

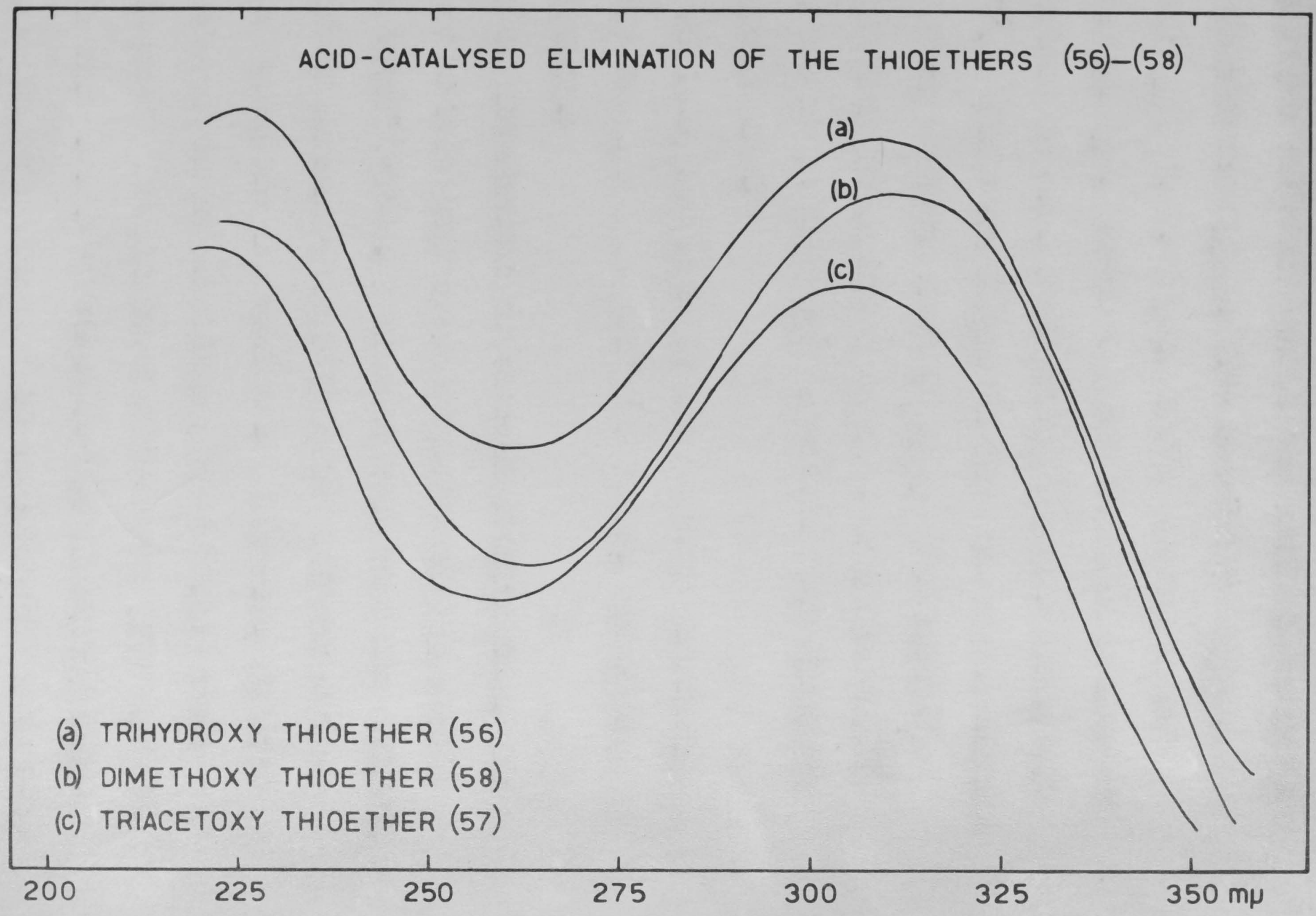


acid, decomposition more extensive than the loss of methyl mercaptan was observed. Subsequent aqueous work-up led to the isolation of only trace amounts of a complex mixture of water-soluble products.

Eliminations for which the products have been characterised, all show loss of one of the $\mathrm{N}$-methoxyl groups. Chemical approaches to the proof of the postulation that this loss occurs from $N-4$ rather than $N-1$, are presented below. Initial studies were based on the proposed elimination of a substrate such as (77) in which $\mathrm{N}-4$ is chemically distinguished from $\mathrm{N}-1$.

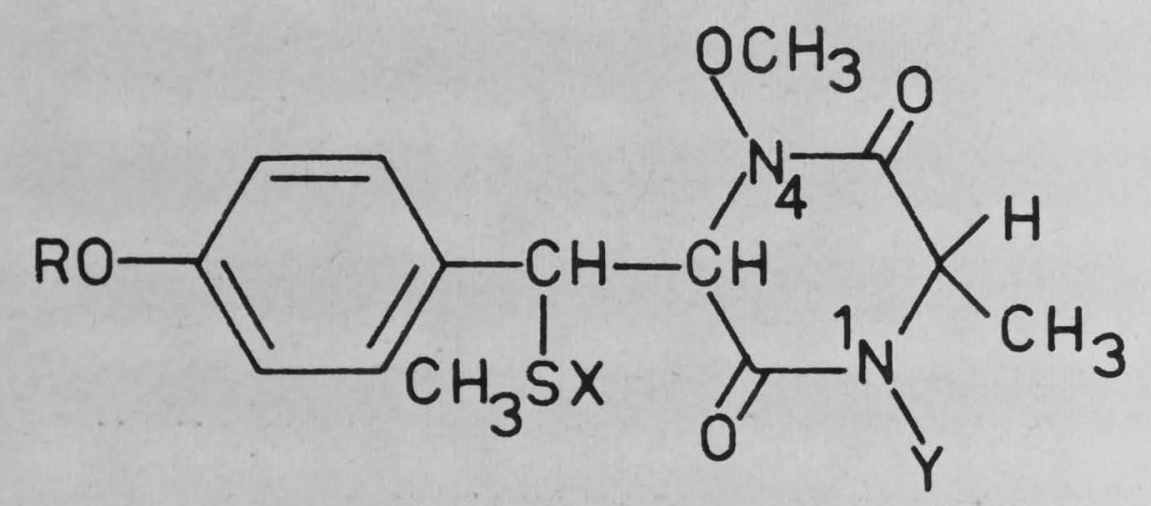

\section{(77)}

With the ultimate aim of synthesising a substrate such as (77) with $\mathrm{Y}=\mathrm{CH}_{3}$, the acyclic hydroxamic acid (55) was treated with methanolic methylamine or ammonia. With both amines complex mixtures of products were produced. This is in direct contrast to the cyclisation of (55) with methanolic hydroxylamine, which is a clean

\$ See Experimental Section. 
reaction leading to the trihydroxy thioether (56) with benz hydroxamic acid as the only significant by-product. Accordingly, an alternative scheme was proposed in which the substrate $(80)$ has the two $N$-methoxyl groups isotopically $\mathrm{y}^{*}$ distinguished. The synthetic operations of this approach are outlined in Chart XIX. Treatment of (55) with ethereal diazomethane afforded the methyl ether (78) as a viscous oil. However, attempted cyclisation of the latter with methanolic hydroxylamine led to a complex mixture, the major component of which was not a hydroxamic acid $\left(t_{\bullet} l_{\bullet} c_{\bullet}\right)$. Although a hydroxamic acid component could be isolated from the crude mixture by partition chromatography on buffered cellulose, insufficient quantities were obtained for characterisation. The failure of the foregoing experiments prompted an attempt to define the position of the amide nitrogen in the elimination product $(76)$. Of the several approaches considered, that involving the ultimate degradation of (76) to $0, N$-dimethyl tyrosine (83), as outlined in Chart XX, was chosen as being the least ambiguous.

* The procedure of van der Merwe et.al. ${ }^{104}$ (Chart XIX) gives 0-methyl groups ca. $50 \%$ trideuterated, which would be sufficient for the present purpose. 
CHART $\times I X$

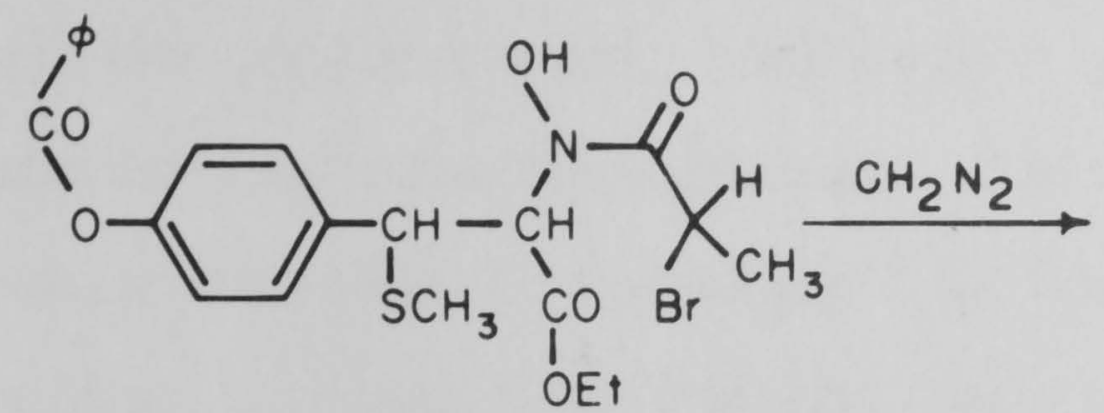

(55)<smiles>CCOC(OCC)C(C([Si])c1ccc(OC=O)cc1)N(OC)C(=O)C(C)Br</smiles>

(78)

$\mathrm{NH}_{2} \mathrm{OH} / \mathrm{CH}_{3} \mathrm{OH}$<smiles>CON1C(=O)C(C)N(OC(C)(C)C)C(=O)C1C(S)c1ccc(OC(C)(C)C)cc1</smiles>

(80)<smiles>CON1C(=O)C(C)N(O)C(=O)C1C(S)c1ccc(O)cc1</smiles>

(79) 
At the present stage, it has been shown that $N$-methylation ${ }^{\text {F }}$ of (76) with ethereal diazomethane was possible and work is in progress towards the completion of the sequence (81) $\rightarrow(83)$

* A second methylation product (ca. $25 \%$ of crude product) having an additional 0-methyl group was formed along with the $\mathrm{N}$-methyl derivative. The former is probably the product of 0 -methylation of the amide function (see Experimental section). 


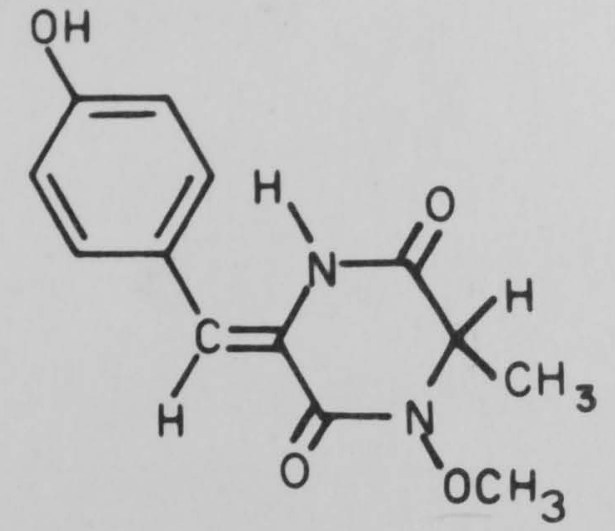

(76)

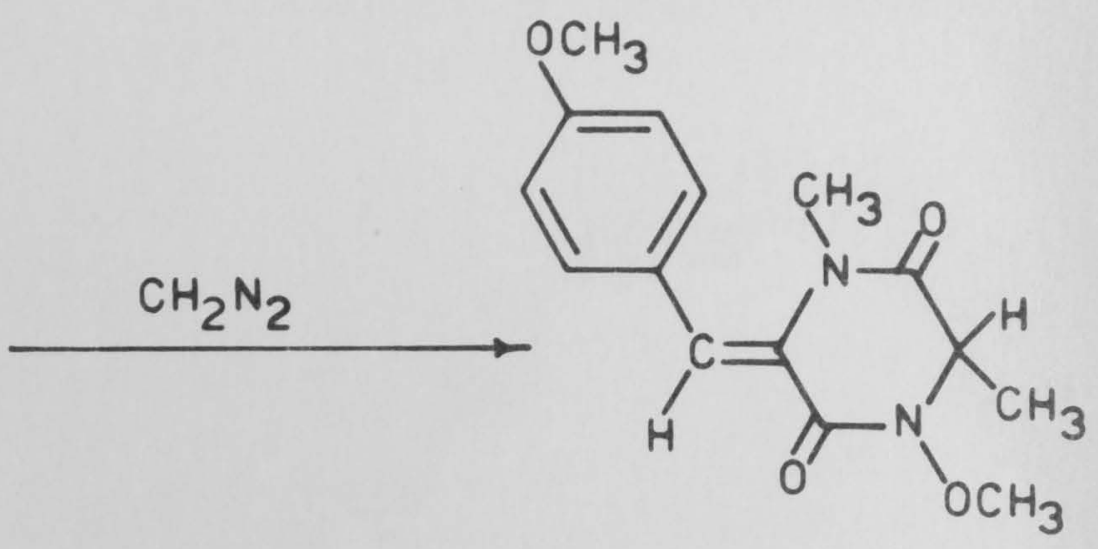

(81)

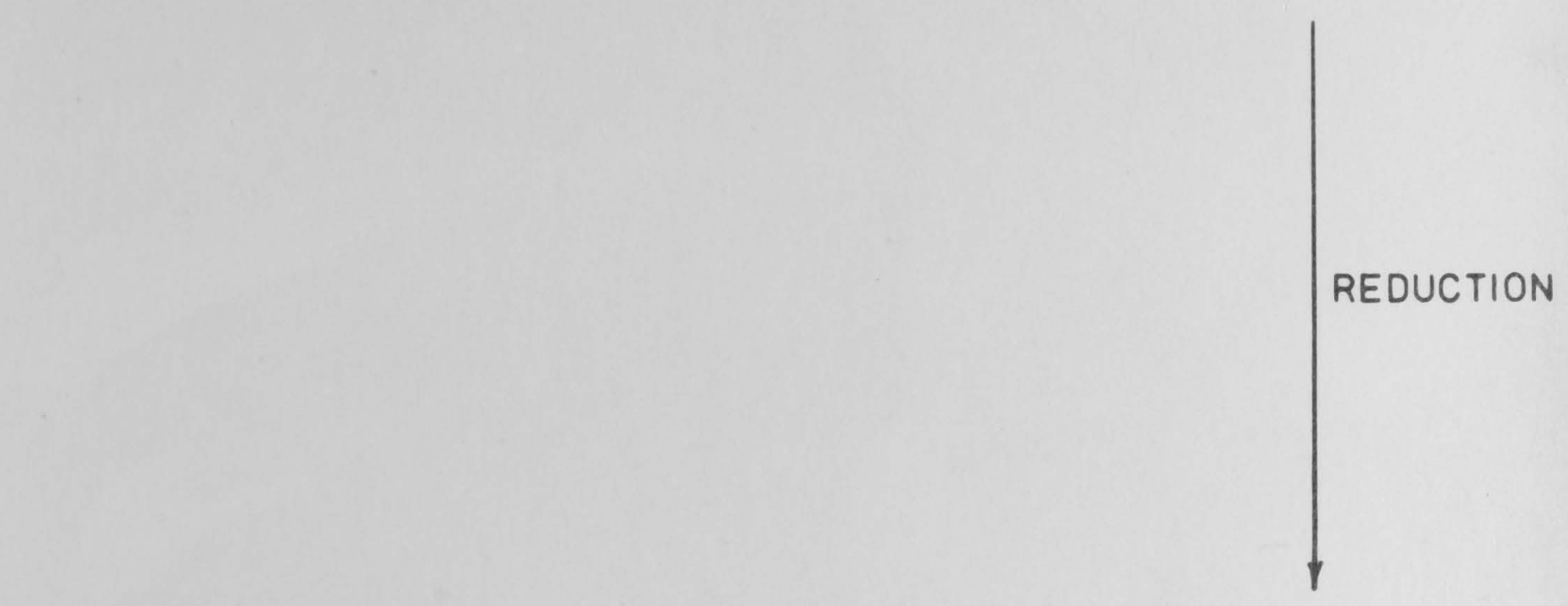

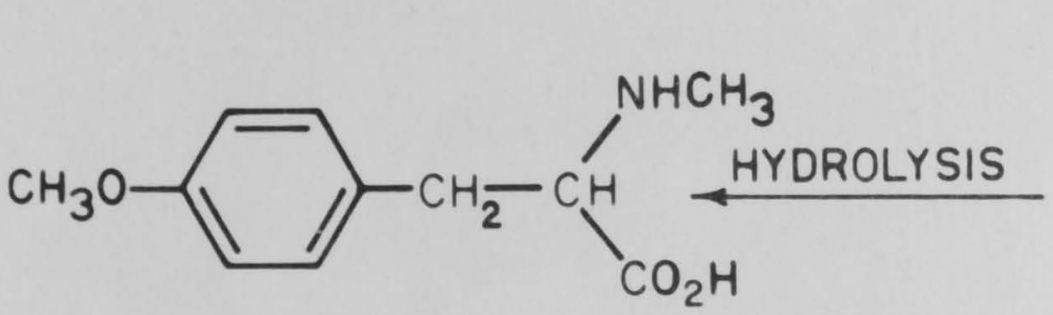

(83)

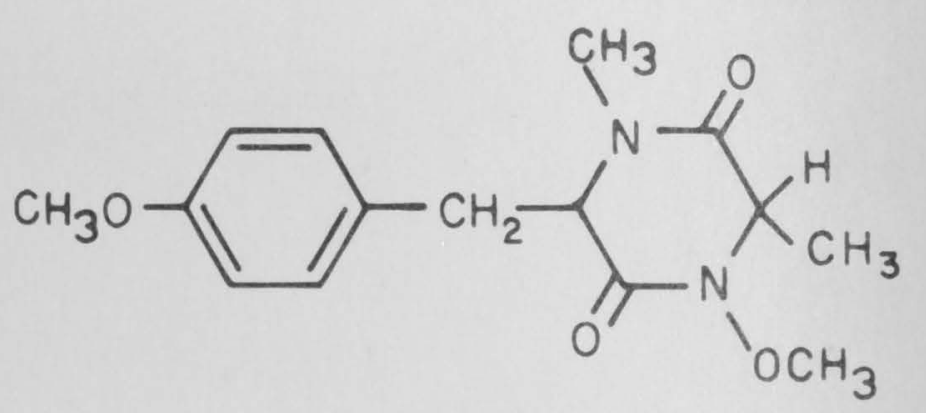

(82) 
(d) Mechanism of the elimination reaction

In view of the anomalous elimination reactions described in the preceding section it is interesting to reconsider the hydrolyses of mycelianamide from a mechanistic point of view.

Birch et. al. in their original studies ${ }^{15,16}$ stated - "In order to explain the products of hydrolysis of mycelianamide itself the formation of an intermediate acyldioxopiperazine would appear necessary. The formula originally assigned to mycelianamide itself, (9), is therefore rather that of such an intermediate".

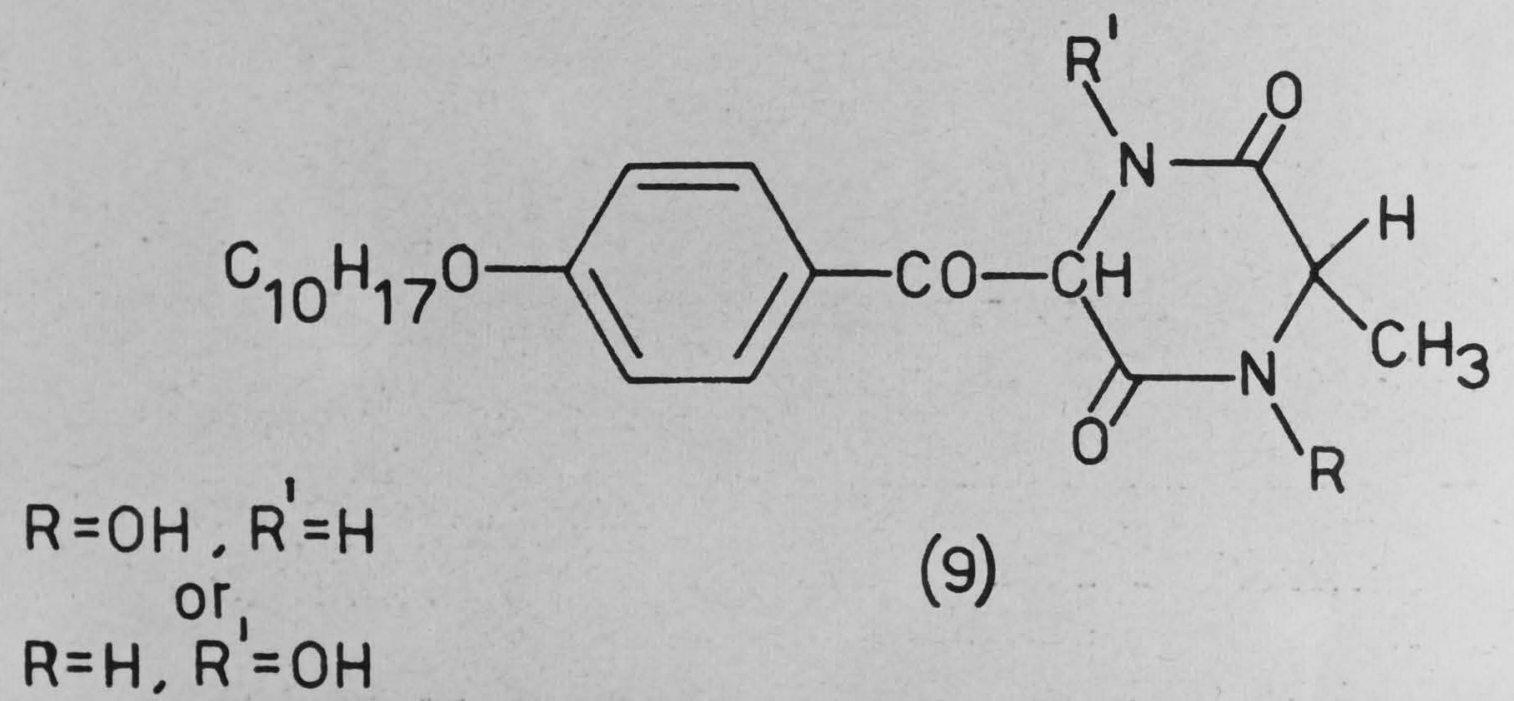

Under conditions of acid hydrolysis, the formation of an intermediate similar to (9) can be rationalised as outlined in Chart XXI. Hydrolysis of intermediate (85) would give rise to the observed $\omega$-amino-p-hydroxyacetophenone (8) and carbon dioxide. The ammonia also produced by acid hydrolysis may arise by further transformation of the intermediate (86). However it is not easy to rationalise the formation of alanine in these 


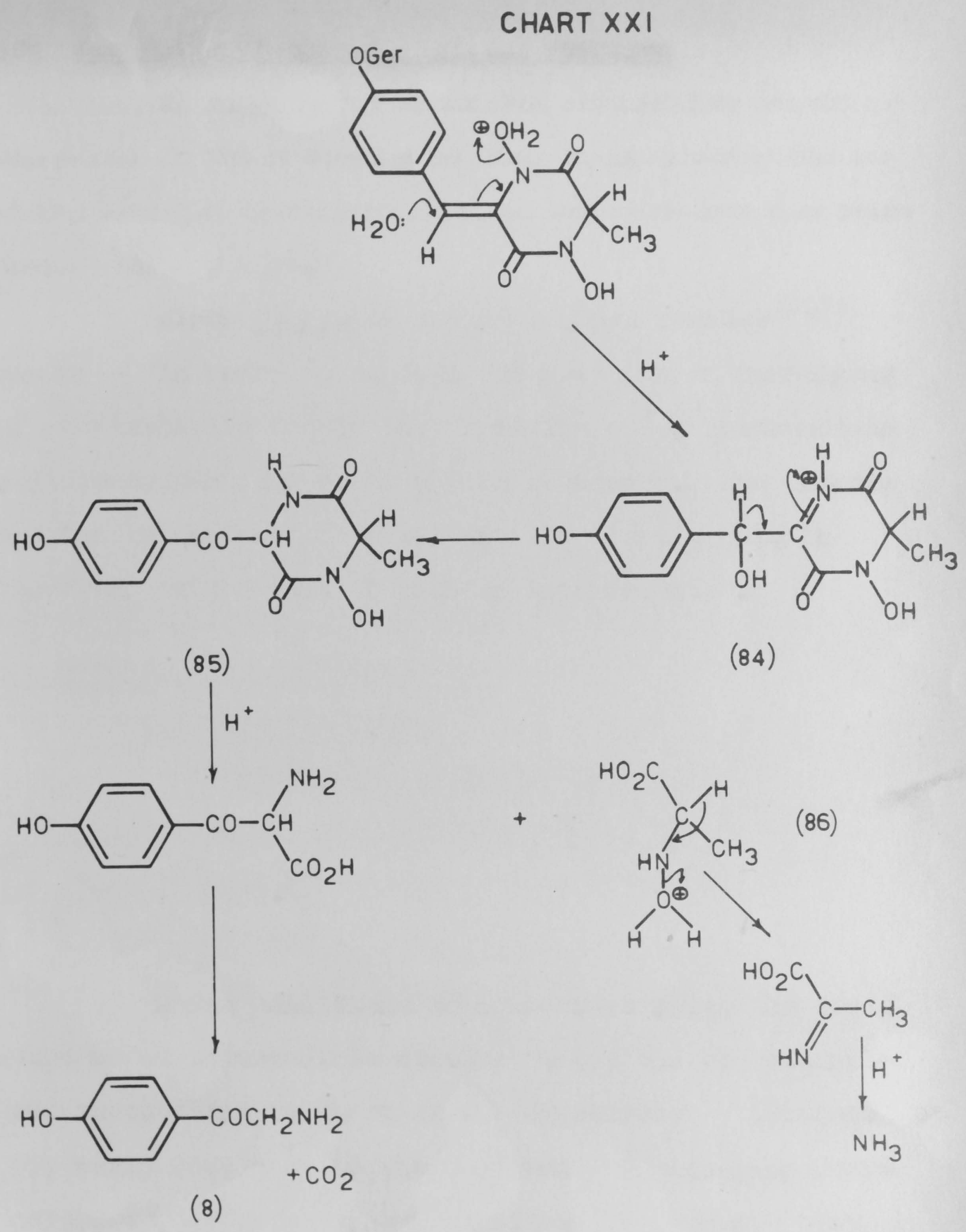


hydrolyses, a reaction which formally must involve a reduction. A similar reaction may be involved in the observation ${ }^{12 a}$ that pyrolysis of $\propto$-hydroxylamino acids yields ammonia, carbon dioxide and the corresponding amino acid.

$$
\text { p-Myceloxybenzoic acid }(7 ; \mathrm{R}=\mathrm{OH}) \text { and } \mathrm{p}-
$$
myceloxybenzamide $\left(7 ; \mathrm{R}=\mathrm{NH}_{2}\right)$, the products of hydrolysis of mycelianamide with sodium hydroxide or sodium carbonate and dilute ammonia respectively, can be explained as the result of basic fission of a $\beta$-diketone such as (9). Although under basic conditions the formation of this intermediate is not easily justified, two possible routes are outlined in Chart XXII.

Irrespective of which mechanisms actually apply in either the acid or base hydrolyses of mycelianamide, it is evident that elimination of the $\mathbb{N}-4$ hydroxyl group is a facile reaction.

$$
\text { Any mechanism proposed for the elimination }
$$
reactions of the present study must explain the highly selective loss of only one of the $\mathrm{N}$-methoxyl groups of the substrates used. The initial observation of this selectivity in the pyrolysis of the sulphoxide (64) prompted a mechanism in which elimination of the methoxyl group from $\mathrm{N}-4$ was a primary step and elimination of the sulphur substituent secondary. One example of this type 
CHART $X X \|$

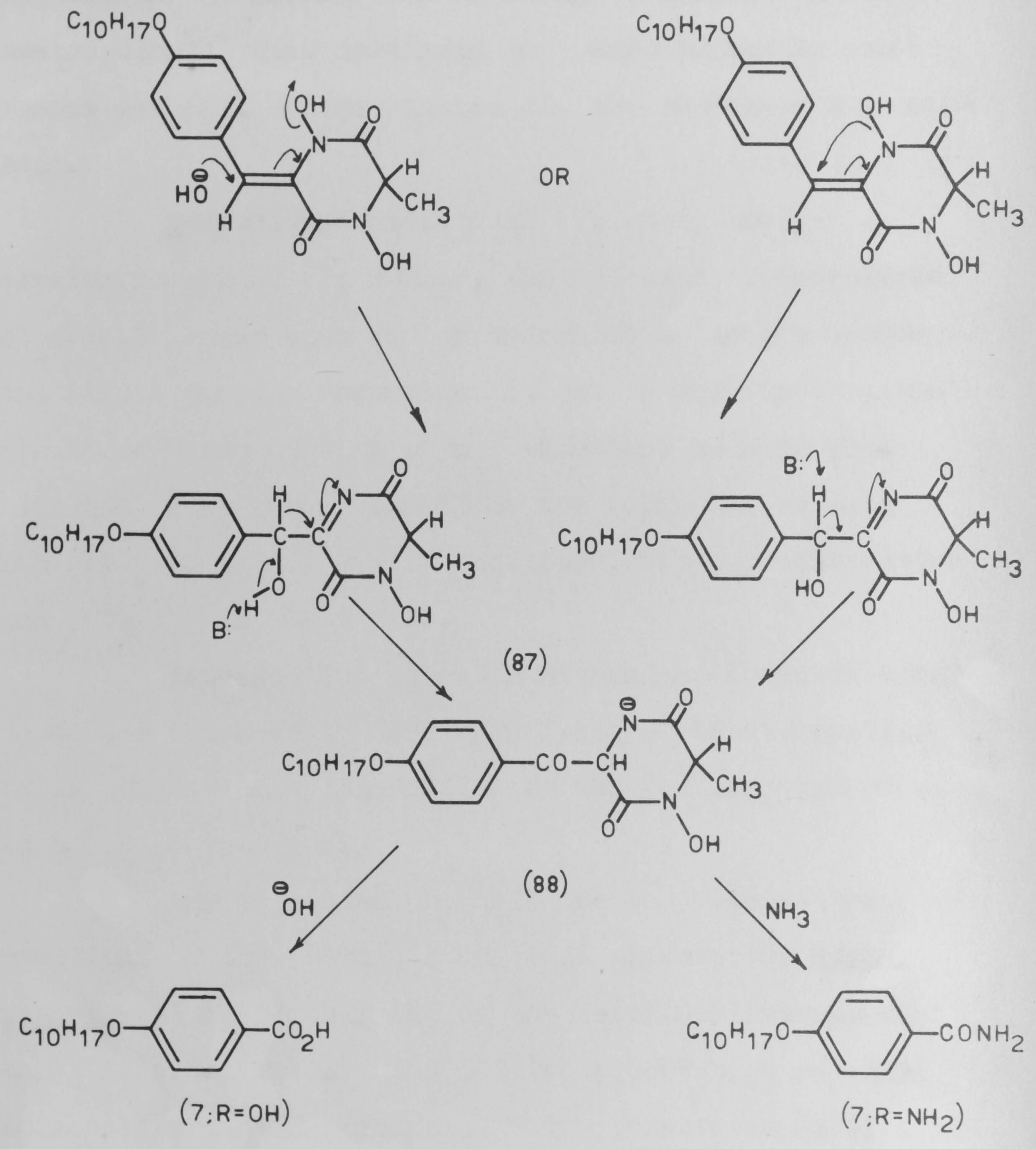


of mechanism is outlined in Chart XXIII. However, when it was found that the thioethers (58) and (59) underwent exactly similar eliminations, such a mechanism became untenable. An alternative mechanism involving elimination in the required sense and then a secondary loss of the methoxyl group, was therefore more favoured. In order to better define the mechanism(s) which were operative, further investigation of the elimination reaction was made.

Initially it was shown that the simple dimethyl ether ( $24 ; \mathrm{R}^{\prime}=\mathrm{CH}_{3}$ ) was recovered unchanged when subjected to the reaction conditions of the present elimination (dioxan $/ 80-85^{\circ} / 60 \mathrm{hr}$ ). Also, when a pyrolysis of the sulphoxide (64) was interrupted after 4 and $10 \mathrm{hr}$. at $80-$ $85^{\circ}$, the only compounds observable by t.l.c. or $n \cdot m \cdot r$. analysis were the final elimination product (75) and unchanged sulphoxide. An n.m.r. study of the same pyrolysis in $d_{6}$-dimethylsulphoxide at $77^{\circ}$ gave essentially similar results, i.e. the spectrum of the elimination product (75) appeared at approximately the same rate as the degeneration of the spectrum of the sulphoxide (64). This behaviour is illustrated in Chart XXIV which displays the n.m.r. spectrum of the pyrolysis mixture at various stages of the elimination. Only absorptions in the range $6-10 \tau$ are shown and signals due to the eliminated 


\section{CHART XXIII}
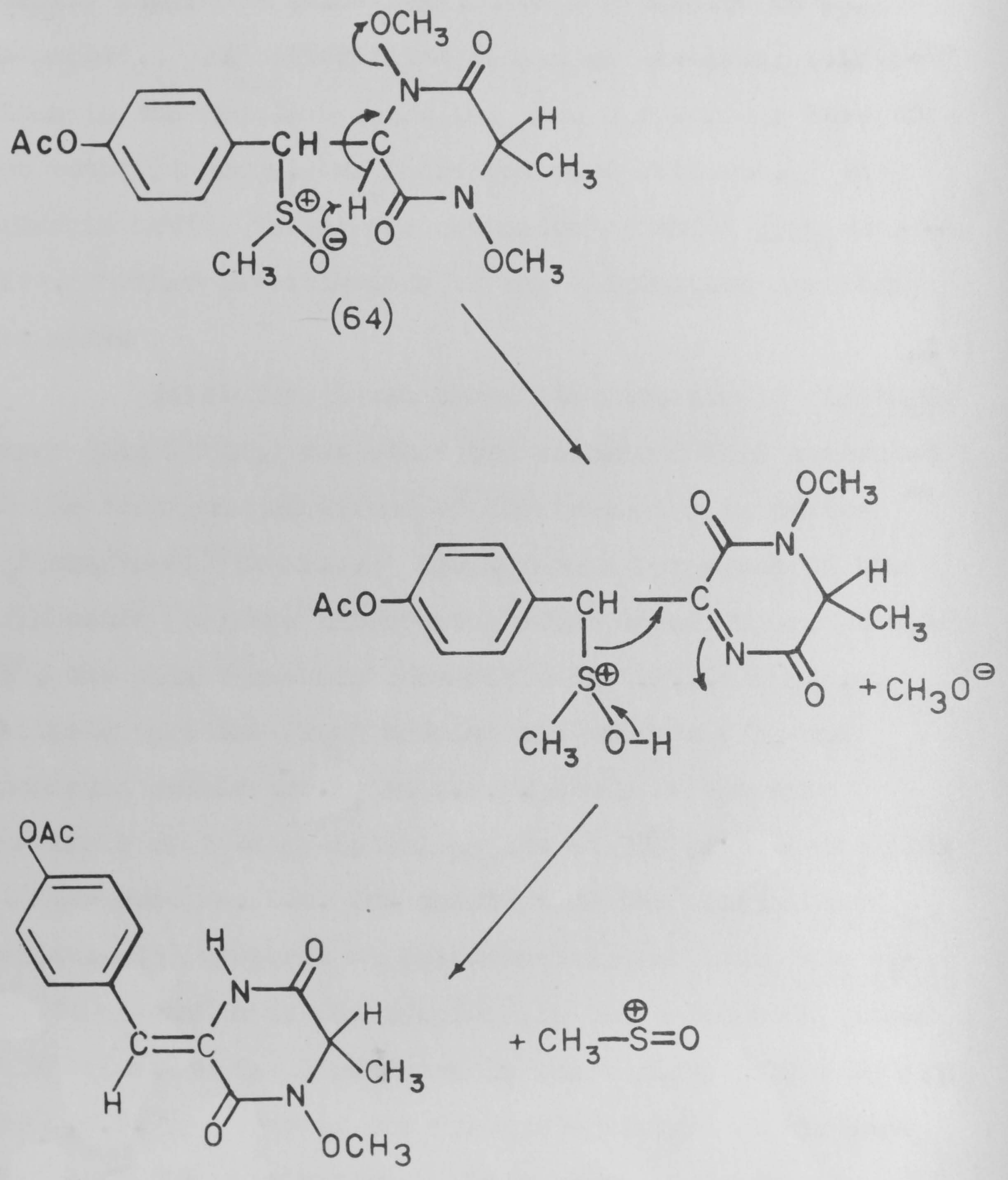

(75) 
$-\mathrm{SOCH}_{3}$ group are deleted for reasons of clarity. The sample of (64) used in this study was contaminated with a small amount of the corresponding sulphone, the spectrum of which remained unchanged throughout the pyrolysis.

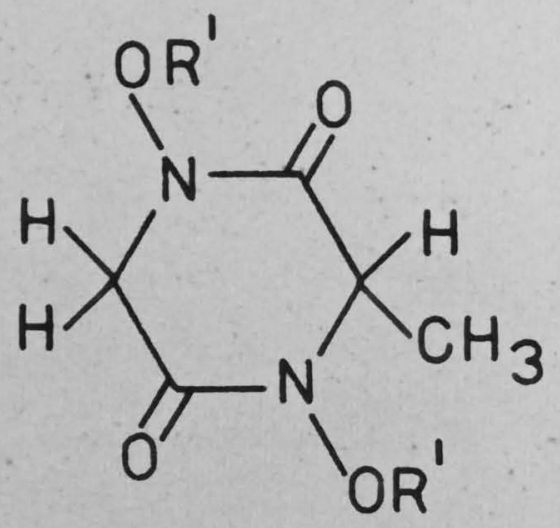

(24)

since no build-up of an intermediate was observable in the foregoing experiments it was inferred that either the elimination was concerted, or that a slow primary step was followed by a fast secondary reaction to give the observed product. A direct analogue of the transient intermediate implied by the latter alternative, would be the dimethyl ether of mycelianamide. Treatment

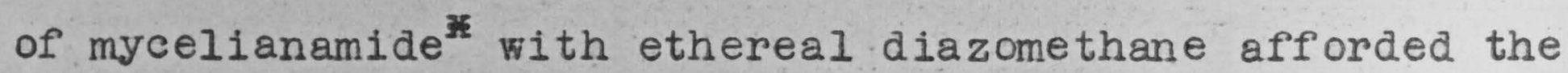
dimethyl ether as a viscous oil. Although the crude product has not yet been fully characterised, it was homogeneous on t.l.c. and the spectral data were consistent with the proposed structure (89).

\# A generous sample was kindly provided by Mr. R.W. Rickards. 


\section{CHART XXIV}
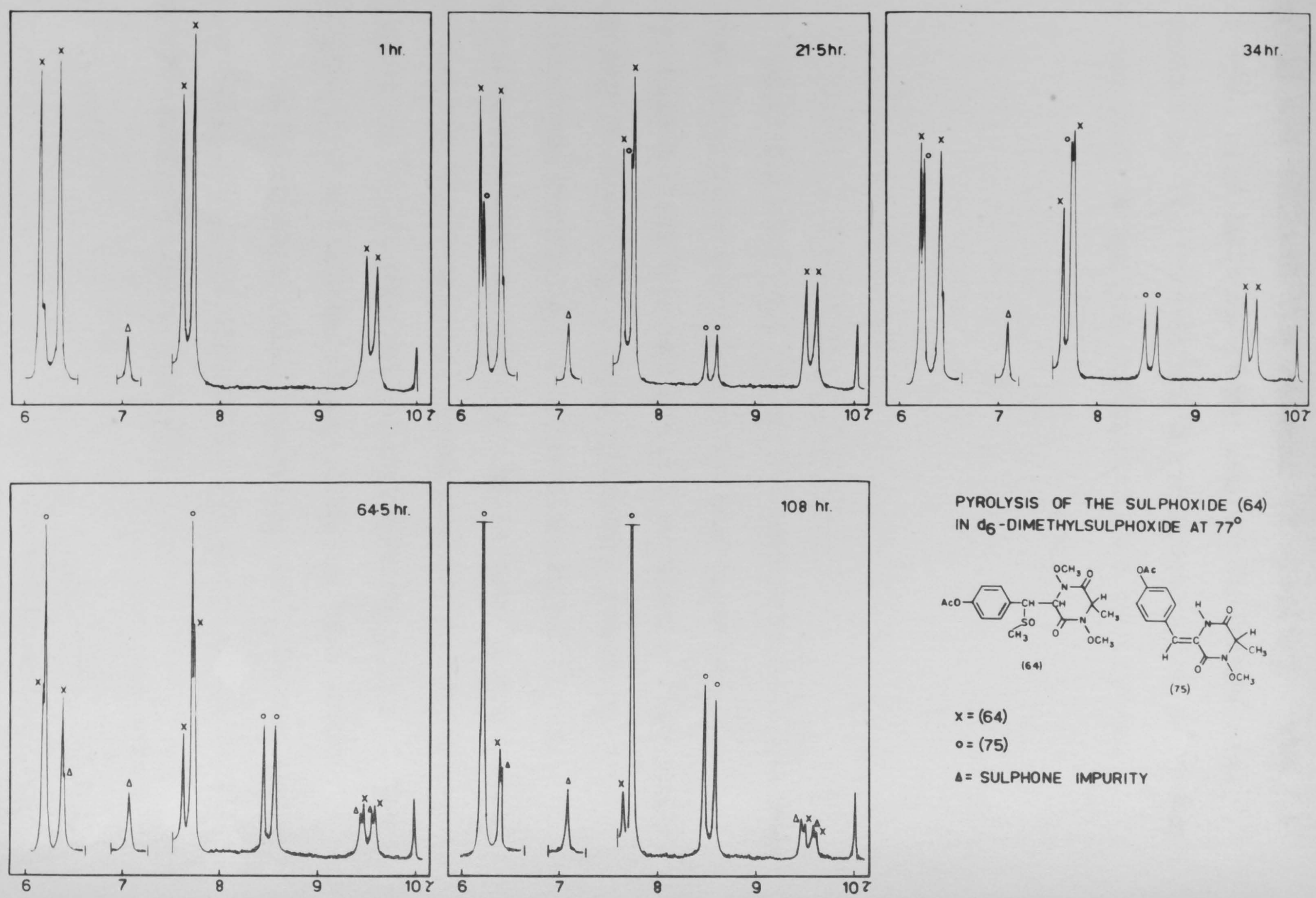

PYROLYSIS OF THE SULPHOXIDE (64)

IN $0_{6}$-DIMETHYLSULPHOXIDE AT $77^{\circ}$

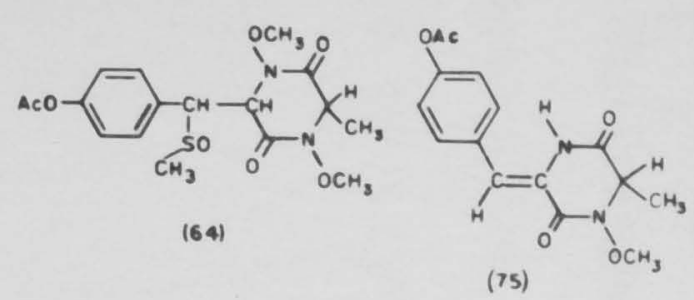

$x=(64)$

$0=(75)$

$\Delta=$ SULPHONE IMPURITY 


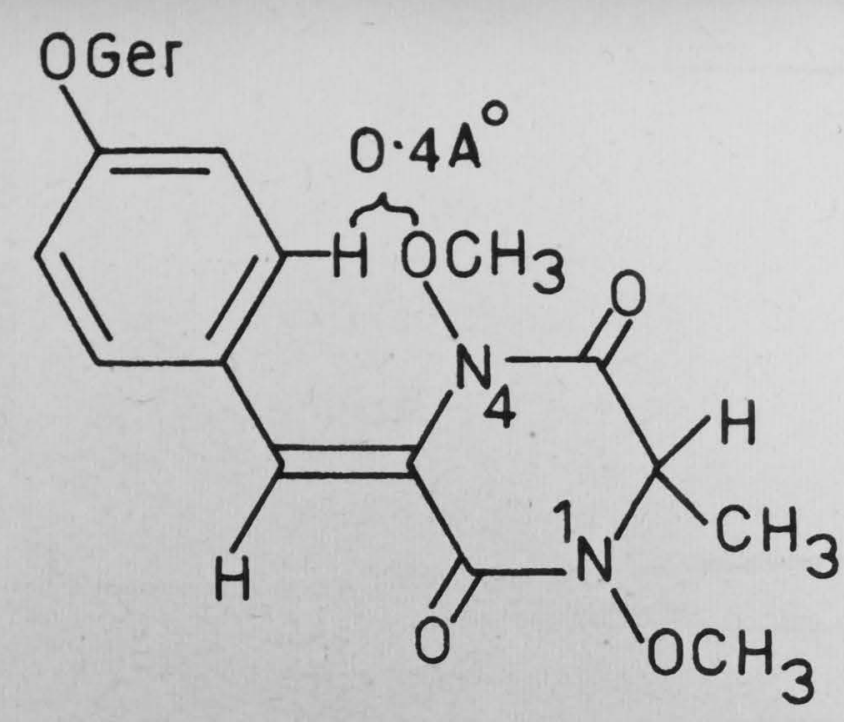

(89)

Inspection of a planar Drieding model of (89) indicates severe steric interaction between the ortho aromatic proton and the $\mathrm{N}-4$ methoxyl oxygen; as shown above these groups are separated by only ca.0.4A ${ }^{\circ}$. The n.m.r. spectrum of (89) (Chart XXIVa) shows absorptions for two distinct 0 -methyl groups at $6.12,6.57 \tau$ (in deuterochloroform) and $6.47,6.89 \tau$ (in benzene). One possible explanation for this preferential shielding is that it is a direct result of the abovedrentioned steric interaction; if the proposed trans stereochemistry of (89) is correct, such interaction might force the aromatic ring out of the plane of the double bond resulting in selective shielding of the $\mathrm{N}-4$ methoxyl group. However this argument is rather tenuous since the $u_{\bullet} v_{\bullet}$ absorption spectrum of $(89)\left(\lambda_{\max }, 228,321 \mathrm{~m} \mu\right)$ is still very similar to that of deoxymycelianamide ( $\lambda_{\max }$. $225,317 \mathrm{~m} \mu)$. In the latter case the steric interaction 
CHART XXIVa

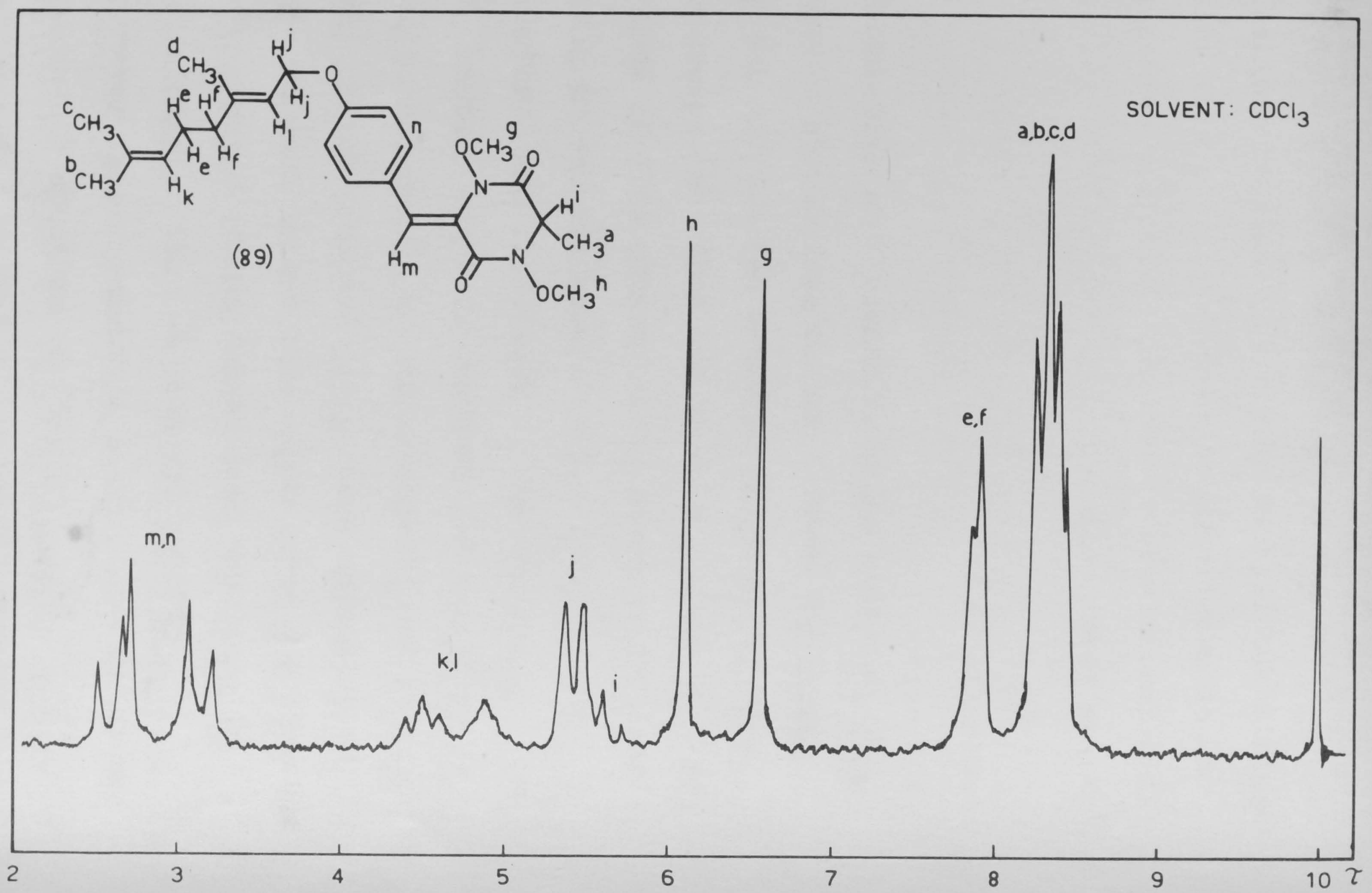


described above would be markedly reduced and would be expected to allow the planarity of the benzylidene linkage. Application of this steric argument to mycelianamide and deoxymycelianamide would in turn predict significant differences in their $u_{\bullet} v_{\bullet}$ spectra; in practice these spectra are very similar (mycelianamide, $\lambda_{\max }, 231,321 \mathrm{~m} \mu$ ). Pyrolysis of a benzene solution of mycelianamide dimethyl ether (89) at $77^{\circ}$ resulted in the selective loss of the high-field methoxyl group (6.89i) within one hour. An n.m.r. study of the same pyrolysis at $65^{\circ}$ is outlined in Chart XXV. At this lower temperature the elimination has a half life of ca. $75 \mathrm{~min}$, and the signal for the lowfield methoxyl group remains unchanged throughout the pyrolysis. After the elimination was complete, a small amount of solid material $(<2 \mathrm{mg} \cdot)$ collected at the top of the sealed evacuated $n \cdot m \cdot r$. tube used in this kinetic study. This solid, which was insoluble in most organic solvents, was shown to be paraformaldehyde by the strong peaks at $\mathrm{m} / \mathrm{e} 30,29$ and 28 in the mass spectrum and by conversion to the 2,4-dinitrophenylhydrazone, which was Identical in all respects with formaldehyde 2,4-dinitrophenylhydrazone $\left(t_{\bullet} l_{\bullet} c_{\bullet}, u_{\bullet} v_{\bullet}, \operatorname{mixed} m_{\bullet} p_{\bullet}\right)$.

This facile and selective elimination of only one methoxyl group as formaldehyde, is best rationalised on the basis of the proposed trans stereochemistry for 
CHART $X X V$
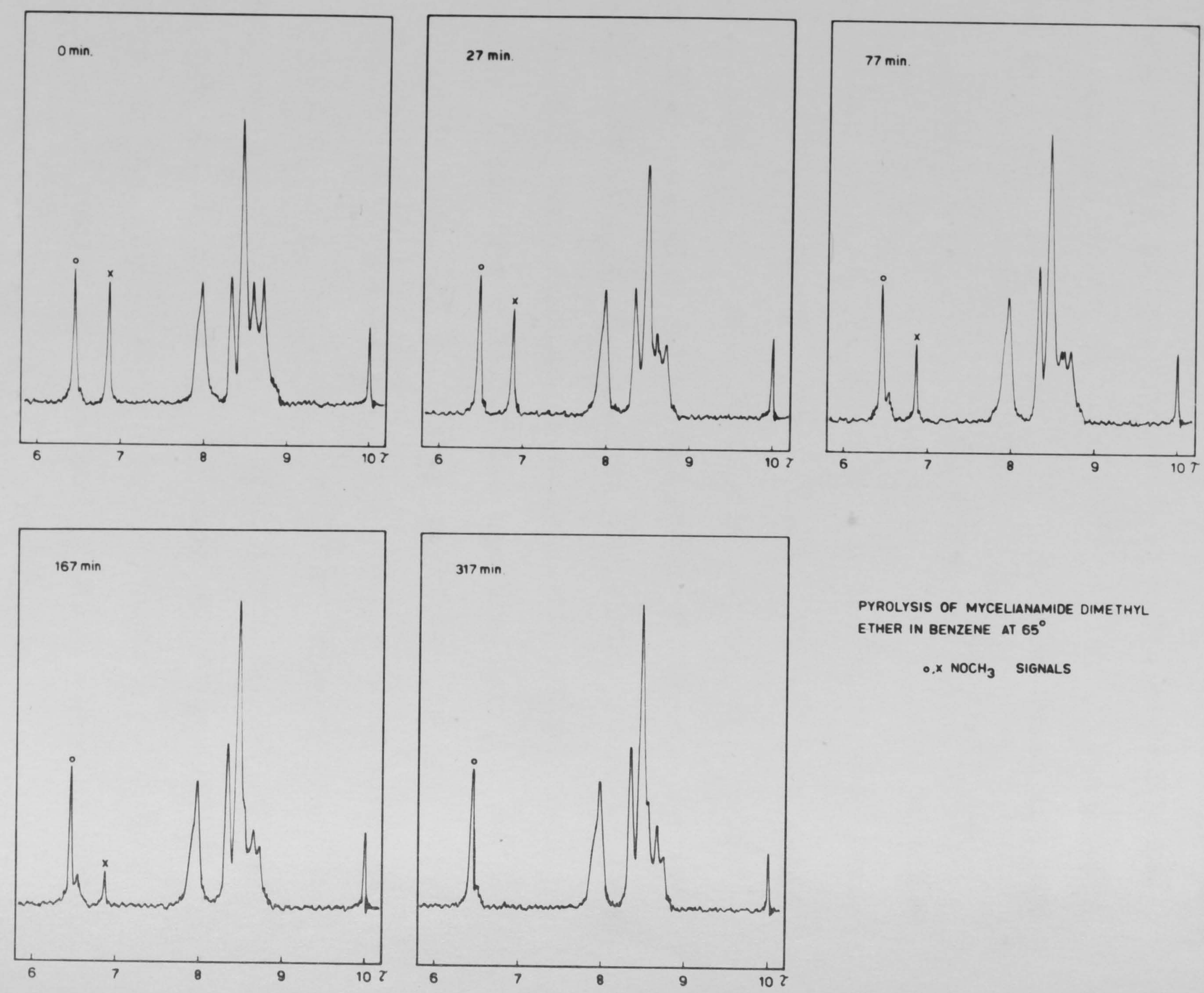

PYROLYSIS OF MYCELIANAMIDE DIMETHYL

ETHER IN BENZENE AT $65^{\circ}$

- $x \mathrm{NOCH}_{3}$ SIGNaLS 
mycelianamide and the dimethyl ether. The severe steric interaction already described would force the $\mathrm{N}-4$ methoxyl group to be anti to the aromatic ring and into close proximity with the hydroxamic carbonyl group. Elimination of the methoxyl group via a favourable cyclic six-membered transition state would lead to the observed formaldehyde as outlined below

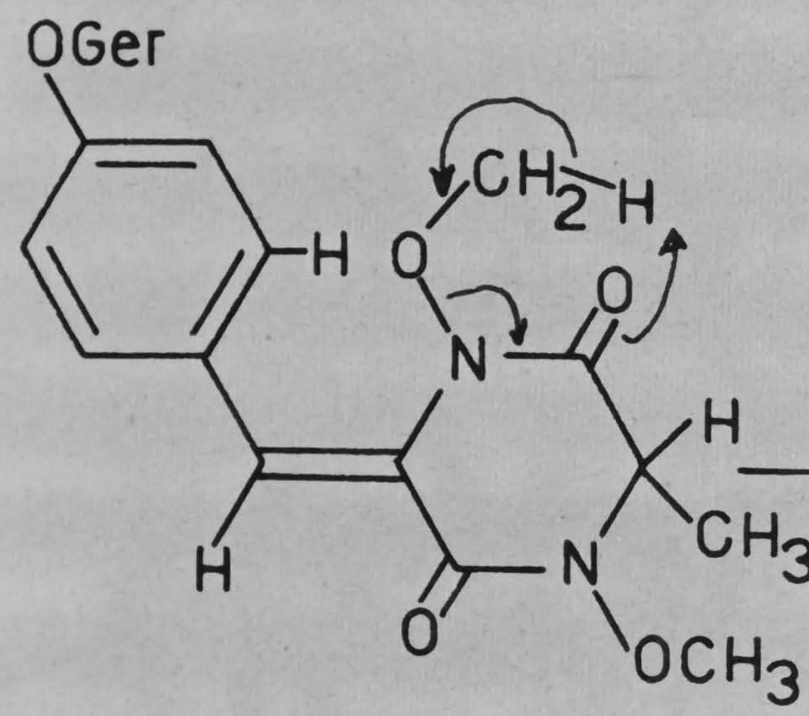

(89)

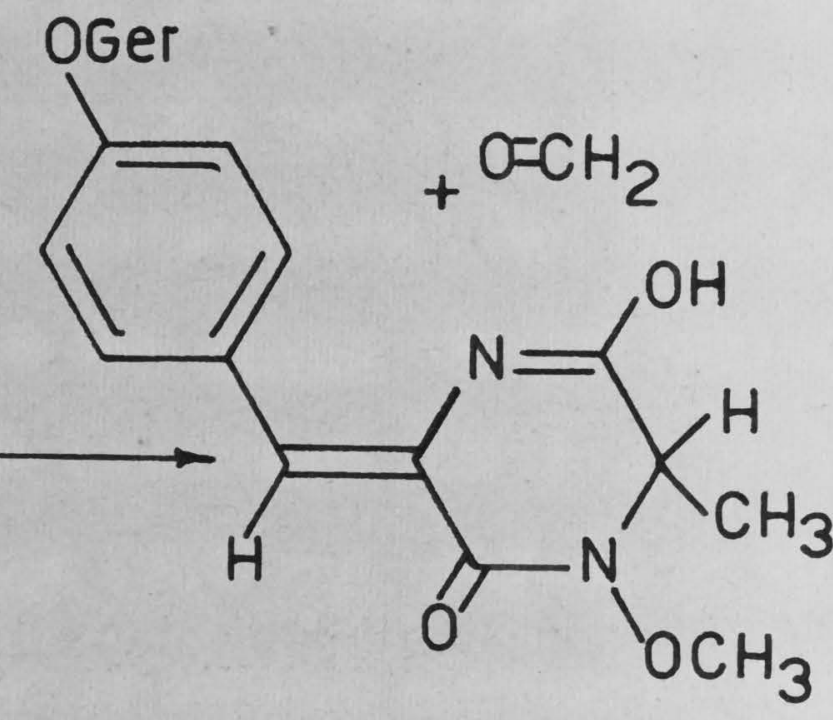

(89a)

An alternative mechanism involving participation of the double bond ( $A$; Chart XXVI) was considered unlikely. Interaction between the double bond and a methoxyl hydrogen in the transition state for this mechanism would be most effective if the approach of the hydrogen was from above or below the plane of the double bond. Inspection of a model of (89) indicates that such an approach is virtually

* The mycelianamide-derived product (89a) from this elimination has not yet been characterised. However, the crude product showed $u_{*} v_{0}$ absorption at 228 and $321 \mathrm{~m} \mu$ and work is in progress towards its characterisation. 
CHART XXVI
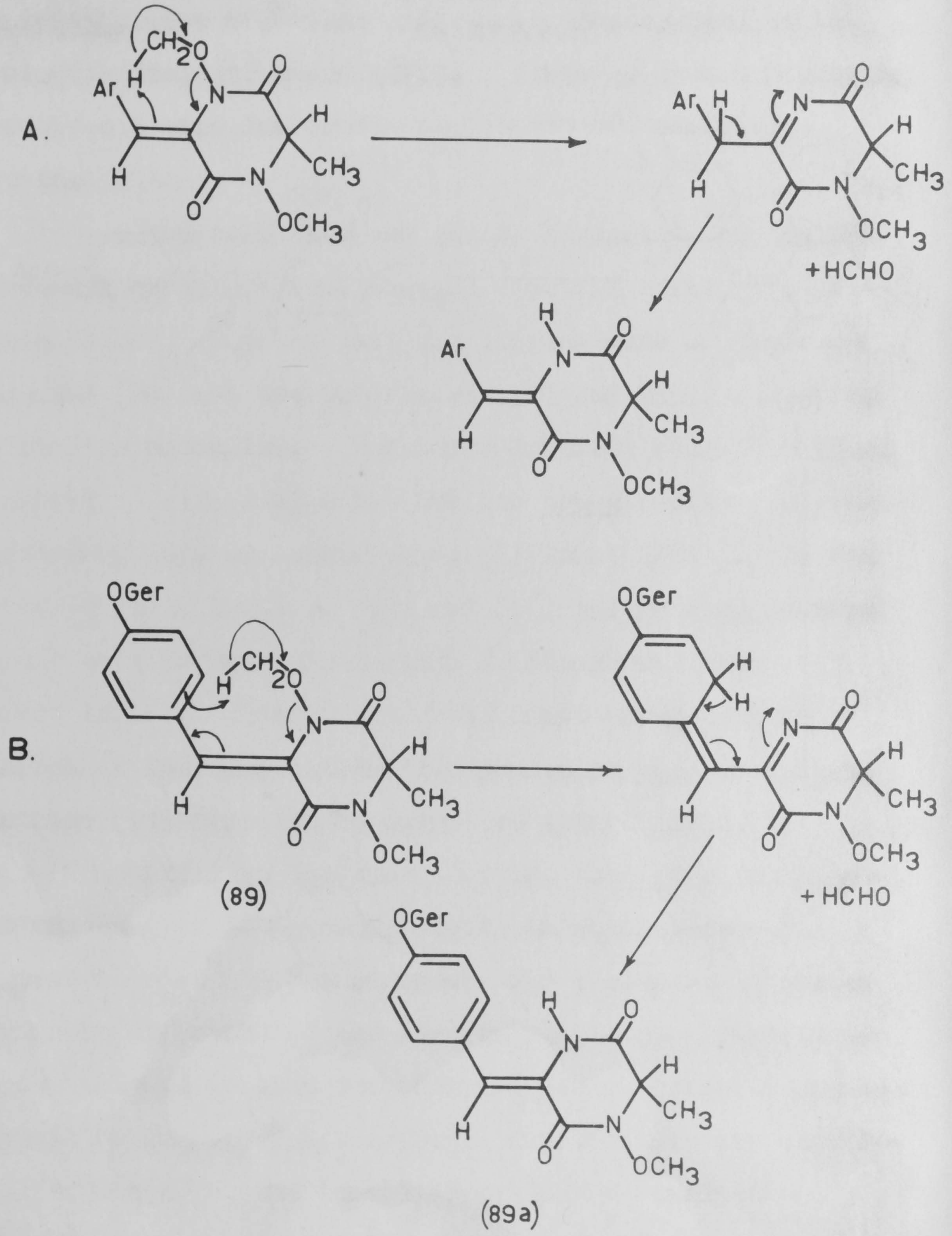
impossible. A third alternative that cannot be excluded a priori, is a mechanism involving participation of the aromatic ring ( $B$; Chart XXVI). However, such a mechanism involves a less favourable eight-membered transition state.

The selective and rapid elimination of the $N-4$ methoxyl group of mycelianamide dimethyl ether (89) provides strong evidence that the eliminations of the sulphoxide (64) and the thioethers (58) and (59) proceed by a similar mechanism. For the sulphoxide (64) this would involve $\beta$ elimination to give the trans olefin (90) and secondary loss of formaldehyde ( $A$; Chart XXVII). In the case of the thioethers (58) and (59) the primary process would be a thermal elimination of methyl mercaptan ( $B$; Chart XXVII). However, for the dimethoxy-p-hydroxy thioether (58) and alternative mechanism via the quinone methide (91) may also be operative (Chart XXVIII).

Although the basic driving force for the elimination reaction is probably steric in nature, several questions remained unanswered. For instance, it was of interest to determine the minimum steric requirement for the elimination since the examples of the present synthetic investigation represent extreme cases. Also any electronic effect(s) of the benzylidene linkage remained undetermined. To this end a study of model compounds has 
CHART XXVII

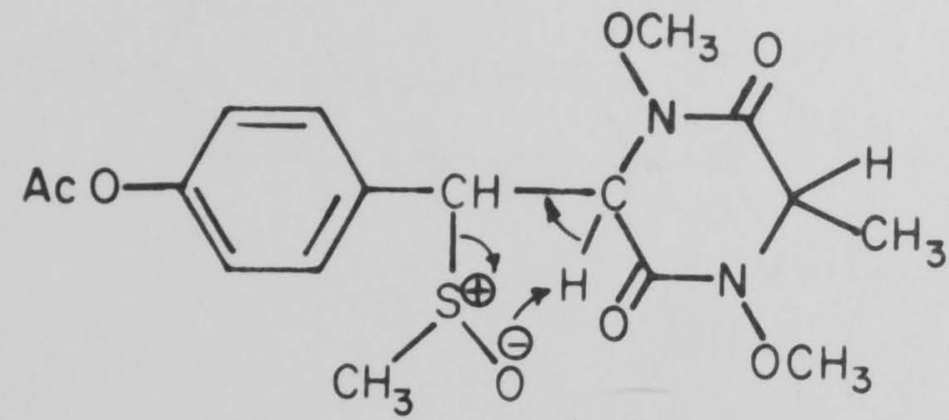

(64)

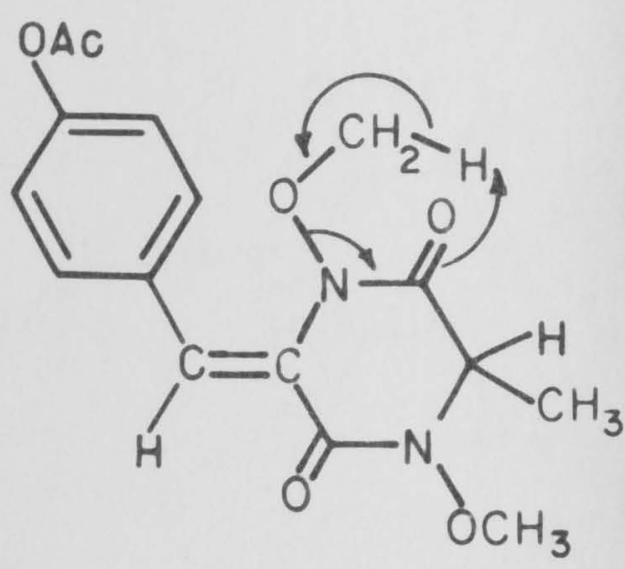

(90)

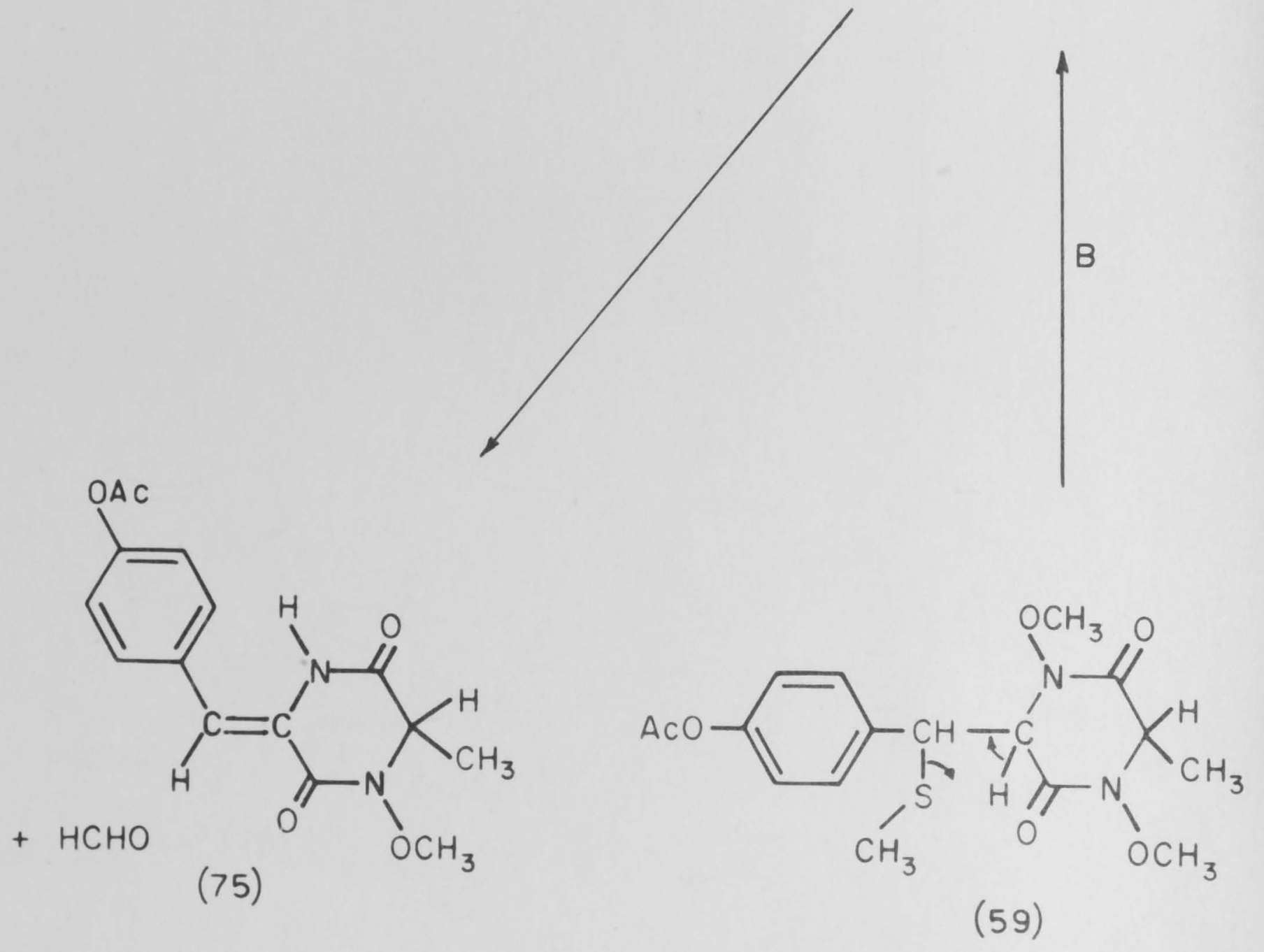


been initiated and although in a very preliminary stage, several interesting facts have emerged.

Thermal rearrangement of 2-alkoxypyridine-Noxides (92) has been shown to afford the corresponding $N$ alkoxy-2-pyridones(93). 105 This reaction which requires temperatures of $100-140^{\circ}$ for $1.5-3.5 \mathrm{hr}$. for completion, does not appear to proceed further than the initial rearrangement. It has also been found that elimination of benzophenone from the benzhydryl ether of $N$-hydroxyphthalimide (94) requires extremely vigorous heating. 106<smiles>[R]COc1cccc[n+]1[O-]</smiles>
(94)

Prompted by the observation of a peak due to the loss of benzaldehyde in the mass spectrum of 1-benzyloxy2-thiouracil, other workers in this Department have investigated the thermal elimination of benzaldehyde from 
several 1-benzyloxy uracils. 107 The approximate halflives for these pyrolyses in $\mathrm{d}_{6}$-dimethylsulphoxide at $140^{\circ}$ are listed below.

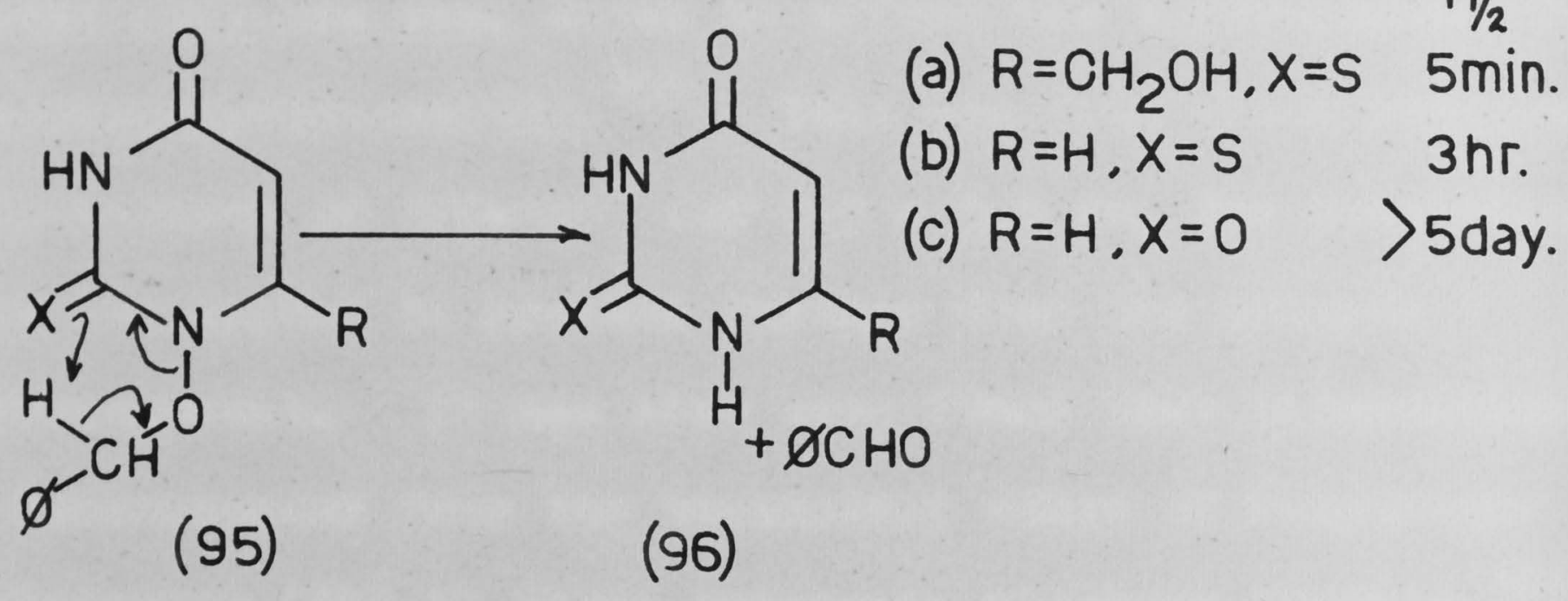

Comparison of the thiouracils (95a) and (95b) reveals the influence of the 6-hydroxymethyl group. While obviously not as effective a buttressing group as the benzylidene linkage of mycelianamide dimethyl ether, this group still results in marked rate acceleration. A similar rate enhancement in the thiouracil (95b) over the uracil (95c) probably reflects the greater steric size of sulphur relative to oxygen. Since any (undefined) electronic effects should be relatively constant throughout the series this study suggests that the ease of elimination is largely governed by steric factors.

In the present work, model compounds which were directly related to the mycelianamide system were chosen. One such system, the synthesis of which will be actively pursued in the future, is the bicyclic compound (97). 
This molecule would have virtually the same stereochemical features as the dimethyl ether of mycelianamide (89) and thermal elimination of the methoxyl group should again be extremely facile.

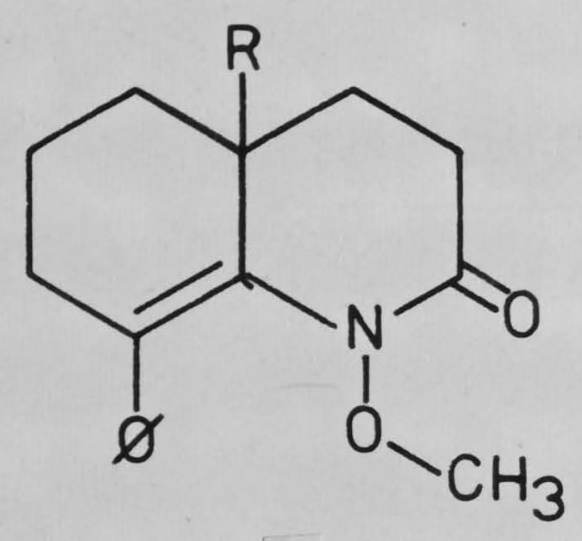

(97)

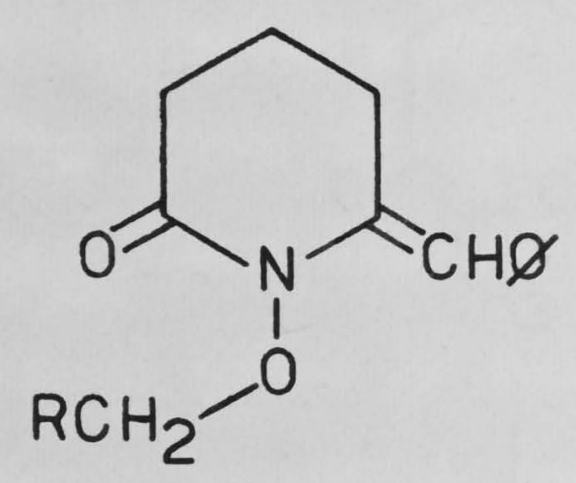

(98)

Preliminary investigation has been made of a related system, the glutarimide derivative (98). A possible synthetic route to this intermediate was suggested by the report ${ }^{108}$ that treatment of $N$-methyl glutarimide with two moles of a Grignard reagent ( $\mathrm{MMgBr}$ ) afforded the linear amido ketone (99) (Chart XXIX). For cases where $R=a l k y l$, cyclisation and dehydration of (99) gave the 4,5 dihydro-6-pyridone (100). Although the same reaction was not reported for the benzyl compound (99; $\left.\mathrm{R}=\mathrm{CH}_{2} \varnothing\right)$, it was predicted that in this case, cyclisation and dehydration would lead to the benzylidene glutarimide (101).

A similar synthetic route was envisaged for the model compound.(98). However, addition of $\mathrm{N}$-benzyloxy 
CHART $X X I X$

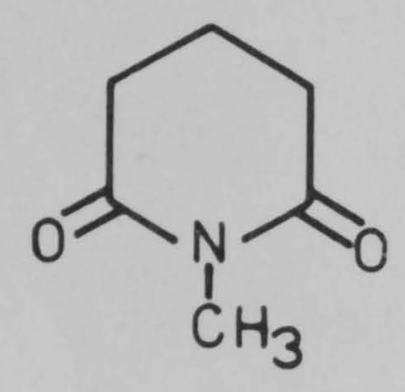

$\mathrm{RMgBr}$

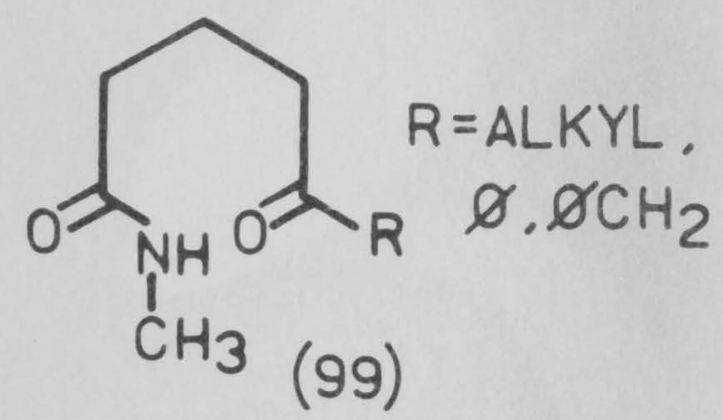

$\mathrm{AC}_{2} \mathrm{O} / \mathrm{REFLUX}$
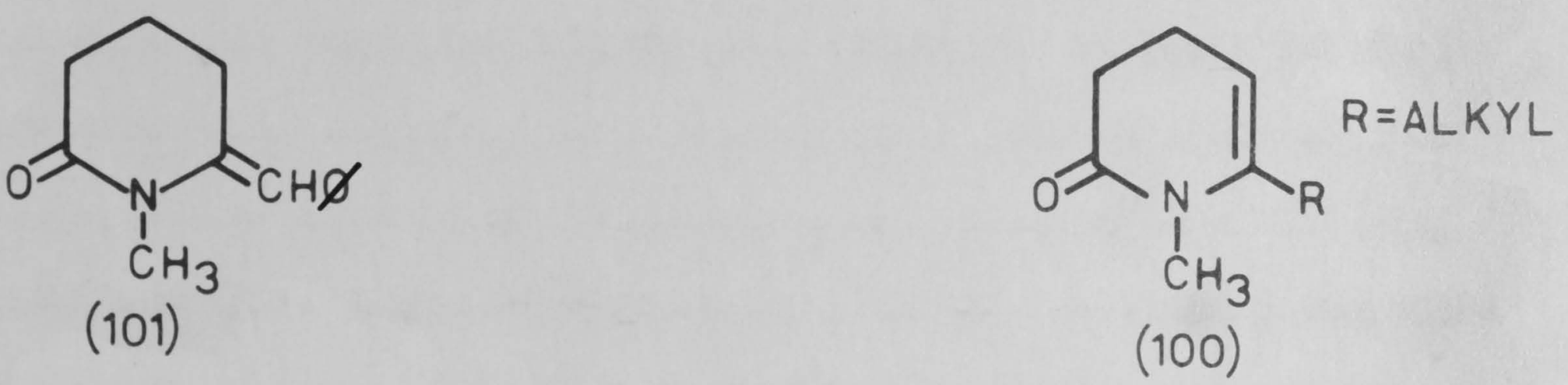
glutarimide $(102)^{*}$ to a cooled solution of two moles of benzylmagnesium bromide led to a bis adduct (104), resulting from the addition of a second mole of the Grignard reagent to the intermediate benzyl ketone (103). Further study of this reaction will be made using inverse addition of only one mole of Grignard reagent and lower reaction temperatures.

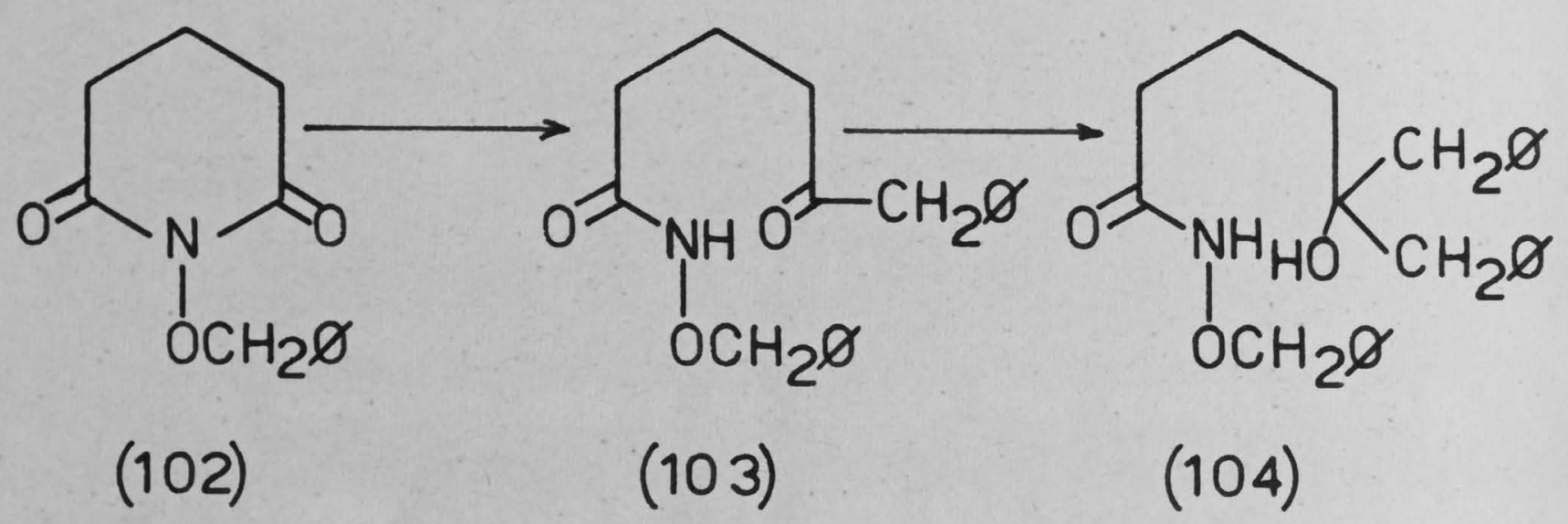

Even if the initial steps of the foregoing synthesis can be achieved, a mixture of isomers could be obtained in cyclisation and dehydration step $(105) \rightarrow(106)$. However, if the isomers of (106) could be separated, such an eventuality would be fortunate. Pyrolysis of (106; $\mathrm{R}=\mathrm{H}, \mathrm{R}^{1}=\varnothing$ ) would be analogous to the elimination of mycelianamide dimethyl ether and therefore be rapid; the rate of elimination of benzaldehyde from the other isomer ( $106 ; \mathrm{R}=\varnothing, \mathrm{R}^{1}=\mathrm{H}$ ) might then reflect any electronic effect * Prepared by the reaction of 0 -benzyl hydroxylamine with
glutaric anhydride at $180^{\circ}$ for $2 \mathrm{hr} .109$ 
exerted by the benzylidene linkage. Photochemical interconversion of such isomers was also considered, but this may itself lead to elimination since the reaction is formally analogous to the photochemical Norrish Type II cleavage. 110

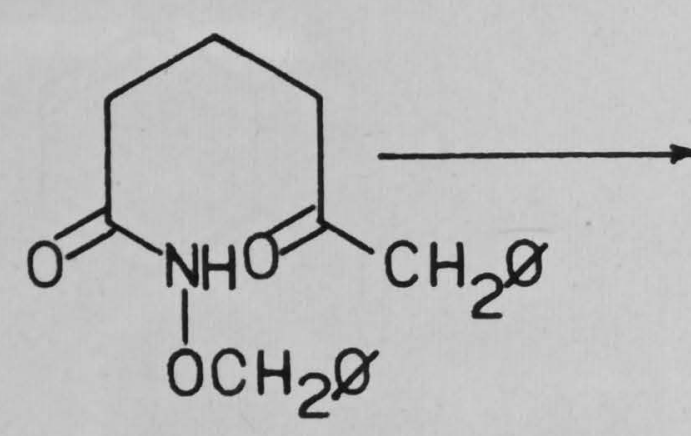

(105)<smiles>[R]C([R])=C1CCCC(=O)N1OC</smiles>

(106)

An obvious means to avoid the complication of isomeric mixtures would be to use the benzhydryl Grignard reagent. However, by analogy with the reactions of potassium diphenylmethide, ${ }^{111}$ proton abstraction rather than carbonyl addition would be the favoured reaction with this Grignard reagent. Another means to this end, the Wittig reaction, would necessitate the use of a deactivated Wittig reagent。

* The benzhydryl ether of $\mathrm{N}$-hydroxyphthalimide is photochemically labile. 106

* Benzhydryl bromide or chloride is difficult to convert to the Grignard reagent due to the facility of the coupling reaction. However, the Grignard reagent can be prepared successfully by the reaction of potassium diphenylmethide and magnesium bromide in ether, 112 
The ready availability of the benzal phthalide $(107)^{113}$ prompted the study of the derived $N$-methoxy phthalimide system (108) as a model for the present elimination.

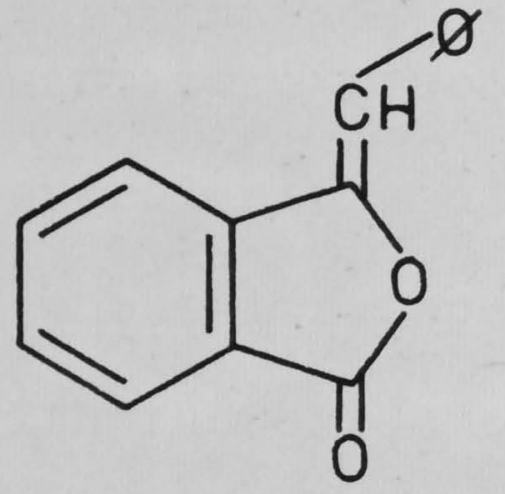

(107)

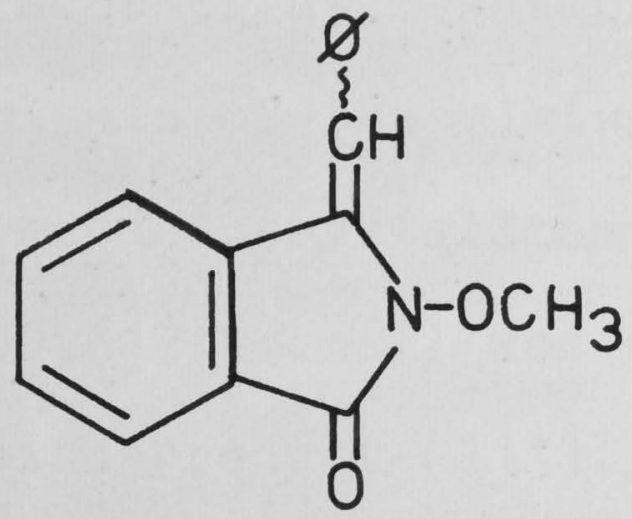

(108)

Treatment of (107) with one mole of anhydrous methanolic hydroxylamine afforded the ring-opened keto hydroxamic acid (109; Chart XXX) ${ }^{*}$. Cyclisation of (109) was effected by refluxing in xylene for ca. $3 \mathrm{hr}$. with azeotropic removal of the water so formed. The resulting hydroxamic acid (110) was predominantly a single isomer but t.1.c. showed the presence of a second compound (isomer). Although the stereochemistry of the stilbene system is left undefined, the similarity of the long wavelength maximum in the $u_{\bullet} v$. spectrum of (110) $\left(\lambda_{\max } 340 \mathrm{~m} \mu\right)$ to that of $(107)\left(\lambda_{\max } 340 \mathrm{~m} \mu\right)$ suggests

* The intermediates in the synthesis of (108) have not yet been characterised fully. However the spectral data (Experimental Section) were consistent with the proposed structures. 
that this stereochemistry is the same in both systems. " Methylation of (110) with ethereal diazomethane gave the $N$-methoxyphthalimide (108) as a viscous oil. Again the methylation product was mainly a single isomer $(\mathrm{N}-\mathrm{OCH} / 3,5.90 \tau)$ but traces of at least one other component were present. Pyrolysis of the mixture (108) for several hours at $165^{\circ}$ afforded a crystalline compound whose i.r. spectrum $\left(3300,1710 \mathrm{~cm}^{-1}\right)$ was consistent with the expected elimination product (111).

Although the study of model systems is still in a preliminary stage, the thermal elimination of aldehydes from 0-alkylated (thio) hydroxamic acids promises to be a general reaction. The rate of elimination of simple models (e.g. the uracil series) indicates that the reaction is largely governed by steric factors, but the steric requirements for a very facile elimination have yet to be fully defined.

\% For example trans stilbene shows $\lambda_{\max } .228,295.5 \mathrm{~m} \mu$ while for cis stilbene a hypsochromic shift to $\lambda$ max. $224,280 \mathrm{~m} \mu$ is observed. 114 
CHART XXX
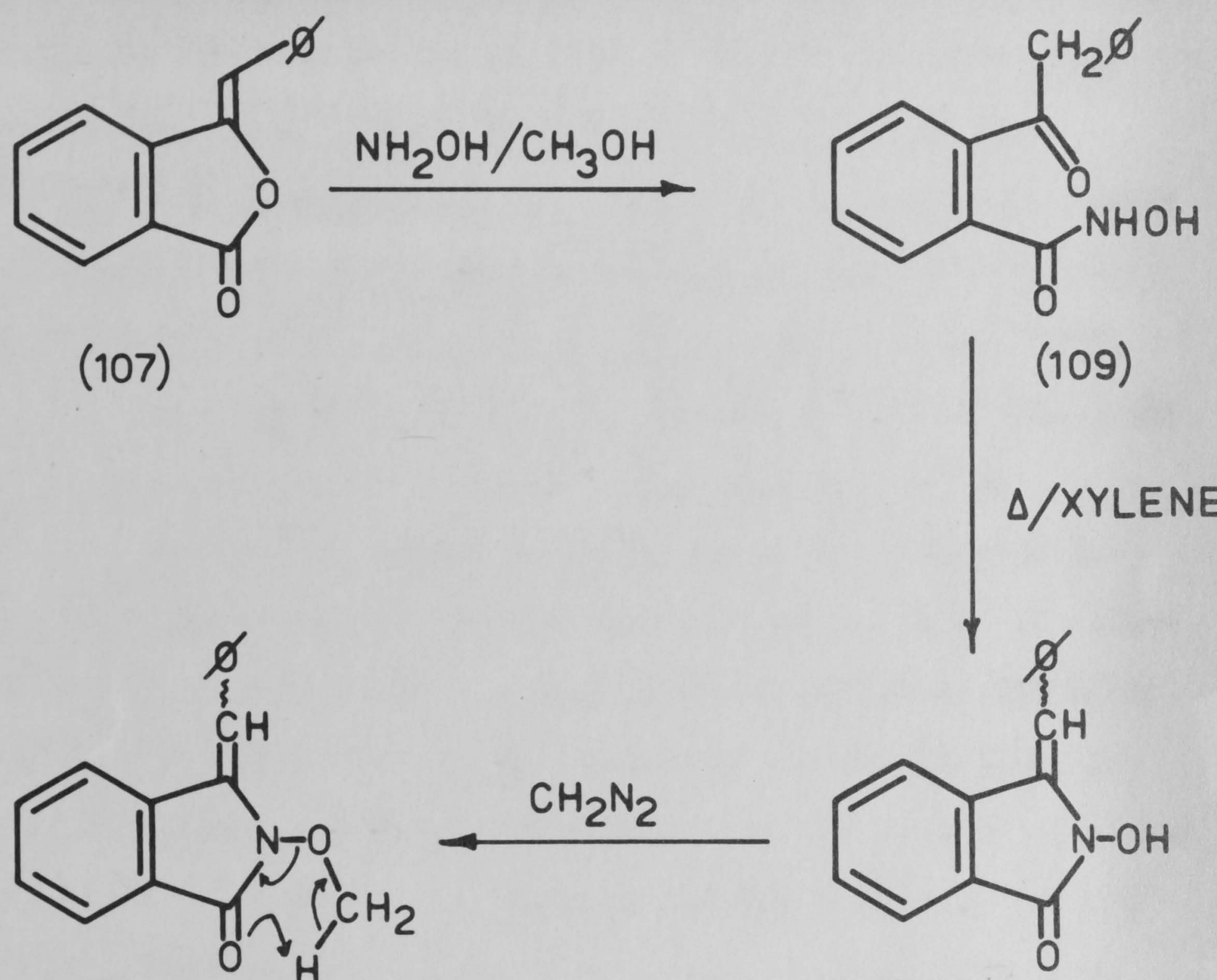

(108)

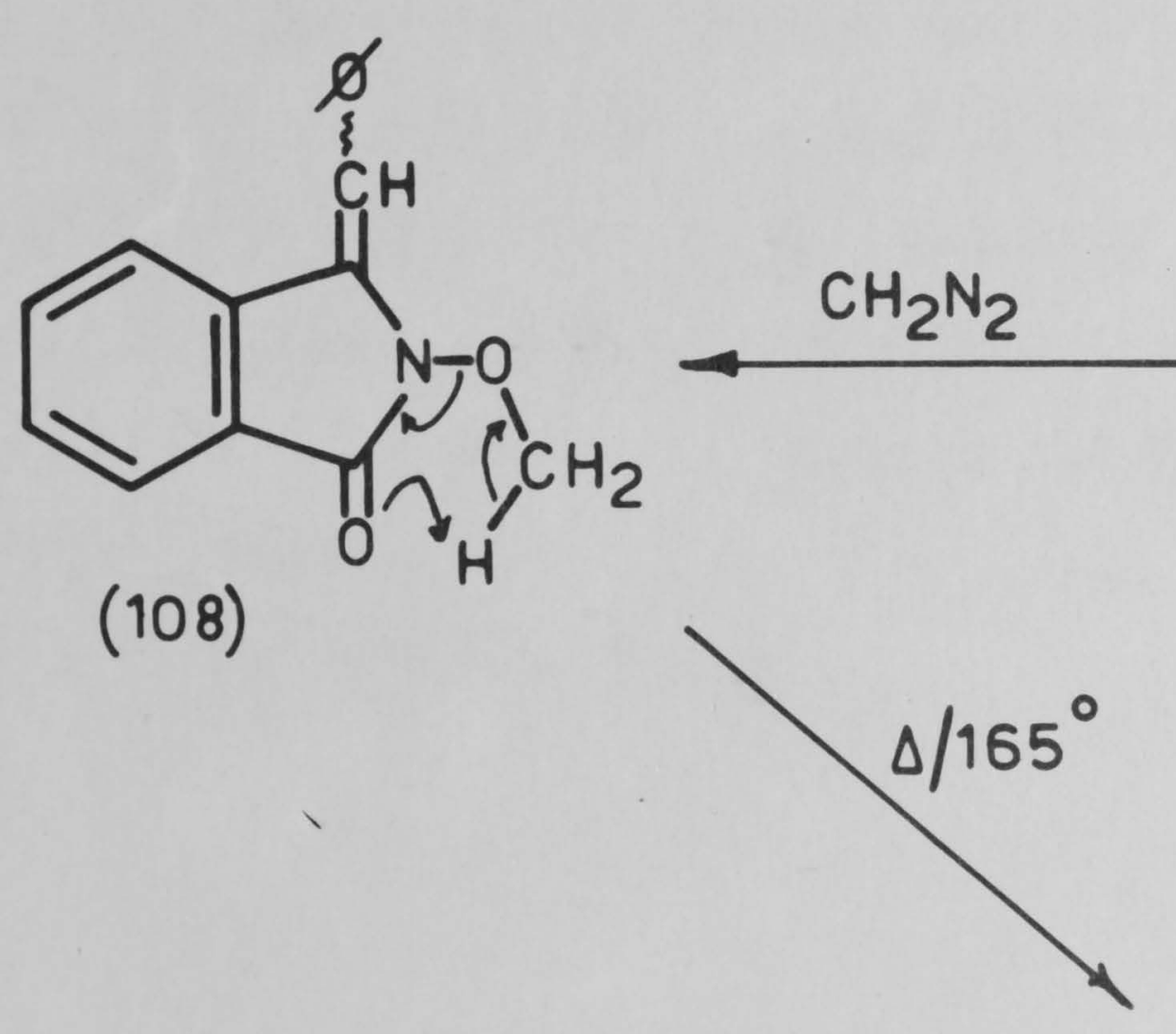

(110)

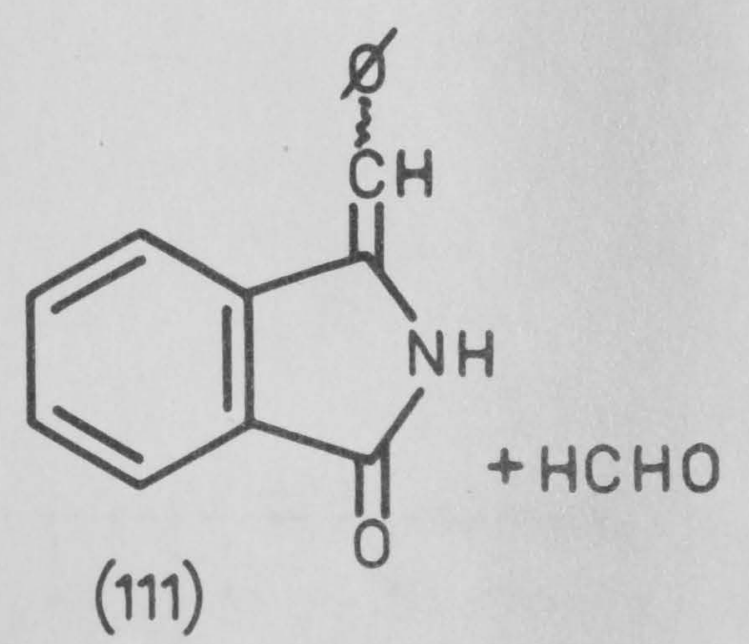




\section{(e) Miscellaneous reactions}

Originally, synthetic schemes which involved protection of the double bond by an oxidation process (eg. epoxidation), were rejected because of the presumed insensitivity of nitroolefins such as ( $47 ; \mathrm{R}=\mathrm{CO} \varnothing)$ to such oxidations. Although conjugation of the double bond to an aromatic ring or other multiple bonds does reduce the susceptibility to electrophi lic attack, epoxidation of such deactivated olefins is often possible with reactive peracids. For example, the $\alpha, \beta$-unsaturated ester (112) is converted to the epoxide (113) by the action of buffered trifluoroperacetic acid. ${ }^{115}$ An example more closely related to the present work is the analogous oxidation of ethyl cinnamate (50) to the epoxide (114) with peracetic acid in ethyl acetate. 116

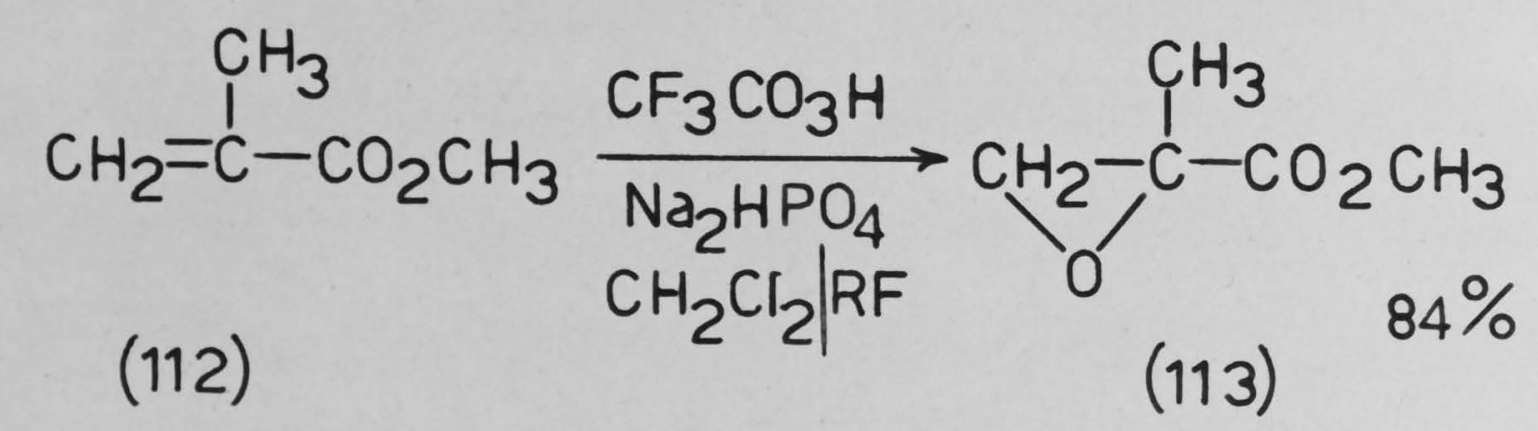<smiles>CCOC(=O)C(C)C(=O)OC1OC1C(=O)OCC</smiles> 
However, the original prediction was confirmed when the high m.p. (trans) isomer of ( $47 ; \mathrm{R}=\mathrm{CO} \varnothing)$ was recovered unchanged from reaction with $\underline{m}$-chloroperbenzoic acid in refluxing chloroform or trifluoroperacetic acid in refluxing methylene chloride. Not unexpectedly, the $\alpha$-nitro group had reduced the electron density of the double bond to a point where electrophilic attack was not possible.

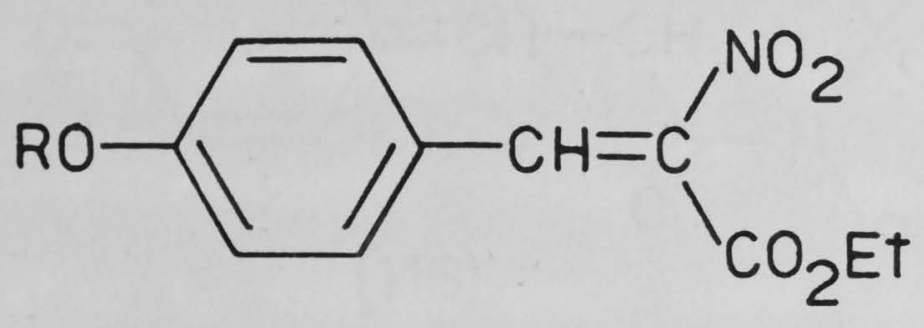

(47)

Another approach investigated was that directed towards the synthesis of the substrate (115). It was thought that dehydrogenation of this intermediate might have been possible with high potential quinones such as dichlorodicyanoquinone. Alternatively, oxidation of (115; $\mathrm{R}=\mathrm{H}$ ) with a one-electron oxidant could give the quinone methide (116) which might then be transformable into the required benzylidene compound. Bromination of (115)

* A complication in this reaction would be the radical dimerisation of the phenol. 
would also allow the elimination of hydrogen bromide as an alternative to sulphoxide and thioether eliminations.

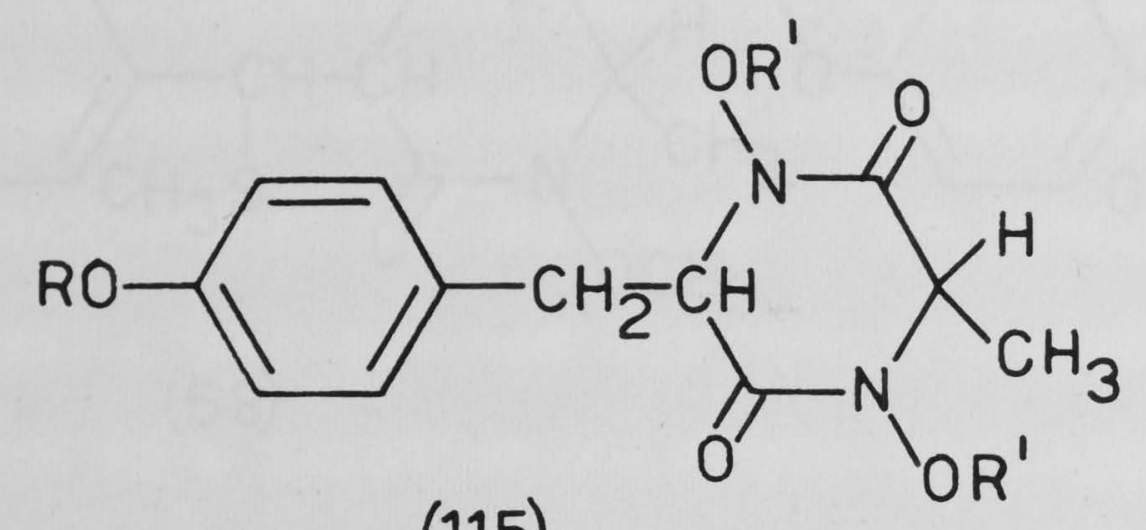

(115)

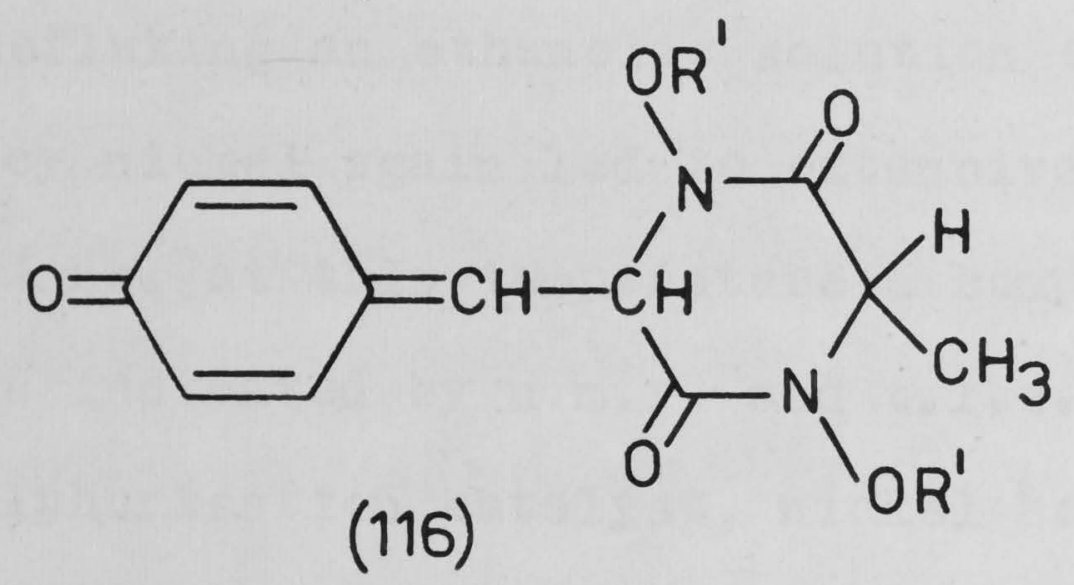

To this end, attempts were made to desulphurise some of the intermediates already available. Even at room temperature, shaking an ethanolic solution of the dimethoxy thioether (58) with 77 Raney nickel afforded a complex mixture of products (at least five components). In contrast, the same thioether was unaffected by 17 Raney nickel which had been deactivated by refluxing in acetone for $0.5 \mathrm{hr}$. Since it seemed that unambiguous desulphurisation of an advanced intermediate such as (58) was not possible, attention was turned to the simple thioether (53; $\mathrm{R}^{-\mathrm{NO}_{2}}$ ). 


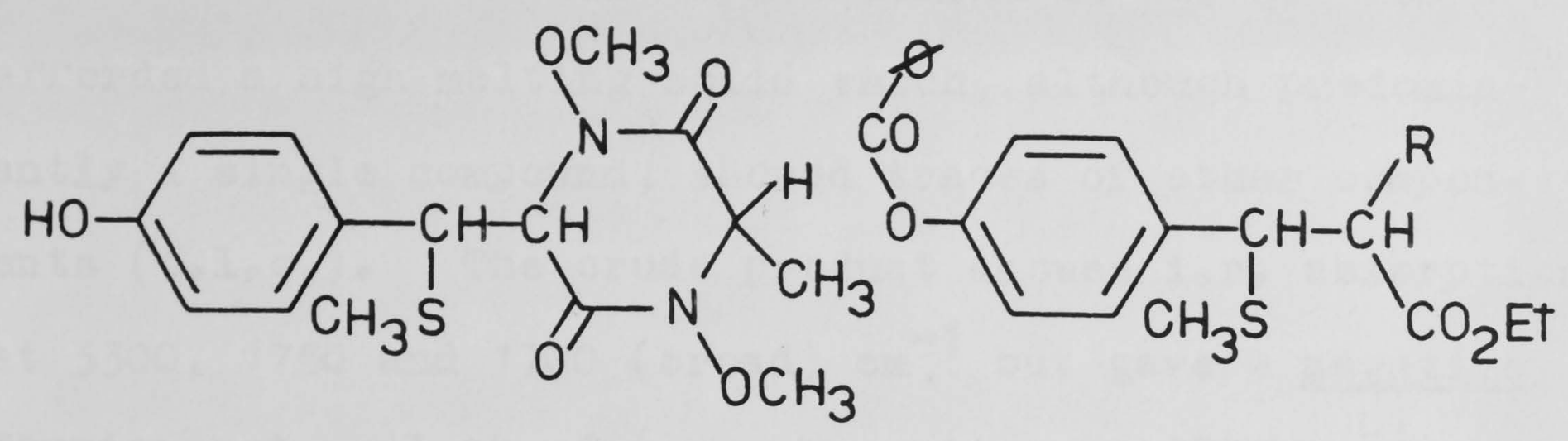

(58)

(53)

Refluxing an ethanolic solution of $\left(53 ; \mathrm{R}=\mathrm{NO}_{2}\right)$ with W7 Raney nickel again led to extensive decomposition. After only $1 \mathrm{hr}$. at this temperature a complex mixture of products was indicated by $n \cdot m \cdot r \cdot$ and $t_{\bullet} l_{\cdot} c_{\text {. }}$ An alternative desulphurisation catalyst, nickel boride 117,118 , did effect the removal of the methylthio group from ( 53 ; $\mathrm{R}=\mathrm{NO}_{2}$ ), but the crude oily product was a mixture of at least two components $\left(t .1 . c_{\bullet}, n_{\bullet} . r_{\bullet}\right)$ which could not be separated by chromatography on silica gel. At room temperature desulphurisation was not effected and instead, a mixture of erythro and threo isomers of $\left(53 ; \mathrm{R}^{2} \mathrm{NO}_{2}\right)$ was produced. It therefore seems that an intermediate such as (115) is not readily available from the synthetic intermediates already in hand.

An alternative route to a halogenated substrate was envisaged via a displacement of the sulphonyl group of the triacetoxy sulphone (62). Reaction of (62) with 
potassium iodide in dimethylformamide at ca. $80^{\circ}$ for $6 \mathrm{hr}$. afforded a high melting solid which, although predominantly a single compound, showed traces of other components $\left(t_{\bullet}\right.$. $\left._{\bullet}\right)$. The crude product showed i.r. absorption at 3300,1750 and 1700 (broad) $\mathrm{cm}^{-1}$ but gave a negative ferric test. Lack of i.r. absorption at $1800 \mathrm{~cm}^{-1}$ indicates that displacement of the hydroxamic acetates had occurred but the structure of the resulting product has not yet been determined. Displacement reactions such as this probably merit further attention as a relatively simple means of obtaining alternative substrates for elimination.<smiles>CC(=O)Oc1ccc(C(C)[R5](C)(=O)=O)cc1</smiles>

(62)

The chloroform solubility of the elimination product (75) prompted an attempt to re-oxidise this molecule to the corresponding hydroxamic acid via the 0-ethyl derivative (117) (Chart XXXI). However, treatment of (75) with two moles of triethyloxonium fluoroborate 37 afforded a mixture of products, the n.m.r. spectrum of 


\section{CHART $X X X 1$}

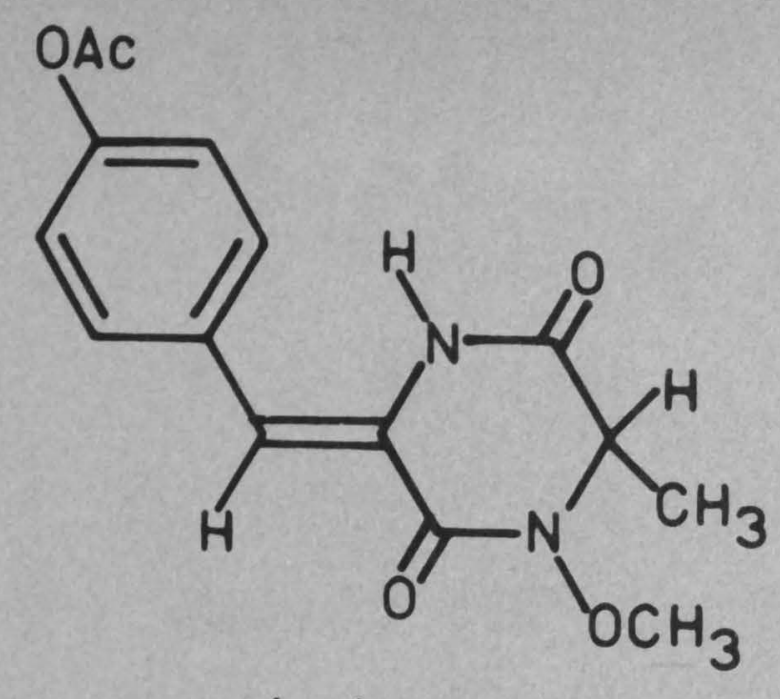

(75)

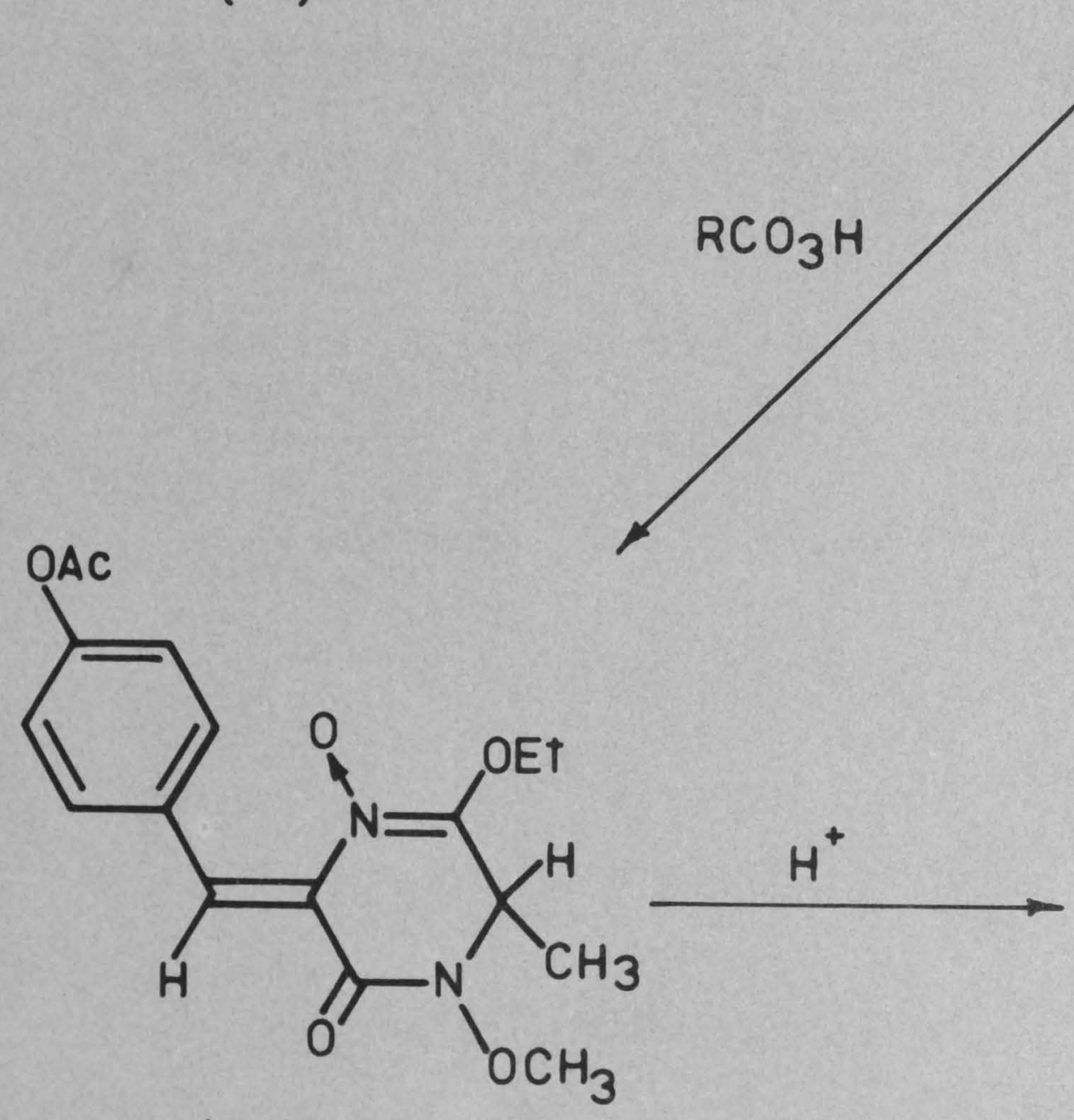

(118)

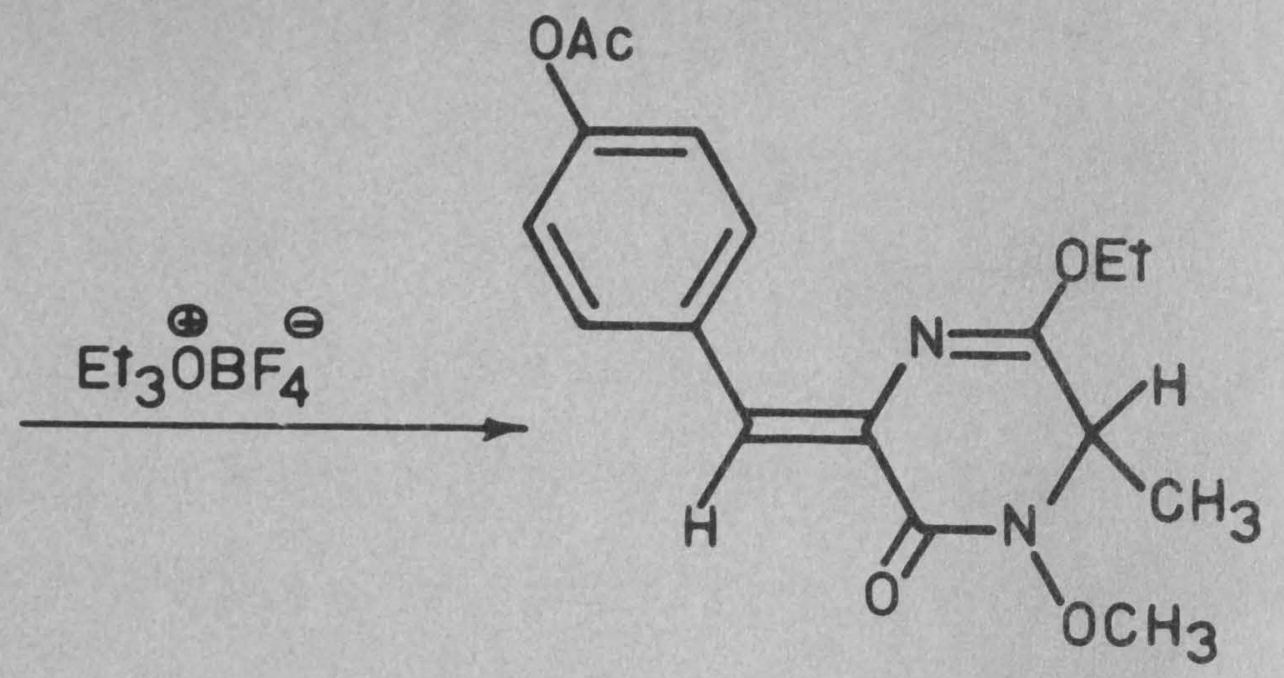

(117)

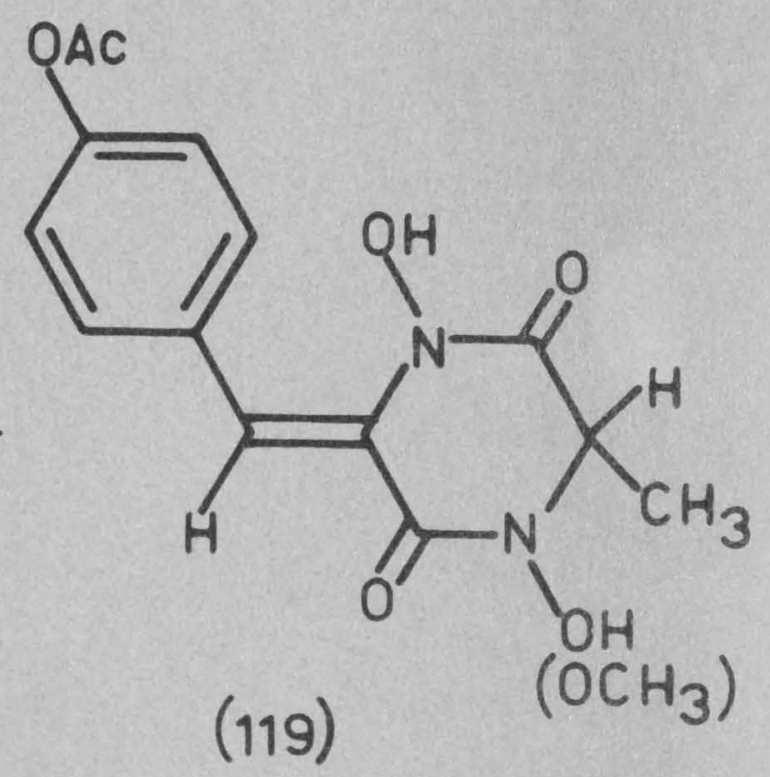


which could not be rationalised even on the basis of 0 and $N$ alkylation. Careful chromatography on silica gel gave two main fractions but these in turn were nonhomogeneous (t.l.c., n.m.r.). Even if the o-ethyl compound (117) could be obtained, it is doubtful that the hydroxamic acid (119) would survive the reaction conditions needed for the hydrolysis of the o-ethyl group. " An attempt to oxidise (75) directly $y^{35}$ to the hydroxamic acid (119) also proved fruitless. Thus the long wavelength absorption of (75) (297 $\mathrm{m} \mu$ ) was destroyed by reaction of (75) with excess m-chloroperbenzoic acid in chloroform at room temperature for several days. No hydroxamic acid was formed in this reaction ( $t_{\bullet}$. $_{\bullet}$, , ferric chloride) and presumably epoxidation of the double bond had occurred.

* eg. Mycelianamide is extremely acid labile (10c. cit.). 
CONCLUSIONS 


\section{CONCLUSIONS}

Evidence which is now available indicates that elaboration of the benzylidene linkage of mycelianamide via thermal elimination of thioethers or the derived sulphoxides already available, will always be complicated by the concomitant elimination of the $\mathrm{N}-4$ protecting group. Despite the extreme facility of the elimination, particularly in the methoxylated cases ${ }^{\mathbf{*}}$, modifications of the present synthesis can be envisaged which could avoid this complication.

The first of these involves the protection of the hydroxamic functions with a group bearing no $\alpha$ hydrogen; such a group could not undergo the pyrolytic elimination of an aldehyde as observed with the methoxyl group. of the presently available protecting groups which satisfy this criterion, the trimethylsilyl group is most favoured since it has the added advantages of ease of introduction, ${ }^{119}$ and removal ${ }^{120}$, under neutral conditions. Another suitable protecting group is the methoxy isopropyl group which can be removed under mildly acidic conditions. ${ }^{121}$ For example, in the simple cases illustrated below, the protecting group can be removed at $\mathrm{pH} 4$.

* Although the mode of decomposition of the unprotected and acetyl protected substrates has not been established, it is probable that their pyrolyses also involve elimination(s) of the N-4 hydroxamic functions. 


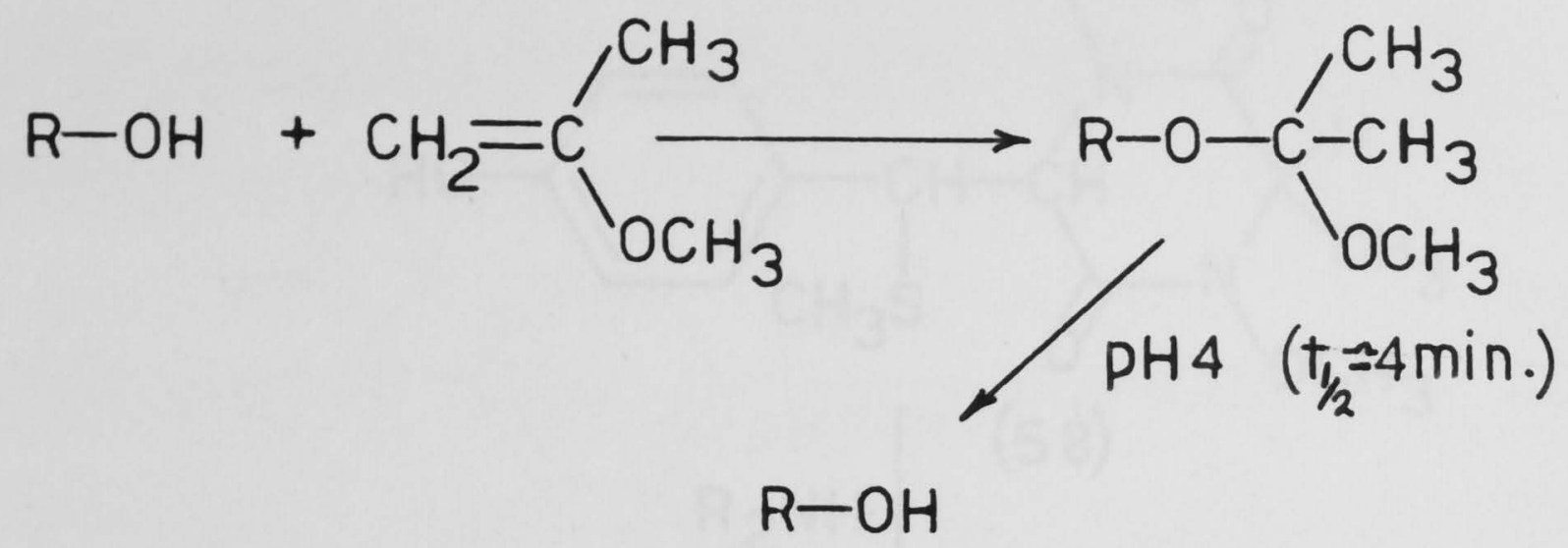

The altemative to the above approach would be to seek means of introducing the benzylidene linkage under conditions mild enough to prevent elimination of the hydroxamic protecting group. Although a substrate for low temperature cope elimination 74,75 could not be obtained from a primary synthesis, displacement of the benzylic sulphur substituent of the presently available intermediates might afford such a substrate (eg. (58) $\rightarrow(120)$ ). An analogous substrate with a benzylic halogen substituent would also be appealing, particularly in view of the recent availability of the new dehydrohalogenating agent 1,5diazabicyclo(4.3.0)-5-nonene(DBN). ${ }^{122}$ The high reactivity of this base allows dehydrohalogenations to be carried out at room temperature in ethereal solution. 
<smiles>CON1C(=O)C(C(SC)c2ccc(O)cc2)N(OC)C(=O)C1C</smiles><smiles>[R]NC(=O)C1C(=O)N(OC)C(C)(C)C(=O)N1OC</smiles>

(120)

Another reaction which might be performed under mild conditions is the metal-assisted elimination of methyl mercaptan from the thioethers alr eady available. An example of such a reaction is provided by the transformation of the thioether (121) to the olefin (122) by the action of lead acetate in aqueous alcoholic solution at $\mathrm{pH} 8-10 .{ }^{123}$ The trihydroxy thioether (56) would be a suitable substrate particularly if the metal used could complex with the hydroxamic acid groups.

* A preliminary experiment of this type has been performed viz. treatment of the triacetoxy thioether (57) with mercuric acetate and triethylamine. No material with $u_{\bullet} v$. absorption near $300 \mathrm{~m} \mu$ was produced but this single experiment does not determine the feasibility of this type of elimination. 


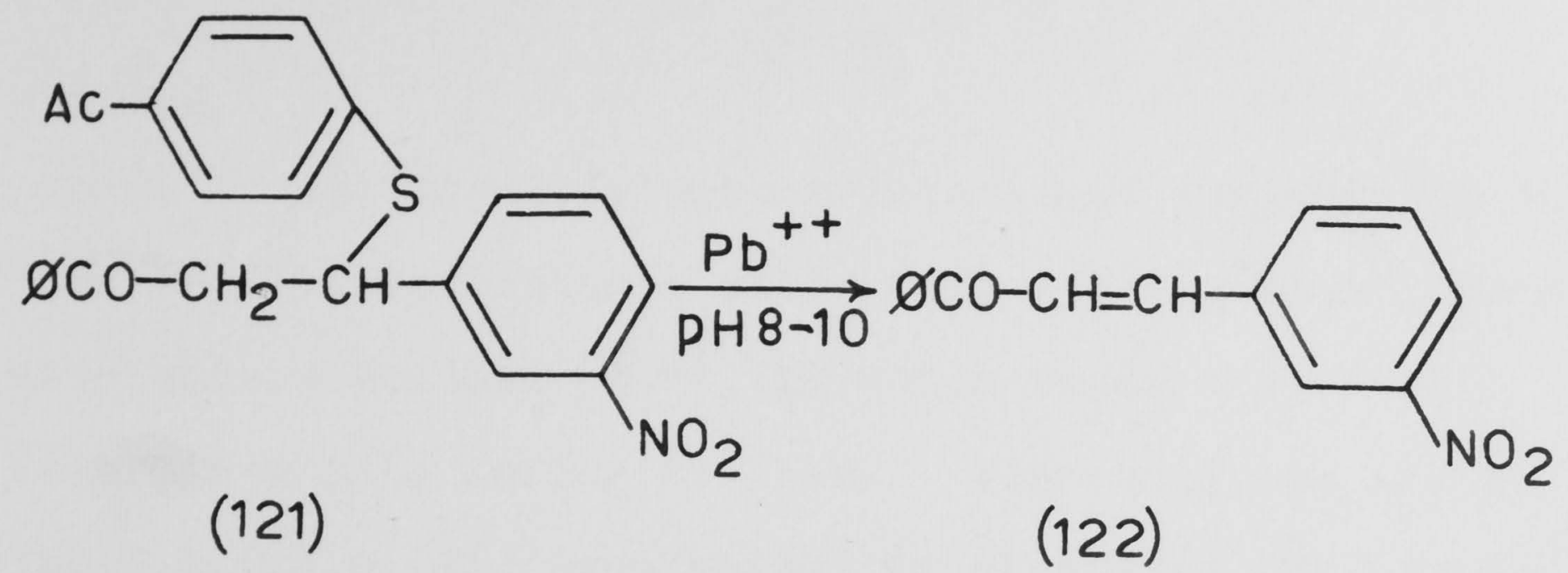

The brief discussion presented above indicates

that further variation is possible within the framework of the present synthetic approach and that a synthesis of mycelianamide may still be effected. 
EXPER IMENTAL 


\section{EXPER IMENTAL}

\section{General}

Melting points were determined for samples in open capillaries using a Gallenkamp Melting Point Apparatus unless denoted (bar), in which cases they were determined on a Kofler hot bar. Microanalyses are by the C.S.I.R.O. Microanalytical Laboratories, Melbourne, under the direction of Dr. K.W. Zimmermann. Infra-red (i.r.) spectra were recorded by a Unicam SP.200 Spectrophotometer using paraffin mulls unless otherwise stated; only those maxima of analytical utility are quoted. Ultra-violet ( $\left.u_{\bullet} v_{\bullet}\right)$ spectra were measured for solutions in $90 \%$ ethanol by either a Unicam SP. 800 spectrophotometer or a Beckman DK-2A Spectrophotometer; all spectra for which extinction coefficients are quoted were measured by the latter instrument. Nuclear magnetic resonance (n•m.r.) spectra were recorded for deuterochlor of orm solutions unless otherwise noted, using a Perkin-Elmer R10 Nuclear Magnetic Resonance Spectrometer. Chemical shifts are quoted as $\tilde{T}$ values relative to tetramethyl silane as internal standard $(10.00 \uparrow)$.

Silica gel, Koch-Light 100-200 mesh, woelm neutral alumina and Whatman cellulose powder, standard grade, were used for preparative chromatography• Thin 
layer chromatography (t.l.c.) was performed using silica gel plates, the mobile phase being indicated in parentheses. Hydroxamic acids were visualised by spraying with methanolic ferric chloride, hydroxylamines with the triphenyltekrazolium bromide reagent ${ }^{t 24}$ and other compounds with a solution of $10 \%$ ceric sulphate in $10 \%$ sulphuric acid or by exposure to iodine vapour. The dioxan used in pyrolysis experiments was purified by the method of Vogel 125 and stored over molecular sieves. Light petroleum refers to the fraction b.p. 60-80 .

The experimental sub-sections correspond to the sections in the body of the thesis and experiments are described in the order in which they were discussed in those sections.

Section Ia.

$\underline{\propto-H y d r o x y l a m i n o p r o p i o n i t r i l e ~}(28 ; \mathrm{R}=\mathrm{CN})^{31}$

A solution of hydroxylamine hydrochloride $(23.0 \mathrm{~g} \cdot ; 0.33 \mathrm{~mole})$ in water $(100 \mathrm{ml}$.) was added to acetaldehyde $(13.2 \mathrm{~g} \bullet ; 0.30 \mathrm{~mole})$, cooled in ice under an atmosphere of nitrogen. Sodium cyanide ( $15.2 \mathrm{~g} \bullet ; 0.31$ mole) in water $(50 \mathrm{ml}$.) was then added with vigorous stirring, over a period of $30 \mathrm{~min}$. and the reaction mixture stirred 
at room temperature for a further 3 days. Continuous ether extraction of the resulting yellow solution afforded a light yellow solid $(8.14 \mathrm{~g} \bullet ; 31 \%)$. A sample of this crude product ( $870 \mathrm{mg}$ ) ) was recrystallised from etherlight petroleum to give $\alpha$-hydroxylaminopropionitrile ( $540 \mathrm{mg} \cdot$ ) as colourless needles, m.p.96-97 (lit. $3197^{\circ}$ ).

\section{Methanolysis of $\alpha-$ hydroxylaminopropionitrile}

The nitrile $(1.04 \mathrm{~g} \bullet$ ) in dry methanol ( $50 \mathrm{ml}$. at $0^{\circ}$, was saturated with dry hydrogen chloride and allowed to stand at room temperature for 3 days. The precipitate of ammonium chloride was removed by filtration and the filtrate evaporated to dryness in vacuo. The residue was taken up in water (a. $20 \mathrm{ml}$.), basified with solid sodium carbonate and continuously extracted with ether for $6 \mathrm{hr}$. The dried ethereal solution, evaporated In vacuo, yielded the methyl ester $\left(28 ; \mathrm{R}=\mathrm{CO}_{2} \mathrm{CH}_{3}\right)$ as a light yellow oil ( $990 \mathrm{mg} ; ; 67 \%$ ). No attempt was made to purify this product but it was homogeneous by t.l.c. (chloroform).

Infra-red: $V \max .3420$ (shoulder), $3260,1735 \mathrm{~cm}^{-1}$.

Methyl $\propto-(N-$ chloroacetyl $-N-$ hydroxylamino $)$ propionate (29). The crude methyl ester (200 mg•; 1.7mmole) and chloroacetyl chloride ( $190 \mathrm{mg} \bullet ; 1.7 \mathrm{mmole})$ in dry chloro- 
form (ca. $15 \mathrm{ml}$.) were heated on the water bath for 45 min. The chloroform solution was extracted with saturated sodium bicarbonate solution ( $8 \times 5 \mathrm{ml}$ ), the basic solution acidified $(\mathrm{pH} 2-3)$ and extracted with chloroform $(10 \times 10 \mathrm{ml}$.). Evaporation of the dried chloroform solution gave a crystalline solid (160 mg.; 47\%) which produced a red colouration with ferric chloride. Recrystallisation from ether-light petroleum and then sublimation afforded methyl $\alpha=(\mathrm{N}-\operatorname{chloroacety} 1-\mathrm{N}-\mathrm{hydroxy} I-$ amino)propionate (29) as colourless needles, m.p. 65-66 . Infra-red: $\quad V_{\max } \cdot 3100,1740,1655,1630 \mathrm{~cm}^{-1}$.

$\begin{array}{lccccc}\text { Analysis: } & \text { C } & \text { H } & \text { CI } & \text { N } & \text { O } \\ \text { Found } & 37.0 & 5.3 & 17.8 & 6.8 & 32.5 \\ \mathrm{C}_{6} \mathrm{H}_{10} \text { CLNO }_{4} \text { req. } & 36.9 & 5.2 & 18.2 & 7.2 & 32.7 \%\end{array}$

1,4-Dihydroxy-3-methyl-2, 5-piperazinedione $\left(24: \mathrm{R}^{1}=\mathrm{H}\right)$. The chloroacetyl compound (1.0g•; 5.1mmole), anhydrous sodium iodide ( $252 \mathrm{mg} \cdot ; 1.7 \mathrm{mmole}$ ) and a methanolic solution of hydroxylamine, from hydroxylamine hydrochloride $(1.43 \mathrm{~g} \cdot ; 20.4 \mathrm{mmole})$ and sodium ( $470 \mathrm{mg} \cdot ; 20.4 \mathrm{mmole})$ in dry methanol (ㄷ․ $50 \mathrm{ml}$.), were heated under reflux in a stream of nitrogen, for $12 \mathrm{hr}$. The reaction mixture was evaporated to dryness in vacuo, taken up in water (ca. 50 ml.) and passed successively through columns of Dowex 50wX-12 (cation exchange resin) and Dowex 1-X8 (anion 
exchange resin, acetate form). Manageable volumes of aqueous solutions were obtained by monitoring the chromatography by means of the ferric test. Evaporation of the final aqueous eluate in vacuo, afforded a faintly pink solid ( $570 \mathrm{mg} \bullet ; 69 \%)$. Recrystallisation from ethanol gave 1,4-dihydroxy-3-methyl-2,5-piperazinedione (24: $\left.\mathrm{R}^{\prime}=\mathrm{H}\right)$ as a colourless crystalline powder, m.p. 235$237^{\circ}$ (sealed capillary)。

Infra-red: $V_{\max } 3200$ (shoulder), $1675,1650 \mathrm{~cm}^{-1}$.

\begin{tabular}{|c|c|c|c|}
\hline Analysis: & $\underline{\mathrm{C}}$ & $\underline{H}$ & $\underline{N}$ \\
\hline Found & 37.5 & 5.1 & $17 \cdot 3$ \\
\hline $\mathrm{C}_{5} \mathrm{H}_{8} \mathrm{~N}_{2} \mathrm{O}_{4}$ req. & 37.5 & 5.0 & $17.5 \%$ \\
\hline
\end{tabular}

Methylation of the dihydroxamic acid $\left(24: R^{1}=H\right)$ 。

The crude dihydroxamic acid ( $570 \mathrm{mg}$ ) in methanol (ca. $100 \mathrm{ml}$ ), was treated with an excess of ethereal diazomethane. The reaction mixture was evaporated to dryness in vacuo and chromatographed on silica gel. Elution with ether gave a crystalline solid which on sublimation $(65 \% .005 \mathrm{~mm}$ ) afforded the dimethyl ether (24; $\left.\underline{\mathrm{R}}^{1}=\mathrm{CH}_{3}\right)(450 \mathrm{mg} \bullet ; 70 \%), \mathrm{m}_{\bullet} \mathrm{p} \cdot 110-112^{\circ}$. Infra-red: $V_{\max } 1675 \mathrm{~cm}^{-1}$.

N.m.r.: Quartet, 5.66 ( $\mathrm{J}=7 \mathrm{cps}$ ) and singlet, 5.75(total 3H); singlet, 6.16(6H); doublet, $8.39 \tau(\mathrm{J}=7 \mathrm{cps} ; 3 \mathrm{H})$. 


\begin{tabular}{|c|c|c|c|}
\hline Analysis: & $\underline{C}$ & $\underline{\mathrm{H}}$ & $\underline{N}$ \\
\hline Found & 45.0 & 6.3 & 14.6 \\
\hline $\mathrm{C}_{7} \mathrm{H}_{12} \mathrm{~N}_{2} \mathrm{O}_{4}$ req. & $44 \cdot 7$ & 6.4 & $14.9 \%$ \\
\hline
\end{tabular}

Section Ib.

Attempted condensations of the dihydroxamic acid (24; $\left.\mathrm{R}^{1}=\mathrm{H}\right)$ with benzaldehydes.

(a) With p-hydroxybenzaldehyde in sodium acetate-acetic anhydride (Run 1, Table I).

The dihydroxamic acid ( $150 \mathrm{mg}$; $0.94 \mathrm{mmole}$ ), p-hydroxybenzaldehyde ( $127 \mathrm{mg} \bullet ; 1.04 \mathrm{mmole})$, anhydrous sodium acetate $\left(0.5 \mathrm{~g}_{\bullet}\right)$ and acetic anhydride $(1.5 \mathrm{~g} \bullet$ ) were heated at $120-130^{\circ}$ for $8 \mathrm{hr}$. The acetic anhydride was removed in vacuo, water (ca. $30 \mathrm{ml}$.) added and the suspension extracted with ether $(5 \times 10 \mathrm{ml}$.). An oily crystalline residue ( $180 \mathrm{mg}$ ), which exhibited negligible u.v. absorption near $300 \mathrm{~m} \mu$, remained on evaporation of the dried ethereal solution. This residue was chromatographed on silica gel, elution with benzene yielding an oily crystalline residue $(113 \mathrm{mg} \bullet$ ). Rechromatography on the same adsorbent and elution with benzene-petrol (4:1) gave a crystalline solid ( $53 \mathrm{mg} \cdot ; 28 \%$, m.p. ca $190^{\circ}$ (bar). The chromatographed product had an i.r. spectrum identical with 
a sample of p-acetoxybenzoic acid (m.p. 187-188 $)$, prepared from p-hydroxybenzoic acid, by the action of acetyl chloride.

(b) With anisaldehyde in sodamide-liquid ammonia (Run 2, Table I).

Finely powdered dihydroxamic acid ( $200 \mathrm{mg} \bullet$; 1.25 mmole) was suspended in liquid ammonia (ca. $150 \mathrm{ml.})$ and sodium ( $100 \mathrm{mg} \bullet ; 4.35 \mathrm{mmole}$ ) added in small pieces. After the blue colour had disappeared the suspension was stirred for 30 min., freshly distilled anisaldehyde ( 187 mg.; 1.38 mmole) in anhydrous ether ( the mixture stirred for a further $3.5 \mathrm{hr}$. Solid ammonium chloride ( $500 \mathrm{mg} \cdot$ ) was added and the ammonia allowed to evaporate. A mixture of ice ( $45 \mathrm{~g} \cdot$ ) and concentrated hydrochloric acid $(5 \mathrm{ml}$.) was added to the residue and the resulting suspension extracted thoroughly with ether $(8 \times 15 \mathrm{ml}$.). Evaporation of the dried ether solution afforded unchanged anisaldehyde (168 mg•; $90 \%)$, identified by the i.r. spectrum (liquid film).

(c) With anisaldehyde in dimethylsulphoxide aniondimethylsulphoxide (Run 3, Table I).

Reactions with the above reagent were carried out in a vessel which enabled the preparation of the anion, standardisation and the required alkylation to be carried out in the same atmosphere of dry nitrogen. Titrations 
and addition of the aldehyde were performed with hypodermic syringes sealed into the apparatus by means of serum caps. Sodium hydride, $50 \%$ suspension in oil (Alfa Inorganics, Inc.) was washed with dry light petroleum and weighed immediately.

A solution of dimethylsulphoxide anion ${ }^{41}$ was prepared from sodium hydride (290 mg•) in dry dimethylsulphoxide and was $0.46 \mathrm{M}$ (standardisation against $\beta$ napthol using triphenylmethane as indicator). The solvent blank of dry dimethylsulphoxide $(20 \mathrm{ml}$.) required $1.4 \mathrm{ml}$. of the reagent. The dihydroxamic acid (150 $\mathrm{mg} \bullet$; 0.94 mmole) in dry dimethylsulphoxide $(20 \mathrm{ml}$.) was treated with an aliquot of the reagent $(9.5 \mathrm{ml} ; 4.37 \mathrm{mmole})$, stirred for $1 \mathrm{hr}$. at room temperature, freshly distilled anisaldehyde ( $160 \mathrm{mg} \bullet ; 1.22 \mathrm{mmole}$ ) added and the mixture stirred for a further $4 \mathrm{hr}$. Water (ca. $50 \mathrm{ml}$ ) was added, the mixture acidified ( $2 \mathrm{~N}$ hydrochloric acid) and extracted with chloroform $(6 \times 30 \mathrm{ml}$.). The chloroform solution was washed thoroughly with water, dried and evaporated in vacuo to yield a light yellow oil (240 mg•). This crude oil had an i.r. spectrum (liquid film) identical with that of the anisaldehyde-dimethylsulphoxide adduct, described below. 
Reaction of dimethyl-sulphoxide anion with anisaldehyde. Anisaldehyde $(300 \mathrm{mg} \bullet$ ) in dry dimethylsulphoxide $(20 \mathrm{ml}$.) containing a trace of triphenylmethane was titrated with dimethylsulphoxide anion solution (unknown concentration) until the red colour of sodium triphenylmethide appeared. The reaction mixture was stirred at room temperature for $4.5 \mathrm{hr}$. and worked up as described for Run 3, to give a light yellow oil ( $190 \mathrm{mg} \bullet$ ).

Infra-red: $V$ max. (Iiquid film) 3350 (broad), 1605, 1510, $1260,1180,1040 \mathrm{~cm}^{-1}$.

Attempted condensations of the dimethyl ether $\left(24 ; \mathrm{R}^{1}=\mathrm{CH}_{3}\right)$ with benzaldehydes.

(a) With p-hydroxybenzaldehyde in sodium acetate-acetic anhydride (Run 4, Table II)。

The dimethyl ether (150 mg•; 0.80 mmole),

p-hydroxybenzaldehyde ( $107 \mathrm{mg} \bullet ; 0.88 \mathrm{mmole}$ ), anhydrous sodium acetate $(0.5 \mathrm{~g} \cdot)$ and acetic anhydride $(3.0 \mathrm{~g} \cdot)$ were heated at $120^{\circ}$ for $8 \mathrm{hr}$. The reaction mixture was worked up as described for Run 1, to yield an oily crystalline residue which exhibited negligible $u_{\bullet} v$. absorption near $300 \mathrm{~m} \mu$. The crude product was chromatographed on silica gel, elution with benzene-light petroleum (19:1) yielding p-acetoxybenzoic acid ( $75 \mathrm{mg} \bullet ; 47 \%$ ), identified by the i.r. spectrum. 
(b) With anisaldehyde in dimethyl sulphoxide aniondimethylsulphoxide (Run 5, Table II).

A solution of dimethylsulphoxide anion was prepared as described for Run 3 and was $0.28 \mathrm{M}$. The solvent blank of dry dimethylsulphoxide $(20 \mathrm{ml}$.) required $1.6 \mathrm{ml}$. of the standardised solution. The dimethyl ether (107mg.; 0.57 mole) in dry dimethylsulphoxide (20 ml。) was treated with an aliquot of the reagent $(4.0 \mathrm{ml} ; 1.12$ mole), stirred for $1 \mathrm{hr}$. at room temperature, freshly distilled anisaldehyde ( $93 \mathrm{mg} \bullet ; 0.68 \mathrm{mmole}$ ) added and the mixture stirred for a further $5 \mathrm{hr}$. Worked up as described for Run 3, the reaction mixture evaporated in vacuo at room temperature overnight, afforded a yellow oil (109 mg•), i.r. spectrum identical with that of the anisaldehyde-dimethylsulphoxide adduct already described.

(c) With piperonal in sodium methoxide-methanol (Run 6, Table II).

The dimethyl ether ( $150 \mathrm{mg} \cdot ; 0.80 \mathrm{mmole}$ ) and piperonal ( $130 \mathrm{mg} \bullet ; 0.87 \mathrm{mmole}$ ) in ary methanol ( $10 \mathrm{ml}$ ) were treated with methanolic sodium methoxide, from sodium ( $55 \mathrm{mg} \cdot 2.40 \mathrm{mmole}$ ) in dry methanol (10 ml。). An immediate yellow colour was produced which deepened to dark red after heating under reflux for $7 \mathrm{hr}$. The methanol was removed in vacuo and the residue extracted with boiling chloroform ( $6 \times 5 \mathrm{ml}$ ) to yield a yellow oil (112 mg•; 86\%). Although oily, the crude product 
exhibited an i.r. spectrum (Iiquid film) identical with that of piperonal (m.p. $37^{\circ}$ ). Thin layer chromatography also confirmed this result.

(d) With piperonal in dimethylformamide-sulphur tri-
oxide.

A solution of sulphur trioxide in dry dimethylformamide was prepared by distilling sulphur trioxide from commercial oleum, into ary dimethylformamide at $0^{\circ}$. A concentration of $8 \%$ sulphur trioxide $(w / w)$ was the maximum obtainable before crystallisation of the sulphur trioxide (or the complex with dimethylformamide) occurred.

(i) Run 7. The dimethyl ether (10.0 mg*;0.053 mmole) and piperonal ( $9.0 \mathrm{mg} \bullet ; 0.060$ mmole) were heated on the water bath for $1 \mathrm{hr}$. with the dimethylformamide reagent ( $106 \mathrm{mg} \bullet$; ca. $1.1 \mathrm{mmole})$. Excess sodium acetate and water (ca. $20 \mathrm{ml}$.) were added and the mixture extracted with chloroform. Evaporation of the dried chloroform extract gave a yellow oil which showed negligible u.v. absorption near $300 \mathrm{~m} \mu$. The crude oil was chromatographed on a very small column of silica gel. Elution with benzene-chloroform (4:1) afforded unchanged piperonal ( $8 \mathrm{mg} \cdot)$, while elution with chloroform gave unchanged dimethyl ether $(8 \mathrm{mg} \cdot)$. Both products were identified by their i.r. spectra. 
(ii) Run 8. This experiment was essentially the same as Run 7 except that an eight molar excess of the reagent was used. Essentially quantitative yields of unchanged starting materials were recovered by chromatography on silica gel.

(iii) Run 2. In this run an eight molar excess of the reagent was used, while piperonal was replaced by p-nitrobenzaldehyde and the period of heating extended to 4.5 $\mathrm{hr}$. Unchanged starting materials were again recovered by chromatography.

(e) With p-nitrobenzaldehyde and potassium fluoride in dimethylformamide. 46 (Run 10, Table II). The dimethyl ether ( $15.0 \mathrm{mg} \bullet ; 0.08 \mathrm{mmole})$, p-nitrobenzaldehyde ( $26 \mathrm{mg} \bullet ; 0.17 \mathrm{mmole}$ ), potassium fluoride $(6.0 \mathrm{mg} \bullet ; 0.1 \mathrm{mmole})$ and dry dimethylformamide (ca. $3 \mathrm{ml}$.) were heated on the water bath for ca. $4 \mathrm{hr}$. Water (ca. $20 \mathrm{ml}$ ) was added and the mixture extracted thoroughly with chloroform. Evaporation of the dried chloroform extract gave a semi-crystalline residue which showed negligible $u_{0} v$. absorption near $300 \mathrm{~m} \mu$. Essentially quantitative recovery of starting materials was obtained by chromatography on silica gel. 
Reaction of the dimethyl ether $\left(24: R^{1}=\mathrm{CH}_{3}\right)$ with sodium acetate in acetic anhydride.

The dimethyl ether ( $30 \mathrm{mg} \bullet$ ), anhydrous sodium acetate $(0.1 \mathrm{~g} \cdot)$ and acetic anhydride $(1 \mathrm{ml} \cdot)$ were heated at $120^{\circ}$ for $6 \mathrm{hr}$. The acetic anhydride was removed in vacuo, water $(15 \mathrm{ml}$.$) added and the mixture extracted$ with chloroform $(5 \times 10 \mathrm{ml}$.). Evaporation of the dried chloroform solution gave a semi-crystalline residue, which, by inspection of the n.m.r. spectrum, was shown to contain $>50 \%$ unchanged dimethyl ether. T.1.c. (ethanol-chloroform 3:47) indicated the presence of three spots $R_{f} 0.51$ (strong), 0.69 (faint) and 0.80 (faint), with the dimethyl ether having an $R_{f}$ of 0.51.

Reaction of 2,5-piperazinedione with sodium acetate in acetic anhydride.

$$
\text { 2,5-Piperazinedione ( } 150 \mathrm{mg} \cdot) \text { anhydrous sodium }
$$

acetate $(0.5 \mathrm{~g} \cdot)$ and acetic anhydride $(3 \mathrm{ml} \cdot)$ were heated at $120^{\circ}$ for $6 \mathrm{hr}$. Chloroform (ca. $20 \mathrm{ml}$ ) was added and the sodium acetate removed by filtration. The filtrate, evaporated to dryness in vacuo, gave a crystaliine residue ( $260 \mathrm{mg} \cdot ; 100 \%)$. Recrystallisation afforded $\mathrm{N}, \mathrm{N}$-diacetyl 2,5-piperazinedione ( $190 \mathrm{mg} \bullet ; 73 \%), \mathrm{m} \bullet \mathrm{p}$. $101^{\circ}\left(1 \mathrm{it},,^{126} 102^{\circ}\right)$. 
Reaction of the dimethyl ether $\left(24 ; \mathrm{R}^{1}=\mathrm{CH}_{3}\right)$ with sodium methoxide in methanol.

The dimethyl ether $(40 \mathrm{mg} \cdot ; 0.21 \mathrm{mmole})$ in dry methanol (ca. $5 \mathrm{ml}$.) was treated with methanolic sodium methoxide, from sodium ( $15 \mathrm{mg} \bullet ; 0.65$ mole) and dry methanol ( $10 \mathrm{ml}$.). An immediate yellow colour resulted, intensifying to a dark red after heating under reflux for $5.5 \mathrm{hr}$. The methanol was removed in vacuo and water (ca. $20 \mathrm{ml}$. ) added to give a dark red solution. No material was extractable from this solution, with chloroform. The aqueous solution was acidified and continuously extracted with ether and then ethyl acetate, to give a semi-crystalline residue (19 mg. total). T.l.c. (ethanol-chloroform 3:47) showed one main spot $R_{f} 0.17$, with at least two more spots of very low $R_{f}$ but no unchanged dimethyl ether $\left(R_{f} 0.50\right)$. The reaction was not investigated further.

Reaction of 2,5 -piperazinedione with sodium methoxide in methanol.

2,5-Piperazinedione $(114 \mathrm{mg} \cdot ; 1.0$ mmole $)$ was treated with methanolic sodium methoxide, from sodium (69 mg.; 3.0 mmole) in dry methanol (30 ml.). The solid dissolved slowly over a period of $6 \mathrm{hr}$. heating under reflux, to give a light yellow solution. The solvent was removed in vacuo and the residue washed with dry methanol 
(ca. $5 \mathrm{ml}$ ) ) to give unchanged 2,5-piperazinedione ( 100 $\mathrm{mg} \cdot ; 88 \%)$.

Reaction of the dimethyl ether $\left(24: R^{1}=C_{3}{ }_{3}\right.$ with potassium t-butoxide in d 6 -dimethylsulphoxide.

To ensure moisture-free conditions all operations were carried out in a nitrogen drybox. The dimethyl ether (40 mg•; 0.21 mole) was treated with $0.5 \mathrm{M}$ potassium t-butoxide in $\mathrm{d}_{6}$-dimethylsulphoxide $(0.35 \mathrm{ml} ; 0.18$ mole) transferred to an n.m.r. tube and sealed - an immediate dark brown solution resulted. The n.m.r. spectrum observed after 15 min. showed no signals for the C-3 or C-5 protons and remained unchanged over a period of $30 \mathrm{hr}$. Water $(15 \mathrm{ml}$.) was added to give a red solution from which no material was extractable with chloroform. The residual aqueous solution was acidified and continuously extracted with ethyl acetate for $10 \mathrm{hr}$. , to yield a yellow glass $(12 \mathrm{mg}$ ) . T.l.c. (ethanolchloroform, 3:47) indicated that the crude product contained a mixture of products running at low $R_{f}$, but no unchanged dimethyl ether $\left(R_{f} 0.50\right)$.

Attempted bromination of the dimethyl ether $\left(24: \mathrm{R}^{1}=\mathrm{CH} 3\right)$. (a) With $\mathrm{N}$-bromosuccinimide

The dimethyl ether (150 mg•; 0.80 mmole), Nbromosuccinimide ( $142 \mathrm{mg} \bullet ; 0.80 \mathrm{mmole}$ ) and a trace of 
benzoyl peroxide were heated under reflux for $3 \mathrm{hr}$. in A.R. carbon tetrachloride $(25 \mathrm{ml})$. After cooling, the precipitated succinimide ( $74 \mathrm{mg} \cdot)$ was removed by filtration and the filtrate evaporated in vacuo to a yellow oil (250 mg•). T.I.c. indicated that this oil was predominantly unchanged dimethyl ether, al though at least two other compounds were present in minor amounts. Chromatography on silica gel led to the recovery of unchanged dimethyl ether (ca. 50\%). No other products were isolated in amounts sufficient for characterisation.

(b) With bromine in acetic acid

The dimethyl ether ( $150 \mathrm{mg} \bullet ; 0.08$ mmole) was heated on the water bath with bromine $17 \mathrm{mg} \bullet ; 0.15$ mmole) in glacial acetic acid ( $2 \mathrm{ml}$ ) until the bromine colour had disappeared ( removed in vacuo to give a red oil which was predominantly unchanged dimethyl ether $\left(t .1 . c_{\bullet}\right)$.

\section{Section IIa.}

Cis and trans ethyl- $\alpha$-nitrocinnamate $(36) .49$

The Schiff bases used in this investigation were prepared by azeotropic removal of water from a solution of an equimolar mixture of the aldehyde and amine 
in toluene-benzene $(1: 1 \mathrm{v} / \mathrm{v})$. The crude products were obtained as viscous oils and were used without purification.

Benzyliden $\mathrm{e}-\mathrm{N}$-butylamine $(8.08 \cdot ; 0.5$ mole) was dissolved in freshly distilled acetic anhydride $(10 \mathrm{ml}$. $)$ and nitroacetic ester ${ }^{127}$ ( $6.6 \mathrm{~g} \cdot 0.05$ mole) added dropwise. A spontaneous exothermic reaction occurred to give a yellow viscous solution. After $4 \mathrm{hr}$. at room temperature the mixture was thrown into water (ca. 100 ml.), stirred for $2 \mathrm{hr}$. and extracted with ether. Evaporation of the dried ethereal solution gave a yellow oil which was filtered in benzene through a column of alumina. The n.m.r. spectrum of the eluted oil showed it to be a mixture of isomers, one of which crystallised on standing. The crystalline isomer was separated by filtration and recrystallised from light petroleum to give almost colourless needles $(6.85 \mathrm{~g} \cdot ; 61 \%), \mathrm{m} \cdot \mathrm{p} \cdot 73^{\circ}\left(1 \mathrm{it} .4^{9} 73^{\circ}\right)$. Infra-red: $\quad \gamma_{\max } 1710,1640,1540 \mathrm{~cm}^{-1}$

Ultra-violet: $\lambda_{\max .} 214 \mathrm{~m} \mu(\varepsilon=14,200), 280 \mathrm{~m} \mu(\varepsilon=18,400)$ N.m.r.: Triplet, $8.63\left(\mathrm{~J}=7.5 \mathrm{cps} ., \mathrm{CO}_{2} \mathrm{CH}_{2} \underline{\mathrm{CH}}_{3}, 3 \mathrm{H}\right)$; quartet, $5.59\left(\mathrm{~J}=7.5 \mathrm{cps} ., \mathrm{CO}_{2} \mathrm{CH}_{2} \mathrm{CH}_{3}, 2 \mathrm{H}\right)$; singlet, 2.57 (aromatic protons, $5 \mathrm{H}$ ); singlet, $2.44 \pi$ (vinylic proton, 1H).

The oily isomer could not be obtained free from the crystalline isomer. 
Ethyl p-tetrahydropyranyloxy $-\alpha$-nitrocinnamate $(47 ; R=T H P)$

This olefin was obtained by a procedure exactly similar to that described for (36) but starting with ptetrahydropyranyloxy benzylidene-N-butylamine. Even after repeated chromatography the olefin was a viscous oil exhibiting very broad $u_{\bullet} v$. absorption at ca. $315 \mathrm{~m} \mu_{\bullet}$ No attempt was made to characterise this intermediate fully.

Cis and trans ethyl-p-benzoyloxy $-\propto$-nitrocinnamate (47: $\underline{R=C O \phi)}$

$$
\text { p-Benzoyloxybenzylidene-N -butylamine (12.70 g•; }
$$

0.045 mole) was dissolved in freshly distilled acetic anhydride $(10 \mathrm{ml} \bullet)$ and nitroacetic ester $(6.00 \mathrm{~g} \bullet ; 0.045$ mole) added dropwise. After an immediate evolution of heat the mixture was heated on the waterbath for $4 \mathrm{hr}$. and then worked up as described for (36). The resultant yellow oil was chromatographed on alumina. Elution with benzene-light petroleum afforded a crystalline residue $(6.8 \mathrm{~g} \bullet ; 44 \%)$ which crystallised from benzene-light petroleum as a mixture of almost colourless needles and yellow prisms. Partial manual separation and repeated recrystallisation of each fraction from benzene-light petroleum afforded in almost equal amounts :-

(a) The high m.p. isomer, colourless needles, m.p. $106^{\circ}$.

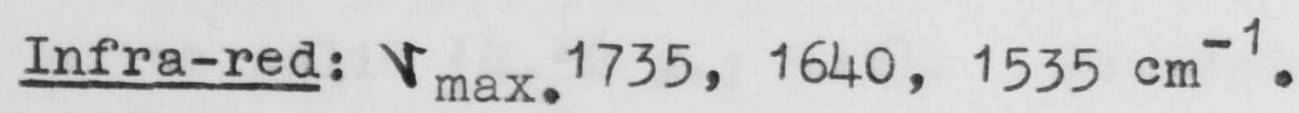


Ultra-violet: $\lambda_{\text {max. }} 223,283 \mathrm{~m} \mu$.

N.m.r॰: Triplet, $8.63\left(\mathrm{~J}=7.5 \mathrm{cps} \cdot, \mathrm{CO}_{2} \mathrm{CH}_{2} \mathrm{CH}_{3}, 3 \mathrm{H}\right)$;

quartet, $5.60\left(\mathrm{~J}=7.5 \mathrm{cps}, \mathrm{CO}_{2} \mathrm{CH}_{2} \mathrm{CH}_{3}, 2 \mathrm{H}\right)$;

complex multiplet, 2.5 and quartet, $1.80 \tau$

(aromatic protons and vinylic proton, total 10H).

Analysi 8:

Found

\begin{tabular}{cccc}
$\underline{\mathrm{C}}$ & $\underline{\mathrm{H}}$ & $\underline{\mathrm{N}}$ & \multicolumn{1}{c}{$\underline{\mathrm{O}}$} \\
63.2 & 4.5 & 4.2 & 27.7 \\
63.3 & 4.4 & 4.1 & $28.1 \%$
\end{tabular}

$\mathrm{C}_{18} \mathrm{H}_{15^{\mathrm{NO}}}$ requires

(b) The low m.p. isomer, yellow prisms, m.p.75-76

Infra-red: $V_{\text {max. }} 1735,1725,1640,1527 \mathrm{~cm}^{-1}$.

U1tra-violet: $\lambda_{\max } 231,317 \mathrm{~m} \mu$.

N.m.r.: Triplet, 8.64 (J=7.5 cps., $\left.\mathrm{CO}_{2} \mathrm{CH}_{2} \mathrm{CH}_{3}, 3 \mathrm{H}\right)$;

quartet, 5.50 ( $\left.\mathrm{J}=7.5 \mathrm{cps} ., \mathrm{CO}_{2} \mathrm{CH}_{2} \mathrm{CH}_{3}, 2 \mathrm{H}\right)$;

complex multiplet, 2.5 and quartet, 1.85

(aromatic protons); singlet, $1.96 \tau$

(vinylic proton) (total 10H).

Analysis:

Found

$\mathrm{C}_{18} \mathrm{H}_{15^{\mathrm{NO}}}$ requires

$\begin{array}{cccc}\underline{\mathrm{C}} & \underline{\mathrm{H}} & \underline{\mathrm{N}} & \underline{\mathrm{O}} \\ 63.2 & 4.7 & 4.0 & 28.4 \\ 63.3 & 4.4 & 4.1 & 28.1 \%\end{array}$

Addition of methylmercaptan to the nitroolefin $(47: R=\operatorname{co} \varnothing)$.

A mixture of the nitroolefins described above ( $4.15 \mathrm{~g} \cdot$ ), pyridine ( $1 \mathrm{drop})$ and methylmercaptan (ca. 10g.) were stirred at $0^{0}$ for $2.5 \mathrm{hr}$. The excess methylmercaptan was allowed to evaporate at room temperature to afford a white solid ( $4.52 \mathrm{~g} \cdot ; 95 \%)$. Recrystallisation from 
benzene-light petroleum gave the nitro ester $\left(53 ; \mathrm{R}=\mathrm{NO}_{2}\right)$ as colourless plates, m.p. 110-112 ${ }^{\circ}$. The n.m.r. spectrum of the crude product was indistinguishable from that of the purified sample.

Infra-red: $\quad Y_{\max } 1750,1715,1555 \mathrm{~cm}^{-1}$.

$\begin{array}{lccccc}\text { Analysis: } & \underline{\mathrm{C}} & \underline{\mathrm{H}} & \underline{\mathrm{N}} & \underline{\mathrm{O}} & \underline{\mathrm{S}} \\ \text { Found } & 58.6 & 4.9 & 3.6 & 24.5 & 8.4 \\ \mathrm{C}_{19^{\mathrm{H}} 19^{\mathrm{NO}} 6^{\mathrm{S}}} \text { requires } & 58.6 & 4.9 & 3.6 & 24.7 & 8.2 \%\end{array}$

Michael additions to the crystalline isomer of the nitroolefin (36).

(a) Methylmercaptan

The nitroolefin ( $500 \mathrm{mg} \bullet)$, pyridine ( 1 arop) and excess methylmercaptan were stirred at $0^{0}$ for $2 \mathrm{hr}$. The excess methylmercaptan was allowed to evaporate at room temperature to give a colourless oil ( $570 \mathrm{mg} \bullet ; 95 \%$ )。 The n.m.r. spectrum of the crude oil indicated that it was a mixture of erythro and threo isomers. Infra-red: $\quad V_{\max } 1750,1565 \mathrm{~cm}^{-1}$.

(b) Methanol

The nitroolefin (ca. $100 \mathrm{mg}$ ) was heated under reflux for $2 \mathrm{hr}$. with dry methanol ( $30 \mathrm{ml}$.) and pyridine (1 drop). Evaporation of the excess solvent in vacuo afforded a viscous oil which was a mixture of erythro and threo isomers (ca. 65:35 mixture at equilibrium) as shown. by the n.m.r. spectrum. 
(c) Dimethylamine

The nitroolefin $(1.0 \mathrm{~g} \cdot)$ and anhydrous dimethylamine (ca. $25 \mathrm{ml}$.) were stirred at $0^{0}$ for $2.5 \mathrm{hr}$. Evaporation of the excess amine in vacuo gave a viscous yellow oil $(1.21 \mathrm{~g} \bullet)$ which on standing, deposited a small amount of crystalline material. The crude oil was a complex mixture as shown by the n.m.r. spectrum. The crystalline deposit (still a mixture) showed no n.m.r. signals for the carbethoxyl group, thus indicating that a displacement reaction at that group had probably occurred. No further study of this reaction was made.

\section{A.luminium amalgam reduction of the nitro ester ( 54 ; $\left.\underline{\mathrm{R}=\mathrm{NO}_{2}}\right)^{92}$}

The above nitro ester $(1.0 \mathrm{~g} 0$ ) in ethyl acetate saturated with water (a. $100 \mathrm{ml}$.) was stirred at $0^{\circ}$ for $2 \mathrm{hr}$. with aluminium amalgam $93(0.8 \mathrm{~g} \cdot)$. The aluminium hydroxide was removed by filtration and the solvent removed in vacuo to give a crystalline residue (736 mg•) which gave a positive test with the triphenyltetrazolium bromide reagent. Recrystallisation of the crude product from ethyl acetate-light petroleum afforded the hydroxylamino ester ( $54 ; \mathrm{R}=\mathrm{NHOH}) \quad(280 \mathrm{mg} \bullet ; 29 \%$ as colourless needles, m.p. $138^{\circ}$.

Infra-red: $\quad V_{\max } 3250,1720,1645 \mathrm{~cm}^{-1}$. 
Analysis:

Found

$\mathrm{C}_{13} \mathrm{H}_{18} \mathrm{~N}_{2} \mathrm{O}_{4}$ requires

$\begin{array}{cccc}\underline{\mathrm{C}} & \underline{\mathrm{H}} & \underline{\mathrm{N}} & \underline{\mathrm{O}} \\ 58.9 & 7.1 & 10.0 & 24.3 \\ 58.6 & 6.8 & 10.5 & 24.0 \%\end{array}$

Aluminium amalgam reduction of the nitro ester $\left(53 ; \mathrm{R}=\mathrm{NO}_{2}\right)$ The above nitro ester $(1.0 \mathrm{~g}$. in ethyl acetate saturated with water ( ca. $50 \mathrm{ml}$.) was stirred at $0^{\circ}$ with aluminium amalgam $(1.0 \mathrm{~g} \bullet)$. The aluminium hydroxide was removed by filtration and the solvent evaporated in vacuo to give a crystalline residue ( $925 \mathrm{mg} \bullet$; 95\%), which gave a positive test with triphenyltetrazolium bromide. Recrystallisation from ethyl acetate-light petroleum gave the hydroxylamino ester $(53 ; \mathrm{R}=\mathrm{NHOH})(680 \mathrm{mg} \bullet ; 70 \%)$ as colourless plates, m.p. $114-116^{\circ}$.

Infra-red: $\quad V_{\max } 3270,1730,1715 \mathrm{~cm}^{-1}$.

Analysis:

Found

$\mathrm{C}_{19} \mathrm{H}_{21} \mathrm{NO}_{5} \mathrm{~S}$ requires

$\begin{array}{ccccl}\underline{\mathrm{C}} & \underline{\mathrm{H}} & \underline{\mathrm{N}} & \underline{\mathrm{O}} & \underline{\mathrm{S}} \\ 60.9 & 5.5 & 3.7 & 20.9 & 8.7 \\ 60.8 & 5.7 & 3.7 & 21.3 & 8.5 \%\end{array}$

Acylation of the hydroxylamino ester ( $23 ; \mathrm{R}=\mathrm{NHOH}$ )

(a) $\alpha$-Bromopropionyl chloride (458 mg•; 2.66 mmole) was added to a solution of the hydroxylamino ester (1.00 $\mathrm{g} \bullet$; 2.66 mmole) in AR carbon tetrachloride (ca. $25 \mathrm{ml}$ ) and the mixture heated under reflux for $1 \mathrm{hr}$. The solvent was removed in vacuo and the crystalline residue chromatographed on silica gel. Elution with benzene-ether (19:1) 
gave the hydroxamic acid (55) as a mixture of isomers (from benzene-light petroleum), (670 mg•; 49\%), m•p. 119-124\%. T.1.C. (chloroform-ethanol, 47:3) showed the presence of two spots $\left(R_{f} 0.52,0.57\right)$. Each isomer, when removed from the plate and rechromatographed, ran as a single spot.

Infra-red: $\quad V_{\max } .3200,1735,1650,1625 \mathrm{~cm}^{-1}$.

Analysis:

Found

$\mathrm{C}_{22} \mathrm{H}_{24}{ }^{\mathrm{BrNO}}{ }_{6}^{\mathrm{S}}$ requires

$\begin{array}{ccccl}\underline{\mathrm{C}} & \underline{\mathrm{H}} & \underline{\mathrm{N}} & \underline{\mathrm{O}} & \underline{\mathrm{S}} \\ 52.0 & 5.0 & 2.6 & 18.6 & 6.4 \\ 51.9 & 4.7 & 2.7 & 18.8 & 6.3 \%\end{array}$

(b) In subsequent experiments the nitro ester was reduced and acylated directly without purification. Under these conditions, the hydroxamic acid (55) isolated in $44 \%$ yield $\left(\max _{\bullet}\right)$ by chromatography and recrystallisation from benzene-light petroleum, was predominantly a single isomer. Repeated recrystallisation afforded the pure isomer of (55) as colourless needles, m.p. $130-132^{\circ}$. Thin layer chromatography now showed a single spot $R_{f} 0.57$. This single isomer was used to seed recrystallisations of subsequent batches of (55). The presence of excess anhydrous sodium acetate during the reaction gave no improvement in the yield. Infra-red: $\quad V_{\max } .3375,1740,1720,1650 \mathrm{~cm}^{-1}$. 
Analysis:

Found

$\mathrm{C}_{22} \mathrm{H}_{24} \mathrm{BrNO}_{6} \mathrm{~S}$ requires

$\begin{array}{ccccc}\underline{\mathrm{C}} & \underline{\mathrm{H}} & \underline{\mathrm{N}} & \underline{\mathrm{O}} & \underline{\mathrm{S}} \\ 51.7 & 4.9 & 2.6 & 19.0 & 6.2 \\ 51.9 & 4.7 & 2.7 & 18.8 & 6.3 \%\end{array}$

Cyclisation of the hydroxamic acid (55)

Anhydrous hydroxylamine was prepared by the decomposition of hydroxylamine phosphate 94 at ca. $120^{\circ} /$ $0.5 \mathrm{~mm}$. It was stored at $\mathrm{O}^{\circ}$ as a ca. $3 \mathrm{M}$ solution in dry methanol.

Preliminary experiments indicated that after ca. $20 \mathrm{hr}$. the hydroxamic acid (55) was completely consumed by reaction with anhyarous methanolic hydroxylamine. T.1.c. (chloroform-ethanol, 47:3) showed the formation of benzhydroxamic acid, $\mathrm{R}_{\mathrm{f}}$ ca. 0.1 and one other ferric positive compound, $\mathrm{R}_{\mathrm{f}} \mathrm{0.05}$. Paper chromatography on paper saturated with aqueous phosphate buffer $(\mathrm{pH} 8.04)^{128}$ using ethyl acetate saturated with the same buffer as the mobile phase, indicated that separation of the hydroxamic acid components of the crude product was feasible. Preparative separations were performed using a partition column prepared as follows :-

Cellulose powaer ( $100 \mathrm{~g} \bullet$ ) was covered with the mobile phase and the buffer solution ${ }^{128}$ ( $40 \mathrm{ml}$.) added in small portions with vigorous shaking. The resultant adsorbent was packed carefully into a column $55 \mathrm{~cm} \times 2.5$ cm. Each run was performed using the mobile phase 
described above and collecting $10 \mathrm{ml}$. fractions with the aid of an automatic fraction collector. The same column could be used indefinitely if washed with the mobile phase (ca. $500 \mathrm{ml}$.) after each run.

$$
\text { The hydroxamic acid (55) ( } 500 \mathrm{mg} \bullet ; 0.98 \text { mmole) }
$$

was treated with anhydrous methanolic hydroxylamine (ca. 20 mmole) in dry methanol $(6 \mathrm{ml}$.$) and allowed to stand at$ room temperature for $20 \mathrm{hr}$. The solvent and excess hydroxylamine were removed in vacuo and the residue extracted with hot mobile phase $(5 \times 5 \mathrm{ml}$.). This solution was chromatographed on the column described above to yield the dihydroxamic acid (56) ( $180 \mathrm{mg} \bullet ; 59 \%$ ) as an almost colourless powder, m.p. 209-210 (dec.). The chromatographed product was not purified further but was converted to several derivatives as described below. Infra-red: $\quad V_{\max }$ 3425, 3175, 1665 (broad) $\mathrm{cm}^{-1}$. Even on the above scale (ca. 1 mmole) the dihydroxamic acid (56) was separated from the by-product, benzhydroxamic acid, by no more than three $10 \mathrm{ml}$. fractions. Therefore no attempt was made to carry out the separation on a larger scale. 


\section{Acetylation of the dihydroxamic acid ( 56 )}

The dihydroxamic acid (200 mg。) was allowed to stand for $12 \mathrm{hr}$. at room temperature with acetic anhydride ( $5 \mathrm{ml} \bullet)$ and pyridine $(2.5 \mathrm{ml}$ ). The reaction mixture was evaporated to dryness in vacuo and the resultant glass chromatographed on silica gel. Elution with benzeneether (4:1) gave the triacetate (57) as colourless needles from benzene-light petroleum (185 mg•; 66\%). This derivative exhibited a double m.p. $110^{\circ}$ and $153-156^{\circ}$ (dec.) which depended on the rate of heating.

\section{Alternatively, the triacetate (57) could be} obtained in $89 \%$ yield by acetylation with refluxing acetyl chloride. Under these conditions the crude product could be recrystallised directly without chromatography.

Infra-red: $\quad V_{\max } 1800,1760,1690$ (doublet) $\mathrm{cm}^{-1}$. $V_{\max }^{\max }$ (chlor of orm) 1805, $1740,1700 \mathrm{~cm}^{-1}$.

Analysis:

Found

$\mathrm{C}_{19} \mathrm{H}_{22} 2_{2} \mathrm{O}_{8} \mathrm{~S}$ requires

$\begin{array}{ccl}\underline{\mathrm{C}} & \underline{\mathrm{H}} & \underline{\mathrm{N}} \\ 52.3 & 5.2 & 6.4 \\ 52.0 & 5.1 & 6.4 \%\end{array}$

Methylation of the dihydroxamic acid (56).

The dihydroxamic acid $(200 \mathrm{mg} \bullet)$ in dry methanol (30 ml.) was treated with an excess of ethereal diazomethane and allowed to stand at room temperature for $2 \mathrm{hr}$. 
The solvent was removed in vacuo and the residue extracted with hot benzene $(5 \times 10 \mathrm{ml}$.). Evaporation of the benzene in vacuo gave a yellow glass which was chromatographed on silica gel. Elution with benzene-ether $(1: 1)$ gave a viscous oil (ㅁ․ $30 \mathrm{mg} \bullet$ ) which was probably a trimethyl ether as shown by the n.m.r. spectrum (three 0-methyl groups at $6.10,6.21,6.26 \uparrow$ ). Further elution with chloroform-ethanol (49:1) and recrystallisation of the product from benzene-light petroleum afforded the dimethyl ether (58) (125 mg•; 58\%). This derivative which crystallised as colourless chunky needles also exhibited a double m.p. $112-114^{\circ}$ and $178-181^{\circ}$ (dec.) which was dependent on the rate of heating. Infra-red: $\quad V_{\max } .3300,1785,1765 \mathrm{~cm}^{-1}$

Analysis: $\quad \underline{H} \quad \underline{H} \quad \underline{N} \quad \underline{M} \quad \underline{H}$. Found $54.5 \quad 6.5 \quad 8.08 .8 \quad 340$ (mass spec.) $\mathrm{C}_{15} \mathrm{H}_{20} \mathrm{~N}_{2} \mathrm{O}_{5}^{\mathrm{s}}$ req. $52.9 \quad 5.9 \quad 8.2 \quad 9.4 \quad 340$

The analysis quoted is the best of four separate attempts. N.m.r. spectroscopy showed that the dimethyl ether tended to include benzene and this may explain the high $\mathrm{C}$ and $\mathrm{H}$ figures. In any case, the n.m.r. spectrum (Table V) and subsequent transformations supported the proposed structure.

Excess diazomethane was essential since an experiment using ca. 2.5 molar excess of standardised 
diazomethane gave a very low yield of (58). Inversely, when a vast excess of diazomethane (at least twenty-fold) was employed, the dimethyl ether was still the predominant product.

Acetylation of the dimethyl ether (58).

The dimethyl ether ( $240 \mathrm{mg}$ •) was acetylated with acetic anhydride and pyridine as described for (57). The resultant gum was chromatographed on silica gel. Elution with benzene-ether $(1: 1)$ afforded the acetoxy dimethyl ether (52), (195 mg•; 72\%) as a colourless gum. This intermediate could not be crystallised despite repeated chromatography but the n.m.r. spectrum (Table V) was consistent with the proposed structure. Infra-red: $\quad V_{\max }\left(\right.$ Iiquid film) $1760,1685 \mathrm{~cm}^{-1}$.

Peracid oxidation of the methylthio nitro ester $\left(53: \mathrm{R}^{2} \mathrm{NO}_{2}\right)$

Initial experiments were performed using $\underline{m}-$ chloroperbenzoic acid (99.5\%) prepared by the general method of silbert et.al. ${ }^{129}$ Subsequently the commercial peracid (Research Organic Chemical Co., ca. $83 \%$ ) was washed with aqueous phosphate buffer ( $\mathrm{pH} 7.6)$ and was of $97 \%$ purity. The peracid was standardised by titration of the iodine liberated from potassium iodide, against standardised thiosulphate. 
m-Chloroperbenzoic acid ( $540 \mathrm{mg} \bullet ; 3.08 \mathrm{mmole}$ ) was added to a solution of the nitro ester ( $600 \mathrm{mg} \bullet$; $1.54 \mathrm{mmole}$ ) in AR chloroform (ca. $100 \mathrm{ml}$ ) and the mixture stirred at room temperature for $15 \mathrm{hr}$. The chloroform solution was washed with saturated aqueous sodium bicarbonate $(5 \times 10 \mathrm{ml}$.) and water $(2 \times 20 \mathrm{ml}$.). Evaporation of the dried chloroform solution gave a crystalline residue. Recrystallisation from benzene afforded the sulphone $(60)$, (410 mg•; 63\%) as a colourless powder, m.p. $168^{\circ}$ (bar, dec.).

Infra-red: $\quad V_{\max } .1750,1730,1565,1130 \mathrm{~cm}^{-1}$.

\begin{tabular}{|c|c|c|c|c|c|}
\hline Analysis: & $\underline{\mathrm{C}}$ & $\underline{H}$ & $\underline{N}$ & $\underline{0}$ & $\underline{\mathrm{S}}$ \\
\hline Found & $54 \cdot 2$ & $4 \cdot 7$ & 3.6 & 30.0 & $7 \cdot 9$ \\
\hline $\mathrm{C}_{19} \mathrm{H}_{19} \mathrm{NO}_{8} \mathrm{~S}$ requires & 54.1 & $4 \cdot 5$ & 3.6 & 30.4 & $7.6 \%$ \\
\hline
\end{tabular}

\section{The triacetoxysulphoxide (61)}

$$
\text { m-Chloroperbenzoic acid (237 mg•; } 1.37 \text { mmole) }
$$

in $\mathrm{AR}$ chloroform (ca. $15 \mathrm{ml}$ ) was added dropwise to a stirred solution of the triacetate (57) (600 mg•; 1.37 mmole) in AR chloroform (ca. $60 \mathrm{ml}$ ) at $0^{\circ}$. After the addition was complete the solution was allowed to warm to room temperature and stirred for a further $12 \mathrm{hr}$. The reaction mixture was worked up as aescribed for (60) and the crude product washed with anhydrous ether ( $2 \times 5 \mathrm{ml}$ ) to give a colourless powder ( $530 \mathrm{mg} \cdot ; 85 \%$. A sample 
( $150 \mathrm{mg} \bullet$ ) was recrystallised from benzene-light petroleum to afford the triacetoxysulphoxide $(61)$ (120 mg), as colourless plates, m.p. 125-127 (dec.).

Infra-red: $\quad V_{\max } 1800,1760,1690,1045 \mathrm{~cm}^{-1}$

$\begin{array}{lccccc}\text { Analysis: } & \underline{\mathrm{C}} & \underline{\mathrm{H}} & \underline{\mathrm{N}} & \underline{\mathrm{O}} & \underline{\mathrm{S}} \\ \text { Found } & 50.2 & 5.0 & 6.1 & 31.2 & 7.0 \\ \mathrm{C}_{19} \mathrm{H}_{22} \mathrm{~N}_{2} \mathrm{O} 9 \mathrm{~S} \text { requires } & 50.2 & 4.9 & 6.2 & 31.7 & 7.0 \%\end{array}$

The triacetoxysulphone (62)

m-Chloroperbenzoic acid ( $58 \mathrm{mg} \bullet ; 0.33$ mmole) was added to a solution of the triacetoxysulphoxide (61) (150 $\mathrm{mg} \bullet$; 0.33 mmole) in AR chloroform (ca. $50 \mathrm{ml}$ ) and the solution stirred at room temperature for $12 \mathrm{hr}$. The reaction mixture worked up as described for (61) yielded a colourless powder (150 mg•; 97\%). Recrystallisation from benzene-light petroleum gave the triacetoxysulphone (62) (125 mg•) as colourless plates m.p. $148-151^{\circ}$ (dec.). The sulphone could also be obtained in comparable yield by oxidation of the triacetate (57) with two moles of $\underline{m}-$ chloroperbenzoic acid.

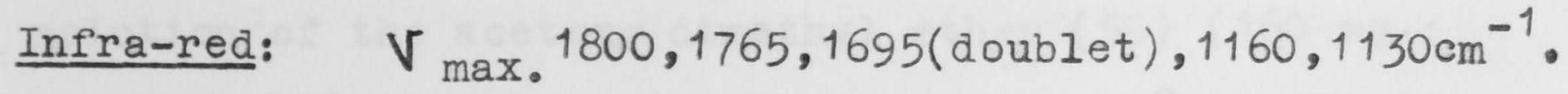

$\begin{array}{lccccc}\text { Analysis: } & \underline{\mathrm{C}} & \underline{\mathrm{H}} & \underline{\mathrm{N}} & \underline{\mathrm{O}} & \underline{\mathrm{S}} \\ \text { Found } & 48.2 & 5.0 & 6.0 & 32.8 & 6.6 \\ \mathrm{C}_{19} \mathrm{H}_{22} \mathrm{~N}_{2} \mathrm{O}_{10} \mathrm{~S} \text { requires } & 48.5 & 4.7 & 6.0 & 34.0 & 6.8 \%\end{array}$


The trihydroxysulphoxide (63).

The triacetoxysulphoxide (61) (200 mg•) in dry methanol (ca. $80 \mathrm{ml} \bullet$ ) at $0^{\circ}$ was saturated with dry ammonia and allowed to stand at room temperature for $1 \mathrm{hr}$. The solvent was removed in vacuo and the semi-crystalline residue triturated with ethanol to give the trihydroxysulphoxide (64) (124 mg•; $88 \%$ ) as a colourless powder, m.p. $208^{\circ}$ (violent dec.). No attempt was made to recrystallise this sulphoxide since it was completely insoluble in boiling methanol; the use of higher boiling solvents such as methoxyethanol was expected to promote decomposition.

Infra-red: $\quad V_{\max } .3250,1665,1010 \mathrm{~cm}^{-1}$.

$\begin{array}{lccccc}\text { Analysis: } & \underline{\mathrm{C}} & \underline{\mathrm{H}} & \underline{\mathrm{N}} & \underline{\mathrm{O}} & \underline{\mathrm{S}} \\ \text { Found } & 47.5 & 5.1 & 8.5 & 28.8 & 9.3 \\ \mathrm{C}_{13} \mathrm{H}_{16} \mathrm{~N}_{2} \mathrm{O}_{6} \mathrm{~S} \text { requires } & 47.5 & 4.9 & 8.5 & 29.2 & 9.8 \%\end{array}$

\section{The acetoxy dimethoxysulphoxide (64).}

$$
\text { m-Chloroperbenzoic acid ( } 65 \mathrm{mg} \bullet ; 0.38 \mathrm{mmole}) \text { in }
$$
AR chloroform ( $10 \mathrm{ml}$.) was added dropwise to a stirred solution of the acetoxy dimethyl ether (59) (160 mg•; $0.42 \mathrm{mmole}$ ) in $\mathrm{AR}$ chloroform $\left(50 \mathrm{ml}\right.$ ) at $0^{\circ}$. After stirring at room temperature for $12 \mathrm{hr}$. the reaction mixture was worked up as described for (61) to give a colourless powder ( $135 \mathrm{mg} \bullet ; 86 \%$ based on peracid). 
Recrystallisation from benzene-light petroleum afforded the acetoxy dimethoxysulphoxide (64) (100 mg•) as colourless plates, m.p. $152-153^{\circ}$ (dec.).

Infra-red: $\quad V_{\max } 1760,1685,1040 \mathrm{~cm}^{-1}$.

Analysis: $\quad \underline{C} \quad \underline{H} \quad \underline{N} \quad \underline{O} \quad \underline{S} \quad \underline{M}$.

$\begin{array}{lllllll}\text { Found } & 51.7 & 5.9 & 6.8 & 28.3 & 7.6 & 398 \text { (mass spec.) }\end{array}$

$\begin{array}{llllllll}\mathrm{C}_{17} \mathrm{H}_{22} \mathrm{~N}_{2} \mathrm{O} & \mathrm{S} \text { req. } 51.3 & 5.6 & 7.0 & 28.1 & 8.0 & 398\end{array}$

If equimolar quantities of peracid and thioether were used, the sulphoxide (64) was accompanied by a trace of the corresponding sulphone. This probably arises because the thioether (59) could never be crystallised and was used directly after chromatography.

Section IIc.

Oxidation of the methylthio nitro ester $\left(53: \mathrm{R}=\mathrm{NO}_{2}\right)$ with one mole of m-chloroperbenzoic acid.

(a) A solution of $\underline{m}$-chloroperbenzoic acid ( $89 \mathrm{mg} \bullet ; 0.51$ mmole) in dry chloroform (ca. $10 \mathrm{ml}$. ) was added dropwise to a stirred solution of the nitro ester ( $53 ; \mathrm{R}=\mathrm{NO}_{2}$ ) (200 mg.; $0.51 \mathrm{mmole)}$ in ary chloroform ( $0^{\circ}$. The solution was allowed to warm to room temperature and stirred for a further $20 \mathrm{hr}$. The reaction 
mixture was washed with saturated aqueous sodium bicarbonate $(5 \mathrm{x} 10 \mathrm{ml} \cdot)$, dried and the solvent removed in vacuo to yield a mixture of the cis and trans isomers of the nitroolefin $(47 ; \mathrm{R}=\mathrm{CO} \varnothing)(170 \mathrm{mg} \cdot ; 96 \%)$. The n.m.r. spectrum indicated a predominance of the high m.p. (trans) is omer.

(b) N.m.r. study of the same reaction The nitro ester ( $67 \mathrm{mg} \bullet$; $0.17 \mathrm{mmole}$ ) and $\mathrm{m}-$ chloroperbenzoic acid ( $30 \mathrm{mg} \bullet$; 0.17 mole) were dissolved in deuterochloroform $(0.6 \mathrm{ml}$.). After $8 \mathrm{~min}$. the n.m.r. spectrum showed that oxidation was complete (no $\mathrm{S}-\mathrm{CH}_{3}$ at $8.00 \tau$ ) and that a small amount of the sulphone (60) had been formed al ong with the sulphoxide $(7.37 \tau$, SOCH $\left.3 ; \quad 8.68 \tau, \mathrm{CO}_{2} \mathrm{CH}_{2} \underline{\mathrm{CH}}_{3}\right)$. The absorptions for the sulphoxide degenerated within $5 \mathrm{hr}$. to be replaced by the spectrum of a mixture of the cis. and trans isomers of ( $47 ; \mathrm{R}=\mathrm{CO} \varnothing$ ) superimposed on that of the sulphone (60).

Oxidation of the methylthio hydroxamic acid (55) with one mole of m-chloroperbenzoic acid

A solution of $\underline{m-c h l o r o p e r b e n z o i c ~ a c i d ~(~} 86.5 \mathrm{mg} \cdot$; 0.50 mmole) in dry chloroform (ca. $15 \mathrm{ml}$.) was added dropwise to a stirred solution of the hydroxamic acid (55) (255 mg•; 0.50 mmole) in ary chloroform (ca. $30 \mathrm{ml}$. ) at $0^{\circ}$. After $2 \mathrm{hr}$. at $\mathrm{O}^{\circ}$ the solution was stirred at room 
temperature for a further $12 \mathrm{hr}$. Evaporation of the solvent in vacuo gave a sticky solid (ca. $340 \mathrm{mg}$.) which exhibited broad u.v. absorption at ca. $285 \mathrm{~m} \mu$ and gave a positive ferric test. The n.m.r. spectrum was extremely complex and in particular showed no absorptions for the S-methyl group or the AB protons. Half the crude product was dissolved in chloroform and a portion of the solution washed with saturated aqueous sodium bicarbonate; extensive decomposition was indicated by an increase in the complexity of the n.m.r. spectrum of the resulting product. Similar decomposition resulted if the crude product was chromatographed on untreated silica gel or neutral alumina.

The remainder of the crude product was chromatographed on silica gel which had been thoroughly washed with concentrated hydrochloric acid, water, E.D.T.A. solution and water, and then reactivated by heating at $120^{\circ}$ in vacuo for 2 days. Elution with ether-benzene (1:9) afforded a colourless glass ( $90 \mathrm{mg} \bullet$ ) which was homogeneous on t.l.c. (single ferric positive spot $R_{f}$ 0.53 , ethanol|chlor of orm, 2:23)。

Ultra-violet: $\lambda_{\max } 285$ (broad) $m \mu$.

N.m.r.: Triplet, $8.63\left(\mathrm{~J}=7.5 \mathrm{cps} \cdot, 4 \cdot 9 \mathrm{H}, \mathrm{CO}_{2} \mathrm{CH}_{2} \mathrm{CH}_{3}\right)$; doublet, $8.17\left(\mathrm{~J}=7 \mathrm{cps} .3 .2 \mathrm{H}, \mathrm{CHCH}_{3}\right)$; overlapping quartets, $5.63\left(\mathrm{~J}=7.5 \mathrm{cps} ., 3.0 \mathrm{H}, \mathrm{CO}_{2} \mathrm{CH}_{2} \mathrm{CH}_{3}\right.$ and $\left.\underline{\mathrm{CHCH}}_{3}\right)$; complex multiplet,1.7-2.9i( (14H, aromatic protons). 
No improvement in the homogeneity of the elimination product was realised by repeated chromatography on acidwashed silica gel.

\section{Acetylation of the hydroxylamino ester ( $23 ; \mathrm{R}=\mathrm{NHOH}$ )}

Acetyl chloride ( $370 \mathrm{mg} \bullet ; 4.68$ mole) was added to a solution of the hydroxylamino ester (direct from reduction)( $1.76 \mathrm{~g} \cdot ; 4.68 \mathrm{mmole})$ in $\mathrm{AR}$ carbon tetrachloride $(50 \mathrm{ml}$.$) and the mixture heated under reflux$ for $1.5 \mathrm{hr}$. The solvent was removed in vacuo to yield a sticky solid $(1.85 \mathrm{~g} \cdot)$. A portion ( $680 \mathrm{mg} \bullet$ ) of the crude product was chromatographed on silica gel. Elution with ether-benzene $(1: 9)$ and recrystallisation of the eluted solid from benzene-light petroleum gave the hydroxamic acid (69)( $450 \mathrm{mg} \bullet ; 63 \%$ ) as a crystalline powder, m.p. $125-127^{\circ}$.

Infra-red: $\quad V_{\max } 3150,1735,1637,1612 \mathrm{~cm}^{-1}$.

$\begin{array}{lccccc}\text { Analysis: } & \text { C } & \text { H } & \text { N } & \text { O } & \text { S } \\ \text { Found } & 60.3 & 5.6 & 3.6 & 23.0 & 7.3 \\ \mathrm{C}_{21} \mathrm{H}_{23}{ }^{\mathrm{NO}} 6^{\mathrm{S}} \text { requires } & 60.4 & 5.6 & 3.4 & 23.0 & 7.7 \%\end{array}$

Oxidation of the methylthio hydroxamic acid (69) with one mole of m-chloroperbenzoic acid.

A solution of $\mathrm{m}$-chloroperbenzoic acid ( $87 \mathrm{mg} \cdot$; $0.50 \mathrm{mmole}$ ) in dry chloroform (ㄹ. $10 \mathrm{ml}$. ) was added dropwise to a stirred solution of the hydroxamic acid (69) 
(209 mg•; $0.50 \mathrm{mmole}$ ) in ary chloroform (30 ml•) at $0^{0}$. The reaction mixture was allowed to warm to room temperature and stirred for a further $15 \mathrm{hr}$. The solvent was removed in vacuo to yield a sticky solid which was chromatographed on acid-washed silica gel. Elution with etherbenzene (1:9) afforded a crystalline solid (140. $\mathrm{mg} \cdot$ ) which was rechromatographed and recrystallised from ethyl acetate-light petroleum to give the olefin (70) (60 mg.) as a buff coloured powder, m.p. 128-132 . Although homogeneous on t.l.c. (single ferric positive spot $R_{f}$ 0.43, ethanol-chloroform, 3:47), the n.m.r. spectrum (Chart XVII) indicated that impurities were still present. Infra-red: $\quad V_{\max } 3100,1735,1707,1630$ (doublet) $\mathrm{cm}^{-1}$. Ultra-violet: $\lambda_{\max } 224 \mathrm{~m} \mu(\varepsilon=20,900), 282 \mathrm{~m} \mu(\varepsilon=24,500)$.

Analysis:

Found

$\mathrm{C}_{20} \mathrm{H}_{19} \mathrm{NO}_{6}$ requires

\begin{tabular}{cccc}
$\underline{\mathrm{C}}$ & $\underline{\mathrm{H}}$ & $\underline{\mathrm{N}}$ & \multicolumn{1}{c}{$\underline{\mathrm{O}}$} \\
64.9 & 5.4 & 4.4 & 24.3 \\
65.0 & 5.2 & 3.8 & $26.0 \%$
\end{tabular}

\section{Pyrolysis of the triacetoxysulphoxide (61)}

(a) In dioxan at $80-85^{\circ}$

A solution of the triacetoxysulphoxide (61)

(120 mg.) in dry dioxan ( $5 \mathrm{ml}$.) was sealed in an evacuated tube and heated at $80-85^{\circ}$ for $60 \mathrm{hr}$. The solvent was removed in vacuo to yield a yellow glass which showed negligible u.v. absorption near $300 \mathrm{~m} \mu$ and was a complex 
mixture as shown by the n.m.r. spectrum and t.l.c. (at least five components). The crude product was extracted with ether-benzene (1:9) to yield a colourless glass ( $100 \mathrm{mg} \cdot$ ) which was chromatographed on silica gel. Elution with chloroform-ethanol (19:1) afforded a yellow glass ( $75 \mathrm{mg} \cdot$ ) which was no more homogeneous than the crude product $\left(n \cdot m \cdot r \cdot, t \cdot l_{\bullet} c_{\bullet}\right)$. Infra-red:

$$
\begin{aligned}
& V_{\max }(\mathrm{film}) 1800,1760,1690 \mathrm{~cm}^{-1} . \\
& \left(\varepsilon_{1760} \bumpeq \varepsilon_{1800}\right)
\end{aligned}
$$

(b) In d 6 -dime thylsulphoxide

Pyrolyses in this solvent were carried out in sealed evacuated n.m.r. tubes and the reaction followed by the change in the n.m.r. spectrum.

(i) At $77^{\circ}$ : Triacetoxysulphoxide (61) (60 m..) in $a_{6}$-dimethylsulphoxide $(0.35 \mathrm{ml} \cdot)$; after $9 \mathrm{hr} \cdot$ at this temperature the spectrum of the sulphoxide ( $\left.\operatorname{soCH}_{3}, 7.51 \uparrow\right)$ had degenerated, to be replaced by that of a complex mixture of products.

(ii) At $65^{\circ}$ : Triacetoxysulphoxide (61) (58mg•) in $\mathrm{d}_{6}$-dimethylsulphoxide $(0.35 \mathrm{ml})$; after $41 \mathrm{hr}$. at this temperature the n.m.r. spectrum was almost identical to that of the pyrolysis at $77^{\circ}$ after $9 \mathrm{hr}$.

The products of runs (i) and (ii) were combined, taken up in chloroform ( $20 \mathrm{ml}$.) and washed thoroughly with water $(10 \times 10 \mathrm{ml}$.). Evaporation of the dried 
chloroform solution gave a yellow glass ( $72 \mathrm{mg} \bullet$ ) which showed no $u_{0} v$. absorption near $300 \mathrm{~m} \mu$. The crude product was again a complex mixture as shown by the n.m.r. spectrum and t.1.c. (at least four main components).

\section{Pyrolysis of the trihydroxysulphoxide (63)}

The trihydroxysulphoxide (63) (56 mg•) in $\mathrm{a}_{6}-$ dimethylsulphoxide $(0.35 \mathrm{ml}$ ) was sealed in an evacuated n.m.r. tube and heated at $77^{\circ}$. After $130 \mathrm{hr}$. at this temperature the sulphoxide had completely decomposed to a complex mixture of products. The solvent was removed in vacuo to yield a dark red gum ( $50 \mathrm{mg} \cdot$ ) which showed very broad u.v. absorption at $\underline{\text { ca }} \cdot 318 \mathrm{~m} \mu$. No effective separation of this mixture was realisable by t.l.c.; with ethanol-chloroform (3:47), the mixture did not move from the baseline while with ethanol-chloroform (1:1) extensive streaking resulted. Similar streaking was encountered when the mixture was chromatographed on buffered paper (mobile phase ethyl acetate saturated with aqueous phosphate buffer $\mathrm{pH} 8.04,{ }^{128}$ paper saturated with the same buffer).

\section{Pyrolysis of the acetoxy dimethoxysulphoxide (64)}

A solution of the sulphoxide (64) (280 mg•) in dry dioxan ( $10 \mathrm{ml}$.) was sealed in an evacuated tube and heated at $80-85^{\circ}$ for $60 \mathrm{hr}$. Evaporation of the solvent 
in vacuo gave a yellow glass which was chromatographed on silica gel. Elution with ether-benzene (1:1) gave a crystalline solid ( $153 \mathrm{mg} \cdot ; 71 \%$ ) Recrystallisation from ethanol afforded the olefin ( 75$)(112 \mathrm{mg} \bullet ; 52 \%)$ as an almost colourless crystalline powder, m.p. 157-158.5 . The n.m.r. spectrum of the product direct from chromatography was identical with that of the recrystallised sample.

Infra-red: $\quad V_{\max } 3250,1760,1690,1640 \mathrm{~cm}^{-1}$. Ultra-violet: $\lambda_{\max } .222 \mathrm{m \mu}(\varepsilon=13,500), 297 \mathrm{~m} \mu(\varepsilon=20,800)$.

Analysis:

Found

$\mathrm{C}_{15^{\mathrm{H}}}{ }_{16} \mathrm{~N}_{2} \mathrm{O}_{5}$ requires

$\begin{array}{ccl}\underline{\mathrm{C}} & \underline{\mathrm{H}} & \underline{\mathrm{N}} \\ 59.3 & 5.0 & 9.4 \\ 59.2 & 5.3 & 9.2 \%\end{array}$

Reaction of the acetoxy dimethoxysulghoxide (64) with potassium t-butoxide in d 6 -dimethylsulphoxide

To ensure moisture-free conditions all operations were carried out in a nitrogen drybox. The sulphoxide (64)( $60 \mathrm{mg} \bullet ; 0.15$ mmole) was dissolved in $0.5 \mathrm{M}$ potassium $\underline{t}$-butoxide in $\mathrm{a}_{6}$-dimethylsulphoxide $(0.4$ ml.; 0.20 mmole), transferred to an n.m.r. tube and sealed. A dark red solution resulted immediately and the n.m.r. spectrum showed that extensive decomposition had occurred even after only $10 \mathrm{~min}$. After $6.5 \mathrm{hr}$. at $33^{\circ}$, water $(15 \mathrm{ml} \bullet)$ was added and the resulting solution extracted 
with chloroform $(8 \times 10 \mathrm{ml}$ ) . Evaporation of the dried chlor oform extract gave a yellow glass ( $39 \mathrm{mg} \bullet$ ) which showed broad $u_{.} v$. absorption at $314 \mathrm{~m} \mu$. However, the crude product was a complex mixture of products as shown by the n.m.r. spectrum and t.l.c. (eleven resolved components). No further study of this reaction was made.

Pyrolysis of the trihydroxy thioether (56)

(a) In d 6 -dimethylsulphoxi de

The thioether (56) (58 mg•) was dissolved in $\mathrm{d}_{6}$-dimethylsulphoxide $(0.35 \mathrm{ml} \cdot)$ and sealed in an evacuated n.m.r. tube. After $125 \mathrm{hr}$. at $77^{\circ}$ the n.m.r. spectrum remained unchanged except that the peak at ca. $0.0 \tau(3 \mathrm{X}-\mathrm{OH})$ had broadened considerably. The pyrolysis temperature was raised to $110^{\circ}$ but even after $90 \mathrm{hr}$. at this temperature the thioether was only ca. $60 \%$ decomposed. A complex mixture of pyrolysis products was indicated by the resulting $n_{\bullet} m_{\bullet} \cdot$ spectrum.

(b) In dioxan

The thioether (56) (150 mg•) was suspended in dry dioxan ( $10 \mathrm{ml}$ ) in a sealed evacuated tube and heated at $110^{\circ}$. After 2 days the solid had completely dissolved and thereafter heating was continued for a further 3 days. The solvent was removed in vacuo to give a dark red gum which showed broad $u_{\bullet} \cdot$. absorption at ca. $318 \mathrm{~m} \mu$ and gave 
a positive ferric test. However, as observed with the pyrolysis products of the trihydroxysulphoxide (63), no effective separation of the components of this pyrolysis mixture was realised by t.l.c. or chromatography on buffered paper.

\section{Pyrolysis of the dimethoxy thioether (58)}

The thioether (58) (280 mg.) in dry dioxan (10 ml.) was sealed in an evacuated tube and heated at $100^{\circ}$ for $100 \mathrm{hr}$. Evaporation of the solvent in vacuo afforded a yellow glass which was chromatographed on silica gel. Elution with chloroform gave a crystalline solid ( $190 \mathrm{mg} \bullet ; 88 \%$ ) Recrystallisation of the chromatographed product (150 mg.) from methanol gave the olefin (76) $(80 \mathrm{mg} \bullet ; 47 \%$ as a light yellow powder, m.p. 185-187 (dec.). The n.m.r. spectrum of the product direct from chromatography was identical with that of the purified sample。

Infra-red: $V_{\max } 3400$ (shoulder), $3300,1690,1630 \mathrm{~cm}^{-1}$.

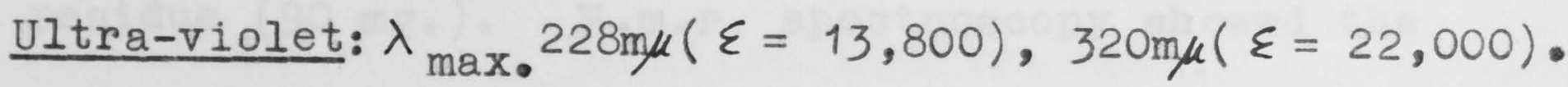

\begin{tabular}{|c|c|c|c|}
\hline Analysis: & $\underline{C}$ & $\underline{\mathrm{H}}$ & $\underline{\mathrm{N}}$ \\
\hline Found & $59 \cdot 9$ & $5 \cdot 7$ & $10 \cdot 8$ \\
\hline $\mathrm{C}_{13} \mathrm{H}_{14} \mathrm{~N}_{2} \mathrm{O}_{4}$ requires & $59 \cdot 5$ & 5.4 & \\
\hline
\end{tabular}




\section{Acetylation of the olefin (76)}

The olefin (76) (36 mg•) was heated under reflux with acetyl chloride (ca. $5 \mathrm{ml}$ ) for $1 \mathrm{hr}$. Evaporation of the excess reagent in vacuo gave a colourless glass (38 mg•) which contained two components $\left(t \cdot l_{\bullet} c_{\bullet}\right)$. The crude product was chromatographed on silica gel. Elution with ether-benzene (1:4) gave a crystalline solid (12mg•) which was probably the $\underline{0, N-d i a c e t y l ~ d e r i v a t i v e ~(t w o ~}$ acetyl groups at 7.57 and $7.70 \%$ in the n.m.r. spectrum). Subsequent elution with ether-benzene (1:1) gave the olefin (75) (15 mg.) identical with the sample obtained previously (i.r., n.m.r. and $u_{\bullet} v_{\bullet}$ spectra).

\section{Pyrolysis of the acetoxy dimethoxy thioether (59)}

The thioether (59) (150 $\mathrm{mg} \cdot$ ) in dry dioxan (8 ml.) was sealed in an evacuated tube and heated at $100^{\circ}$ for $70 \mathrm{hr}$. Evaporation of the solvent in vacuo gave a yellow glass which was chromatographed on silica gel. Elution with ether-benzene $(1: 1)$ gave a crystalline residue $(90 \mathrm{mg} \bullet) \cdot N_{\bullet} m_{\bullet} r_{\bullet}$ spectroscopy showed the chromatographed product to be the olefin (75) contaminated with unchanged thioether (59) ( $14 \%$ by integration). The actual yield of the olefin (75) was therefore $77 \mathrm{mg}$ • (65\%). Recrystallisation of the chromatographed product from ethanol afforded pure (75) ( $45 \mathrm{mg} \bullet$ )。 
Acid-catalysed elimination of the dimethoxy thioether (58)

Preliminary experiments showed that when the thioethers (56), (58) and (59) were dissolved in concentrated sulphuric acid and water added, methyl mercaptan was evolved. The u.v. spectra of the resulting aqueous solutions (Chart XVIII) were similar to those of the elimination products (75) and (76).

The thioether (58) (60 mg.) was dissolved in concentrated sulphuric acid $\left(0.35 \mathrm{ml}\right.$ ) and the $n_{\bullet} \cdot m_{\bullet}$. spectrum of the resulting red solution observed. Even after $10 \mathrm{~min}$. it was evident that decomposition more extensive than elimination of methyl mercaptan had occurred. After $1.25 \mathrm{hr}$. the reaction solution was added to ice-water (ca. $50 \mathrm{ml}$.) and the yellow solution continuously extracted with chloroform for $12 \mathrm{hr}$. Evaporation of the dried chloroform solution gave a yellow glass ( $10 \mathrm{mg} \bullet$ ) which exhibited broad $u_{\bullet} v$. absorption at $320 \mathrm{~m} \mu$. T.1.c. showed the crude product to be a complex mixture (at least five close-running components). No further study of this reaction was made.

\section{Attempted cyclisation of the hydroxamic acid (55)}

(a) With methanolic methylamine

The hydroxamic acid (55) ( $51 \mathrm{mg} \bullet ; 0.1 \mathrm{mmole}$ ) in dry methanol $(0.5 \mathrm{ml}$.) was treated with $4 \mathrm{M}$ methanolic 
methylamine $(0.5 \mathrm{ml} . ; 2.0 \mathrm{mmole})$ and allowed to stand at room temperature for $14 \mathrm{hr}$. The solvent and excess amine was removed in vacuo and the residue extracted with chloroform. Evaporation of the chloroform solution gave a red glass ( $40 \mathrm{mg} \bullet$ ). The n.m.r. spectrum of the crude product indicated that a complex mixture of products had resulted; in particular there was no absorption for the S-methyl group. T.1.c. (ethanol-chloroform, 3:47) showed at least three spots of $R_{f}<0.1$ and at least one other of $R_{f}$ ca. 0.35. Essentially the same results were obtained when the reaction was run for only $1 \mathrm{hr}$.

(b) With methanolic ammonia

The hydroxamic acid (55) ( $51 \mathrm{mg} \bullet ; 0.1 \mathrm{mmole})$ in dry methanol ( $0.5 \mathrm{ml}$ ) was treated with $6.7 \mathrm{M}$ methanolic ammonia $(0.3 \mathrm{ml} . ; 2.0 \mathrm{mmole})$ and allowed to stand at room temperature for $16 \mathrm{hr}$. The solvent and excess amine were removed in vacuo to yield a red gum which was shown by t.1.c. (ethanol-chloroform, 3:47) to contain at least five components. Extraction of the crude product with chloroform yielded a yellow gum ( $32 \mathrm{mg} \bullet$ ) which was similarly inhomogeneous. 
Methylation of the hydroxamic acid (55)

The hydroxamic acid (55) (200 $\mathrm{mg} \bullet$ ) in methanol $(20 \mathrm{ml}$.) was treated with excess ethereal diazamethane. Evaporation of the solvent in vacuo gave a colourless glass which was chromatographed on silica gel. Elution with benzene gave the methyl ether (78) as a colourless glass (110 mg•; 54\%). Although non-crystalline, the chromatographed product was homogeneous on t.1.c. $\left(R_{f} 0.67\right.$, ethanol-chloroform, 1:24).

N.m.r.r.: Doublet, $8.64\left(\mathrm{~J}=7 \mathrm{cps}, \mathrm{CHCH}_{3}\right)$ and triplet, 8.64 $\left(\mathrm{J}=7.5 \mathrm{cps} ., \mathrm{CO}_{2} \mathrm{CH}_{2} \mathrm{CH}_{3}\right.$, total $\left.6 \mathrm{H}\right)$; singlet, 8.01

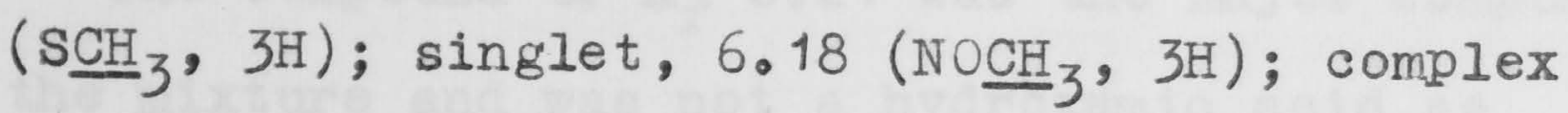
multiplet, $5.6\left(\mathrm{CO}_{2} \mathrm{CH}_{2} \mathrm{CH}_{3}, \mathrm{CHCH}_{3}\right.$ and $\mathrm{CHCO}_{2} \mathrm{Et}$, total 4H); doublet, $4.55\left(\mathrm{~J}=11 \mathrm{cps} ., \underline{\mathrm{CHSCH}}_{3}, 1 \mathrm{H}\right)$; complex multiplet, $2.6(7 \mathrm{H})$ and quartet, $1.83 \pi(2 \mathrm{H})$ (aromatic protons).

Reaction of the methyl ether (78) with anhydrous methanolic hydroxylamine

The methyl ether (78) (60 mg•; 0.12 mmole) was treated with $3.1 \mathrm{M}$ anhydrous methanolic hydroxylamine 94 $(0.75 \mathrm{ml} \bullet ; 2.32 \mathrm{mmole})$ and allowed to stand at room temperature for $11 \mathrm{hr}$. Evaporation of the solvent and excess hydroxylamine in vacuo gave a colourless glass ( $65 \mathrm{mg}$ ). The n.m.r. spectrum of the chloroform- 
soluble portion of the crude product was extremely complex and in particular showed no absorption for the $\mathrm{N}-\mathrm{OCH}_{3}$ group. The t.l.c. (ethanol-chloroform, 1:24) of the crude product is summarised below.

\begin{tabular}{|l|l|}
\hline \multicolumn{1}{|c|}{ Spray Reagent } & $\mathrm{R}_{\mathrm{f}}$ \\
\hline Ferric chloride & $\begin{array}{l}0.00 \text { (brown), } 0.05 \text { ( orange), } \\
0.08(\text { blue), } 0.21 \text { (v•faint) }\end{array}$ \\
\hline $\begin{array}{l}10 \% \text { Ceric sulphate } \\
\text { in } 10 \% \mathrm{H}_{2} \mathrm{SO}_{4}\end{array}$ & $\begin{array}{l}0.00,0.05,0.08, \\
0.21 \text { (most intense), } 0.33\end{array}$ \\
\hline
\end{tabular}

The compound of $R_{f} 0.21$ was the major component of the mixture and was not a hydroxamic acid as judged by the very weak colour produced with ferric chloride.

Chromatography on buffered paper using the system already described, showed that separation of the hydroxamic acid components of the mixture was possible (two spots $R_{f} 0.55$ and 1.0 ). This separation was reproduced by preparative chromatography on a buffered cellulose column, using the same system that was successful for the purification of the trihydroxy thioether (56). However the quantity (ca. $4 \mathrm{mg}$.) of the hydroxamic acid obtained was insufficient for characterisation. 
Methylation of the olefin (76)

The olefin (76) (63 mg•) in methanol (20 ml•)

was treated with a slight excess of distilled ethereal diazomethane ${ }^{130}$ and allowed to stand at room temperature for $2 \mathrm{hr}$. The solvent was removed in vacuo to yield a yellow glass $(65 \mathrm{mg} \bullet$ ) which was chromatographed on silica gel. Elution with ether-benzene $(1: 4)$ gave two main fractions, F4 (16 mg•) and F5 (23 mg•) as colourless glasses. Fraction 5 was almost exclusively the N-methyl olefin (81), the spectral data for which are collected below. Fraction 4 was a $40: 50$ mixture of (81) and a structurally similar compound which showed an additional 0-methyl group at $6.05 \tau$. The latter product is probably the result of 0 -methylation of the amide function. A more careful chromatography will certainly effect a better separation of the two methylation products. Ultra-violet: $\lambda_{\max } \cdot 231,318 \mathrm{~m} \mu$.

N.m.r. : Doublet, $8.42\left(\mathrm{~J}=7 \mathrm{cps} ., \mathrm{CHCH}_{3}\right)$; singlet, 7.08 $\left(\mathrm{NCH}_{3}\right)$; singlets, 7.13,7.16 ( $\mathrm{NOCH}_{3}$ and $\left.\mathrm{p}-\mathrm{OCH}_{3}\right)$; quartet, 5.58 ( $\left.\mathrm{J}=7 \mathrm{cps}, \mathrm{CHCH}_{3}\right)$; multiplet, $2.9 \hat{\imath}$ (vinylic proton and aromatic protons). 
Section IId

Pyrolysis of the simple dimethyl ether $\left(24: \mathrm{R}^{1}=\mathrm{CH}_{3}\right)$

The dimethyl ether (100 mg.) in dry dioxan (6ml.)

was heated in a sealed evacuated tube at $80-85^{\circ}$ for $60 \mathrm{hr}$. Evaporation of the solvent in vacuo gave a crystalline residue which on sublimation $(90 \% 0.3 \mathrm{~mm}$.) gave unchanged dimethyl ether $(70 \mathrm{mg} \cdot)$. The residue from the sublimation was also essentially unchanged starting material as shown by t.l.c.

Qualitative kinetic study of the pyrolysis of the acetoxy dimethoxysulphoxide (64)

(a) In dioxan at $85-90^{\circ}$

The sulphoxide $(90 \mathrm{mg} \cdot)$ in dry dioxan (4 m..) was sealed in an evacuated tube and heated at $85-90^{\circ}$. After $4 \mathrm{hr}$. the pyrolysis was interrupted and the solvent removed in vacuo; the only compounds in the crude pyrolysate detectable by n.m.r. or t.l.c., were the olefin (75) and unchanged sulphoxide (64). The n.m.r. spectrum indicated that the elimination had proceeded ca. $30 \%$ to completion. The crude product was dissolved in dry dioxan (4ml.) and heating continued for a further $6 \mathrm{hr}$. After this reaction time the elimination was ca. $70 \%$ 
complete and once more only (75) and unchanged sulphoxide were detectable.

(b) In d 6 -dimethylsulphoxide at $77^{\circ}$

A solution of the sulphoxide $(40 \mathrm{mg} \cdot)$ in $\mathrm{a}_{6}-$ dimethylsulphoxide $(0.35 \mathrm{ml}$ ) was sealed in an evacuated n.m.r. tube and heated at $77^{\circ}$. The progress of the elimination could be followed most effectively by the rate of appearance of the doublet at $8.52 \tau$ and the corresponding rate of degeneration of the doublet at 9.54 $T$. By this means an approximate half-life of $45 \mathrm{hr}$. was derived. The n.m.r. spectrum of the pyrolysis mixture at various stages during the elimination is illustrated in Chart XXIV. After $108 \mathrm{hr}$. the solvent was removed in vacuo to yield a light yellow glass which crystallised when seeded with the olefin (75) . N.m.r. spectroscopy (indeuterochloroform) showed that the crude product was virtually pure (75) contaminated with a trace of the sulphone, an impurity which had remained unchanged throughout the pyrolysis.

\section{Methylation of mycelianamide}

Mycelianamide $(35 \mathrm{mg} \bullet)$ in dry methanol (20 $\mathrm{ml} \bullet$ ) at $0^{0}$ was treated with a slight excess of distilled ethereal diazomethane. 130 After two hours at room 
temperature the solvent was removed in vacuo to yield mycelianamide dimethyl ether (89) (37 mg.) as a yellow glass. Although non-crystalline the crude product showed the spectral data expected of (89) and was $>90 \%$ homogeneous by t.l.c. (single spot $R_{f} 0.48$ and traces of impurity, $\mathrm{R}_{\mathrm{f}}$ 0.40, ethanol-chloroform, 3:47). Ultra-violet : $\quad \lambda_{\max } 228,321 \mathrm{~m} \mu$ N.m.r. : See Chart XXIVa.

Pyrolysis of mycelianamide dimethyl ether (82)

(a) At $77^{\circ}$. The crude dimethyl ether ( $40 \mathrm{mg} \cdot$ ) in dry benzene $(0.35 \mathrm{ml}$.$) was sealed in an evacuated n.m.r.$ tube and heated at $77^{\circ}$. Within $1 \mathrm{hr}$. at this temperature the absorption for the high-field methoxyl group (6.89 $\tau$ ) had degenerated while the low-field methoxyl $(6.47 \pi$ ) remained virtually intact.

(b) At $65^{\circ}$. A solution of the crude dimethyl ether ( 42 mg.) in dry benzene $(0.35 \mathrm{ml}$.) was sealed in an evacuated $n \cdot m \cdot r \cdot$ tube and heated at $65^{\circ}$. The n.m.r. spectrum of the pyrolysis mixture at various stages during the reaction is illustrated in Chart XXV; inspection of these spectra enabled the derivation of an approximate half-life of $75 \mathrm{~min}$. for the loss of the high-field methoxyl group. After the elimination was complete, a 
small amount $(<2 \mathrm{mg} \cdot)$ of a white solid had collected at the top of the n.m.r. tube. This solid was insoluble in most organic solvents and showed strong peaks at $\mathrm{m} / \mathrm{e} 30,29$ and 28 in the mass spectrum. These observations suggested its identity as paraformaldehyde; this was confirmed by conversion to the 2,4-dinitrophenylhydrazone as follows:- The remainder of the solid was treated with 2,4-dinitrophenylhydrazine reagent (2,4dinitrophenylhydrazine in methanol-sulphuric acid ${ }^{131}$ ) ( 3 drops) and warmed on the water bath. On cooling, the derivative separated as orange needles which were recrystallised from a very small. volume of ethanol. T.1.c. showed that the recrystallised sample was still contaminated with a trace of 2,4-dinitrophenylhydrazine; accordingly the derivative was chromatographed on a small column of silica gel. Elution with benzene gave the pure 2,4-dinitrophenylhydrazone, m.p. and mixed m.p. 161-163 on admixture with an authentic sample of formaldehyde 2,4dinitrophenylhydrazone, m.p. 163-164\%. For comparison, a mixture of formaldehyde and acetaldehyde 2,4-dinitrophenylhydrazones showed a m.p. of $120-125^{\circ}$. The identity of the derivative was confirmed by the $u_{\bullet} v_{\bullet}$ spectrum $\left(\lambda_{\max .} 348 \mathrm{~m} \mu, 1 i t .{ }^{132}, \lambda_{\max .} 348 m \mu\right)$ and the $t_{.1 .}$. results summarised below. 


\begin{tabular}{|l|c|c|c|}
\hline \multirow{2}{*}{$\begin{array}{l}\text { Solvent } \\
\text { system }\end{array}$} & $\begin{array}{c}\text { Present } \\
2,4-D N P\end{array}$ & $\begin{array}{c}\text { Formaldehyde } \\
2,4-D N P\end{array}$ & $\begin{array}{c}\text { Acetaldehyde } \\
2.4-D N P\end{array}$ \\
\hline Chloroform & 0.38 & 0.38 & 0.40 \\
\hline Benzene & 0.31 & 0.32 & 0.32 \\
\hline $\begin{array}{l}\text { Ethanol- } \\
\text { Chloroform } \\
(1: 24)\end{array}$ & 0.68 & 0.68 & 0.73 \\
\hline
\end{tabular}

The original benzene solution was evaporated in vacuo to give a yellow glass (ca. $40 \mathrm{mg} \cdot$ ) which showed u.v. absorption at 228 and $321 \mathrm{~m} \mu$. Work is in progress towards the characterisation of this product.

The five remaining experiments in this subsection (IId), are at a very preliminary stage and in most cases the intermediates have been characterised only by their spectral data. The final two experiments, methylation of the hydroxamic acid (110) and pyrolysis of the methyl ether (108) were performed by Dr. R.F.C. Brown。

Reaction of $\mathrm{N}$-benzyloxyglutarimide with benzylmagnesium bromide

A solution of $N$-benzyloxyglutarimide $e^{109}(2.03 g$; 0.01 mole) in anhydrous benzene $(60 \mathrm{ml}$.) was added drop- 
wise to a stirred, cooled $\left(10-15^{\circ}\right)$ ethereal solution of benzylmagnesium bromide, from magnesium ( $0.48 \mathrm{~g} \bullet ; 0.02$ mole) and benzyl chloride ( $2.50 \mathrm{~g} \bullet$; 0.02 mole) in anhydrous ether $(60 \mathrm{ml} \cdot)$. The reaction mixture was stirred at room temperature for $1 \mathrm{hr}$. and then added to a stirred mixture of ice (ca.50 g.), water $(50 \mathrm{ml} \cdot)$, and concentrated hydrochloric acid (10 $\mathrm{ml}$ ).

During this treatment a white powder $(2.04 \mathrm{~g} \bullet), m_{\bullet}$. ca. $125^{\circ}$ (bar), precipitated at the interface of the organic and aqueous layers. The spectral data presented below, are consistent with this product being the bis adduct (104). The dried benzene solution was evaporated in vacuo to give a sticky solid ( $1.52 \mathrm{~g}$ o). Washing this product with ether $(2 \times 5 \mathrm{ml}$.) gave a white powder (670 mg•), which from the i.r. spectrum was predominantly unchanged $\mathrm{N}$-benzyloxyglutarimide containing a small amount of the bis adduct (104). Infra-red: $\quad V_{\max }, 3320,3140,1660 \mathrm{~cm}^{-1}$. N.m.r.: Broad multiplet, 7.8-8.8 ( $6 \mathrm{H}$, methylene protons); singlet, $7.23\left(4 \mathrm{H}, \mathrm{COH}\left(\mathrm{CH}_{2} \phi\right)_{2}\right)$; singlet, 5.21 $\left(2 \mathrm{H}, \mathrm{OCH}_{2} \varnothing\right)$; singlets, $2.79,2.69 \tau$ (total 15H, aromatic protons). 
Reaction of benzal phthalide (107) with anhydrous methanolic hydroxylamine

Anhydrous 3.1M methanolic hydroxylamine $(6.6 \mathrm{ml}$; 20 mmole) was added to a solution of benzal phthalide 113 (4.448.; $20 \mathrm{mmole})$ in ary methanol (60 ml.) and the reaction mixture stirred at room temperature for $3.5 \mathrm{hr}$. The solvent was removed in vacuo to yield a sticky glass (ca. $5.2 \mathrm{~g} \cdot$ ) which was dissolved in chloroform (ca. $50 \mathrm{ml}$. ); addition of light petroleum precipitated the keto hydroxamic acid 109 as an amorphous powder $(3.21 \mathrm{~g} \cdot)$. The crude product was homogeneous by t.l.c. $\left(R_{f} 0.18\right.$, ethanolchloroform, 3:47, blue colour with ferric chloride). Infra-red: $V_{\max } 3250\left(\right.$ broad), $1700($ doublet $) \mathrm{cm}^{-1}$. Ultra-violet: $\lambda_{\max _{\bullet}} 216,260$ (inflexion) $m \mu$.

N.m.r. Singlet, $6.66\left(2 \mathrm{H}, \mathrm{COCH}_{2} \varnothing\right)$; singlet, 3.00 ( in $\mathrm{d}_{6}$-DMSO) and complex multiplet $2.5 \tau$ (total 9H, aromatic protons).

Cyclisation of the keto hydroxamic acid (109)

The crude keto hydroxamic acid (300 $\mathrm{mg} \cdot$ ) was heated under reflux in toluene (or preferably xylene) for 3 hr. with azeotropic removal of the water formed in the reaction. The solvent was removed in vacuo and the residue triturated with light petroleum to give the hydroxamic acid (110) as a yellow powder (235 mg•). This 
crude product was a mixture of two main components as shown by t.1.c. (two spots, $R_{f} 0.32$ (major component) and 0.37 , ethanol-chloroform 3:47, green colour with ferric chloride). Recrystallisation from benzene-light petroleum did not improve the homogeneity of the crude product.

Infra-red: $\quad V_{\max }, 3100,1785,1755 \mathrm{~cm}^{-1}$. Ultra-violet: $\quad \lambda_{\max _{0}} 219$, ca. 275 (broad), $340 \mathrm{~m} \mu$. N.m.r.: Complex multiplet, 2.0-3.0 ; no absorption $>3.0 \tau$.

Methylation of the hydroxamic acid (110).

The crude hydroxamic acid $(550 \mathrm{mg} \cdot)$ in methanol (2 ml.) was treated with a slight excess of distilled ethereal diazomethane. The solvent was removed in vacuo to give a red gum. This crude product was extracted with ether-ligh, petroleum (b.p. 40-60 $)(1: 1)$ and the solution chromatographed on silica gel. Elution with the same solvent mixture afforded the methyl ether (108) as a pale pink glass ( $360 \mathrm{mg} \bullet$ ). Infra-red: $\quad V_{\max }\left(\right.$ film) 1725 (broad) $\mathrm{cm}^{-1}$. Ultra-violet: $\quad \lambda_{\max } 218,285$ (inflexion), $337 \mathrm{~m} \mu$. N.m.r.: $\quad$ Singlet, 5.89 ( $\left.\mathrm{NOCH}_{3}\right)$; singlet, 3.19 (vinylic proton); singlet, 2.50 and multiplet, 2.4-2.9 $T$ (aromatic protons). 


\section{Pyrolysis of the methyl ether (108).}

The chromatographed methyl ether ( $150 \mathrm{mg} \cdot$ ) in mesitylene $\left(4 \mathrm{ml}\right.$.) was heated under reflux $\left(165^{\circ}\right)$ while a slow stream of nitrogen was passed through the reaction vessel. The eluate gases were bubbled through a solution of 2,4-dinitrophenylhydrazine ( $40 \mathrm{mg}$ ) in water ( $5 \mathrm{ml}$ ) and perchloric acid $(0.8 \mathrm{ml}, ; 70 \%$. After $7 \mathrm{hr}$ appreciable amounts of a crystalline 2,4-dinitrophenylhydrazone had precipitated in the trap. A further amount was obtained by treating the white solid (paraformaldehyde) which had collected at the top of the reaction vessel, with the 2,4-dinitrophenylhydrazine reagent. The crude derivative was washed with aqueous perchloric acid to give orange needles ( $30 \mathrm{mg}$ ). Recrystallisation from ethanol afforded formaldehyde 2,4-dinitrophenylhydrazone $(24 \mathrm{mg} \bullet), m_{\bullet} p_{*}$ and mixed $m_{\bullet} p_{0} 166^{\circ}$.

The mesitylene solution was evaporated in vacuo and the semi-crystalline residue chromatographed on silica gel. Elution with methylene chloride gave unchanged methyl ether (108) ( $88 \mathrm{mg} \bullet$ ). Subsequent elution with methylene chloride-ethanol (49:1) gave a sticky solid ( $58 \mathrm{mg}$ •) which was recrystallised from aqueous methanol to afford the benzal phthalimide (111) (25 mg•) as a yellow powder, m॰p. 185-186 . 
Infra-red: $\quad V_{\max } 3300,1710 \mathrm{~cm}^{-1}$.

Ultra-violet: $\quad \lambda_{\max _{0}} 220 \mathrm{~m} \mu(\varepsilon=18,900), 225 \mathrm{~m} \mu(\varepsilon=18,500)$, $231 \mathrm{~m} \mu(\varepsilon=16,300), 242 \mathrm{~m} \mu(\varepsilon=8,600), 292 \mathrm{~m} \mu$ (inflexion, $\varepsilon=12,300), 338 \mathrm{~m} \mu(\varepsilon=24,900)$.

N.m.r.: Singlet, 3.43 (vinylic proton); singlet, 2.54 and multiplet, $2-3$ (aromatic protons); broad absorption, $1.4 \tau(\mathrm{N} \underline{\mathrm{H}})$.

Section IIe.

Attempted epoxidation of the high m.p. (trans) isomer of the nitroolefin $(47 ; \mathrm{R}=\operatorname{COD})$

(a) With m-chloroperbenzoic acid

A solution of m-chloroperbenzoic acid ( $173 \mathrm{mg} \bullet$; $1.0 \mathrm{mmole}$ ) in dry chloroform ( $10 \mathrm{ml}$.) was added dropwise to a solution of the nitroolefin ( $330 \mathrm{mg} \cdot 0.97 \mathrm{mmole}$ ) in chloroform $\left(20 \mathrm{ml}\right.$ ) at $0^{\circ}$. After $23 \mathrm{hr}$, at room temperature the $u_{\bullet} v_{\bullet}$ spectrum of the reaction mixture showed the presence of unchanged nitroolefin $\left(\lambda_{\max }\right.$. $283 \mathrm{~m} \mu)$. The starch-potassium iodide test also indicated that excess peracid still remained. Thereafter, the reaction mixture was heated under reflux for a further $25 \mathrm{hr}$. after which time a negative starch-potassium iodide test resulted. The reaction mixture was washed 
with saturated aqueous sodium bicarbonate ( $5 \mathrm{x} 10 \mathrm{ml}$.) and the dried chlor of orm solution evaporated in vacuo to give unchanged nitroolefin ( $318 \mathrm{mg} \bullet ; 96 \%$ ) as shown by the n.m.r. and i.r. spectra. Subsequently it was shown that a sample of $\underline{m-c h l o r o p e r b e n z o i c ~ a c i d ~ i n ~ c h l o r o f o r m ~}$ gave a negative starch-potassium iodide test after heating under reflux for $24 \mathrm{hr}$.

(b) With trifluoroperacetic acid. ${ }^{115}$

A solution of trifluoroperacetic acid was prepared as follows:- Trifluoroacetic anhydride $(2.10 \mathrm{ml}$, $3.15 \mathrm{~g} \bullet ; 15.0 \mathrm{mmole}$ ) was added to a stirred suspension of $85 \%$ hydrogen peroxide ( $500 \mathrm{mg} \bullet ; 12.5 \mathrm{mmole}$ ) in dry methylene chloride $(10 \mathrm{ml}$.$) at 0^{\circ}$ and the resulting solution stirred at $0^{\circ}$ for 15 min.

An aliquot of the cold peracid solution $(1.2 \mathrm{ml}$; ca. 1.25 mmole) was added via a syringe and serum cap, over a period of 5 min., to a stirred suspension of anhydrous disodium hydrogen phosphate (568 mg•; 4.0 mmole) in a refluxing solution of the nitroolefin ( $341 \mathrm{mg}$ : $1.0 \mathrm{mmole})$ in dry methylene chloride $(9 \mathrm{ml}$ ). The reaction mixture was heated under reflux for a further $7 \mathrm{hr}$, water $(15 \mathrm{ml}$ ) added and the mixture stirred until the inorganic salts had dissolved. The organic layer was separated and the aqueous layer extracted with methylene chloride $(15 \mathrm{ml}$ ) . Evaporation of the combined 
methylene chloride extracts gave a solid residue (350mg•) which was almost pure nitroolefin $\left(n \cdot m_{\bullet} r_{0}\right)$. The crude product was filtered in benzene through a column of silica gel to afford unchanged nitroolefin ( $317 \mathrm{mg} \bullet$; $93 \%$.

Attempted desulphurisation of the dimethoxythioether (58). (a) With W7 Raney nickel ${ }^{133}$ at room temperature A solution of the thioether (58) (45 $\mathrm{mg} \bullet$ ) in ethanol ( $15 \mathrm{ml}$.) was shaken with excess $\mathbf{7} 7$ Raney nickel (ca. $400 \mathrm{mg}$ ) for $19 \mathrm{hr}$. at room temperature. The Raney nickel was removed by filtration and the solvent evaporated in vacuo to give a yellow glass ( $40 \mathrm{mg} \cdot)$. T.l.c. (ethanol-chloroform, 2:23) showed the presence of at least five components $R_{f} 0.51,0.53,0.57,0.63$ and 0.71 . In the same solvent system the thioether (58) showed an $R_{f}$ of 0.63 .

(b) With deactivated W7 Raney nickel

W7 Raney nickel was deactivated by washing four times with acetone and refluxing for $0.5 \mathrm{hr}$. in the same solvent. A solution of the thioether (58) (35 mg•) in acetone $(10 \mathrm{ml}$.) was heated under reflux for $19 \mathrm{hr}$. with excess deactivated $\mathbf{W}$ Raney nickel. The Raney nickel was removed by filtration and the solvent evaporated 
in vacuo to give a crystalline residue ( $32 \mathrm{mg} \bullet$ ). N.m.r. spectroscopy showed the crude product to be $>90 \%$ unchanged thioether. T.1.c. also confirmed this result.

Attempted desulphurisation of the methylthio nitro ester (53: $\mathrm{R}=\mathrm{NO}_{2}$ )

(a) With W7 Raney nickel

A solution of the nitro ester $(200 \mathrm{mg} \bullet$ ) in

ethanol ( $20 \mathrm{ml}$.) was heated under reflux for $1 \mathrm{hr}$. with excess W7 Raney nickel (ㄹ. $2 \mathrm{~g}$ ). The Raney nickel was removed by filtration and the solvent removed in vacuo to give a yellow glass ( $130 \mathrm{mg}$ ). This crude product was a complex mixture of products as shown by n,m.r. and t.1.c. (at least four components).

(b) With nickel boride ${ }^{117,118}$

A solution of nickel acetate tetrahydrate $(1.74 \mathrm{~g} \cdot ; 7$ mole) in water (ca. $100 \mathrm{ml}$ ) was flushed with nitrogen for $15 \mathrm{~min}$. at room temperature. To this solution was added dropwise, a solution of potassium borohydride $(1.14 \mathrm{~g} \bullet ; 21 \mathrm{mmole})$ in water $(30 \mathrm{ml} \bullet)$ 。 After the evolution of hydrogen had ceased, the black granular nickel boride was filtered and washed with ethanol ( $3 \times 50 \mathrm{ml}$.). 
The nickel boride prepared above was added to a solution of the nitro ester ( $200 \mathrm{mg} \cdot ; 0.7$ mmole) in ethanol ( $30 \mathrm{ml}$.$) and the mixture heated under reflux for$ $3 \mathrm{hr}$. The nickel boride was removed by filtration and the solvent removed in vacuo to give a dark yellow glass (140 mg•). The n.m.r. spectrum of the crude product showed that desulphurisation had been effected but that a mixture of products had been produced. No separation of the components of the mixture was realised by careful chromatography on silica gel; the chromatographed product had an n.m.r. spectrum identical with that of the crude product and was a mixture of at least two main components $\left(t_{\bullet} I_{\bullet} c_{\bullet}\right)$. When the same reaction was carried out at room temperature, desulphurisation was not effected. Under these conditions the crude product was a mixture of the erythro and threo isomers of the nitro ester, as shown by the n.m.r. spectrum.

Reaction of the sulphone (62) with potassium iodide in dimethylformamide

A solution of the sulphone ( $60 \mathrm{mg} \cdot ; 0.13 \mathrm{mmole})$ and anhydrous potassium iodide ( $90 \mathrm{mg} \bullet ; 0.54 \mathrm{mmole})$ in dry dimethylformamide $(5 \mathrm{ml}$.$) was heated at ca. 80^{\circ}$ for $6 \mathrm{hr}$. The solvent was removed in vacuo and the residue partitioned between water $(200 \mathrm{ml}$ ) and chloroform (50ml.). 
The chloroform solution was washed with water ( $3 \times 20 \mathrm{ml}$.), dried and evaporated in vacuo to give a yellow glass. This crude product was washed with ether to afford a solid residue $(40 \mathrm{mg} \cdot), \mathrm{m} \cdot \mathrm{p} \cdot$ ca. $165^{\circ}$ (bar), which gave a negative ferric test. Infra-red: $\quad V_{\max } 3300,1750,1700 \mathrm{~cm}^{-1}$. Attempted 0-alkylation of the olefin (75).

A solution of triethyloxonium fluoroborate 37 was prepared as follows:- Epichlorhydrin ( $8.88 \mathrm{~g} \bullet$; 0.096 mole) was added dropwise to a stirred solution of freshly distilled boron trifluoride diethyletherate $(18.20 \mathrm{~g} \cdot ; 0.13 \mathrm{~mole})$ in anhydrous ether $(60 \mathrm{ml})$. The addition was made at such a rate that the solution remained in constant gentle reflux. After the addition was complete, the reaction mixture was stirred at room temperature for $2 \mathrm{hr}$. The solvent was decanted and the solid triethyloxonium fluoroborate washed thoroughly with anhydrous ether and dissolved in dry methylene chloride (total volume $250 \mathrm{ml}$.). Based on epichlorhydrin, the solution was then $0.38 \mathrm{M}$ in $t$ riethyloxonium fluoroborate. An aliquot of this solution ( $1.8 \mathrm{ml} \bullet ; 0.68$ mole) was stirred at $10-15^{\circ}$ while a solution of the olefin (75) ( $100 \mathrm{mg} \cdot ; 0.33 \mathrm{~mole}$ ) in dry methylene chloride (10 ml.) was added dropwise. The solution was allowed to warm to 
room temperature and stirred for a further $12 \mathrm{hr}$. Aqueous potassium carbonate $(1 \mathrm{ml} \cdot ; 50 \% \mathrm{w} / \mathrm{W})$ was added and the reaction mixture allowed to stand for $30 \mathrm{~min}$. The precipitated solid was removed by filtration, the solid washed thoroughly with methylene chloride and the combined methylene chloride extracts dried and evaporated. in vacuo to give a yellow glass (108 $\mathrm{mg} \cdot$ ). This crude product showed broad $u_{\bullet} v$. absorption at ca. $305 \mathrm{~m} \mu$ but was a complex mixture as shown by n.m.r. and t.l.c. Accordingly the crude product was chromatographed on silica gel. Elution with ether-benzene (1:9) afforded a solid residue ( $30 \mathrm{mg}$.) which was a complex mixture of products as shown by t.1.c. (four main components $R_{f} 0.43$, $0.48,0.67$ (most intense) and 0.79 , ethanol-chloroform, $3: 47)$.

Ultra-violet: $\lambda_{\max } 300$ (inflexion), 313,325(inflexion)m $\mu$. N.m.r.: Multiplet, 8.72, 8.60,8.50, 8.39 (total 8.9H); singlet, $7.71(3.7 \mathrm{H})$; singlet, $6.12(3.3 \mathrm{H})$; overlapping quartets, $5.6(3.0 \mathrm{H})$; multiplet, $2.8(4.1 \mathrm{H})$; broad singlets, 1.90, 2.05个 (1.7H). Subsequent elution with ether-benzene (1:4) gave a colourless glass ( $37 \mathrm{mg} \bullet$ ) which showed broad $\mathrm{u}_{\bullet} \mathrm{v}_{\bullet}$ absorption at $300 \mathrm{~m} \mu$. Although apparently a mixture of only two main components ( $R_{f} 0.43$ and 0.53 , ethanol-chloroform, 3:47), the n.m.r. spectrum of this fraction was at least as complex as that of the previous fraction. 
Attempted direct oxidation 35 of $(75)$ to the hydroxamic acid

The olefin (75) (5.0 mg•; 0.017 mole) and mchloroperbenzoic acid ( $6.0 \mathrm{mg} \bullet ; 0.035$ mole) were dissolved in $\mathrm{AR}$ chloroform $(1.0 \mathrm{ml}$.) and allowed to stand at room temperature. The progress of the reaction was studied by the change in the $u_{\bullet} v$ spectrum and t.1.c. of the reaction mixture. The former technique showed the slow degeneration of the long wavelength maximum (297 $\mathrm{m} \mu)$ of (75). Parallel with this observation t.l.c. showed the formation of a single reaction product which was not a hydroxamic acid $\left(R_{f} 0.41\right.$, ethanol-chloroform, $\left.3: 57 ; \mathrm{R}_{\mathrm{f}}(75)=0.55\right)$. After 7 days chloroform (10 m. $)$ was added and the solution washed with saturated aqueous sodium bicarbonate $(3 \times 5 \mathrm{ml}$ ). Evaporation of the dried chloroform solution gave a colourless glass (ca. 5mg•) which gave a negative ferric test and showed no u.v absorption above $250 \mathrm{~m} \mu$. 
REFERENCES 


\section{REFEREN CES}

1. H. Bickel, E. Gaumann, W. Keller-Schierlein,

V. Prelog, E. Vischer, A. Wettstein, and H. Zahner, Experientia, 16, 129 (1960).

2. T. Emery and J.B. Neilands, J.Am. Chem. Soc., 83, 1626 (1961).

3. S.J. Rogers, R.A.J . Warren, and J.B. Neilands, Nature, 200, 167 (1963).

4. W. Keller-Schierlein, Angew。Chem., 74, 296 (1962).

5. V. Prelog and A. Walser, Helv. Chim.Acta., 45 ,
$1732(1962)$.

6. G.A. Snow, J. Chem.Soc., 4080 (1954).

7. G.A. Snow, Biochem. J., 94, 160 (1965).

8. A. Stoll, J.Renz and A. Brack, Helv. Chim. Acta., $\underline{\underline{3}}, 862(1951)$.

9. R.F.C. Brown, G. Buchi, W. Keller-Schierlein, V. Prelog, and J. Renz, ibid., 43. 1868 (1960).

10. J.D. Dutcher, J. Biol. Chem., 171, 321, 341 (1947).

11. G.T. Newbold, W. Sharp and F.S. Spring, J. Chem. S.oc., 2679 (1951).

12. A.H. Cook and C.A. Slater, ibid., 4133 (1956).

12a. Idem., ibid., 4130 (1956).

13. J.C. MacDonald, Can.J. Chem., 41, 165 (1963).

14. A.E. Oxford and H. Raistrick, Biochem. J., 42,
$323(1948)$.

15. A.J. Birch, R.A. Massy-Westropp, and R.W. Rickards, Chem. Ind. London, 1599 (1955).

16. Idem., J. Chem. Soc., 3717 (1956).

17. R.B. Bates, J.H. Schauble, and M. Soucek, Tetrahedron Letters, 1683 (1963). 
18. C. Gallina, A. Romeo, G. Tarzia, and V. Tortorella, Gazz. Chim. Ital., 94, 1301 (1964).

19. C. Gallina, A. Romeo, V. Tortorella, and G. D'Agnolo, Chem. Ind. London, 1300 (1966).

20. T. Sasaki, Chem. Ber., 54, 163 (1921).

21. L.R. Richardson, C.E. Welch, and S. Calvert, J.Am. Chem. Soc., 51, 3074 (1929).

22. E. Ueda, J. Chem. Soc. J apan, 50, 502 (1929). Chem. Abs., 26, 91 (1932).

23. A.J . Birch, R.A. Massy-Westropp, R.W. Rickards, and H. Smith, Proc.Chem. Soc., 98 (1957).

24. Idem., J. Chem. Soc., 360 (1958).

25. A.J . Birch, R.J. English, R.A. Massy-Westropp, and H. Smith, Proc. Chem. Soc., 233 (1957).

26. Idem., J. Chem. Soc., 369 (1958).

27. A.J . Birch, M. Kocor, N. Sheppard, and J . Winter, ibid., 1502 (1962).

28. A.J. Birch and H. Smith in "CIBA Foundation Symposium on Amino Acids and Peptides with Antimetabolic Activity", Ed. G.E.W. Wolstenhome and C.M. O'Connor, J «A. Churchill Ltd., London, 1958 ,
p.251.

29. W.B. Whalley in "Biogenesis of Natural Compounds", Ed. P. Bernfeld, Pergamon Press, 1963, p.820。

30. G. Dunn, J .J. Gallagher, G.T. Newbold, and F.S. Spring, J.Chem. Soc., S126 (1949).

31. I. Neelakantan and W.H. Hartung, J. Org. Chem., $\underline{\underline{23}}, 964(1958)$.

32. P. Mamalis, J. Green, and D. McHale, J. Chem. Soc.,
$229(1960)$.

33. G.T. Newbold and F.S. Spring, ibid., 1864 (1948).

34. K.G. Cunningham, G.T. Newbold, F.S. Spring, and J. Stark, ibid., 2091 (1949). 
35. W.A. Iott and E. Shaw, J.Am. Chem. Soc., 71, 70 (1949)。

36. E. Shaw, ibid., 11, 67 (1949)。

37. H. Meerwein, E. Battenberg, H. Gold, E. Pfeil, and G. Willfang, J. Prakt. Chem., 154, 83 (1939).

38. E. Bertele, H. Boos, J.D. Dunitz, F. Elsinger, A. Eschenmoser, I. Felner, H.P. Gribi, H. Gschwend, E.F. Meyer, M. Pesaro, and R. Scheffold, Angew. Chem. Intern. Ed. Engl., 3, 490 (1964)。

39. I.A. Paquette, J.Am. Chem.Soc., 86, 4096 (1964).

40. N. Kornblum and G.P. Coffey, J.Org. Chem., 31, 3447 (1966).

41. E.J. Corey and M. Chaykovsky, J.Am. Chem. Soc., 84, 866 (1962).

42. Idem., J. Org. Chem., 28, 254 (1963)。

43. C. Walling and L. Bollyky, ibid., 28, 256 (1963).

44. G.A. Russell, E.G.J anzen, H.D. Becker, and F.J. Sment owski, J.Am. Chem. Soc., 84, 2652 (1962).

45. E. Baltazzi and E.A. Davis, Chem. Ind. London, 929 $(1962)$.

46. H. Baba, H. Midorikawa, and S. Asyama, J.Sci.Res. Inst.2 (Tokyo), 52, 99 (1959), through G.W.K. Cavill and F.B. WhitfieId, Australian J. Chem., 17, 1245 (1964).

47. Private communication, R.B. Bates, University of Arizona.

48. W.S. Wadsworth and W.D. Emmons, J.Am. Chem. Soc., $\underline{\underline{83}}, 1733(1961)$.

49. A. Dornow and H. Menzel, Ann., 588, 40 (1954).

50. I. Bouveault and A. Wahl, Bull. Soc. Chim. France, [3], 29, 519 (1903).

51. A. Wahl, ibid., 3, 25, 918 (1901). 
52. J.F.W. McOmie in "Advances in Organic Chemistry, Methods and Results", Ed. R.A. Raphael, E.C. Taylor, and $\mathrm{H}$. Wynberg, Interscience Publishers, New York, London, 1963, p.191.

53. E.J. Corey and R.A.E. Winter, J.Am. Chem. Soc., $\underline{\underline{85}}, 2677(1963)$.

54. E.J. Corey, F.A. Carey, and R.A.E. Winter, ibid., 87, $934(1965)$.

55. G. Crank and F.W. Eastwood, Australian J. Chem., 17, $1392(1964)$ 。

56. M. Sander, Chem. Rev., 66, 297 (1966).

57. J. Fishman, M. Torigoe, and H. Guzick, J. Org. Chem., 28, $1443(1963)$.

58. C.B. Scott, 卢id., 22, 1118 (1957).

59. J.W. Cornforth, R.H. Cornforth and K.K. Mathew, J.Chem. Soc., 112 (1959).

60. H.0. House, "Modern Synthetic Reactions", W.A. Benjamin, Inc., New York, Amsterdam, 1965, p.134.

61. F. Badea, S. Rosca, I.G. Dinulescu, M. Avram, and C.D. Nenitzescu, Revue Roumaine de Chimie, 10, 1201 (1965) and references therein.

62. E.R. Alexander and A. Mudrak, J.Am. Chem. Soc., 72, $1810(1950)$.

63. Idem., ibid, I2, 3194 (1950).

64. Idem•, ibid., I3, 59 (1951).

65. D.Y. Curtin and D.B. Kellom, ibid., 75, 6011 (1953).

66. D.H.R. Barton, A.J. Head, and R.J. Williams, J.Chem. Soc., 1715 (1953).

67. W.J. Bailey and R.A. Baylouny, J.Am. Chem. Soc., $\underline{81}, 2126$ (1959).

68. A.C. Cope, T.T. Foster, and P.H. Towle, ibid., 11, 3929 (1949). 
69. W. Hanhart and C.K. Ingold, J. Chem. Soc., 997 (1927).

70. A.C. Cope, R.A. Pike, and C.F. Spencer, J.Am. Chem. Soc., 75, $3212(1953)$.

71. D.J. Cram and J.E. McCarty, ibid., 76, 5740 (1954).

72. A.C. Cope, N.A. LeBel, H.H. Lee, and W.R. Moore, ibid., 79,4720 (1957).

73. A.C. Cope, C.I. Bumgardner, and E.E. Schweizer, ibid., 79, 4729 (1957).

74. D.J.
1734 (1962), M.R.V. Sahyun, and G.R. Knox, ibid., 84,

75. M.R.V. Sahyun and D.J. Cram, ibid., 85, 1263 (1963).

76. C.A. Kingsbury and D.J. Cram, ibid., 82, 1810 (1960).

77. T. Colclough and J.I. Cunneen, Chem. Ind. London, 626 (1960).

78. I.D. Entwistle and R.A.W. J ohnstone, Chem. Comm., $29(1965)$.

79. D.G. Barnard-Smith and J.F. Ford, ibid., 120 (1965).

80. D.W. Emerson, A.P. Craig, and I.W. Potts, J. Org. Chem., $\underline{32}, 102$ (1967)。

81. C. Walling and I. Bollyky, ibid., 29, 2699 (1964).

82. S.I. Golberg and M.S. Sahli, Tetrahedron Letters, 4441 (1965).

83. D.N. J ones and M.A. Saeed, Proc. Chem. Soc., 81 (1964)。

84. J.E. Hofmann, T.J.Wallace, and A. Schriesheim, J.Am. Chem. Soc., 86, 1561 (1964) and references

85. R. Barker and M.J. Spillett, Chem. Comm., 757 (1966). 86. $J_{11} F_{(1967)}$. Bunnett and E. Bacciochi, J. Org. Chem., 32, 
87. P. Haake, W.B. Miller, and D.A. Tyssee, J.Am. Chem. Soc., 86, 3577 (1964).

88. R.L. Heath and A. Lambert, J. Chem. Soc., 1477 $(1947)$.

89. E.D. Hughes, C.K. Ingold, G.A. Maw, and L.I. Woolf, ibid., 2077 (1948).

90. A.A. Dudinskaya, G.A. Shvekhgeimer, S.S. Novikov, and V.I. Slovetskii, Izvest. Akad. Nauk S.S.S.R., $\frac{\text { Otdel. Khim. Nauk, }}{18559 \mathrm{e}(1961)}$.

91. "NMR Spectra Catalog", Varian Associates, Palo Alto, California, 1962, Spectrum 290. 92. G. Stefanovic and J. Bojanovic, J. Org. Chem., 17,
$816(1952)$.

93. A.I. Vogel, "A Text-Book of Practical Organic Chemistry", Longmans, Great Britain, third edition, $1961, p .198$.

94. "Handbook of Preparative Inorganic Chemistry", Ed. G. Brauer, Translation Ed. R.F. Riley, Academic Press, New York, London, Volume 1, second edition, $1963, p .501$.

95. J.P. Freeman, J.Am. Chem. Soc., 80, 5954 (1958).

96. K. Nakanishi, "Infrared Absorption Spectroscopy Practical ",Holden-Day, Ine., San Francisco and Nankodo Company Limited, Tokyo, 1962, p.44.

97. L. Hough and M.I. Taha, J.Chem. Soc., 2042 (1956).

98. C.A. Kingsbury and D.C. Best, J. Org. Chem., 22,
$6(1967)$.

99. J.R. Dyer, "Applications of Absorption Spectroscopy of Organic Compounds", Prentice-Hall, Inc., Englewood Cliffs, N.J., 1965, p.84.

100. R.B. Corey, J. Am. Chem. Soc., 60, 1598 (1938).

101. S. Gambarjan and 0. Cialtician, Chem. Ber., 60,
$390(1927)$. 
102. See reference 96, p.54.

103. A.I. Scott, "Interpretation of the Ultraviolet Spectra of Natural Products", Pergamon Press, Great Britain, 1964, p.107.

104. K.J. van der Merwe, P.S. Steyn, and S.H. Eggers, Tetrahedron Letters, 3923 (1964).

105. F.J. Dinan and H. Tieckelmann, J. Org. Chem., 29,
$1650(1964)$.

106. Private communication, R.F.C. Brown, Australian National University.

107. Private communication, E.N. Cain, Australian National University.

108. R. Iukes, A. Fabryova, S. Dolezal and I. Novotny,

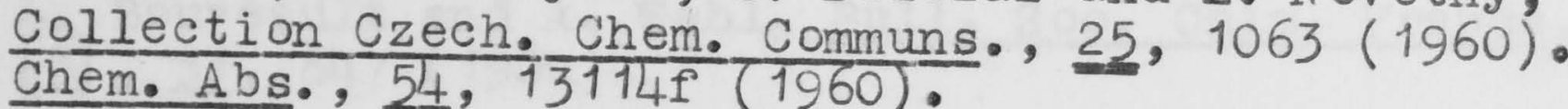

109. D.E. Ames and T.F. Grey, J.Chem. Soc., 631 (1955).

110. R. Srinivasan, J.Am. Chem. Soc., 81, 5061 (1959) and

111. P.J. Hamrick and C.R. Hauser, $\underline{i b i a ̄ ., ~ 81, ~} 2096$ (1959).

112. C.R. Hauser and D.S. Hoffenberg, ibid., 77, 5742
$(1955)$.

113. R. Weiss, org. Syn. Coll. Vol. 2, 61 (1943).

114. See reference 103, p.99.

115. W.D. Emmons and A.S. Pagano, J.Am. Chem. Soc., 77,
$89(1955)$.

116. D.I. MacPeek, P.S. Starcher, and B. Phillips, ibid., 81, 680 (1959)。

117. C.A. Brown and H.C. Brown, ibid., 85, 1003 (1963).

118. W.E. Truce and F.M. Perry, J. Org. Chem., 30 ,
$1316(1965)$.

119. J.F. Klebe, H. Finkbeiner, and D.M. White, J.Am. Chem. Soc., 88, $3390(1966)$. 
120. R.W. Martin, ibid., 74, 3024 (1952).

121. C.B. Reese, R. Saffhill, and J.E. Sulst on in a paper presented to The Chemical Society Autumn Conference, September 1966, University of Sussex.

122. H. Oediger, H.J. Kabbe, F. Moller, and K. Eiter, Chem. Ber., 29, 2012 (1966).

123. A.H. Herz and D.S. Tarbell, J.Am. Chem. Soc., I5, 4657 (1953).

124. G.A. Snow, J. Chem.Soc., 2588 (1954).

125. See reference 93, p.177.

126. A.P.N. Franchimont and H. Friedmann, Rec. Trav。 Chim., 2], 192 (1908).

127. I. Bouveault and A. Wahl, Bull. Soc. Chim. France, [3], 31, $847(1904)$.

128. A.I. Vogel, "A Text-Book of Quantitative Inorganic Analysis, Theory and Practice", Longmans, Green and Co., London, second edition, 1957, p.870.

129. L.S. Silbert, E. Siegel, and D. Swern, J. Org. Chem., 27, 1336 (1962)。

130. See reference 93, p.969.

131. See reference 93, p.1061.

132. C.J. Timmons, J. Chem. Soc., 2613 (1957).

133. H.R. Billica and H. Adkins, Org. Syn., Coll. Vol.3, 176 (1955). 
APPENDIX 


\section{APPENDIX}

Photodimerisation of $\underline{\text { cis }}$ and trans ethyl-p-benzoyloxy$\alpha$-nitrocinnamate.

\section{Discussion of results}

A sample of the high m.p. (trans) isomer of the nitroolefin ( $47 ; \mathrm{R}=\mathrm{CO} \varnothing$ ) which had been allowed to stand on the laboratory bench for 7 months was found to have been transformed into a new high m.p. $\left(239-241^{\circ}\right)$ compound. The most likely inference was that this compound was the result of photochemical dimerisation of the nitroolefin, a reaction which is now fairly general for $\alpha, \beta-$ unsaturated olefins. ${ }^{1}$ A directly analogous reaction is the reported photodimerisation of $\beta$-nitrostyrene to the cyclobutane dimer $(1) 0^{2}$

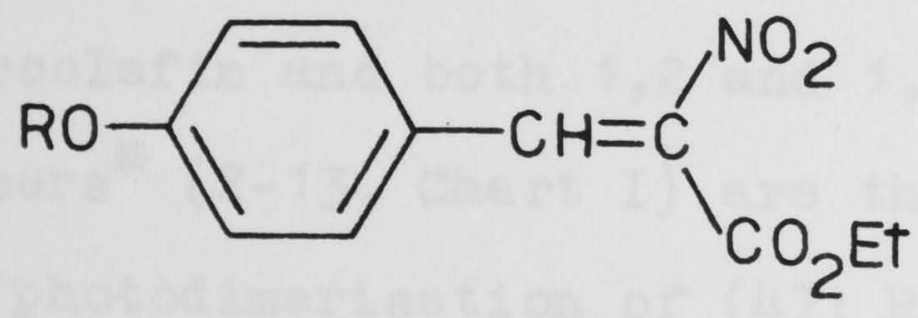

(47)

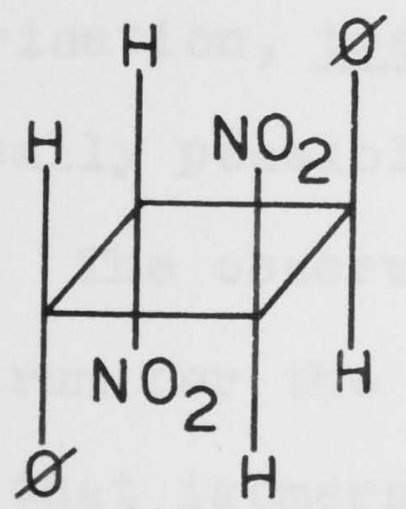

(1)

That the product from ( $47 ; \mathrm{R}=\mathrm{CO} \varnothing)$ was also most probably a cyclobutane dimer was indicated by the lack 
of any $u_{\bullet} v_{\bullet}$ absorption near $283 \mathrm{~m} \mu$ and by the $n_{\bullet} m_{\bullet} r$. spectrum which showed absorptions for the aromatic protons and the carbethoxyl group, plus a sharp singlet at $3.69 \%$. The dimeric nature of the photoproduct was confirmed by analysis.

Subsequently it was found that the dimer could be prepared most conveniently in 58\% yield by irradiation of the solid nitroolefin with ultra-violet light of wavelength greater than $300 \mathrm{~m} \mu$ (pyrex filter) from a high pressure mercury lamp. The same dimer was produced in comparable yield ( $64 \%$ ) by a similar irradiation of a mixture of the cis and trans isomers of $(47 ; \mathrm{R}=\mathrm{CO} \varnothing)$. In contrast, the dimer was not formed by irradiation of an ethereal solution of the high $m_{\bullet} p_{\text {e }}$ isomer of $(47 ; R=C O \varnothing)$, although decomposition of the olefin to an undefined mixture of products did occur.

Assuming an allowed cis-trans isomerism of the nitroolefin and both 1,2 and 1,3 dimerisation, twelve isomers $^{*}(2-13$, Chart I) are theoretically possible from the photodimerisation of $(47 ; \mathrm{R}=\mathrm{CO} \varnothing)$. The observation of a sharp singlet in the n.m.r. spectrum for the cyclobutane protons of the dimer, suggests that isomers (4), (5), and (11) may be rejected. In these isomers

* Counting a DL racemate as a single isomer. 
the cyclobutane protons have different chemical environments and should absorb at different chemical shifts. However this inference would require independent confirmation. Although the exact definition of the structure of the dimer is a problem of some magnitude, a combination of hydrolysis and ozonolysis experiments can theoretically at least reduce the number of possibilities. The analytical use of these experiments depends on the formation of anhydrides from cis 1,2 and 1,3 diacids but not from the trans isomers :-

(a) Hydrolysis to a diacid-diphenol.

(b) Ozonolysis to a diacid-diester.

(c) Ozonolysis and hydrolysis to a tetra-acid. Application of the processes (a)-(c) would divide the twelve possible isomers into four groups.

Group A: (2),(3),(8),(9) - anhydride formation after process (a) or (b).

Group B: (5),(11) - anhydride formation after process (a) but not (b).

Group C: (4),(10) - anhydride formation after process (b) but not (a).

Group D: (6), (7),(12),(13) - anhydride formation only after process (c).

* The conditions for anhydride formation must preclude epimerisation. 
CHART I

1,2 DIMERISATION

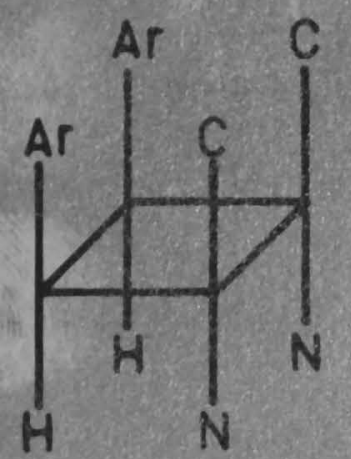

(2)

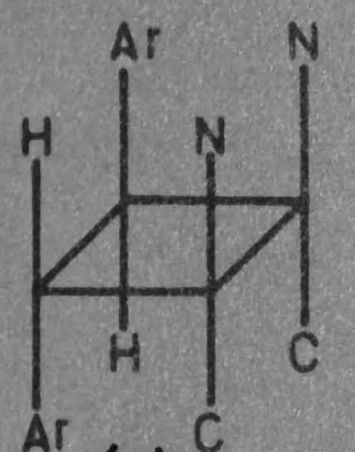

(5)

1,3 DIMERISATION

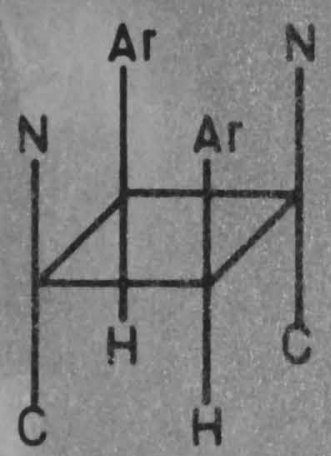

(8)

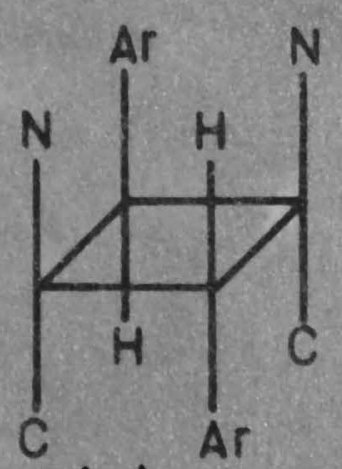

(11)

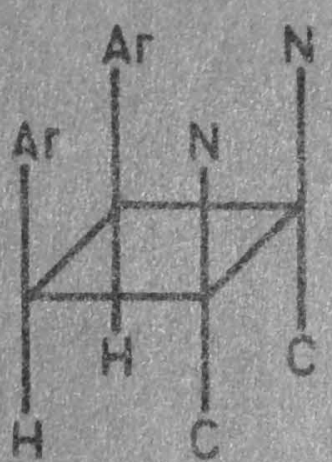

(3)

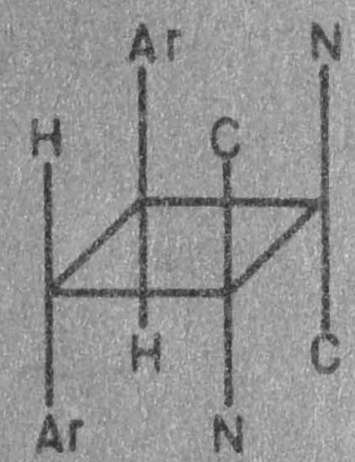

(6)

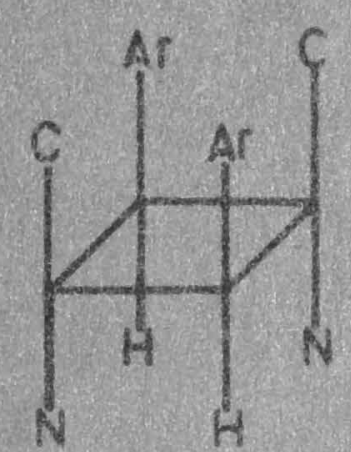

(9)

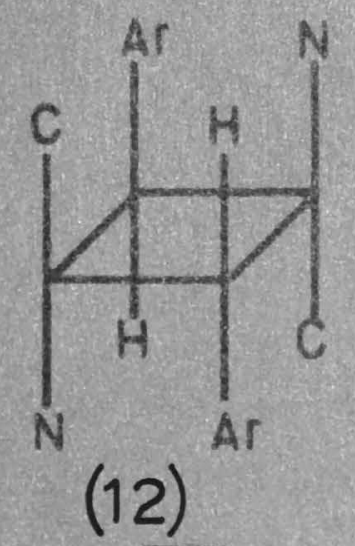

$A r=\sqrt{1}-0 \cos$

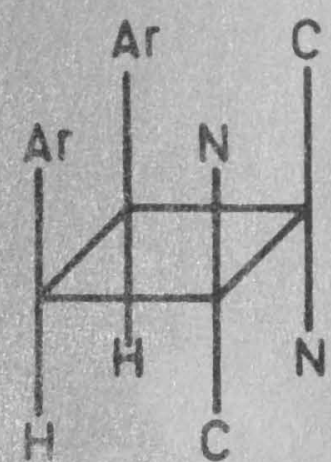

(4)

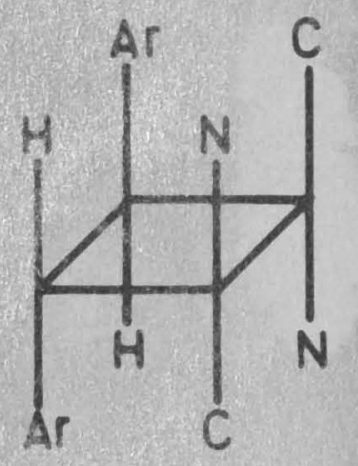

(7)

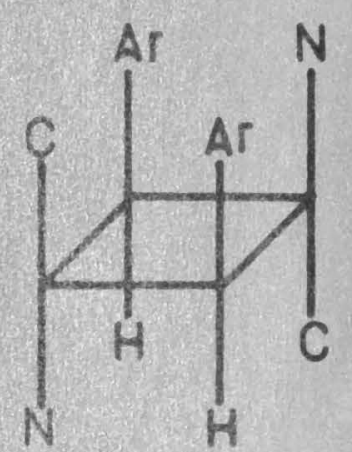

(10)

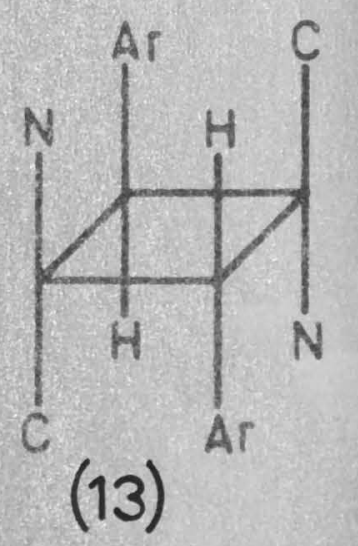

$\mathrm{C}=\mathrm{CO}_{2} \mathrm{Et}$ 
Hydrolysis of the dimer was complicated by its extreme insolubility in most alcoholic solvents (e.g. ethanol, methanol). A homogeneous reaction was possible with sodium hydroxide in refluxing dioxan-water (1:3), but the hydrolysis product was an intractable red gum. Ozonolysis experiments were no more successful; in chloroform at $0^{\circ}$ the aromatic rings remained intact while in glacial acetic acid at room temperature, although ozonolysis was probably effected, decomposition of the ozonide again afforded intractable gums. If the dimer possessed two cis disposed carbethoxyl groups it was thought that these could be linked via apyclic hydrazide. However, benzoic hydrazide was the only rational product isolated from the reaction of the dimer with hydrazine hydrate in chloroform.

These preliminary experiments indicate that even a partial definition of the structure of the dimer will be a difficult task. Milder conditions for hydrolysis must be sought but such reactions will always be complicated by the nature of the hydrolysis product; in the extreme case this would be a nitro acid-phenol, a system which would probably be water soluble and very susceptible to oxidation. 


\section{Experimental}

Photodimerisation of ethyl-p-benzoyloxy- $\propto$-nitrocinnamate (47: $\mathrm{R}=\operatorname{CO\phi }$ )

The photolysis vessel consisted of a 101. roundbottomed flask into which the lamp housing was fitted by means of a ground glass joint. All photolyses were carried out using a Hanovia (UK) high pressure lamp (500w).

The high m.p. (trans) isomer of the nitroolefin $(47 ; \mathrm{R}=\operatorname{CO} \varnothing)(1.07 \mathrm{~g} \cdot)$ was evaporated from an ethereal solution onto the inside surface of the photolysis vessel, and irradiated for $45 \mathrm{hr}$. using a pyrex filter $(\lambda>300 \mathrm{~m} \mu)$. The crude pyrolysate was removed from the flask as a solution in chloroform. Evaporation of the chloroform in vacuo gave a solid residue which was washed thoroughly with boiling ethanol to leave a white powder (620 mg; $58 \%)$ Recrystallisation from benzene-light petroleum afforded the dimer as colourless prisms, m.p. 239-241\% The same dimer was produced in $64 \%$ yield by a similar irradiation of a mixture of the cis and trans isomers of the nitroolefin.

Infra-red: $\quad V_{\max }{ }^{1760}$ (doublet), $1560 \mathrm{~cm}^{-1}$. 
N.m.r. : Triplet, $9.06\left(\mathrm{~J}=7.5 \mathrm{cps}, 3 \mathrm{H}, \mathrm{CO}_{2} \mathrm{CH}_{2} \mathrm{CH}_{3}\right)$; quartet, $5.96\left(\mathrm{~J}=7.5 \mathrm{cps} ., 2 \mathrm{H}, \mathrm{CO}_{2} \mathrm{CH}_{2} \mathrm{CH}_{3}\right)$; sharp singlet, 3.69 ( $1 \mathrm{H}$, cyclobutane proton); singlet, 2.73; multiplet, 2.5 and quartet $1.8 \tau$ (total $9 \mathrm{H}$, aromatic protons).

Analysis:

Found

C $\quad$ H N $\quad$ M.wt.

$\mathrm{C}_{36}{ }^{\mathrm{H}} 30^{\mathrm{N}} \mathrm{O}_{12}$ requires

$63.1 \quad 4.6 \quad 3.9$

598(Rast)

$63.3 \quad 4.4 \quad 4.1 \% \quad 682$

Photolysis of the high m.p. (trans) isomer of the nitroolefin ( $47 ; \mathrm{R}=\mathrm{CO} \varnothing)$ in ethereal solution

The above nitroolefin ( $500 \mathrm{mg}$ ) in peroxidefree ether ( $190 \mathrm{ml}$.) was irradiated for $7 \mathrm{hr}$. (corex filter) after which time the nitroolefin had been completely consumed (no $u_{\bullet} v \cdot$ absorption at $283 \mathrm{~m} \mu$ ). The solvent was removed in vacuo to yield a red gum (ca. $500 \mathrm{mg} \cdot$ ) which was completely soluble in cold ethanol (the dimer is virtually insoluble in boiling ethanol). Chromatography of the crude product on silica gel did afford a small amount ( $12 \mathrm{mg} \cdot$ ) of a crystalline material (eluted with ether-benzene, 1:9) but the majority of chromatography fractions were intractable gums. 


\section{Hydrolysis of the dimer}

The dimer ( $100 \mathrm{mg}$ ) was heated under reflux for $3 \mathrm{hr}$. with sodium hydroxide solution $(5 \mathrm{ml}$; $1.6 \mathrm{M}$ in dioxan-water, 1:3). The dark red solution was cooled and unchanged dimer ( $20 \mathrm{mg}$ ) ) removed by filtration. The filtrate was acidified (no precipitate), evaporated to dryness and extracted with dry ethanol. Evaporation of the ethanol solution in vacuo gave an intractable water-soluble red gum ( $50 \mathrm{mg}$ •).

\section{Ozonolysis of the dimer}

(a) The dimer (116 mg.) in chloroform (30 ml.) was cooled to $0^{\circ}$ and ozonised oxygen passed through the solution for $7 \mathrm{hr}$. Formic acid $(5 \mathrm{ml}$ ), hydrogen peroxide $\left(0.8 g_{\bullet} ; 27.5 \%\right)$, and enough methanol to ensure miscibifity were added, and the solution stirred at room temperature for $16 \mathrm{hr}$, and refluxed $1 \mathrm{hr}$. The reaction mixture was evaporated to dryness and extracted with chloroform to give a yellow gum ( $110 \mathrm{mg} \bullet$ ). The $n_{\bullet} m_{\bullet} r_{\bullet}$ spectrum showed the crude product to be a complex mixture and in particular still showed aromatic absorptions.

(b) Ozonised oxygen was passed for $24 \mathrm{hr}$. through a suspension of the dimer ( $200 \mathrm{mg}$ ) in glacial acetic acid $(60 \mathrm{ml}$.$) at room temperature. The dimer had completely$ 
dissolved after ca. $12 \mathrm{hr}$. Hydrogen peroxide (2.0g•; $27.5 \%$ was added and the solution stirred at room temperature for 4 days. The reaction mixture was evaporated in vacuo and the residue extracted with ether. Evaporation of the ethereal solution gave an intractable yellow gum (175 mg•). Although complex, the n.m.r. spectrum of the crude product showed no aromatic absorptions。

Reaction of the dimer with hydrazine

The dimer ( $100 \mathrm{mg} \cdot ; 0.15 \mathrm{mmole}$ ) and hydrazine hydrate ( $40 \mathrm{mg} \bullet ; 0.80 \mathrm{mmole}$ ) in chloroform ( $20 \mathrm{ml}$.) were heated under reflux for $6 \mathrm{hr}$. The reaction mixture was evaporated in vacuo to give a red gum which was chromatographed on silica gel. Elution with ethanol-chloroform (1:19) afforded a crystalline solid (25 mg.), the 1.r. spectrum of which was identical with that of benzoic hydrazide prepared from ethyl benzoate and hydrazine hydrate. Previous chromatography fractions were intractable red gums.

\section{References}

1. R.N. Warrener and J.B. Bremner, Rev. Pure and Appl. Chem., 16, $117(1966)$.

2. R.D. Campbell and R.F. Ofstead, Proc. Iowa Acad. Sci., 71, 197 (1964). Chem. Abs. 63, 14734e (1965). 